JOÃO PAULO RIBEIRO DANTAS

\title{
INVESTIGAÇÃO EXPERIMENTAL DA FADIGA EM LAJES DE PONTES ARMADAS COM BARRAS OU TELAS SOLDADAS
}

Dissertação apresentada à Escola Politécnica da Universidade de São Paulo para a obtenção do Título de Mestre em Engenharia 


\section{JOÃO PAULO RIBEIRO DANTAS}

\section{INVESTIGAÇÃO EXPERIMENTAL DA FADIGA EM LAJES DE PONTES}

ARMADAS COM BARRAS OU TELAS SOLDADAS

Dissertação apresentada à Escola Politécnica da Universidade de São Paulo para a obtenção do Título de Mestre em Engenharia

Área de Concentração: Engenharia de Estruturas

Orientador: Prof. Dr. Fernando Rebouças Stucchi

\section{São Paulo}




\section{FICHA CATALOGRÁFICA}

Dantas, João Paulo Ribeiro

Investigação experimental da fadiga em lajes de pontes armadas com barras ou telas soldadas / J.P.R. Dantas. -- São Paulo, 2010.

$137 \mathrm{p}$.

Dissertação (Mestrado) - Escola Politécnica da Universidade de São Paulo. Departamento de Engenharia de Estruturas e Geotécnica.

1. Fadiga das estruturas 2 . Pontes de concreto armado 3. Fadiga dos materiais 4. Lajes I. Universidade de São Paulo. Escola Politécnica. Departamento de Engenharia de Estruturas e Geotécnica II. t. 
Dedico este trabalho aos meus pais e irmã. 


\section{AGRADECIMENTOS}

Ao professor Doutor Fernando Rebouças Stucchi pela orientação, atenção, incentivo que me foi concedida ao longo de todo este trabalho.

Aos meus queridos pais, minha imã pelo grande exemplo, amor, apoio e suporte.

Aos meus grandes amigos que mesmo distante se fizeram presentes em vários momentos, durante esta etapa da minha vida.

Ao professor Doutor Pedro Almeida de Oliveira por todo suporte dado na parte experimental da pesquisa.

A toda equipe de funcionários do Laboratório de estruturas e materiais por todas as sugestões e serviços prestados nesta pesquisa.

Ao Instituto brasileiro de telas soldadas por acreditar nesta pesquisa e fornecer recursos financeiros para o desenvolvimento deste trabalho.

À empresa HOLCIM por fornecer a brita utilizada no concreto utilizado nas lajes.

Ao Instituto de Pesquisas Tecnológicas - IPT, Centro de Tecnologia de Obras de Infra-Estrutura e Laboratório de Metalurgia e Materiais Cerâmicos pelo apoio aos ensaios de caracterização dos materiais.

À diretoria do Laboratório de Estruturas e materiais pela utilização do espaço e aparelhos do laboratório.

A CAPES pelo apoio financeiro e ao contribuinte brasileiro que através dos seus impostos permitiram que esta bolsa fosse possível.

A todos que de alguma forma colaboraram nesta pesquisa. 


\section{RESUMO}

Este trabalho apresenta estudos, ensaios e análises de resultados a respeito do comportamento à fadiga das estruturas de concreto armadas com barras isoladas ou telas soldadas, começando pelas lajes de pontes, seus elementos mais sensíveis à fadiga.

A parte experimental desta pesquisa consiste na investigação experimental do comportamento à fadiga de lajes de concreto armado, executadas com e sem pré-lajes armadas com barras de aço isoladas ou em tela soldada.

Foram realizados ensaios de fadiga de barra ao ar em 36 corpos de prova de CA50 $\$ 10 \mathrm{~mm}$, barras isoladas ou em telas, com o objetivo de construir a Curva de Wöhler dessas barras de produção nacional.

Além disso, foram ensaiadas 20 lajes de concreto executadas com ou sem pré-lajes de concreto, montadas com diversas configurações de armadura, submetidas a ensaios estáticos e dinâmicos. A configuração de armadura adotada nas lajes da pesquisa foi baseada nas utilizadas com frequiência em lajes de pontes.

A escassez de dados precisos a respeito do comportamento de lajes armadas com barras ou com telas soldadas de fabricação brasileira submetidas a ações cíclicas conduziu ao propósito de se elaborar uma pesquisa de caráter experimental sobre esse tema, cujos resultados e conclusões pudessem fornecer informações mais precisas a respeito do desempenho das lajes.

Palavras-chave: Fadiga em lajes de concreto armado, Ensaios dinâmicos, Ensaios de barra ao ar, Fadiga de barras de aço, Fadiga em telas soldadas. 


\begin{abstract}
This research presents the studies, tests and the analysis of the results about the behavior of concrete structures reinforced with rebars or steel mesh due to fatigue loading, starting with bridge slabs which are the most susceptible elements to fatigue.

The experimental part of this research consists in testing the behavior due to fatigue of concrete slabs, with or without pre-slabs and reinforced with continuous bars or steel mesh.

Axial testing in air of 36 specimens of CA50 $\$ 10 \mathrm{~mm}$ in continuous bars and mesh were made in order to build the Wöhler Curve for Brazilian conditions.

Beyond that, tests were made in 20 concrete slabs with pre-slabs, with several reinforcement's arrangement. The 20 slabs were submitted to static and dynamic loading. The reinforcement configuration was based on the commonly used for these elements.

The scarcity of more precise data about the behavior of concrete slabs reinforced with rebars or welded mesh made in Brazil submitted to cycle loading was the major reason to make a research based on the testing results about this theme, wich results and conclusions are capable of producing more accurate information about the behavior of the slabs.
\end{abstract}

Key words: Fatigue in reinforced concrete slabs, Dynamic tests, Axial testing in air, Fatigue in rebars, Fatigue in mesh. 


\section{SUMÁRIO}

1 INTRODUÇÃO...............................................................................................................

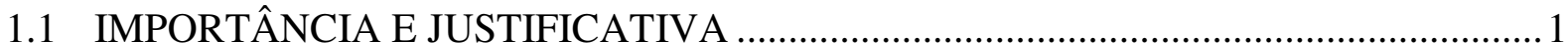

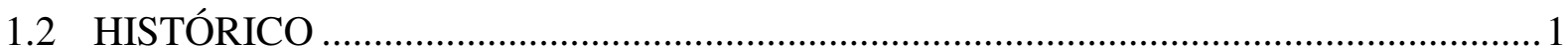

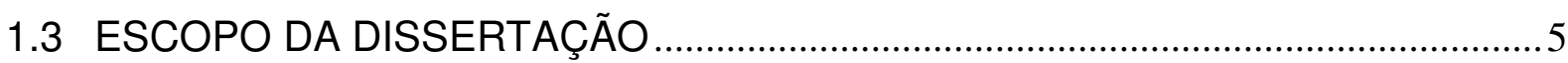

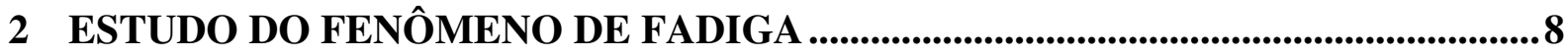

2.1 INTRODUÇÃ

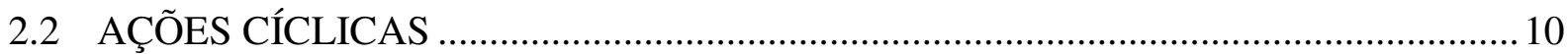

2.2.1 Cargas cíclicas de grande amplitude e baixa ciclagem ..............................................13

2.2.2 Cargas cíclicas de baixa amplitude e grande ciclagem ........................................13

2.3 HIPÓTESE DE PALMGREN-MINER (DANO CONTÍNUO LINEAR) ....................... 14

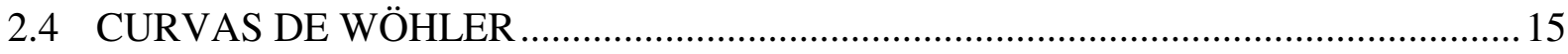

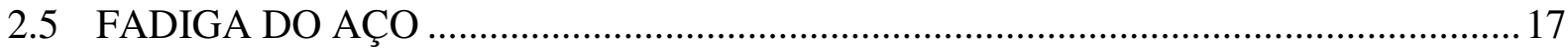

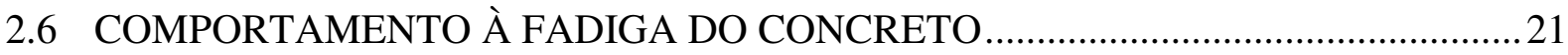

2.6.1 Comportamento do concreto à compressão ...............................................................21

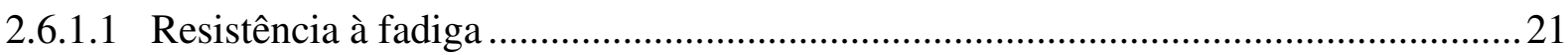

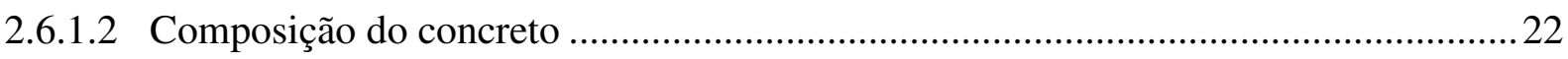

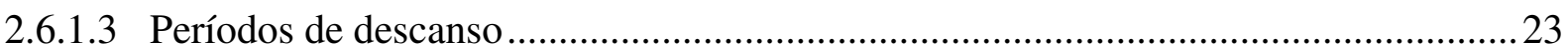

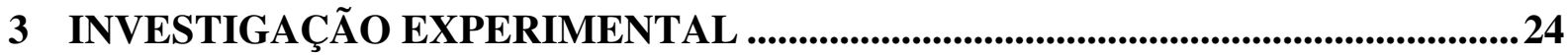

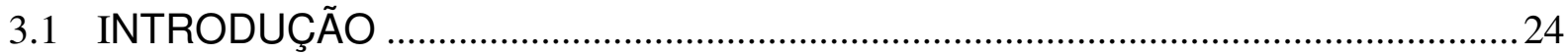

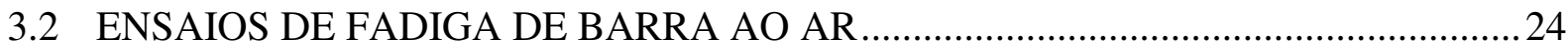

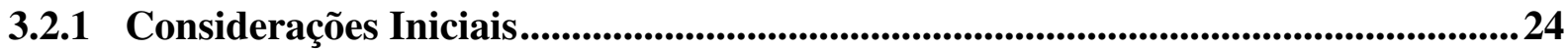

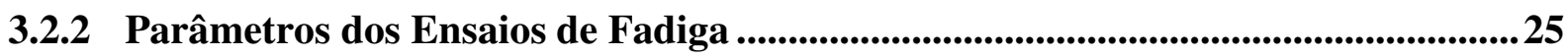

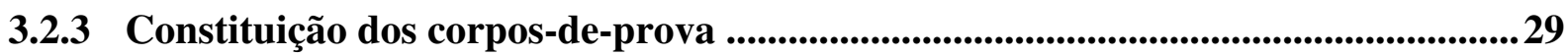

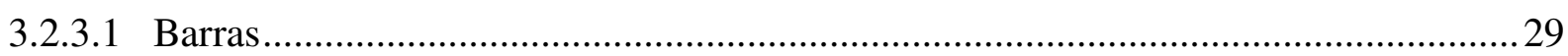

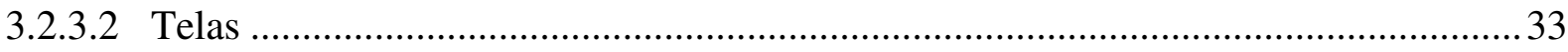

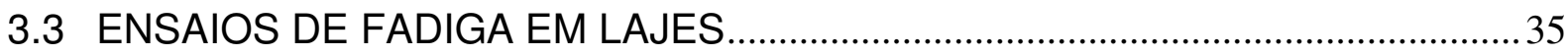

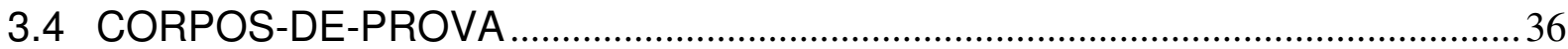

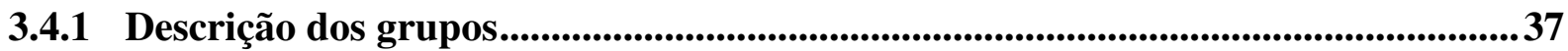

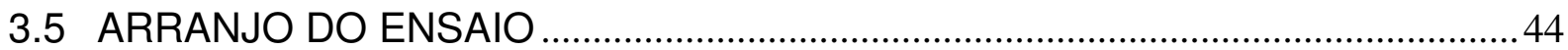

3.5.1 Instrumentação das lajes .....................................................................................52 


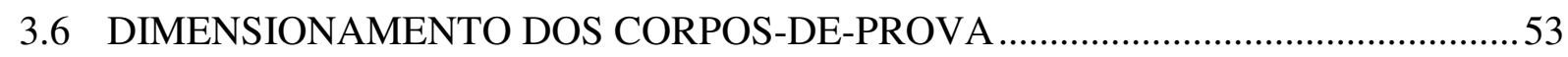

3.6.1 Dimensionamento para o ELU de ruptura ...............................................................53

3.6.2 Dimensionamento para o ELU de fadiga ........................................................57

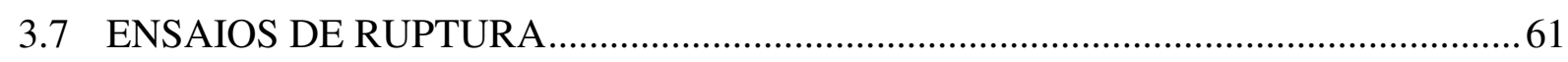

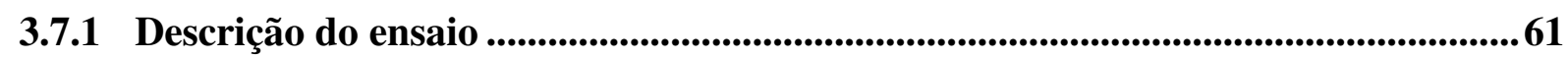

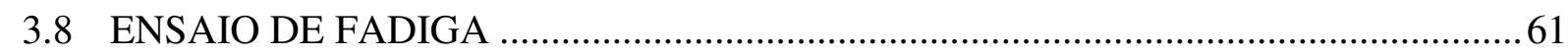

3.8.1 Descrição do ensaio .............................................................................................................61

3.9 ENSAIOS DE CARACTERIZAÇÃO DOS MATERIAIS ..........................................62

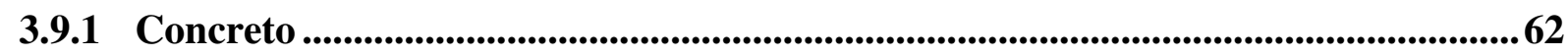

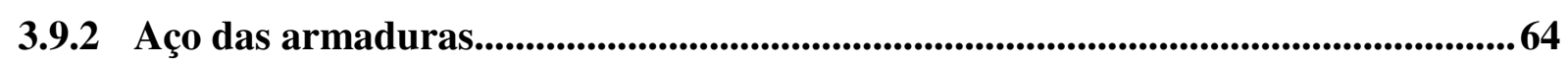

4 RESULTADOS E ANÁLISES DOS RESULTADOS ...................................................69

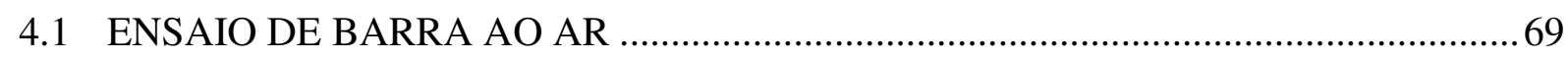

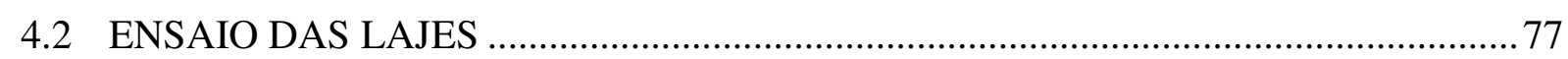

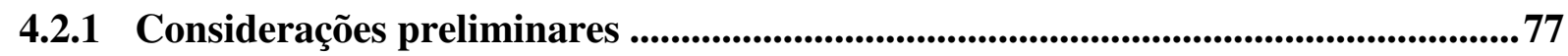

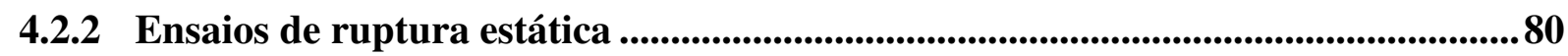

4.2.2.1 Análise do individual do comportamento das lajes no ensaio estático ...................... 80

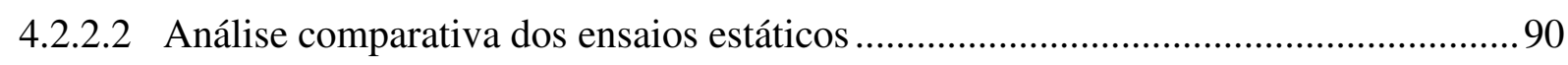

4.2.2.3 Análise comparativa do desempenho das lajes armadas com barras isoladas com as

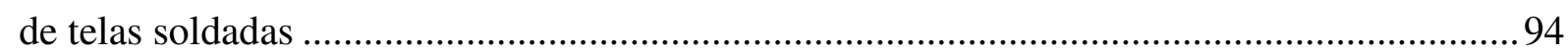

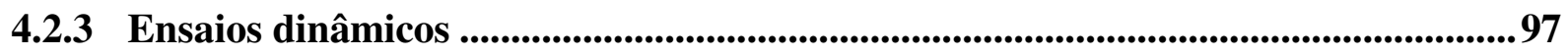

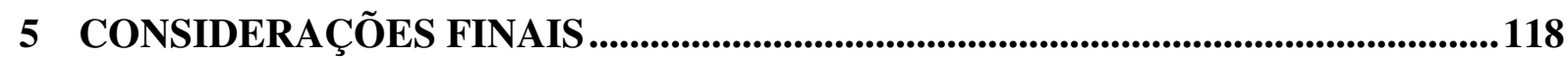

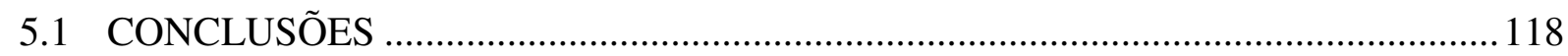

5.2 SUGESTÕES PARA TRABALHOS FUTUROS ........................................................ 120

ANEXO A - ANÁLISE DAS RUPTURAS POR FADIGA ................................................121

ANEXO B - TABELAS DOS RESULTADOS OBTIDOS PARA OS DIVERSOS

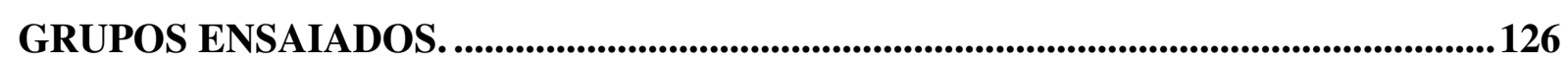

ANEXO C - EQUIPE TÉCNICA DO LABORATÓRIO DE ESTRUTURAS E

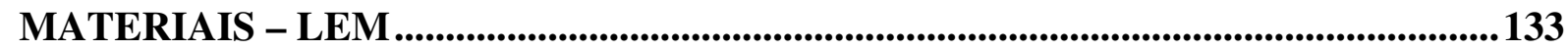

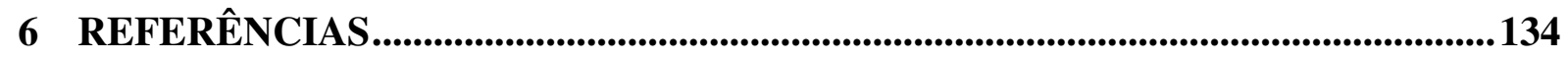




\section{LISTA DE FIGURAS}

Figura 1 - Tensão x tempo com reversão completa.............................................................. 3

Figura 2 - Esquema típico da curva de Wöhler ................................................................... 4

Figura 3 - Progresso de abertura de fissuras até a ruptura por fadiga - (CEB-FIP MC, 1990) ..8 Figura 4 - Carregamento cíclico com amplitude constante. Caso (a) tensões completamente reversas, $\left(\sigma_{m}\right)=0$; (b) tensão média $\left(\sigma_{m}\right)$ diferente de zero e (c) zero-tração, $\left(\sigma_{\text {min }}=0\right) \ldots 12$

Figura 5 - Carga cíclica com amplitude constante ............................................................... 13

Figura 6 - Carga cíclica com amplitude variável............................................................... 14

Figura 7 - Regra de Palmgren-Miner para estimativa da vida à fadiga para carregamento cíclico completamente reverso e de amplitude variável....................................................... 15

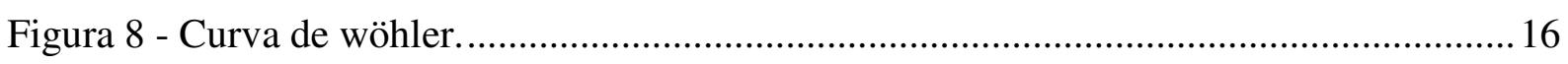

Figura 9 - Curva S-N segundo a NBR 6118:2003 ….......................................................... 16

Figura 10 - À esquerda, fratura típica em uma barra de aço e, à ............................................ 18

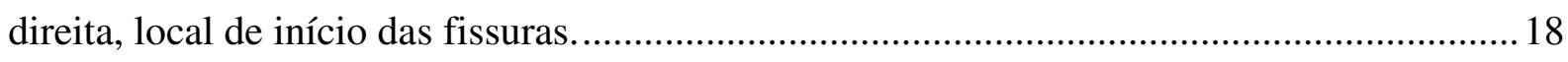

Figura 11 - Curva S-N típica de concreto em compressão (Klausen, 1978). .......................... 22

Figura 12 - Ensaios de fadiga de barra ao ar - Dartec...........................................................25

Figura 13 - Esquematização da variação das tensões nos diferentes ensaios, mantida $\sigma_{\max }$

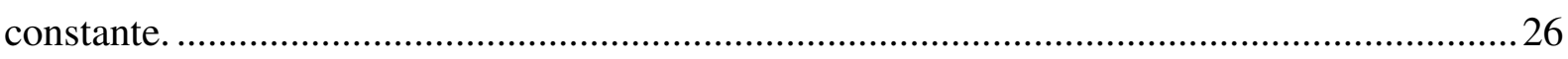

Figura 14 - Curva Classe R1 - Dados de fadiga publicados para barras de diâmetros menor ou igual a 16mm - “Bulletin D'Information N. 188 - Fatigue of Concrete Structures - State of

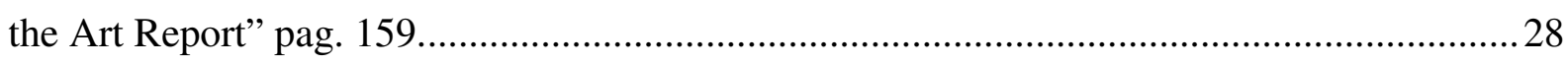

Figura 15 - Curva Classe R2 - Dados de fadiga publicados para barras de diâmetros maiores que 16mm - "Bulletin D'Information N. 188 - Fatigue of Concrete Structures - State of the

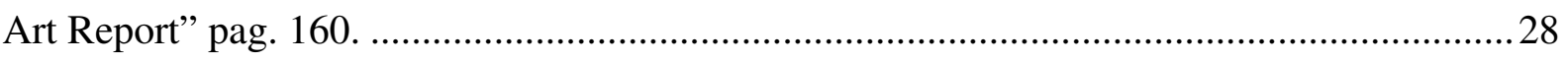

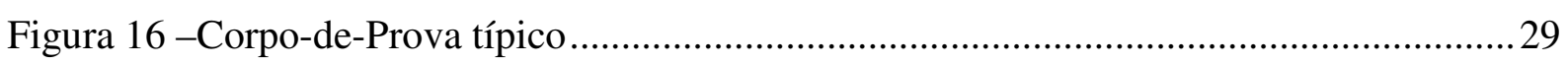

Figura 17 - Dartec - Máquina do ensaio de eadiga. ............................................................ 30

Figura 18 - Corpo-de-prova durante ensaios .................................................................. 30

Figura 19 - Corpos-de-Prova granalhados, com garras de epóxi.......................................... 31

Figura 20 - Clavete e copos - Corpo-de-prova ................................................................ 31

Figura 21 - Corpo-de-prova protegido com mangueira plástica........................................... 32

Figura 22 - Semicanas de alumínio e conjunto completo de fixação do corpo-de-prova......... 32 
Figura 23 - Corpos-de-prova granalhados, com clavete e alumínio .....

Figura 24 - Exemplo esquemático de corte de tela para confecção do corpo-de-prova. .......... 34

Figura 25 - Corpo-de-prova - telas

Figura 26 - Corpo-de-prova protegido com mangueira plástica pronto para procedimento de

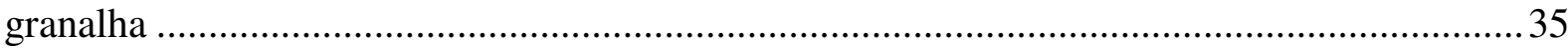

Figura 27 - Lajes envolvidas por lona plástica para a cura adequada …................................ 36

Figura 28 - Desenho esquemático das etapas de concretagem ............................................... 38

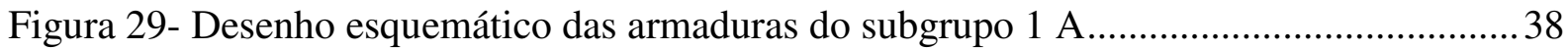

Figura 30 - Foto após a primeira etapa concretagem, com a armadura negativa montada. ..... 39

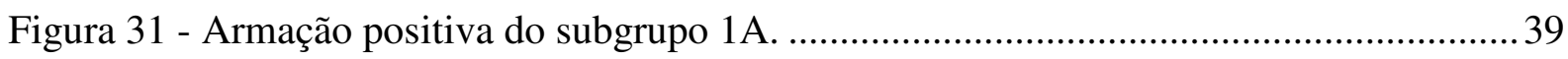

Figura 32 - Desenho esquemático das armaduras do subgrupo 1B ...................................... 40

Figura 33 - Desenho esquemático das armaduras do subgrupo 2A....................................... 41

Figura 34 - Desenho esquemático das armaduras do subgrupo 2B...................................... 42

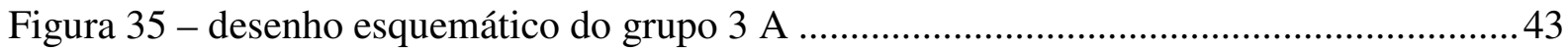

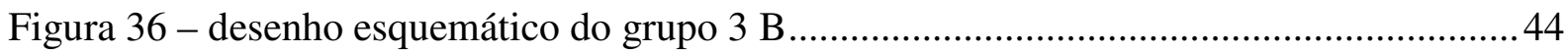

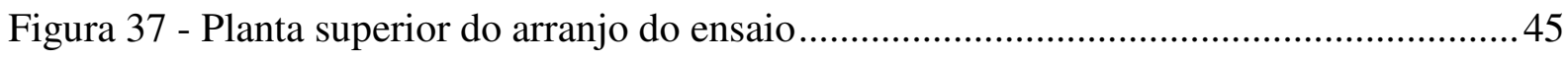

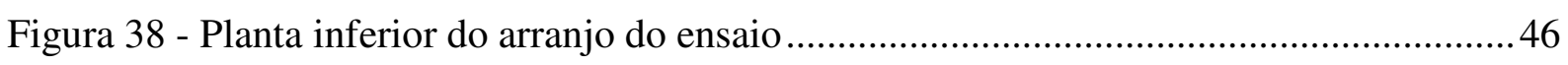

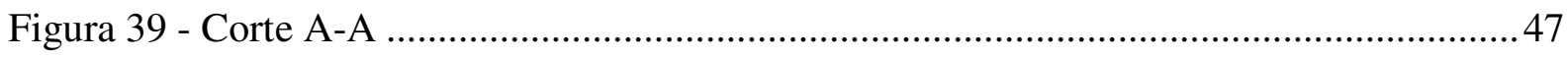

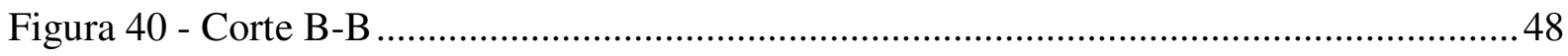

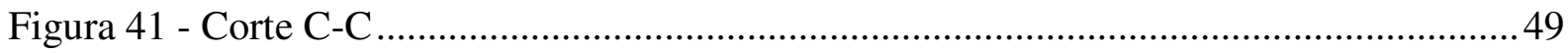

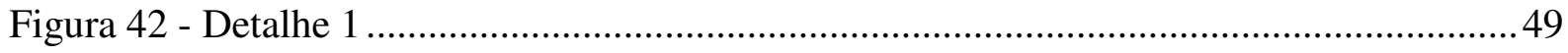

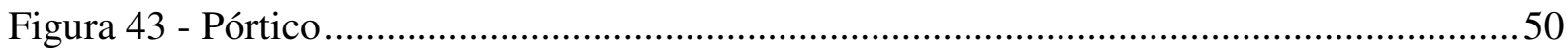

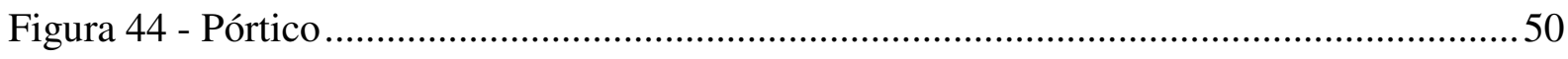

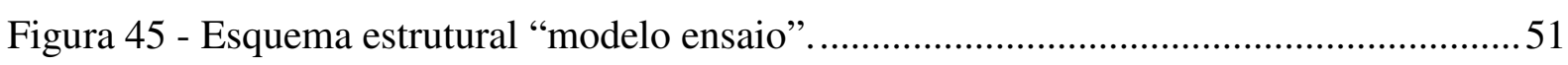

Figura 46 - Esquema estrutural “ ponte" .......................................................................... 51

Figura 47 - Posicionamento dos extensômetros na armadura da laje com $\mathrm{A}_{\mathrm{s}}=2 \mathrm{~cm}^{2}-4$ barras

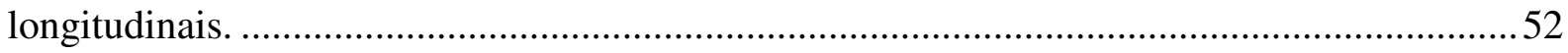

Figura 48 - Posicionamento dos extensômetros na armadura da laje com As $=4 \mathrm{~cm}^{2}-5$ barras

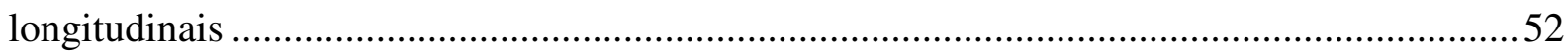

Figura 49 - Sistema de aquisição de dados ........................................................................53

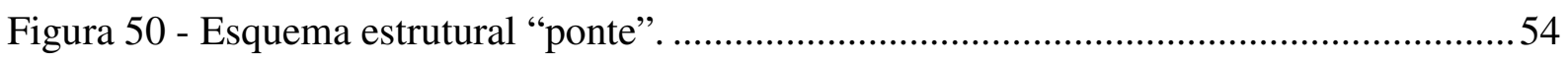

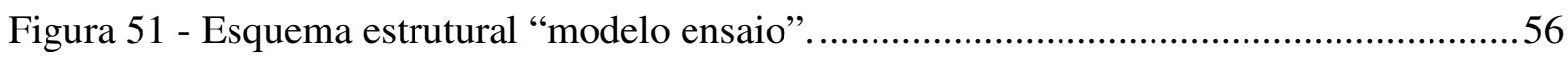

Figura 52- Corpo-de-prova do ensaio de módulo de elasticidade .........................................62

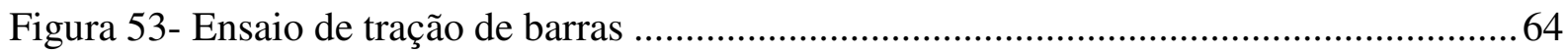


Figura 54- Ensaio de tração de barras

Figura 55 - Distribuição Normal para Barras Isoladas. ...................................................... 71

Figura 56 - Distribuição Normal para Telas Soldadas....................................................... 72

Figura 57 - Curvas de Wöhler para barras isoladas. ............................................................ 73

Figura 58 - Curvas de Wöhler para Telas Soldadas............................................................. 74

Figura 59- Curvas de Wöhler para Barras Isoladas e Telas Soldadas. .....................................74

Figura 60 - Comparação entre as Curvas de Wöhler das Barras Isoladas. .............................. 75

Figura 61- Comparação entre Curvas de Wöhler das Telas Soldadas.................................... 75

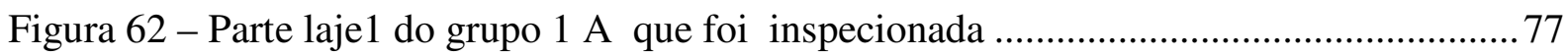

Figura 63 - abertura na laje evitando o contato do extensômetro com o concreto ...................78

Figura 64 - Esquema do posicionamento do extensômetro externo ...................................... 78

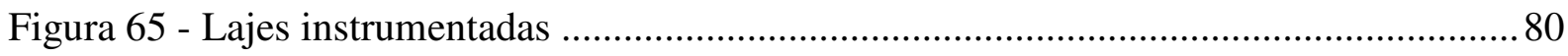

Figura 66 - Gráfico do ensaio de ruptura da laje 1 ......................................................... 81

Figura 67 - Gráfico força $\mathrm{x}$ deslocamento do ensaio de ruptura da laje 1 ............................. 81

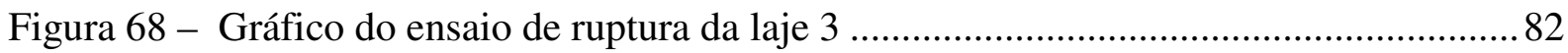

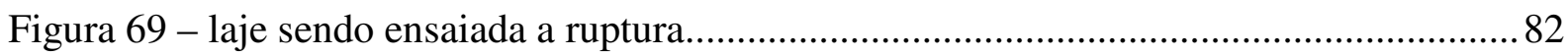

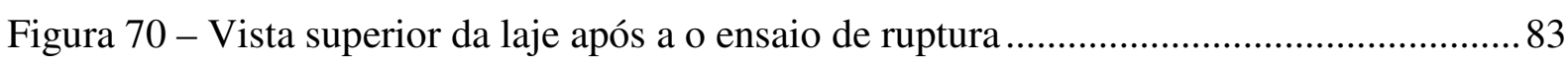

Figura 71 - gráfico do ensaio de ruptura das lajes 1 e 3 .....................................................91

Figura 72 - Gráfico do ensaio de ruptura das lajes 2 e 3 ..................................................... 92

Figura 73 -Gráfico do ensaio de ruptura das lajes 1, 2 e 3................................................93

Figura 74 - Gráfico do ensaio de ruptura das lajes 1,2 e 3...............................................94

Figura 75 - Gráfico do ensaio de ruptura das peças não fadigadas.........................................95

Figura 76 - Gráfico do ensaio de ruptura das peças fadigadas ..............................................96

Figura 77 - Gráfico do ensaio ruptura das peças após o ensaio dinâmico ................................97

Figura 78 - Comportamento da laje 2 durante os momentos iniciais do ensaio dinâmico ...... 99

Figura 79 - Comportamento da laje 2 durante a primeira hora do ensaio dinâmico ............... 100

Figura 80 - Comportamento da laje 2 durante a última hora do ensaio dinâmico................... 101

Figura 81 - Comportamento da laje 1 durante os primeiros momentos do ensaio dinâmico 103

Figura 82 - Comportamento da laje 1 durante a primeira hora do ensaio dinâmico ............... 104

Figura 83 - Comportamento da laje 1 durante a segunda hora do ensaio dinâmico............... 105

Figura 84 - Comportamento da laje 1 durante a terceira hora do ensaio dinâmico................ 106

Figura 85 - Comportamento da laje 1 durante a quarta hora do ensaio dinâmico .................. 107

Figura 86 - Comportamento da laje 1 durante a quinta hora do ensaio dinâmico .................. 108

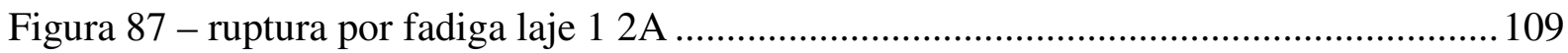


Figura 88 - Comportamento da laje 2 durante os primeiros instantes do ensaio dinâmico .... 110 Figura 89 - Comportamento da laje 2 durante a primeira hora do ensaio dinâmico

Figura 90 - Comportamento da laje 3 no momento da ruptura aproximadamente 1,6 milhões de ciclos.

Figura 91 - Comportamento da laje 2 durante a primeira hora do ensaio dinâmico 114

Figura 92 - Comportamento da laje 2 durante a última hora do ensaio dinâmico 115

Figura 93 - Comportamento da laje 2 durante a última hora do ensaio dinâmico. 117

Figura A1 - Representação das zonas de uma ruptura por fadiga.

Figura A2 - Visualização da superfície de ruptura de uma barra após o ensaio de barra ao ar

Figura A3 - Ponto de nucleação da fissura

Figura A3 - Região da ruptura abrupta 123

Figura A4 - Visualização da superfície de ruptura de uma barra da laje 1 do subgrupo 2 A. 124

Figura A5 - Ponto de nucleação da fissura 124

Figura A6 - Região da ruptura abrupta 125 


\section{LISTA DE TABELAS}

Tabela 1 - Resistência característica do aço à fadiga segundo o

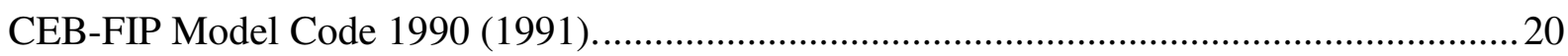

Tabela 2 - Variação na tensão admissível na armadura segundo NBR 6118:2003................. 20

Tabela 3 - Valores de k equivalentes ao desempenho médio e de projeto - "Bulletin D'Information N. 188 - Fatigue of Concrete Structures - State of the Art Report" pag.160 ..27

Tabela 4 - Resumos dos seis conjuntos de ensaios que foram realizados. .............................29

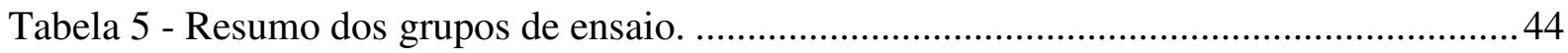

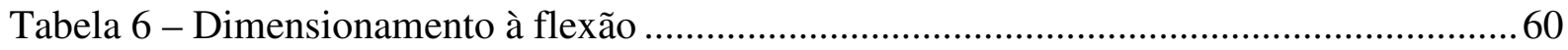

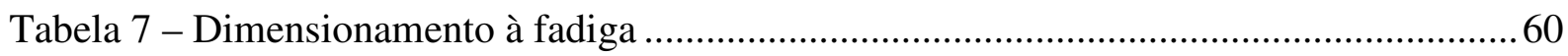

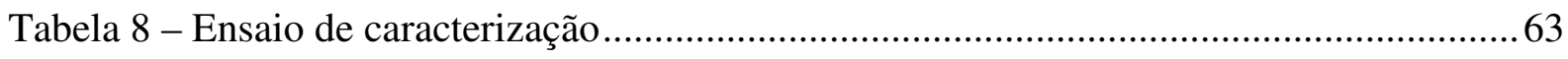

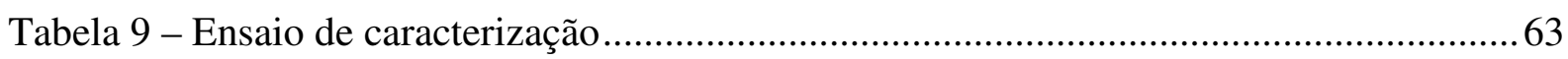

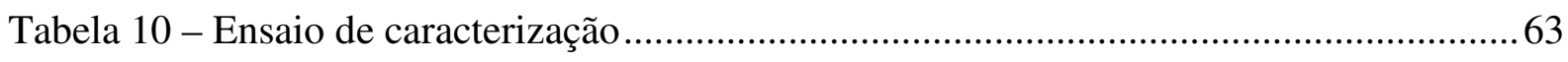

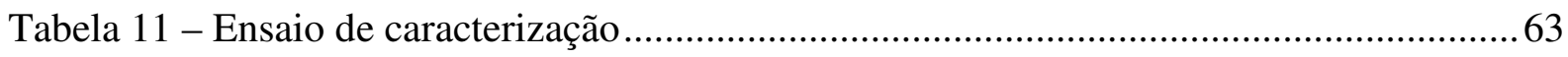

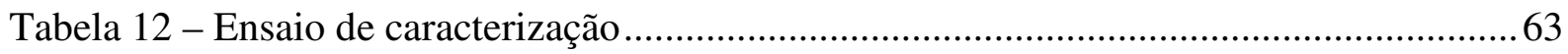

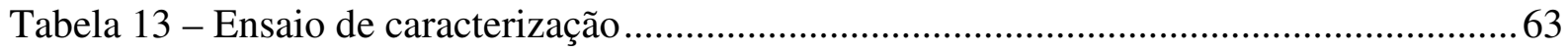

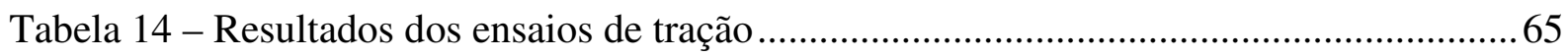

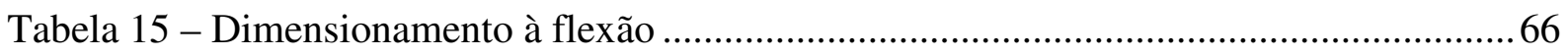

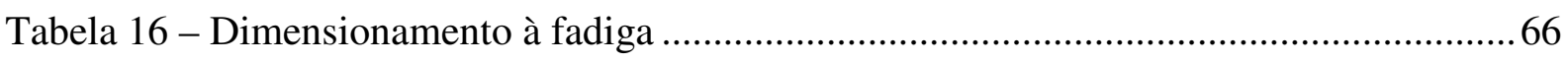

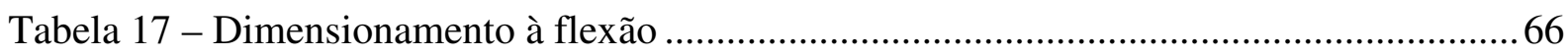

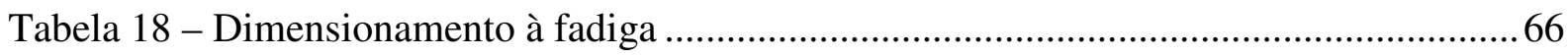

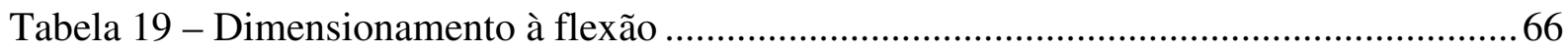

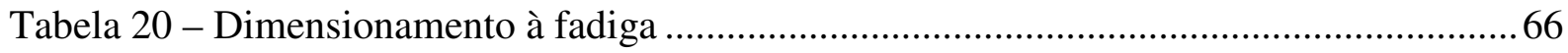

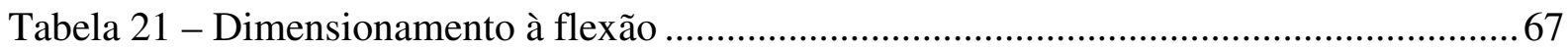

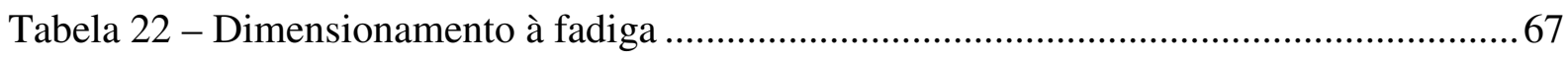

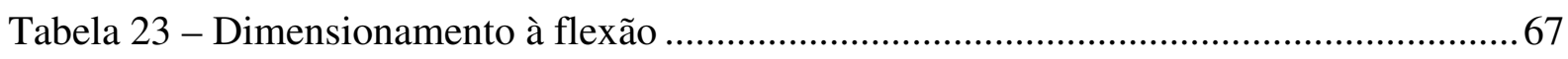

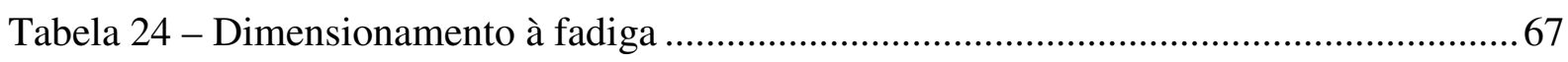

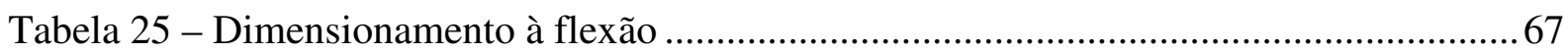


Tabela 26 - Dimensionamento à fadiga

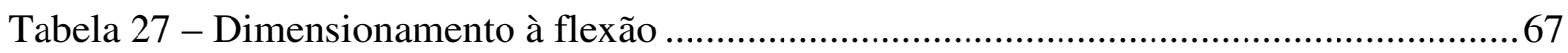

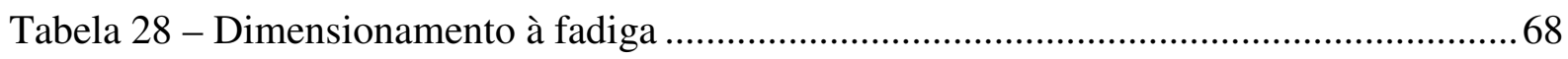

Tabela 29 - Resultados obtidos para os grupos 1,2 e 3; barras isoladas. ................................69

Tabela 30 - Resultados obtidos para o grupo 4,5 e 6; telas soldadas.....................................69

Tabela 31 - Resultados obtidos para os grupos 1 e 2 ........................................................... 70

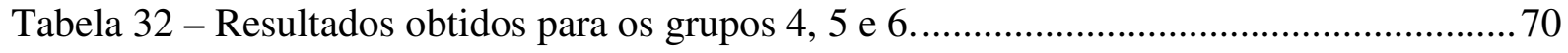

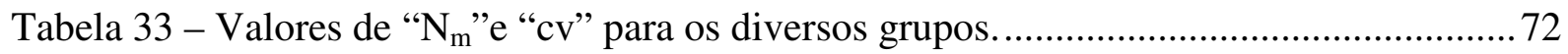

Tabela 34 - Valores de " $\mathrm{N}_{\mathrm{k}}$ " para os diversos grupos......................................................... 73

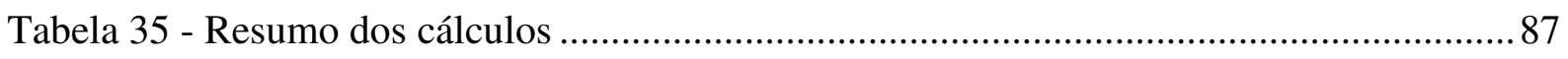

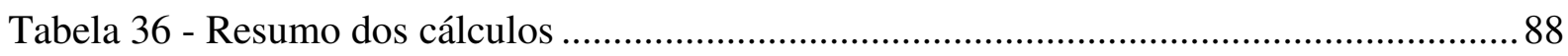

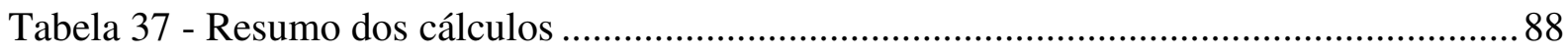

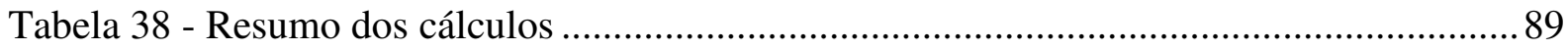

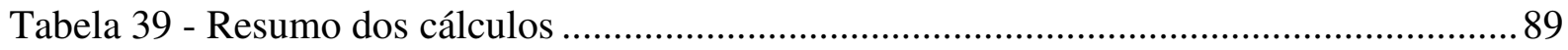

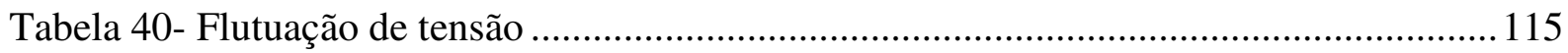

Tabela 41- Flutuação de tensão .................................................................................. 117

Tabela B.1 - Resultados do ensaio de ruptura da laje L1 do Grupo 1A................................ 126

Tabela B.2 - Resultados do ensaio de ruptura da laje L2 do Grupo 1A............................... 126

Tabela B.3 - Resultados do ensaio de ruptura da laje L3 do Grupo 1A................................ 127

Tabela B.4 - Resultados do ensaio de ruptura das lajes L2 e L4 do Grupo 1B...................... 127

Tabela B.5 - Resultados do ensaio de ruptura da laje L4 do Grupo 1B................................ 128

Tabela B.6 - Resultados do ensaio de ruptura da laje L2 do Grupo 2A.................................. 128

Tabela B.7 - Resultados do ensaio de ruptura da laje L3 do Grupo 2A............................... 129

Tabela B 8 - Resultados do ensaio de ruptura da laje L1 do Grupo 3A. ................................ 129

Tabela B.9 - Resultados do ensaio de ruptura da laje L2 do Grupo 3A............................... 130

Tabela B.10 - Resultados do ensaio de ruptura da laje L3 do Grupo 3A. .............................. 130

Tabela B.11 - Resultados do ensaio de ruptura da laje L1 do Grupo 3B. .............................. 131

Tabela B.12 - Resultados do ensaio de ruptura da laje L2 do Grupo 3B. ............................. 131

Tabela B.13 - Resultados do ensaio de ruptura da laje L3 do Grupo 3B. ............................ 132 


\section{INTRODUÇÃO}

\subsection{IMPORTÂNCIA E JUSTIFICATIVA}

A fadiga pode ser bem identificada nas estruturas de aço tanto na etapa de projeto quanto na inspeção e manutenção da estrutura durante sua vida útil de serviço. A ruptura por fadiga também acontece em estruturas de concreto armado e protendido.

As fissuras de fadiga no concreto não possuem um padrão definido, ao contrário do que acontece no aço. Por este motivo é muito difícil identificar o fenômeno da fadiga em estruturas de concreto. Contudo já existem alguns métodos que permitem identificá-la.

É sabido que em muitos países as normas de projeto ainda não mencionam a fadiga. A França, por exemplo, que nunca havia exigido verificação da fadiga em suas normas de projeto de pontes, passou a fazê-lo agora com a adoção do Eurocode 2 (2005) - "Design of Concrete Structures", opcional entre 2006 e 2009, mas obrigatório a partir de 2010.

É incontestável a importância crescente que as pesquisas, as normas e as práticas de diversos países desenvolvidos vêm dando à segurança das estruturas de concreto armado, no que diz respeito ao estado limite de fadiga.

O dimensionamento de estruturas de concreto armado levando em consideração o fenômeno da fadiga, no Brasil, é feito desde 1967. Os procedimentos de para o cálculo estavam descritos na EB3 (1967) - "Barras e fios destinados a armaduras de concreto armado", os critérios de projeto foram revisados algumas vezes até a última versão com a NBR6118 (2003)- "Projeto de Estruturas de Concreto", contudo é sabido que ainda é necessário um melhor conhecimento dos materiais brasileiros e das ações cíclicas.

É necessário que se conheça com propriedade o comportamento a fadiga do aço e do concreto, assim como as ações cíclicas que podem provocar o estado limite de fadiga. Para que seja possível o correto dimensionamento das estruturas de concreto sujeitas a ações que podem causar fadiga.

\subsection{HISTÓRICO}

A etimologia da palavra fadiga é o latim "fatigare", significa "cansar, estar cansado", e vem designar as falhas de materiais que sofreram carregamentos cíclicos. 
O primeiro pesquisador a publicar estudos a respeito de fadiga em peças metálicas foi o alemão W. A. J. Albert em 1829. Mas foi Wöhler que, durante o período de 1852 a 1869, na Alemanha, aplicou pela primeira vez carregamentos de flexão rotativa e de torção.

Uma das primeiras definições sobre o conceito de fadiga foi apresentada pela Internacional Organization for Standardization em 1964, em Genebra, que define a fadiga como um termo que se aplica às mudanças nas propriedades que podem ocorrer em um material metálico devido à aplicação repetida de forças (ou tensões), embora geralmente este termo se aplique especialmente para aquelas mudanças que conduzem ao fraturamento ou falha.

A definição anterior tem sua validade também e principalmente para a fadiga de materiais não metálicos, uma vez que as falhas podem ocorrer de várias formas, destacando-se: Fadiga mecânica, Fadiga térmica e Fadiga por corrosão.

Desde a metade do século XIX, uma classificação de cientistas e engenheiros tem feito pioneiras contribuições para entender a fadiga numa ampla variedade de materiais metálicos e não-metálicos, frágeis e dúcteis, monolíticos e compostos, naturais e sintéticos.

Com o crescimento da utilização do aço como material estrutural, principalmente em pontes e sistemas ferroviários, o interesse pelo estudo da fadiga começou a se desenvolver. Segundo Suresh (1991), os primeiros relatos sobre fadiga foram escritos por volta de 1829, quando o engenheiro alemão W. A. J. Albert realizou alguns ensaios em correntes de aço usadas nas mineradoras.

A fadiga foi identificada pelas primeiras vezes por volta de 1800. Nesta época foi percebido que os eixos das locomotivas começaram a falhar com pouco tempo de uso. Apesar do material usado nesses eixos ser dúctil, e ainda assim este apresentava uma superfície de fratura frágil e rápida, pois este processo de falha inicia-se com uma fissura de nível microscópico,ponto de nucleação, originados a partir de um ponto de concentrações de tensões ou até mesmo defeitos internos da estrutura, que irão se propagar até a ruptura repentina da peça.

A explicação para estas rupturas repentinas só surgiu no ano de 1843, quando Rankine publicou um artigo entitulado de "On the Causes of Unexpected Breakage of Journals of Railway Axles" que explicava que a causa das falhas era que o material tinha cristalizado e tornado-se frágil devido às flutuações de tensões. O que de fato aconteceu é que quando os eixos foram projetados apenas foram considerados os 
esforços estáticos, isto é não foram feitas verificações à fadiga; contudo, com o advento dos mecanismos movidos a vapor, os carregamentos dinâmicos surgiram como um novo fenômeno. Estes eixos eram acoplados nas rodas dos vagões e durante o movimento eram submetidos a uma flexão rotativa, na forma de reversão completa como visto na figura1.

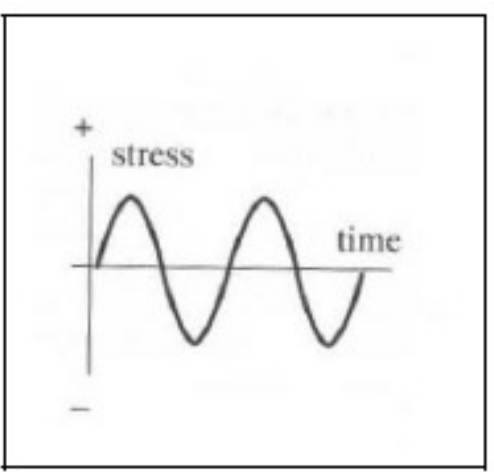

Figura 1 - Tensão x tempo com reversão completa

O pioneiro a utilizar o termo fadiga foi Poncelet em 1839. O processo da falha ainda não tinha sido explicado, mesmo de materiais dúcteis, então começou-se a acreditar que os materiais ficavam cansados devido a tantas variações de carregamentos. Contudo anos depois foi Wöhler, que através de ensaios de tração, mostrou que os eixos fraturados permaneciam dúcteis e fortes. Mas mesmo assim o termo fadiga permanece quando se diz respeito a cargas que variam em função do tempo.

A primeira investigação científica que se tem registro (que teve uma duração de aproximadamente 20 anos), do que é chamado hoje de "falha por fadiga" foi realizada por Wöhler.

Em 1871 Wöhler publicou os resultados do seu trabalho e concluiu que os responsáveis por uma falha por fadiga estão relacionados com a variação de tensão e o número de ciclos e também observou a existência do limite de fadiga $\left(\sigma_{\mathrm{e}}\right)$ para aços, que representa um nível de tensão aplicada onde o material pode trabalhar por milhões de ciclos com tensões totalmente reversas sem caminhar para a fratura. A curva S-N ou de Wöhler tornou-se um padrão na caracterização dos comportamentos dos materiais e é usada até hoje, sendo representada na Figura 2. 


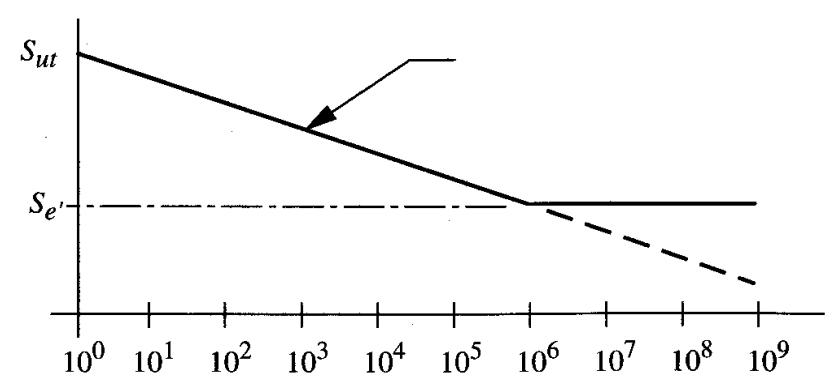

Figura 2 - Esquema típico da curva de Wöhler

Em 1910, o americano O. H. Basquin representou a curva de Wöhler em forma logarítmica e propôs a fórmula:

$$
\sigma_{a}=C \times K^{n}
$$

Em 1924, Palmgen foi o primeiro a sugerir um modelo linear de dano para análise da fadiga , neste modelo era possível levar em consideração o histórico dos carregamentos aplicados, e acumular o dano relativo de cada carregamento.

O modelo de Palmgren-Miner surgiu em 1945 quando Miner apresentou uma equação de dano liner devido à fadiga. Este modelo estima o valor do acumulado para cada ciclo de flutuação de tensão correspondente a uma probabilidade de ruptura, para um determinado número de ciclos. A ruptura por fadiga acontece no momento em que $\frac{\sum n}{N}=1$, sendo $\mathrm{n}$ o número de ciclos solicitantes para uma determinada intensidade de tensão e $\mathrm{N}$ o número admissível de ciclos para essa mesma intensidade.

A soma do dano acumulado, seguindo o modelo linear de Palmgren-Miner, é maior que 1 quando a intensidade da tensão aumenta gradualmente e menor que 1 quando antes é aplicada uma tensão mais alta. AGARWAL et al. (1994) afirmam que curvas de fadiga, com base em ciclos constantes, podem resultar em projetos contra a segurança, em casos onde o carregamento é variável e tem natureza transiente. Propõem a utilização de princípios probabilísticos na consideração da fadiga.

Assim como aconteceu com o aço as pesquisas sobre fadiga em estruturas de concreto, tiveram seu início com o intuito de solucionar os problemas práticos que estavam acontecendo na época

Entretanto o concreto armado era um material mais complexo para ser analisado, uma vez que existia a necessidade de se estudar o comportamento de dois materiais trabalhando em conjunto. Por volta de 1958 , acreditava-se que a inter-relação entre os materiais era considerada complexa para o carregamento estático e presumia-se que, para o carregamento cíclico, as dificuldades seriam ainda maiores. 
Além disso, a geração de curvas S-N com alto grau de confiabilidade deriva de numerosos testes de fadiga, os quais fornecem resultados sujeitos a grande dispersão. Para alguns aços o limite à fadiga aparece após 1 milhão de ciclos, enquanto que, para outros, a curva não se torna assintótica após 100 milhões de ciclos (MALLET, 1991). No concreto não existe um limite à fadiga evidente, embora se saiba que um número elevado de ciclos de carregamento com baixos níveis de tensão já possibilita a ocorrência de danos por fadiga.

Após mais de 150 anos de estudos, as falhas por fadiga continuam sendo um dos maiores problemas em projetos de engenharia. Os custos de prevenção e/ou reparos de fraturas em componentes estruturais são muito grandes. Dowling (2007) estima que $80 \%$ desses custos em componentes mecânicos envolvem situações onde o carregamento cíclico e a fadiga são fatores contribuintes.

Em termos de avaliação da segurança à fadiga em estruturas de concreto, verifica-se que as normas de projeto CEB-FIP Model Code 1990 (1991), NBR 6118 (2003) e as recomendações do ACI 215 (1997), por exemplo, incorporaram alguns procedimentos simplificados de verificação. O estudo do comportamento mecânico dos materiais à fadiga é essencial para o aprimoramento destes critérios e desenvolvimento de métodos analíticos mais avançados para análise da fadiga e estimativas de falha. Além de servir para prevenir falhas, informações sobre a tendência e rapidez de acúmulo de danos e perda de desempenho estrutural ao longo dos ciclos de carga são fundamentais para o gerenciamento das atividades de prevenção e manutenção.

\subsection{ESCOPO DA DISSERTAÇÃO}

Este trabalho faz parte de um projeto de pesquisa realizado conjuntamente com dois alunos do programa de mestrado da Escola Politécnica da USP, Edielce Cristina Caixeta e Paulo de Sá Pereira Cavalcanti, com o intuito de se estudar a investigação experimental da fadiga em lajes de pontes armadas com barras isoladas e telas soldadas, executadas com ou sem pré-lajes. O mestrado destes dois alunos se encontra em andamento e os títulos de seus trabalhos são respectivamente Investigação experimental da fadiga em lajes de pontes com ou sem pré-lajes e Fadiga da ligação capa-pré-laje em tabuleiros de pontes rodoviárias. 
Este trabalho apresenta estudos e resultados de ensaios realizados a respeito do comportamento à fadiga dos aços e de telas soldadas utilizados nas estruturas de concreto, bem como a análise do comportamento à fadiga do próprio concreto, começando pelas lajes de pontes, seus elementos mais sensíveis à fadiga, sejam as maciças, sejam sobretudo as executadas com pré-lajes.

Várias são as estruturas de concreto sujeitas a solicitações cíclicas que podem sofrer ruptura por fadiga, como estruturas de pontes, sobretudo as lajes, e estruturas industriais, como as vigas de rolamento, entre outras.

Assim os objetivos desta pesquisa são:

a) Investigação experimental do comportamento à fadiga ao ar de barras de aço $\phi 10$ $\mathrm{mm}$ isoladas e em tela;

b) Investigação experimental do comportamento à fadiga do concreto e do aço em lajes armadas com barras e telas soldadas e saber até que ponto as soldas influenciam a resistência à fadiga;

c) Fornecer subsídios para o aprimoramento dos critérios de projeto para dimensionamento de estruturas de concreto submetidas à fadiga, com base nos resultados experimentais e confiabilidade.

Com o intuito de facilitar a pesquisa neste trabalho, o resumo do conteúdo de cada capítulo é apresentado:

No Capítulo I são apresentadas as motivações, objetivos e o alcance do trabalho bem como um breve histórico sobre a fadiga no concreto armado.

No Capítulo II são apresentados os fundamentos necessários para o entendimento da fadiga no concreto armado e no aço. Neste capítulo serão abordadas de forma sucinta algumas das recomendações existentes para o cálculo de fadiga.

No Capítulo III é feita uma descrição detalhada da metodologia utilizada para alcançar os objetivos propostos onde são apresentados os critérios de cálculo utilizados, a justificativa dos ensaios realizados e dos modelos ensaiados.

No Capítulo IV serão apresentados e interpretados os resultados dos ensaios de ruptura e fadiga realizados. Neste capítulo é feita uma análise estatística dos resultados obtidos nos ensaios de fadiga das lajes para que sejam determinadas com mais precisão as curvas de Whöler, verificado até que ponto as soldas influenciam a 
resistência das telas e, por fim, será feita uma comparação dos resultados obtidos com os atuais critérios de projeto.

No Capítulo V serão feitos comentários e conclusões de acordo com todos os resultados obtidos neste trabalho.

Finalmente No Capítulo VI serão apresentadas as referências bibliográficas utilizadas nesta pesquisa. 


\section{ESTUDO DO FENÔMENO DE FADIGA}

\subsection{INTRODUÇÃO}

A fadiga é um processo de dano que gradualmente vai reduzindo a capacidade do componente estrutural, ocasionada por carregamentos cíclicos, então é natural que o fator mais importante para uma ruptura por fadiga seja a flutuação de tensões.

A ruptura por fadiga é um ruptura frágil, portanto acontece de forma repentina. Por ser um processo de dano progressivo as rupturas por fadiga acontecem sem que as tensões ultrapassem o limite plástico do material.

Nas verificações de segurança do concreto e do aço o fenômeno da fadiga, deve levar em conta o histórico da flutuação do carregamento em serviço, para que se determinem os esforços solicitantes e as tensões de serviço e assim serem feitas as verificações necessárias.

O processo que leva uma peça a romper por fadiga esta relacionado com a quantidade de ciclos e a flutuação de tensão a que a peça esta exposta. O processo de deterioração tem início através do aparecimento e/ou propagação de falhas préexistentes no material. Nos elementos estruturais as fissuras têm início nos pontos de concentração de tensões.

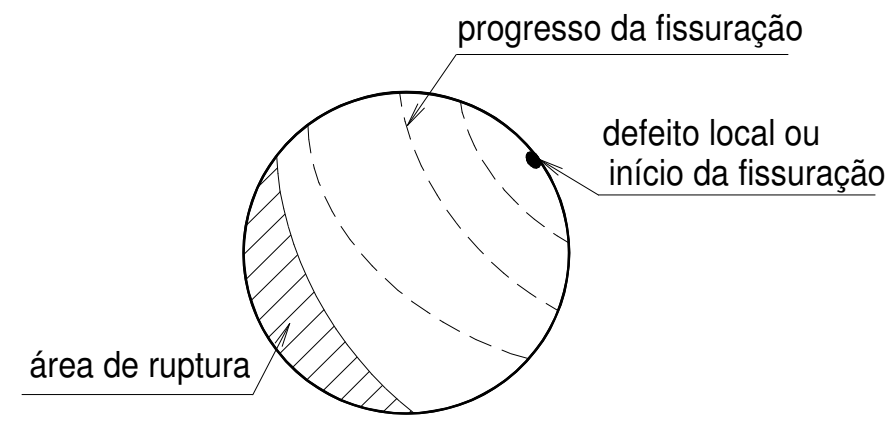

Figura 3 - Progresso de abertura de fissuras até a ruptura por fadiga - (CEB-FIP MC, 1990)

Nos materiais o processo de fadiga se inicia em um nível microscópico através da nucleação da trinca. Esta fase inicial do processo acarreta uma diminuição da rigidez do elemento estrutural. 
O processo de fadiga é composto por três estágios que tem como consequência o enfraquecimento progressivo das estruturas, abaixo estão descritos os 3 estágios de uma peça por fadiga:

a) Etapa 1:

- Em um ponto de concentração de tensão, acontece a nucleação da fissura a um nível microscópico, pré-existência de microfissuras devido a falhas previamente ao processo de fadiga.

b) Etapa 2:

Esta etapa se caracteriza pelo crescimento estável da fissura em plano perpendicular ao plano da tensão principal de tração (propagação da fissura), a cada ciclo de tensões a um aumento do tamanho da falha e uma diminuição da rigidez do elemento estrutural. A fratura neste estágio já atingiu o nível macroscópico, isto é, pode ser vista a olho nu.

c) Etapa 3:

-Ruptura final, que ocorre de forma repentina, uma vez que a fissura que está avançando atingiu sua abertura crítica necessária para a propagação instável.

Para que a ruptura por fadiga ocorra de fato, é necessário que haja a propagação da fissura, até que ela alcance a abertura crítica necessária para que a propagação deixe ser estável e passe a ser instável. Então é natural que exista um nível de tensão mínimo para que exista a propagação da fissura.

As propriedades de um material no que diz respeito à fadiga podem ser obtidas através de experimentos. A forma mais usual de apresentar os resultados é analisando as tensões e deformações desde o início do ensaio até a ruptura.

Nos estudos de fadiga, no que diz respeito ao comportamento dos materiais ensaiados podem-se obter dois resultados que estão diretamente relacionados à ordem de grandeza da flutuação de tensão $(\Delta \sigma)$ aplicada. O primeiro comportamento é quanto maior for a flutuação de tensão menor a quantidade de ciclos suportados pela peça, o segundo é que para flutuações abaixo de um determinado valor não acontecerá a ruptura por fadiga, isto é, a flutuação de tensão não é suficiente para garantir a propagação da fissura. 
Um parâmetro importante que define o desempenho de um elemento à fadiga é a quantidade de ciclos $(\mathrm{N})$ que um material suporta quando submetido a um determinado nível de flutuação de tensão.

Como se sabe os testes de fadiga apresentam uma dispersão significativa nos resultados, ou seja, para um determinado nível de flutuação de tensão pode-se obter diversos valores de N. Então é natural que os resultados obtidos devam ser analisados estatisticamente, de modo que se possam obter números confiáveis para a caracterização dos materiais e, deste modo, projetar as estruturas de forma segura.

A dispersão nos resultados obtidos pode ser explicada pelo fato de existir um grande número de variáveis envolvidas no que diz respeito à resistência à fadiga, variáveis estas difíceis de controlar. Dentre elas podem-se citar: condições de moldagem dos corpos-de-prova, o alinhamento do corpo-de-prova no equipamento de teste, a tensão média, a freqüência dos testes, defeitos pré-existentes no material, dentre outros.

No que diz respeito aos procedimentos de cálculo de estrutura o CEB (1991) possui a verificação à fadiga, baseada na hipótese de Palmgren-Miner (1945); contudo, anteriormente a esta publicação, não existiam regras para dimensionamento à fadiga na maioria dos países europeus. A NBR 6118 (2003) também apresenta um capítulo destinado ao dimensionamento das estruturas de concreto à fadiga.

\subsection{AÇÕES CÍCLICAS}

O carregamento cíclico pode ser definido como um carregamento que oscila entre um valor máximo e mínimo com o tempo. Os carregamentos cíclicos que geram fadiga são expressos em função das tensões máximas e mínimas aplicadas durante um intervalo de tempo. A figura 4 apresenta um carregamento cíclico típico definido por uma função senoidal. A duração de um ciclo coincide com o período da função $\sigma(t)$, ou seja, um ciclo de carregamento é definido como aquele que provoca uma variação de tensões entre um valor máximo e mínimo, retornando ao ponto inicial.

A variação de tensão é definida através da diferença entre os valores das tensões máxima e mínima $(\Delta \sigma)$. Com estes valores também é calculada a tensão média $\left(\sigma_{m}\right)$, que na minoria dos caso pode ser zero ,como ilustrado na Figura 4(a), a figura 4(b) ilustra uma flutuação de tensão que acontece mais frequentemente nas peças , uma tensão média diferente de zero. A amplitude $\left(\sigma_{a}\right)$ corresponde à metade da variação 
das tensões, ou à variação da tensão a partir da média. As expressões matemáticas para essas definiç̧ões básicas são:

$$
\begin{aligned}
& \Delta \sigma=\sigma_{\text {máx }}-\sigma_{\text {min }} \\
& \sigma_{m}=\left(\frac{\sigma_{\text {max }}+\sigma_{\text {min }}}{2}\right) \\
& \sigma_{a}=\frac{\Delta \sigma}{2}=\left(\frac{\sigma_{\text {max }}-\sigma_{\text {min }}}{2}\right)
\end{aligned}
$$

O termo tensão alternante é usado por alguns autores e tem o mesmo significado de amplitude. Das Equações 2.1 e 2.3 pode-se notar que:

$$
\sigma_{\text {máx }}=\sigma_{m}+\sigma_{a}, \quad \sigma_{\text {min }}=\sigma_{m}-\sigma_{a} \quad(2.4: \mathrm{a}, \mathrm{b})
$$

Os sinais de $\sigma_{a}$ e $\Delta \sigma$ são sempre positivos, sendo que $\sigma_{\text {máx }}>\sigma_{\min }$ e as tensões de tração são sempre consideradas positivas. As quantidades de $\sigma_{\text {máx }}, \sigma_{\text {min }} \mathrm{e}$ $\sigma_{m}$ podem ser positivas ou negativas. As seguintes relações entre estas variáveis são muitas vezes usadas:

$$
R=\frac{\sigma_{\min }}{\sigma_{\max }}, \quad A=\frac{\sigma_{a}}{\sigma_{m}} \quad(2.5: \mathrm{a}, \mathrm{b})
$$

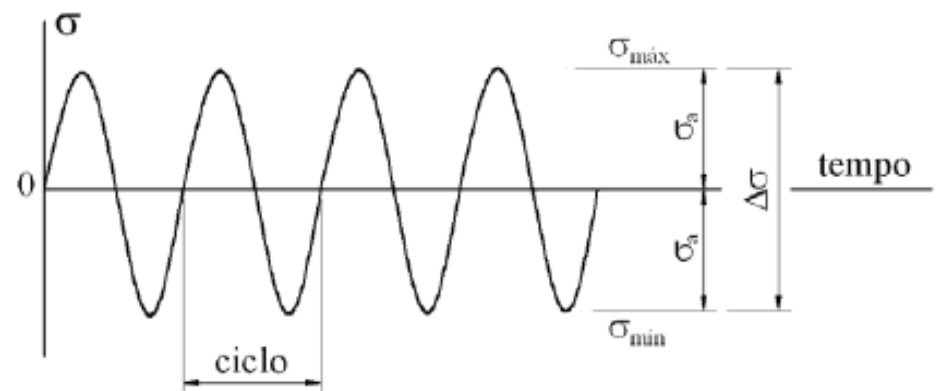

(a)

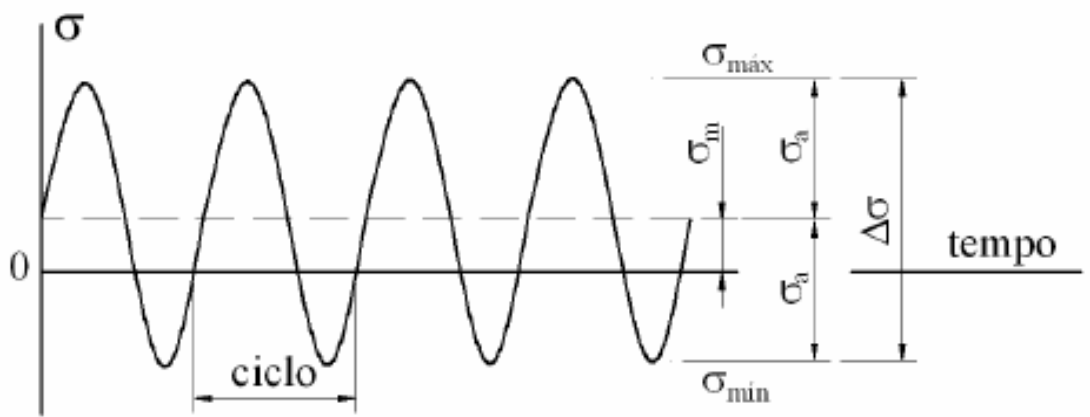

(b) 


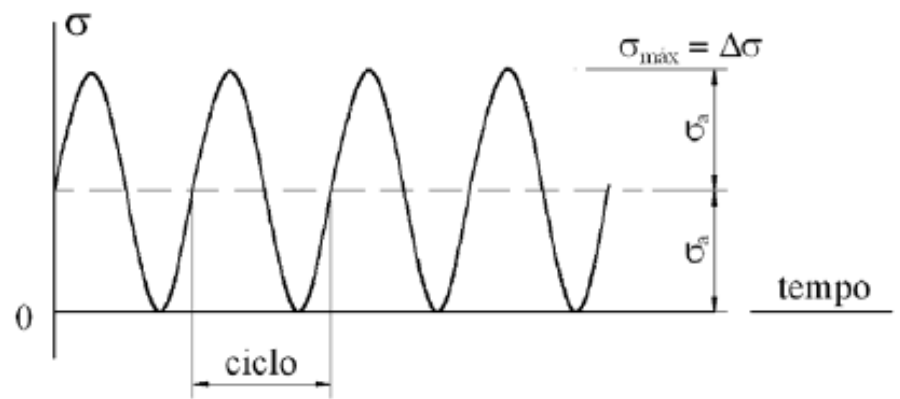

(c)

Figura 4 - Carregamento cíclico com amplitude constante. Caso (a) tensões completamente reversas, $\left(\sigma_{m}\right)=0 ;$ (b) tensão média $\left(\sigma_{m}\right)$ diferente de zero e (c) zero-tração, $\left(\sigma_{\text {min }}=0\right)$

Sendo R denominada relação de tensão e A de relação de amplitude. Algumas relações adicionais derivam das equações precedentes:

$$
\begin{array}{ll}
\sigma_{a}=\frac{\Delta \sigma}{2}=\frac{\sigma_{\text {max }}}{2}(1-R), & \sigma_{m}=\frac{\sigma_{\text {máx }}}{2}(1+R) \\
R=\frac{1-A}{1+A}, & A=\frac{1-R}{1+R}
\end{array}
$$

Tensões cíclicas com média zero podem ser especificadas pela amplitude, $\left(\sigma_{a}\right)$, ou pelo valor absoluto da tensão máxima, $\left(\sigma_{\text {máx }}\right)$. Se a média for diferente de zero, dois valores independentes são necessários para especificar o carregamento. Combinações de $\left(\sigma_{a}\right)$ e $\left(\sigma_{m}\right),\left(\sigma_{\text {máx }}\right)$ e $\mathrm{R},(\Delta \sigma)$ e $\mathrm{R},\left(\sigma_{\text {máx }}\right)$ e $\left(\sigma_{\text {min }}\right)$ e $\left(\sigma_{a}\right)$ e A podem ser usadas.

Ciclos de carga completamente reversos são usados para descrever a situação em que $\left(\sigma_{m}\right)$ é igual a zero, ou de R igual a -1, como mostrado na Figura 4(a). Casos onde omín e R são iguais a zero são chamados de zero-tração, como pode ser visto na Figura 4(c).

Várias são as ações cíclicas que causam fadiga nas estruturas como, cargas móveis, vento, ações de máquinas, etc. As ações repetitivas que podem causar dano por fadiga em estruturas são aquelas que atuam com alto número de ciclos.

De uma maneira geral, as cargas cíclicas ou repetitivas podem ser classificadas como: 


\subsubsection{Cargas cíclicas de grande amplitude e baixa ciclagem}

São cargas sob as quais as tensões ultrapassam o limite elástico provocando plastificações e a ruptura sobrevém com baixo número de ciclos. Por isso esse fenômeno não deve ser chamado de fadiga. Pode-se chamá-lo fadiga de baixo ciclo e citar como, por exemplo, os sismos.

\subsubsection{Cargas cíclicas de baixa amplitude e grande ciclagem}

Cargas cíclicas com amplitude constante: Como a própria definição sugere são carregamentos com amplitude constante, isto é, a variação de tensão se mantém a mesma do início ao fim da vida útil da peça, um exemplo disto são as máquinas. Como por exemplo, das ações a considerar no projeto de fundações de máquinas, como ilustrado na Figura 5.

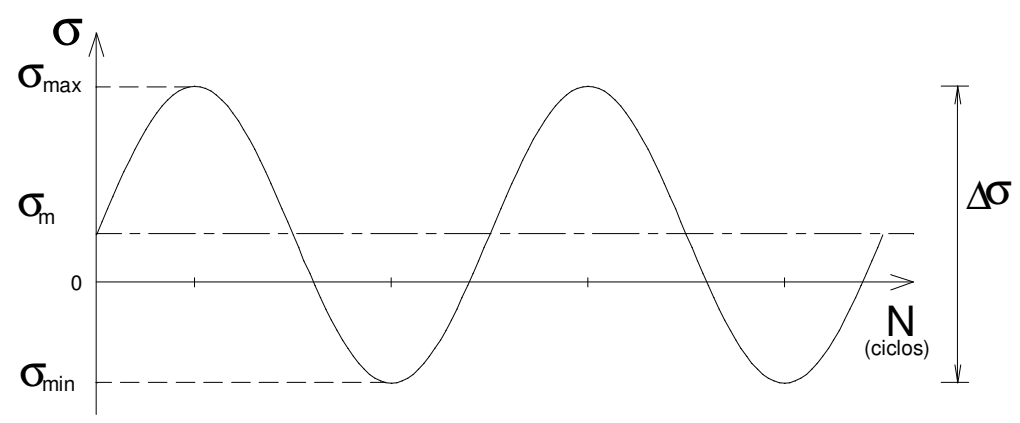

Figura 5 - Carga cíclica com amplitude constante

Alguns fatores a serem considerados:

a) A variação ou amplitude de tensão $(\Delta \sigma)$, diferença entre a tensão máxima $\sigma_{\max }$ e a tensão mínima $\sigma_{\min }$ se aplica sempre dentro do regime elástico;

b) A relação entre a tensão mínima e a tensão máxima $(\mathrm{R})$, pode variar muito caracterizando problemas diferentes. Se o valor da relação de tensão $\mathrm{R}=-1$, diz-se que há inversão completa da tensão. $\mathrm{Se} R=0$, então o carregamento varia de zero até um determinado valor máximo (de tração) da tensão considerada e, finalmente, se $0 \leq R \leq 1$, o carregamento provoca tração oscilante. 
- Cargas cíclicas com amplitude variável: São aquelas que normalmente atuam em estruturas, e que como o nome sugere as variações de tensões não são constantes, como por exemplo, o tráfego em pontes, carga de vento, etc, como ilustra a Figura 6.

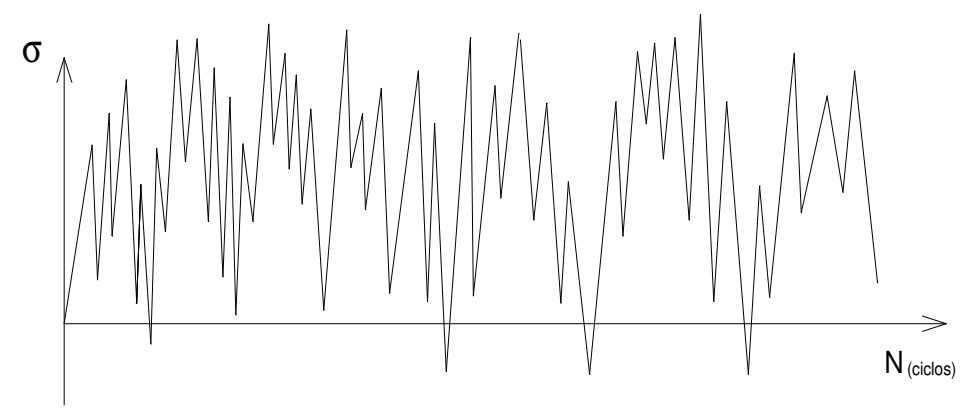

Figura 6 - Carga cíclica com amplitude variável

Existe uma forma para analisar os carregamentos de amplitude variável. Admite-se por hipótese que o carregamento variável é composto por vários trechos de carregamentos de amplitude constante, então se deve calcular dano de cada trecho de segmento constante e depois fazer o somatório dos danos.

Os efeitos cumulativos dos carregamentos de amplitude variável podem ser determinados por meio da regra de Palmgren-Miner, a qual é mostrada a seguir.

\subsection{HIPÓTESE DE PALMGREN-MINER (DANO CONTÍNUO LINEAR)}

O método de PALMGREN-MINER lança mão de um modelo linear de dano por fadiga, onde se leva em consideração o histórico dos carregamentos aplicados a uma estrutura através do dano acumulado de cada carregamento.

Esta regra foi sugerida por A. Palmgren, na Suécia, em 1920, mas somente após a publicação de Miner, em 1945, é que este método tornou-se conhecido e largamente utilizado.

Pela regra de Palmgren-Miner estima-se o valor do dano acumulado a partir dos carregamentos correspondentes a uma probabilidade de ruptura para um determinado número de ciclos. A ruína por fadiga se dá quando $\sum \frac{n}{N}=1$, sendo "n"o 
número de ciclos solicitantes para uma determinada intensidade de tensão e "N"o número admissível de ciclos para essa mesma intensidade.

Situações de amplitude de carregamento variável, conforme ilustradas na Figura 7 podem ser analisadas usando a regra de Palmgren-Miner. Certa amplitude de tensão, $\sigma_{a 1}$, é aplicada para certo número de ciclos, N1, onde o número de ciclos até a falha correspondente a esta amplitude é $N_{f 1}$. A fração da vida utilizada vale $\frac{N_{1}}{N_{f 1}}$. Outras amplitudes de tensão são aplicadas e com isso mais frações da vida à fadiga são utilizadas. Quando a soma destas parcelas alcança a unidade atinge-se 100\% da vida útil à fadiga.

$$
\frac{N_{1}}{N_{f 1}}+\frac{N_{2}}{N_{f 2}}+\frac{N_{3}}{N_{f 3}}+\ldots=\sum \frac{N_{j}}{N_{f j}}=1
$$
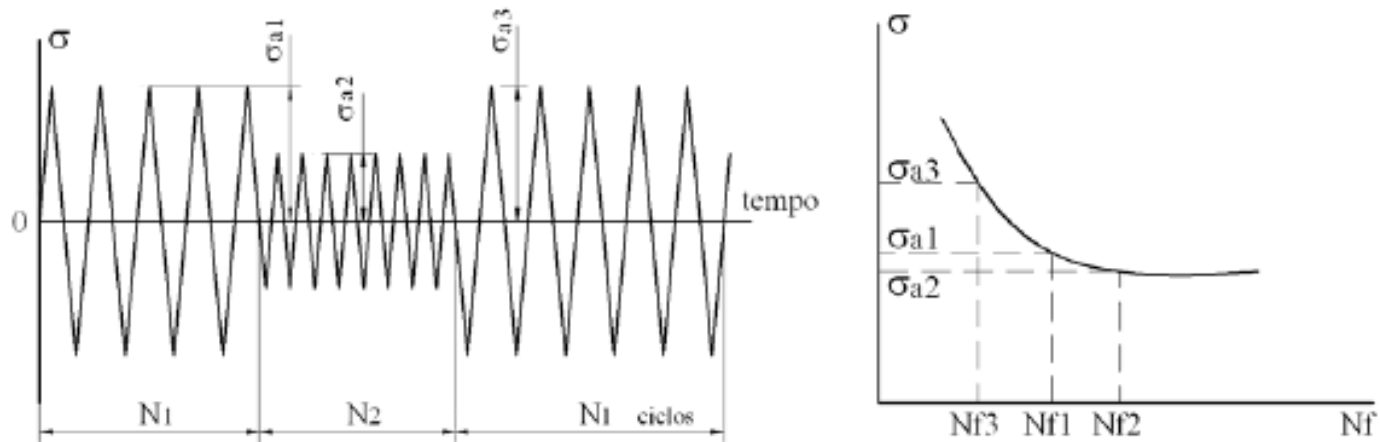

Figura 7 - Regra de Palmgren-Miner para estimativa da vida à fadiga para carregamento cíclico completamente reverso e de amplitude variável.

$\mathrm{O}$ requisito inicial para estimativa da vida à fadiga de um elemento estrutural reside na identificação da seção crítica e do espectro do carregamento cíclico de serviço, verificando a freqüência de aplicação das cargas e as tensões máximas e mínimas provocadas. Tendo em mãos uma curva S-N apropriada, determina-se o limite de resistência à fadiga para cada variação de tensão em função do carregamento cíclico aplicado. Com isso, o dano por fadiga é calculado usando a regra de Palmgren-Miner, ou seja, efetuando-se a divisão $\frac{n}{N}$, (MALLET, 1991).

\subsection{CURVAS DE WÖHLER}

As propriedades a fadiga de um material podem ser determinadas através de ensaios. Uma forma de apresentar os resultados é através das curvas S-N, também 
denominadas de curvas de Wöhler. Estas curvas caracterizam o comportamento de um material à fadiga.

As curvas S-N, mostradas na Figura 8, são construídas a partir de resultados de ensaios de laboratório, nos quais uma peça ou estrutura é submetida a carregamentos cíclicos de amplitude constante até a ruptura.

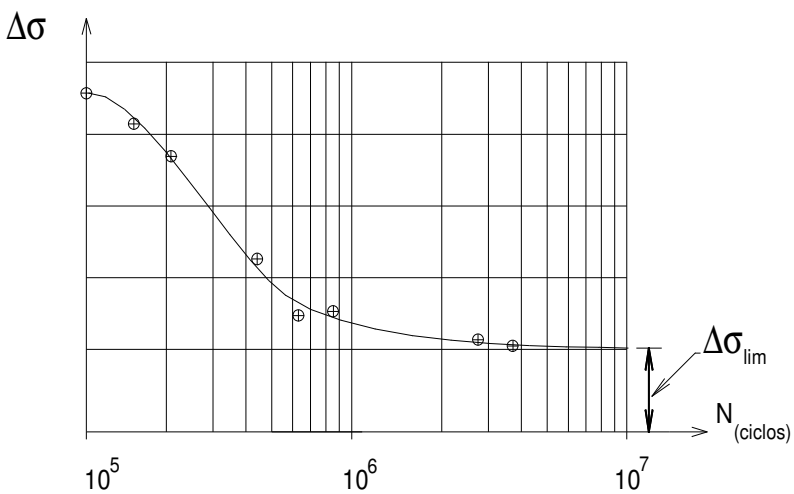

Figura 8 - Curva de wöhler.

Para barras de aço retas ou dobradas com diâmetro superior a 25 vezes o diâmetro da barra, o CEB-FIP MC (1990) adota curvas de Wöhler simplificadas (bilineares em escala log-log) que relacionam o número de ciclos com a máxima variação de tensão admissível, $\Delta \mathbf{f}_{\mathrm{sd}}$, fad, como ilustrado na Figura 9. Observar que nesse caso não foi proposto patamar.

A NBR-6118 (2003) adota um diagrama semelhante, com pequenas diferenças nos valores de $\Delta \mathrm{f}$ sd,fad.

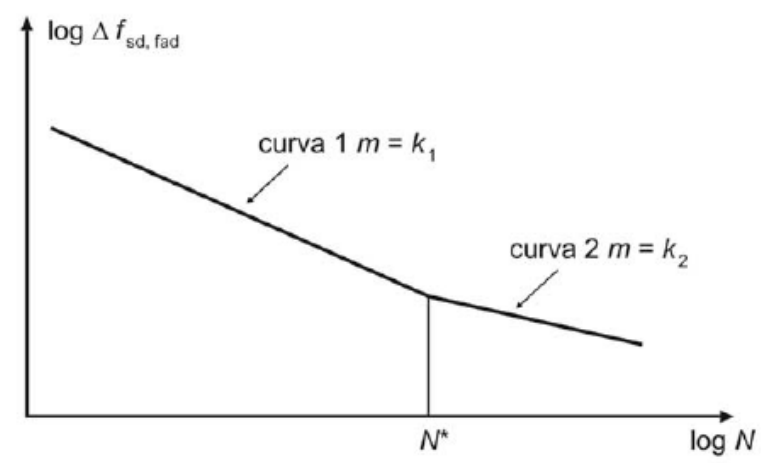

Figura 9 - Curva S-N segundo a NBR 6118:2003

A resistência à fadiga dos aços para concreto armado depende de vários fatores como (CEB, 1988); (MALLET, 1991): 
a) Conformação superficial das barras: as nervuras das barras de alta aderência reduzem a resistência à fadiga devido à concentração de tensões em comparação com as barras lisas;

b) Diâmetro das barras: a resistência à fadiga das barras reduz com o aumento do diâmetro. A resistência à fadiga de uma barra $\phi 40 \mathrm{~mm}$ é $25 \%$ menor do que a resistência à fadiga de uma barra de $\phi 16 \mathrm{~mm}$;

c) Curvatura das barras: as tensões localizadas nas curvaturas das barras diminuem a resistência à fadiga;

d) Amplitude da flutuação de tensão: o número de ciclos que ocasiona a fadiga em uma barra é tanto maior quanto menor for a amplitude da flutuação de tensões na armadura;

e) Tipo de aço, isto é, o aço CA-25 possui capacidade resistente à fadiga diferente do CA-50 por exemplo.

f) Emendas;

g) Ancoragens.

\subsection{FADIGA DO AÇO}

A determinação da resistência de barras de aço à fadiga pode ser feita através de ensaios axiais com barras expostas ao ar ou em ensaios de flexão com a barra mergulhada no concreto.

Os ensaios axiais podem ser realizados com freqüência de até $150 \mathrm{~Hz}$ (CEB 188, 1988). Apesar de apresentarem a vantagem de ser ensaios relativamente rápidos, especial atenção deve ser tomada com o alinhamento das barras e com as garras da máquina de teste. Essas zonas tendem a concentrar altas tensões, que podem culminar na ruptura da barra, descaracterizando o comportamento da mesma.

Diferentemente, os ensaios de flexão são mais atraentes, pois simulam as condições de serviço de um elemento de concreto armado. No entanto, possuem a desvantagem da freqüência do carregamento ser limitada em cerca de $3 \mathrm{~Hz}$ a $5 \mathrm{~Hz}$, a fim de evitar problemas de elevação da temperatura. Geralmente estes ensaios são feitos em pequenas vigas, submetidas à flexão em três ou quatro pontos.

Conforme o documento do ACI 215R-2 (1997), a resistência das barras de aço à fadiga é afetada principalmente pelo diâmetro, curvatura e emenda das barras, tipo de viga, geometria das deformações e tensão mínima aplicada. Ainda segundo o ACI 
215R-2, o aumento da tensão mínima e o aumento do diâmetro da barra reduzem a resistência à fadiga do aço. A diminuição da resistência à fadiga com o aumento do diâmetro da barra é explicada pelo estado de tensões que o efeito escala provoca e também pelo fato de haver a possibilidade de uma maior quantidade de defeitos em uma mesma seção transversal. Esse fenômeno é mais pronunciado em ensaios axiais do que em ensaios de flexão. No caso da tensão mínima, verificou-se que, para uma mesma variação de tensão, a resistência à fadiga é menor quando essa tensão foi aumentada.

A natureza da deformação, se de alongamento ou de encurtamento, influencia a resistência da barra de aço, uma vez que nos pontos onde a fissuração por fadiga é iniciada concentram-se altas tensões. As soldas também atuam como concentradores de tensões o que, como consequência, reduzem a resistência à fadiga.

Outro fator que afeta o desempenho à fadiga das barras de aço é a corrosão. Sob fadiga, pontos de corrosão possuem o mesmo efeito de um entalhe, causando concentração de tensão e diminuindo a resistência. Resultados experimentais obtidos por Tilly (1988), citados em Mallet (1991), apontaram fatores de redução da resistência à fadiga de 1,35 para barras de aço com perda de seção transversal de $25 \%$ e 1,7 para redução acima deste valor. Essas barras faziam parte de uma estrutura de ponte e foram avaliadas após 20 anos em serviço.

A fratura típica por fadiga de uma barra de aço pode ser visualizada na Figura 10, à esquerda. A zona 1 indicada na figura mais polida, sem brilho, com aspecto superficial de borracha, é a que indica as fissuras de fadiga. A zona 2 remanescente, com aspecto de entalhe, é a parte que finalmente fraturou após a formação das fissuras de fadiga. É importante notar que as fissuras por fadiga não se iniciam na parte inferior das barras de aço. Ao invés disso, o processo de fadiga se inicia longitudinalmente à barra, na base de um estribo, como mostrado na Figura 10 à direita.
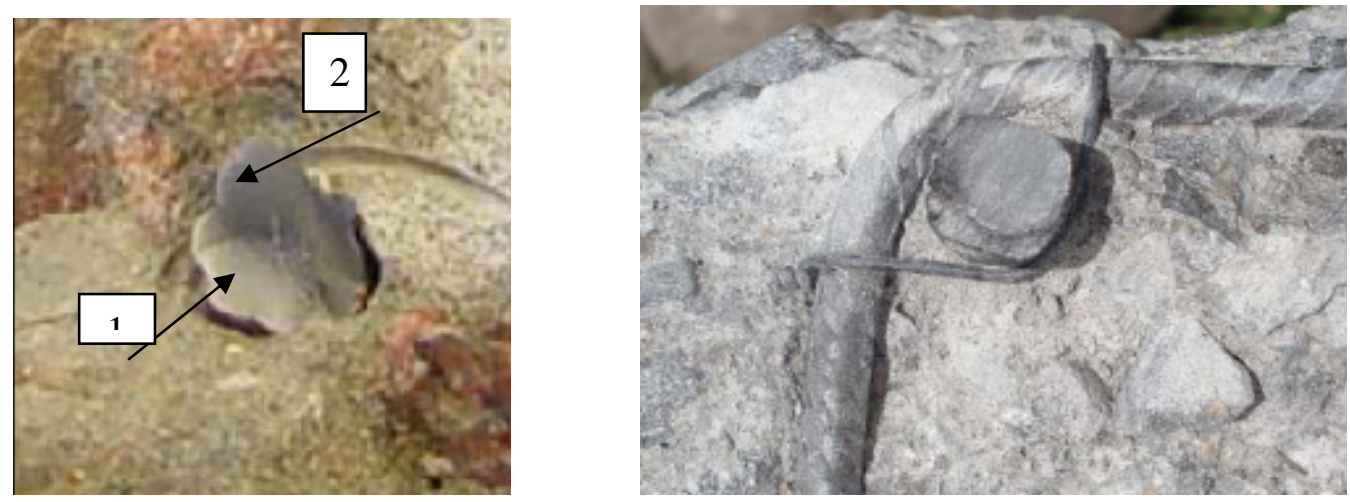

Figura 10 - À esquerda, fratura típica em uma barra de aço e, à direita, local de início das fissuras. 
Helagson e Hanson (1974) apresentaram um modelo estatístico para representar a região de vida finita à fadiga das barras de armadura em função da variação da tensão e do logaritmo do número de ciclos. A expressão matemática que representa este modelo é dada por:

$$
\log N=6,96899-5,5549 \times 10^{-3} \Delta \sigma \quad(\mathrm{MPa})
$$

A variável predominante encontrada na região de vida finita à fadiga foi a variação de tensão $(\Delta \sigma)$. O nível da tensão mínima, embora não afetasse à resistência à fadiga no mesmo grau, mostrou ser altamente significativo estatisticamente. Outros fatores, tais como, o diâmetro da barra e a tensão de escoamento, também mostraram significância estatística, enquanto que a profundidade da barra, não. As interações entre estes fatores não foram relevantes. A resistência à fadiga para uma vida infinita foi estabelecida para uma variação de tensão aproximadamente igual a $165 \mathrm{MPa}$.

Posteriormente, Tilly e Moss (1982) apud CEB 188 (1988) apresentaram outro modelo em escala log-log, no qual a fadiga da armadura está dividida em duas classes: R1 para barras com diâmetro de até 16 mm (Equação 2.9) e R2 para barras com diâmetro maior que 16 mm (Equação 2.10).

$$
\begin{aligned}
& \log \Delta \sigma=2,99-\frac{\log N}{9} \text { ou }(\Delta \sigma)^{9}=0,75 \times 10^{27} \\
& \log \Delta \sigma=2,87-\frac{\log N}{9} \text { ou }(\Delta \sigma)^{9}=0,07 \times 10^{27}
\end{aligned}
$$

A fadiga das armaduras não é um fator determinante no dimensionamento das estruturas de concreto armado. Todavia, o emprego cada vez maior destas estruturas em situações de carregamento cíclico, juntamente com o fato de que os procedimentos de cálculo atualmente adotados estão baseados no estado limite último - permitindo que se utilizem altos níveis de tensão nas armaduras - fazem com que o efeito da fadiga seja particularmente importante. Vale ressaltar que a mais baixa variação de tensão registrada que causou uma falha por fadiga numa barra de aço foi de $145 \mathrm{MPa}$. Essa ruptura ocorreu após 1.250 .000 ciclos de carregamento repetido numa viga com barras de aço de 35 mm de diâmetro e tensão mínima de 121MPa (ACI 215R-2, 1997).

Baseado nos estudos de Helagson e Hanson (1974), o comitê 215 do ACI (1997) estabeleceu um critério de segurança à fadiga para as barras de aço para concreto armado, conforme representado na Equação 2.11. 


$$
\Delta \sigma=161-0,3 \sigma_{\min }(\mathrm{MPa})
$$

Em que $\Delta \sigma$ não necessita ser menor do que $138 \mathrm{MPa}$. Para barras fletidas ou barras que tiveram um reforço adicional soldado, a variação na tensão obtida pela Equação 2.11 deve ser reduzida em 50\%.

Segundo o CEB-FIP Model Code 1990 (1991), a verificação da segurança à fadiga das barras de aço para concreto armado deve atender aos limites constantes na Tabela 1.

Tabela 1 - Resistência característica do aço à fadiga segundo o CEB-FIP Model Code 1990 (1991).

\begin{tabular}{lccc}
\hline & $\mathrm{N}^{*}$ & $\Delta \sigma_{\text {Rsk }}$ para $N^{*} \operatorname{ciclos}(\mathrm{MPa})$ & $\Delta \sigma_{\text {Rsk }}$ para $10^{8}$ ciclos $(\mathrm{MPa})$ \\
\hline Barras com $\phi \leq 16 \mathrm{~mm}$ & $10^{6}$ & 210 & 125 \\
Barras com $\phi>16 \mathrm{~mm}$ & $10^{6}$ & 160 & 95 \\
Barras soldadas & $10^{7}$ & 50 & 30 \\
\hline
\end{tabular}

Já a norma brasileira (NBR 6118, 2003) recomenda valores para a variação na tensão admissível da armadura para uma vida de 2.000 .000 ciclos em função do diâmetro da barra e do tipo de aplicação destas estruturas, como indica a Tabela 2 , sendo D o diâmetro dos pinos de dobramento das barras de aço.

Tabela 2 - Variação na tensão admissível na armadura segundo NBR 6118:2003.

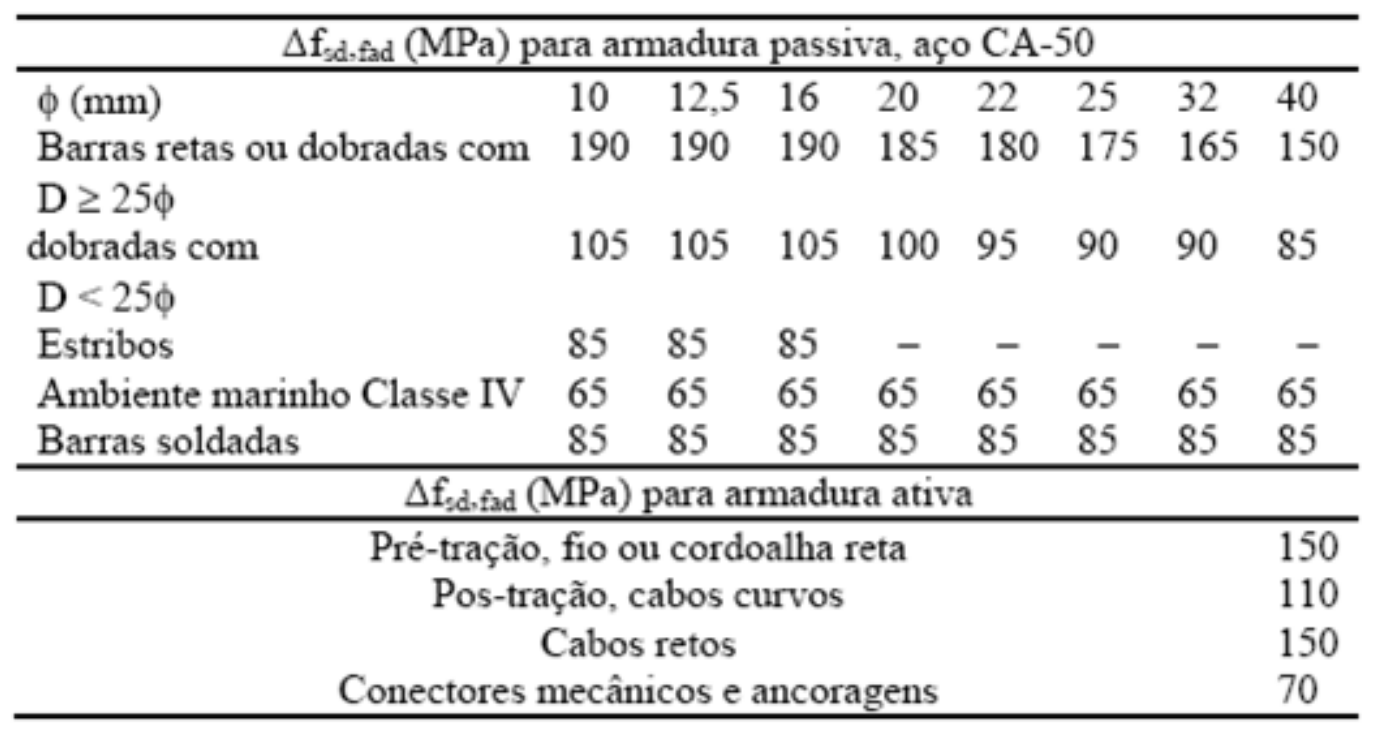




\subsection{COMPORTAMENTO À FADIGA DO CONCRETO}

O concreto não é um material homogêneo. A fadiga no concreto é um processo progressivo de propagação de micro-fissuras que conduz a macro-fissuras, as quais podem levar a peça à ruptura com cargas inferiores à sua resistência em ensaios estáticos (CEB, 1988); (CEB, 1996); (MALLET, 1991).

A propagação das fissuras causa uma redução na seção transversal da peça e concentrações de tensões que afetam a rigidez da peça e uma diminuição na aderência entre o concreto e o aço; (CEB, 1988); (MALLET, 1991); (FERNANDES, 2001).

Os principais fatores que influenciam a resistência à fadiga do concreto os principais são: tensão máxima, amplitude de tensão, história do carregamento e características do concreto.

A resistência do concreto à fadiga depende ainda do tipo de solicitação: compressão, tração, cisalhamento, etc. Tanto o Código Modelo CEB-FIP CM (1990) quanto à norma brasileira NBR-6118:2003 apresentam critérios para verificação da fadiga do concreto. No entanto, os casos de ruínas imputáveis à fadiga, sejam do aço e menos ainda do concreto, não têm se mostrado na prática, mesmo em obras com cargas variáveis muito altas e frequientes, como as pontes ferroviárias e as metroviárias. Por isso foi escolhida a laje executada com pré-laje como objeto de pesquisa. Além de muito exposta à fadiga por conta das ações, essa laje resulta com uma junta de dois concretos diferentes, mais sensíveis à fadiga.

Esse tipo de laje de tabuleiro corresponde a um percentual muito alto das

obras rodoviárias brasileiras $(>50 \%)$ e está invadindo as obras ferroviárias e metroviárias de hoje em dia.

Para o Comité Euro-Internacional du Béton (CEB, 1988), as fissuras por fadiga não têm um padrão definido, tornando-se difícil identificar a fadiga nas estruturas de concreto. Contudo, existem algumas formas de acompanhar o processo de fadiga de uma peça. A qual pode ser através da observação do desenvolvimento das fissuras, emissões acústicas e também mudanças de volume podem ser indicadores de danos por fadiga.

\subsubsection{Comportamento do concreto à compressão}

\subsubsection{Resistência à fadiga}

A resistência a fadiga pode ser definida como uma fração da resistência estática que pode ser suportada repetidamente após um determinado número de ciclos. 
Ela pode ser representada por curvas de vida à fadiga, representadas pelas curvas S-N de Wöhler, como mostra a figura 11.

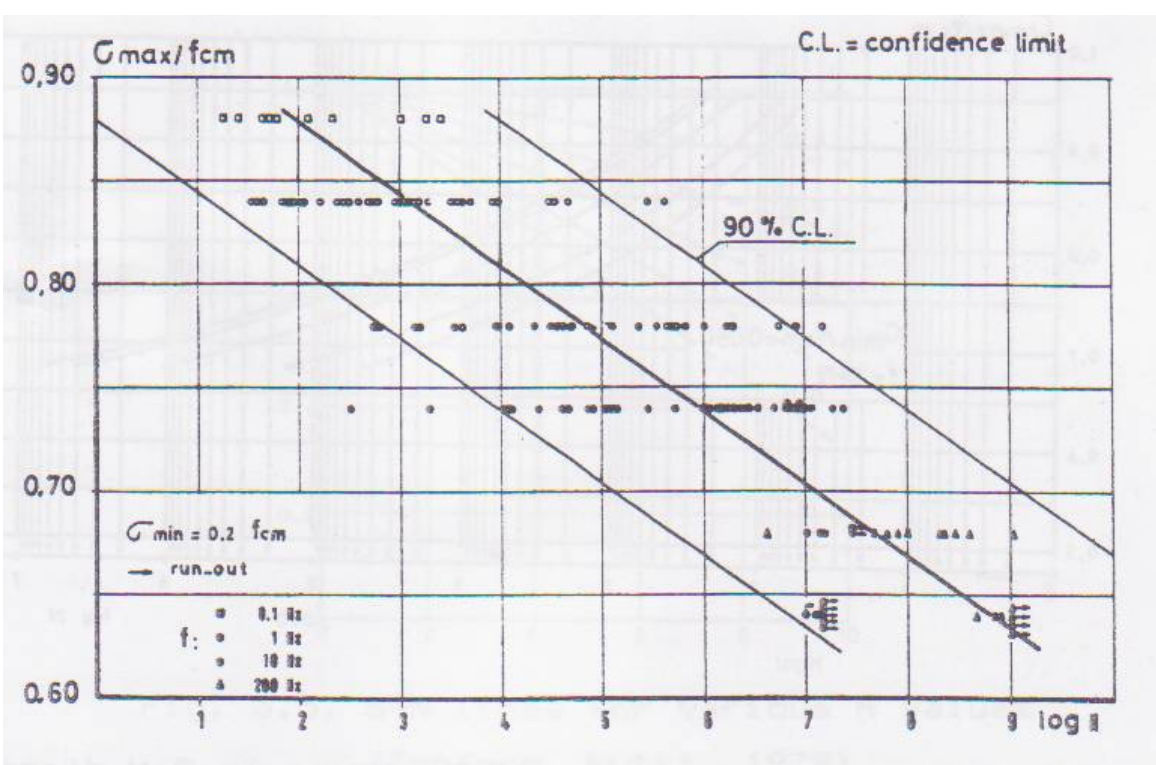

Figura 11 - Curva S-N típica de concreto em compressão (Klausen, 1978).

Deve ser observado que os ensaios de fadiga apresentam uma grande dispersão na quantidade de ciclos de ruptura para cada nível de variação de tensão. Por isso, se faz necessário efetuar uma quantidade razoável de ensaios para cada nível de flutuação de tensão, de modo a se obter uma curva $\mathrm{S}-\mathrm{N}$ de um determinado concreto. De acordo com o CEB, através da aplicação de procedimentos estatísticos é possível obter uma relação entre a probabilidade de ruína e o numero de ciclos.

A resistência a fadiga no concreto depende não só da máxima tensão a que a peça esteja submetida, mas também da mínima tensão aplicada durante os ciclos de carregamento. Isto quer dizer que a resistência a fadiga é governada pela variação de tensão sofrida pela estrutura, ou seja, quanto maior a variação de tensão menor a quantidade de ciclos que a estrutura vai suportar.

Ao contrário do aço, ainda não se conhece o limite à fadiga do concreto, isto é, não existe uma variação de tensão que aplicada ao concreto que o permita suportar uma quantidade infinita de ciclos (CEB, 1988).

\subsubsection{Composição do concreto}

Quando as resistências à fadiga foram expressas em função do $\mathrm{f}_{\mathrm{cm}}$, variáveis como a relação água-cimento, teor de argamassa, quantidade de ar incorporado, condições de cura e idade do carregamento não influenciam a resistência a fadiga, caso 
ela seja expressa em função da resistência estática da peça. De acordo com o Comité Euro-Internacional du Béton (CEB, 1988), vários ensaios foram realizados em concretos com resistências de até $60 \mathrm{MPa}$, testando vários tipos de concreto, com idades superiores há 5 anos e submetidos a diversos tipos de cura.

\subsubsection{Períodos de descanso}

$\mathrm{O}$ efeito de períodos de repouso da estrutura proporciona um aumento na resistência da estrutura à fadiga. É no período de repouso que a estrutura é capaz de melhorar sua capacidade resistente.

Foram realizados ensaios de compressão com pequenos períodos de repouso, e não foi possível conseguir mudanças significativas no ganho de resistência. Este fato se deve principalmente pela dispersão obtida nos resultados. Contudo se os períodos de descanso forem maiores, haverá um tempo maior para uma redistribuição de tensões, diminuição de tensões na ponta da fissura, resultando em uma maior vida útil à fadiga. Isto só é possível se as tensões no período de repouso forem baixas. 


\section{INVESTIGAÇÃO EXPERIMENTAL}

\subsection{INTRODUÇÃO}

A parte experimental desta pesquisa consiste na investigação experimental do comportamento à fadiga de barras de aço, isoladas ou em tela, para concreto armado e lajes concretadas com e sem pré-lajes armadas com essas barras ou telas soldadas.

Foram efetuados ensaios de fadiga de barra ao ar CA50 $\$ 10 \mathrm{~mm}$, isoladas e em tela para a construção da Curva de Wöhler. Além disso, foram ensaiadas lajes e prélajes de concreto, submetidas a flexões cíclicas, armadas com bitolas, bastante freqüentes nas obras.

A primeira idéia é determinar com mais precisão a Curva de Wöhler por meio dos ensaios de barras ao ar, isoladas, demonstrando, inclusive, se existe ou não o patamar $\Delta \sigma_{\text {lim }}$ para $\mathrm{N}>2 \times 10^{6}$ ciclos. A segunda idéia é verificar até que ponto as soldas na tela afetam os resultados, reduzindo ou não a resistência da barra. A terceira idéia é a verificação do resultado final nas lajes e pré-lajes.

Há escassez de dados precisos a respeito do comportamento de lajes armadas com telas soldadas submetidas a ações cíclicas. Conduziu ao propósito de se elaborar uma pesquisa de caráter experimental sobre esse tema, cujos resultados e conclusões pudessem fornecer subsídios para que sejam adotados critérios de dimensionamento mais rigorosos e econômicos.

\subsection{ENSAIOS DE FADIGA DE BARRA AO AR}

\subsubsection{Considerações Iniciais}

Para o desenvolvimento do programa experimental desta etapa foram pesquisadas as seguintes normas que consideram a fadiga de barras de aço para concreto armado:

NBR 7480: "Barras e fios de aço destinados a armaduras para concreto armado".

NBR 7478: "Método de Ensaio de Fadiga de Barras de Aço para concreto Armado".

NBR 6152: "Materiais Metálicos. Determinação das Propriedades Mecânicas à Tração". 
NBR 6118: "Projeto de estruturas de concreto".

Para a escolha correta do tipo de garra a ser utilizada nos ensaios de barras ao ar foi considerado também o Relatório Técnico de ensaios de fadiga de barra ao ar, feitos pelo Laboratório de Estruturas e Materiais Estruturais - LEM, da Escola Politécnica da Universidade de São Paulo (BUELTA, 2002).

\subsubsection{Parâmetros dos Ensaios de Fadiga}

Os ensaios de fadiga de barra ao ar foram executados com a finalidade determinar a curva de Wöhler. Os ensaios foram feitos em um servo-atuador DARTEC, como ilustrado na Figura 12.
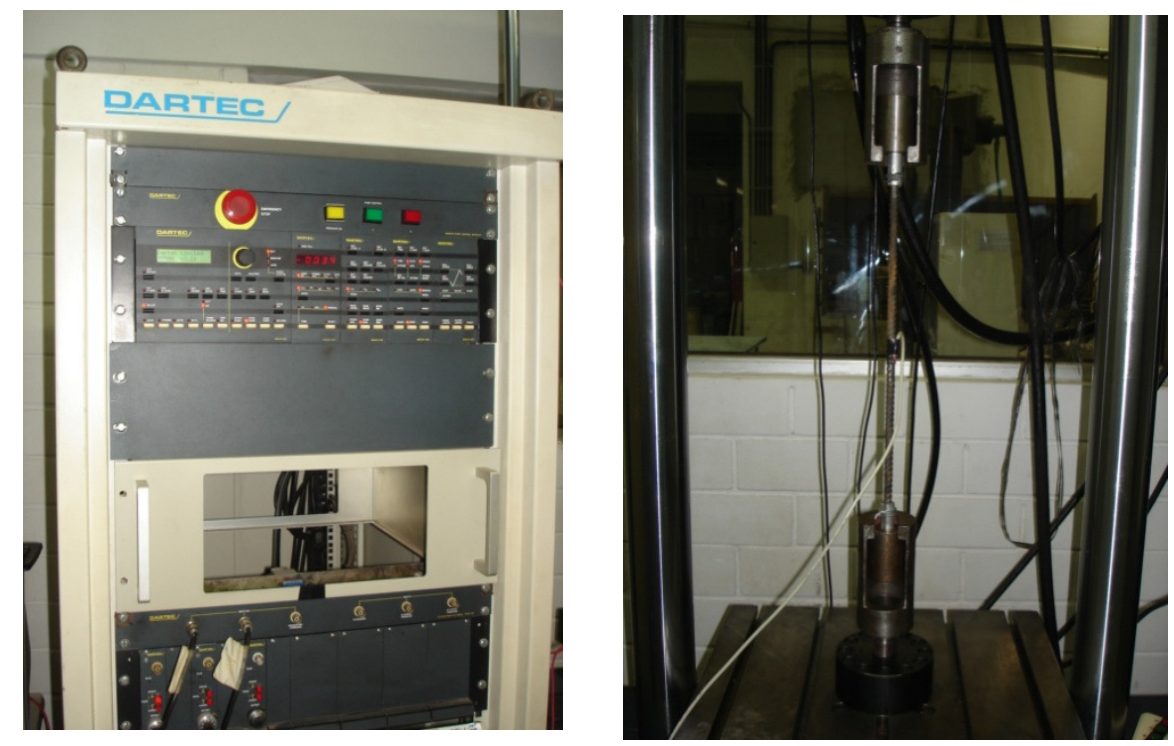

Figura 12 - Ensaios de fadiga de barra ao ar - Dartec

Os pontos para a construção da curva de Wöhler serão determinados a partir do valor da tensão máxima, fixada em $80 \%$ da resistência característica de escoamento do aço à tração no ensaio estático $\left(f_{y}\right), \sigma_{\max }=0,8 f_{y}$. Esta situação está esquematizada na Figura 13, onde:

$f_{y}$ é a tensão de escoamento do material da barra;

$\sigma_{s}, \sigma_{s, \text { min }}$ e $\sigma_{s, \text { máx }}$ são, respectivamente, a tensão aplicada, a tensão mínima e a máxima;

$\Delta \sigma_{s}=\Delta \sigma_{s, \text { máx }}-\Delta \sigma_{s, \text { minn }}$ é a amplitude de variação das tensões; 
$f_{f a d, k}$ é a amplitude de variação das tensões que levou à ruptura por fadiga em k ciclos.

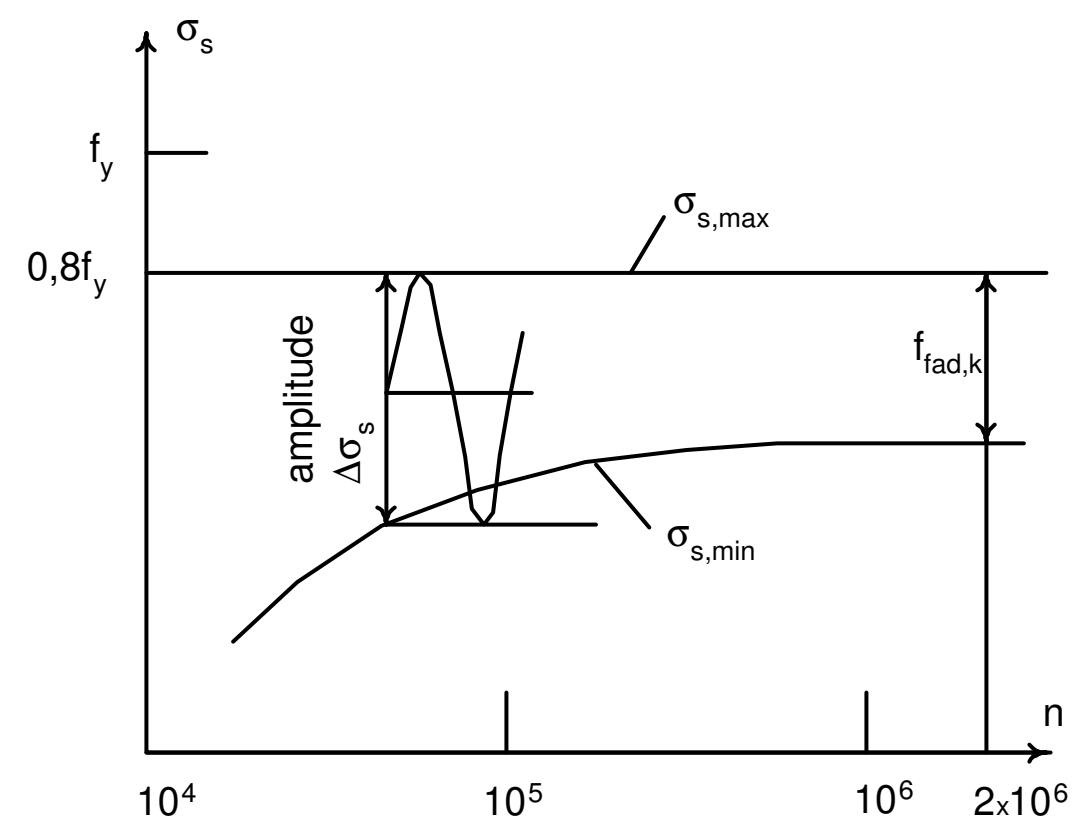

Figura 13 - Esquematização da variação das tensões nos diferentes ensaios, mantida $\sigma_{\max }$ constante.

Deve-se notar que este coeficiente 0,8 é maior do que os coeficientes de serviço usuais, a favor da segurança. As verificações de fadiga feitas nos projetos usuais de pontes utilizam níveis de tensão bem inferiores, em torno de $0,6 f_{y}$. Ensaios dessa natureza demandam muito tempo de pesquisa e uso de equipamentos especializados, tornando-se, assim, muito dispendiosos. Ensaios com pequeno número de amostras limitam as conclusões e não dão representatividade estatística aos resultados.

A frequiência adotada para os ensaios foi de $10 \mathrm{~Hz}$. A NBR 7478:1982 recomenda para essa freqüência um valor entre $4 \mathrm{~Hz}$ e $6 \mathrm{~Hz}$, mas não se pode esquecer que essa norma se aplica a ensaios realizados com a barra mergulhada no concreto, cujos corpos-de-prova são maiores e mais pesados, com baixas frequências naturais de vibração. Já o projeto de norma MERCOSUL (1996), para ensaios da barra ao ar, recomenda ensaios feitos com freqüência de 3 a 10 Hz. Como afirma BUELTA (2002), é possível mostrar que a frequiência natural em vibração longitudinal do trecho de barra que forma o corpo-de-prova é muito superior a $10 \mathrm{~Hz}$, não havendo, portanto, qualquer problema de amplificação dinâmica das forças aplicadas, justificando-se, com sobras, a utilização dessa frequência.

Foram executados seis conjuntos de ensaios, com seis corpos-de-prova para cada nível de flutuação de tensão $\Delta \sigma$ pré-fixada, sendo três conjuntos utilizando barras e três conjuntos com telas soldadas. Desta forma será obtida uma representatividade 
estatística de cada ponto da curva de Wöhler, sendo possível estimar o valor característico $\mathrm{N}_{\mathrm{k}}$ do número de ciclos até a ruptura para cada flutuação de tensão $\Delta \sigma$.

Os três primeiros conjuntos de ensaios serão realizados com barras de $\phi 10 \mathrm{~mm}$ e os outros três conjuntos com telas soldadas de $\phi 10 \mathrm{~mm} \mathrm{c} / 10 \mathrm{~cm}$ x $\phi 8 \mathrm{~mm}$ $\mathrm{c} / 20 \mathrm{~cm}$ (trechos de barras).

O primeiro conjunto, que definirá um ponto da curva de Wöhler, será feito para uma flutuação de tensão $\Delta \sigma$ que provoque ruptura por fadiga com aproximadamente $10^{5}$ ciclos. O segundo conjunto, que definirá também um ponto da Curva de Wöhler, ruptura com aproximadamente $10^{6}$ ciclos e um terceiro conjunto com aproximadamente igual a $4 \times 10^{6}$ ciclos. Os outros três conjuntos, compostos de telas soldadas, serão feitos da mesma forma.

Para o cálculo das variações de tensão, será utilizada a seguinte equação, segundo “Bulletin D'Information N. 188 - Fatigue of Concrete Structures - State of the Art Report", pag. 158:

$$
\Delta \sigma^{9} \times N=K(\text { eq. } \mathrm{X})
$$

Onde:

$\Delta \sigma=$ Variação de tensão em MPa.

$\mathrm{N}=$ Número de ciclos para ruptura.

$\mathrm{K}$ = Constante que depende do diâmetro da barra e do tipo de carregamento aplicado, que pode ser definido segundo a tabela abaixo:

Tabela 3 - Valores de k equivalentes ao desempenho médio e de projeto - "Bulletin D'Information N. 188 - Fatigue of Concrete Structures - State of the Art Report" pag.160

\begin{tabular}{|c|c|c|c|c|c|}
\hline \multirow[b]{2}{*}{$\mathrm{mm}$} & \multirow{2}{*}{$\begin{array}{c}\text { Size of the bar } \\
\text { diameter }\end{array}$} & \multirow[b]{2}{*}{ Type of loading } & \multicolumn{2}{|c|}{$\mathrm{K} \times 10^{27}$} & \multirow[b]{2}{*}{$\Delta$} \\
\hline & & & Mean & Design & \\
\hline \multirow[t]{2}{*}{$\mathrm{R} 1$} & 6 to 16 & Axial in air & 11,20 & 0,75 & 0,2588 \\
\hline & & $\begin{array}{l}\text { Bending in } \\
\text { concrete }\end{array}$ & 60,60 & 3,09 & \\
\hline \multirow[t]{2}{*}{$\mathrm{R} 2$} & 20 to 50 & Axial in air & 0,81 & 0,07 & 0,2588 \\
\hline & & $\begin{array}{l}\text { Bending in } \\
\text { concrete }\end{array}$ & 6,38 & 0,31 & \\
\hline
\end{tabular}




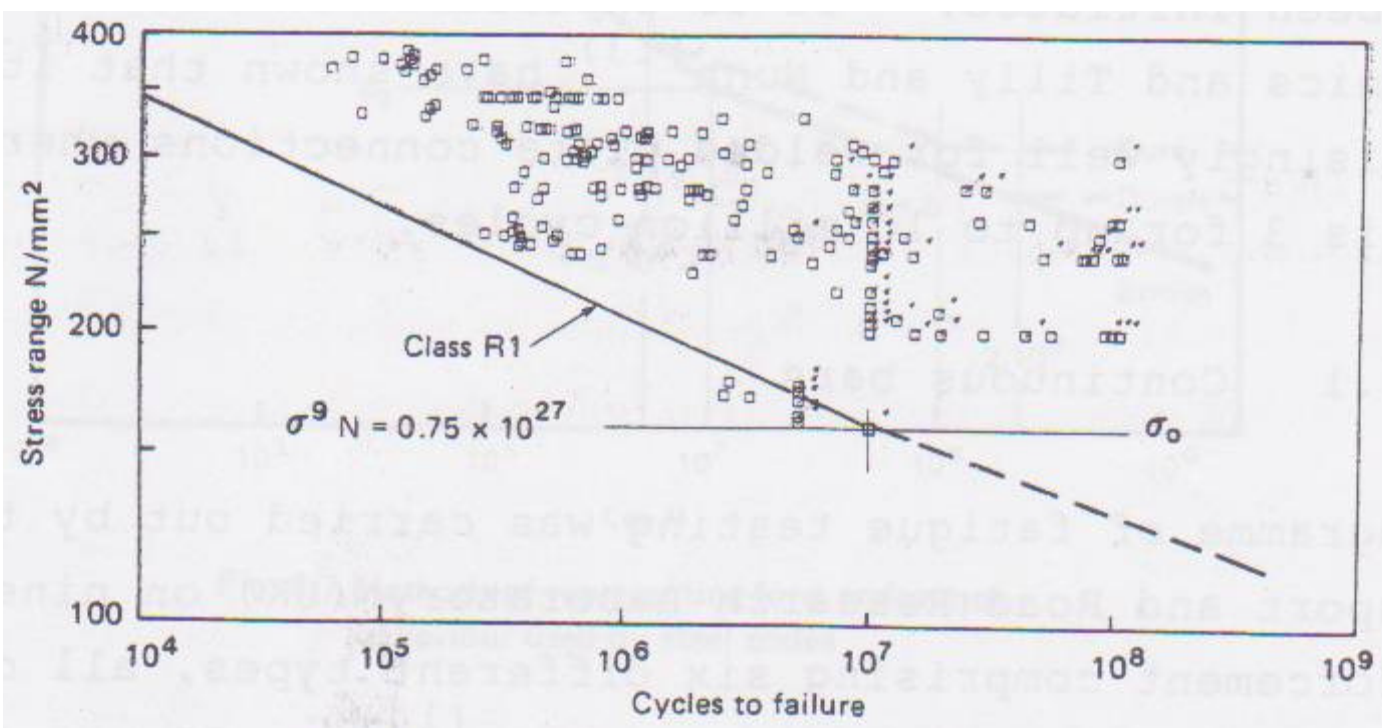

Figura 14 - Curva Classe R1 - Dados de fadiga publicados para barras de diâmetros menor ou igual a 16mm - "Bulletin D'Information N. 188 - Fatigue of Concrete Structures - State of the Art Report" pag. 159.

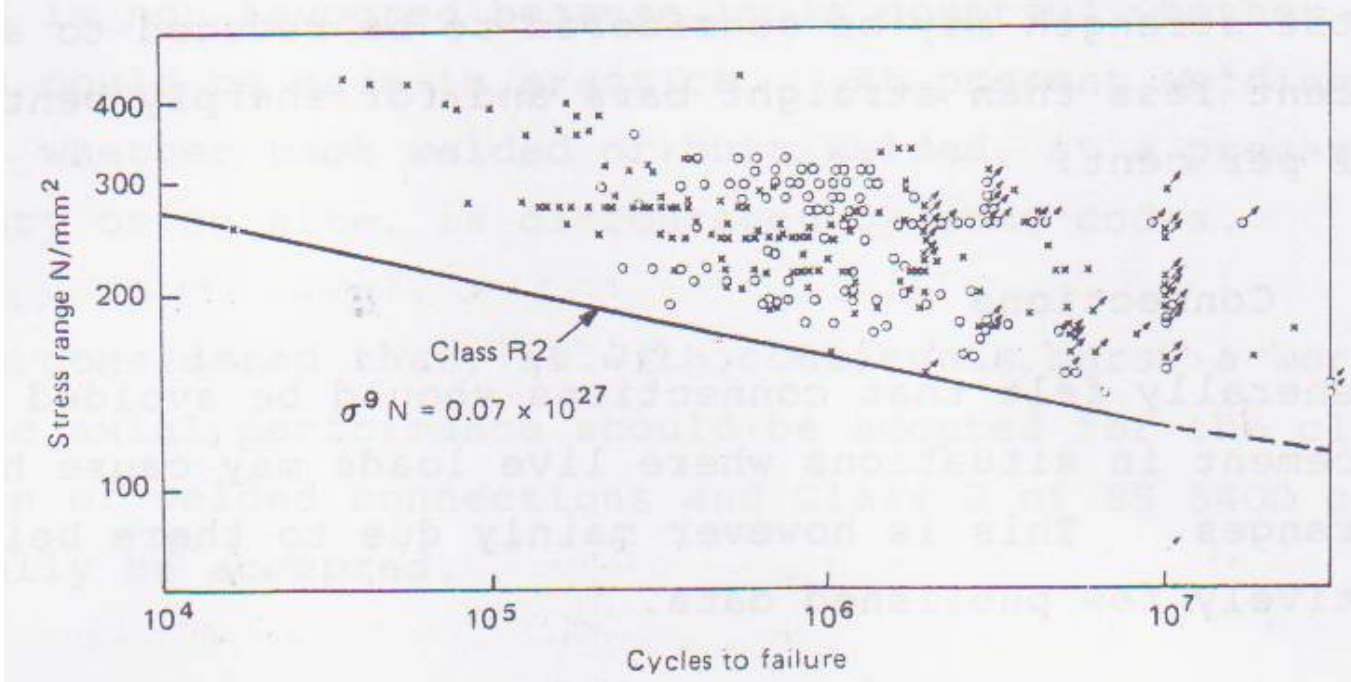

Figura 15 - Curva Classe R2 - Dados de fadiga publicados para barras de diâmetros maiores que 16mm - "Bulletin D'Information N. 188 - Fatigue of Concrete Structures - State of the Art Report" pag. 160.

Com a definição do valor da variação de tensão e adotando-se como valor de tensão máxima, $80 \%$ da resistência teórica de escoamento do aço à tração no ensaio estático $\left(f_{y}\right), \sigma_{\max }=0,8 f$, pode-se calcular o valor da tensão mínima prevista para tal ensaio segundo o CEB.

A tabela abaixo resume a previsão para os seis conjuntos de ensaios: 
Tabela 4 - Resumos dos seis conjuntos de ensaios que foram realizados.

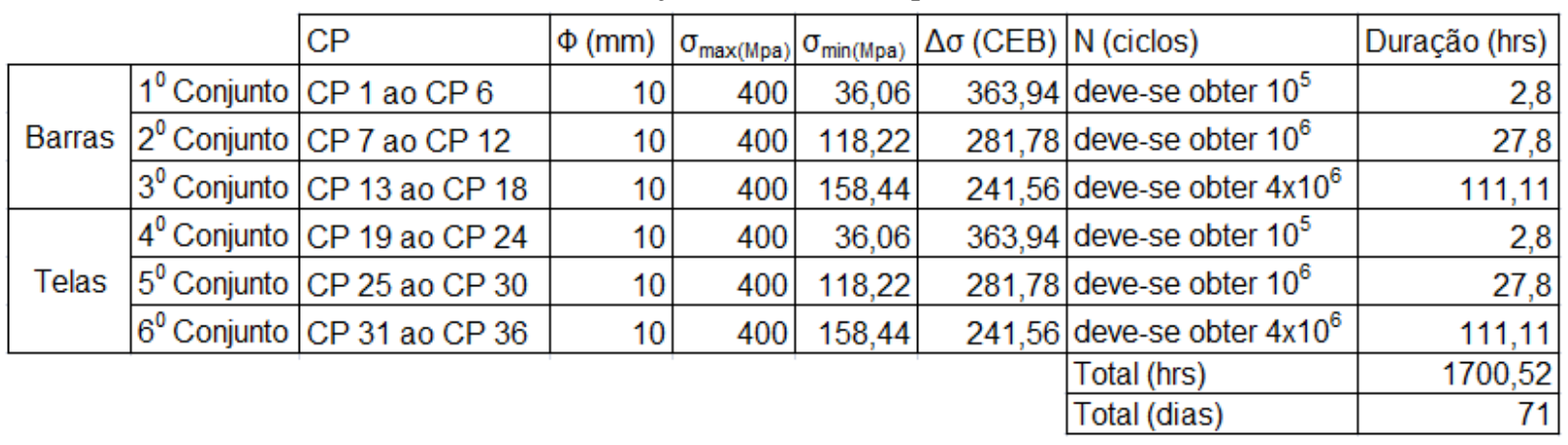

\subsubsection{Constituição dos corpos-de-prova}

\subsubsection{Barras}

Os corpos-de-prova são constituídos de um trecho de barra de $600 \mathrm{~mm}$ de comprimento (tamanho máximo que a máquina de granalha suporta) com garras nas extremidades (Figura 16), para fixação na máquina de ensaios DARTEC M1000/RK $100 \mathrm{KN}$. Através do sistema de controle M9500, o corpo-de-prova é fixado à máquina (Figuras 17), a qual o submete às cargas cíclicas de tração.

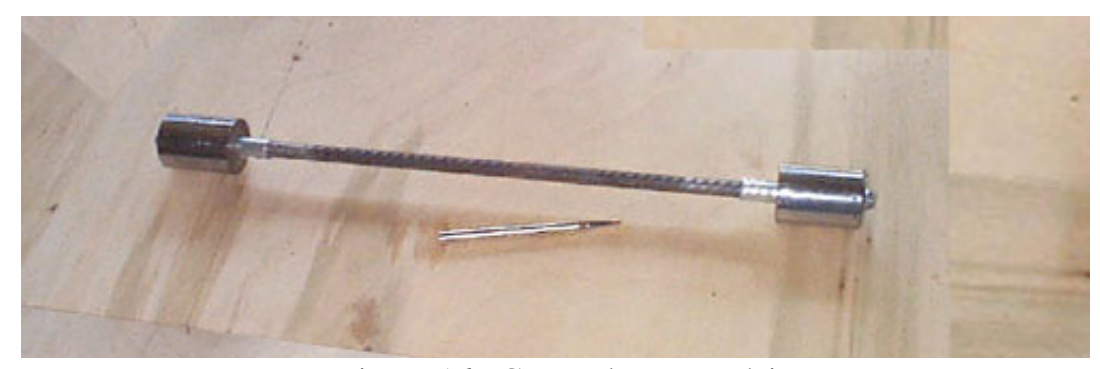

Figura 16 -Corpo-de-Prova típico

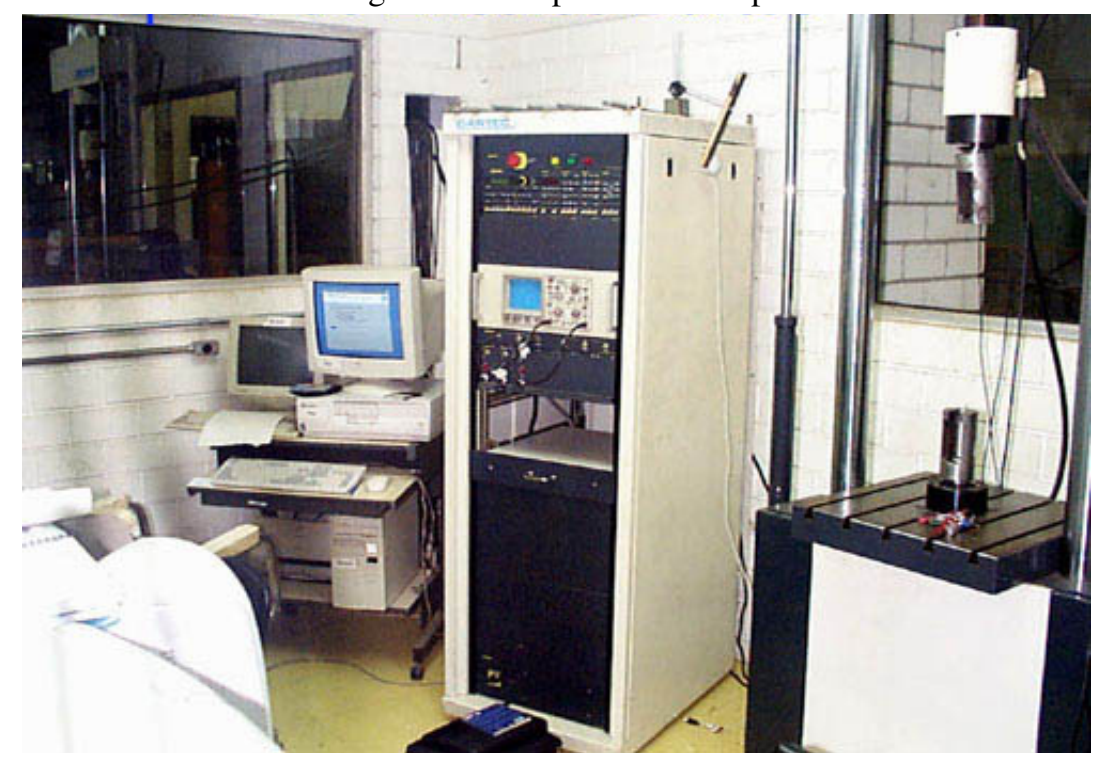


Figura 17 - Dartec - Máquina do ensaio de eadiga.

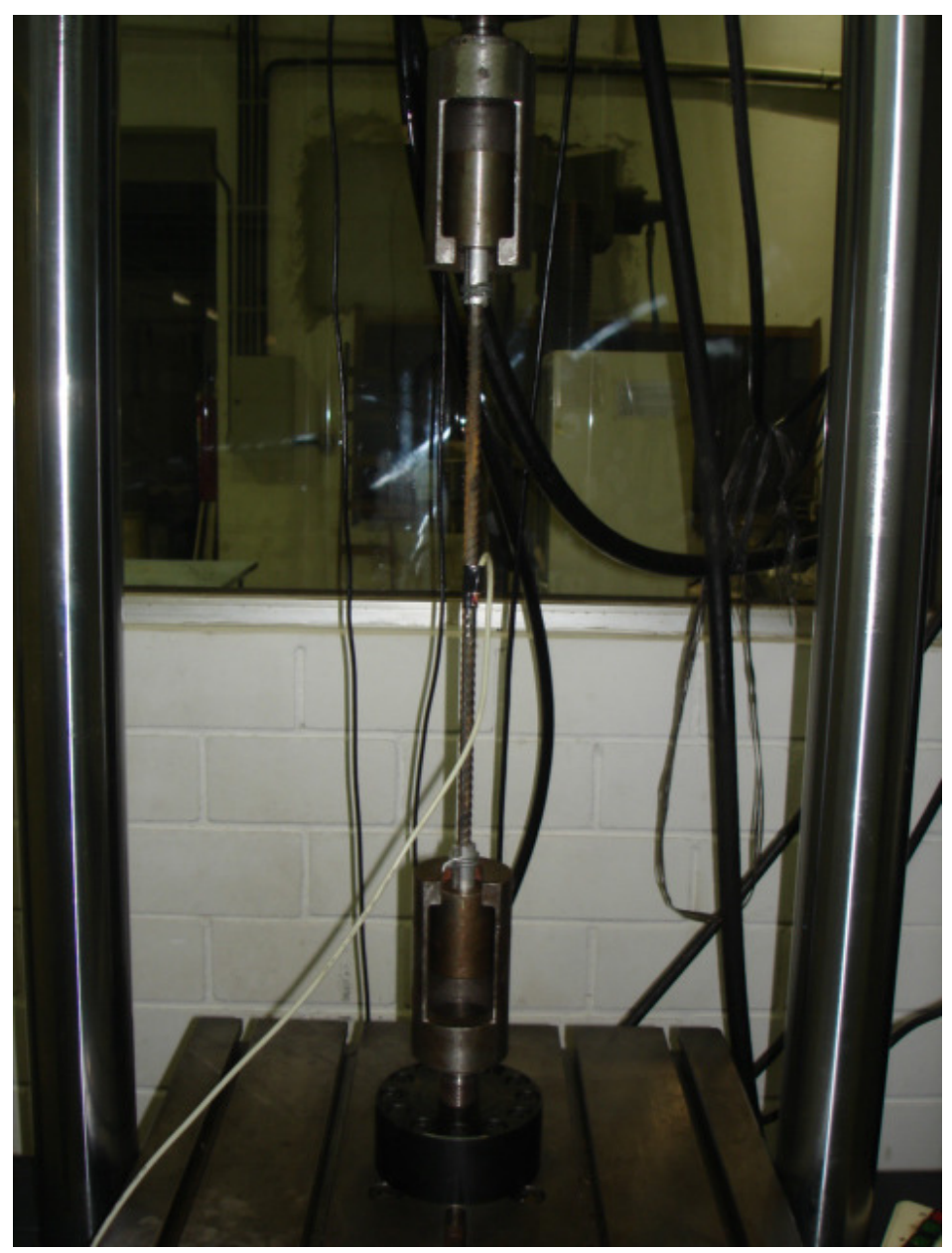

Figura 18 - Corpo-de-prova durante ensaios.

Deve-se ter em conta que os corpos-de-prova devem ser constituídos de tal forma que a ruptura por fadiga não ocorra nas garras, e sim, fora delas, estando assim bem representado o seu comportamento, tendo em vista que as garras não existem na operação normal, dentro do concreto. Portanto, o tipo de garra a ser utilizado neste ensaio é de fundamental importância para que não ocorra uma excessiva concentração de tensões nessa região, e que, por conseguinte, leve à ruptura por fadiga em outras regiões da barra.

Para a escolha correta do tipo de garra a ser utilizada neste ensaio, levouse em consideração a pesquisa realizada pelo Laboratório de Estruturas e Materiais Estruturais (LEM) da Universidade de São Paulo e sua contratante Gerdau (R.T. No 01 / 026). Segundo esta pesquisa, após várias tentativas com diversos tipos de fixação, concluiu-se pela utilização de dois diferentes corpos-de-prova, sendo eles:

a) Corpos-de-prova com extremidades granalhadas e garras mais flexíveis, constituídas de um tronco cônico de epóxi de alta resistência, o qual é moldado cobrindo a 
extremidade da barra. Este, por sua vez, se acomoda dentro de um copo internamente cônico, como mostrado na figura 19. Além disso, uma arruela é soldada à da ponta barra, de tal forma que o epóxi seja um pouco menos solicitado, já que em algumas situações ele vinha a romper. Esta opção, pela maior dificuldade de execução, foi reservada para situações em que se sabia a priori que a ruptura por fadiga se daria para um número de ciclos maior que 1,5 milhões.

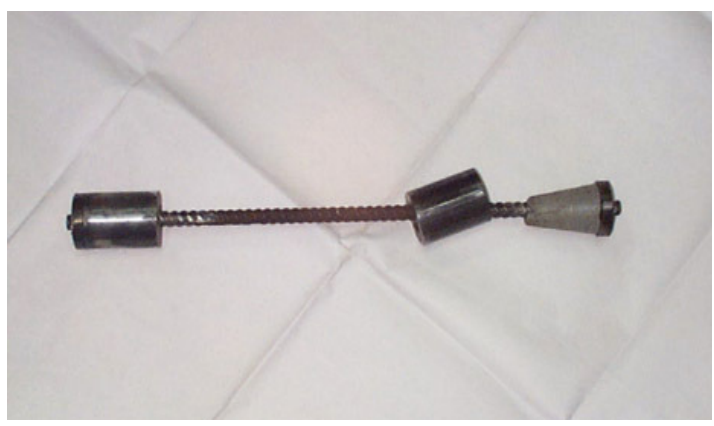

Figura 19 - Corpos-de-Prova granalhados, com garras de epóxi

b) corpos de prova com extremidades granalhadas e garras constituídas de clavetes e copos (Figura 20), o qual foi utilizado nesta pesquisa.
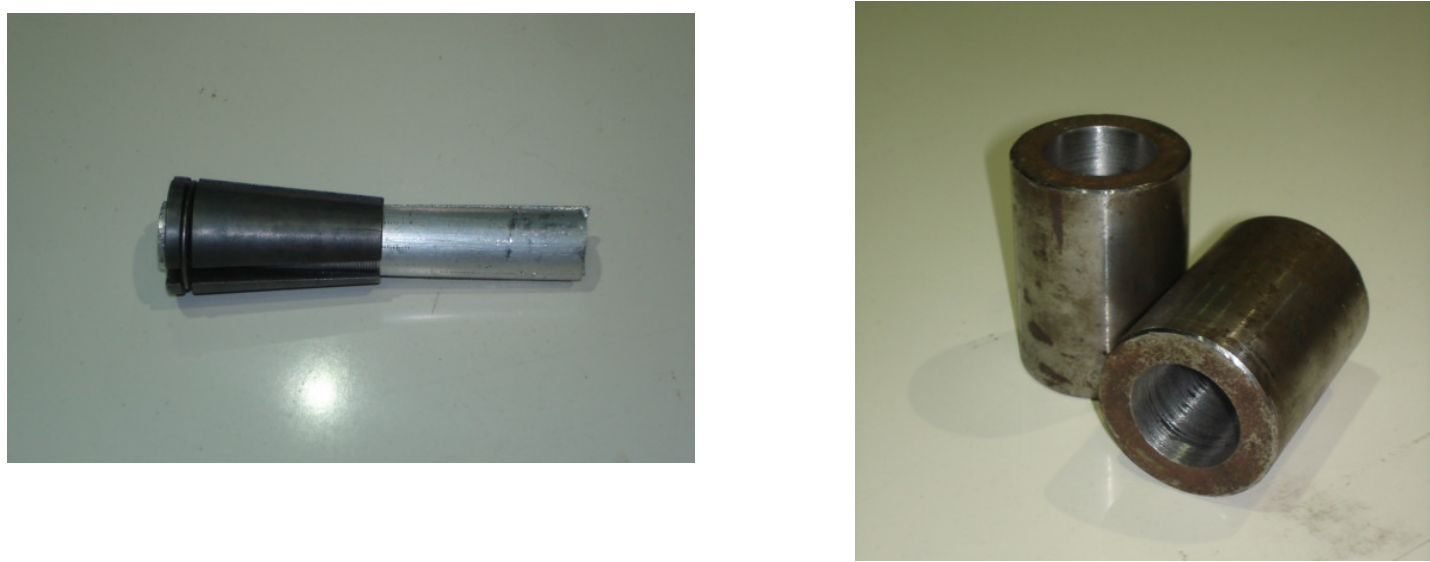

Figura 20 - Clavete e copos - Corpo-de-prova

Os corpos-de-prova foram primeiramente granalhados em suas extremidades (10 $\mathrm{cm}$ de cada lado), sendo o restante da barra protegido com uma mangueira plástica presa nas extremidades com arame (figura21).
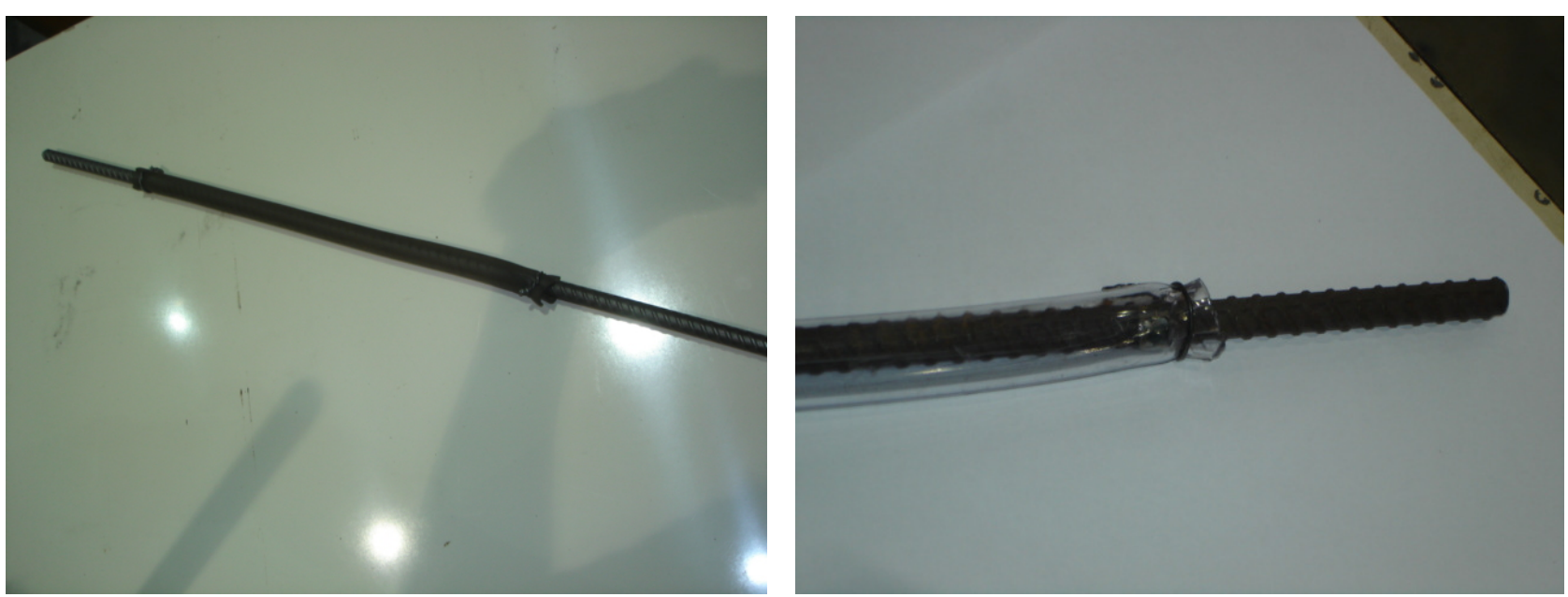
Figura 21 - Corpo-de-prova protegido com mangueira plástica.

Após serem granalhados, os corpos-de-prova foram preparados inserindo-se entre a clavete e a barra duas semicanas de tubos de alumínio, como mostra a figura 22.
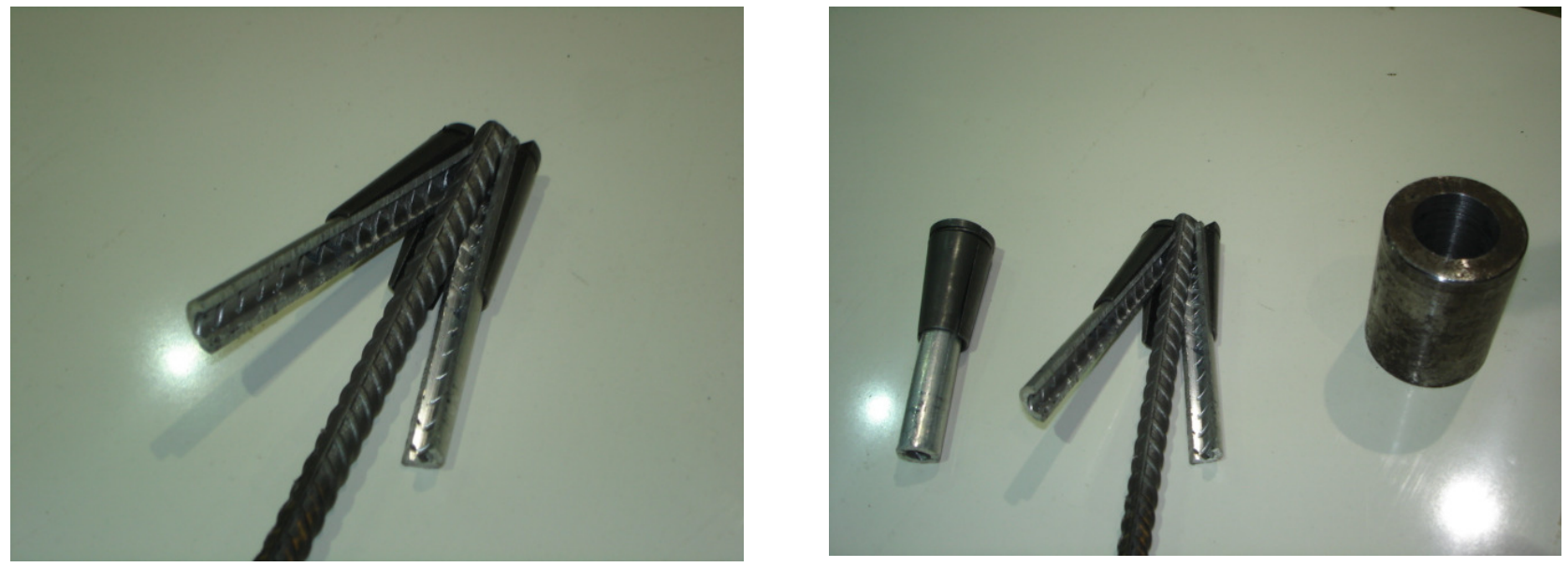

Figura 22 - Semicanas de alumínio e conjunto completo de fixação do corpo-de-prova.

Este procedimento, ilustrado na figura 22 , fez com que a concentração de tensões na região das garras fosse minorada, resultando em uma ruptura do corpo-deprova fora da garra. Esses corpos-de-prova foram utilizados para um nível de variação de tensão em que se sabia a priori que a ruptura por fadiga se daria para um número de ciclos menor que $1,5 \times 10^{6}$. Isto porque a ruptura, para um número de ciclos maior, na maioria dos casos ocorria nas garras, pois a própria clavete ou o alumínio rompiam, precipitando a ruptura da barra. 


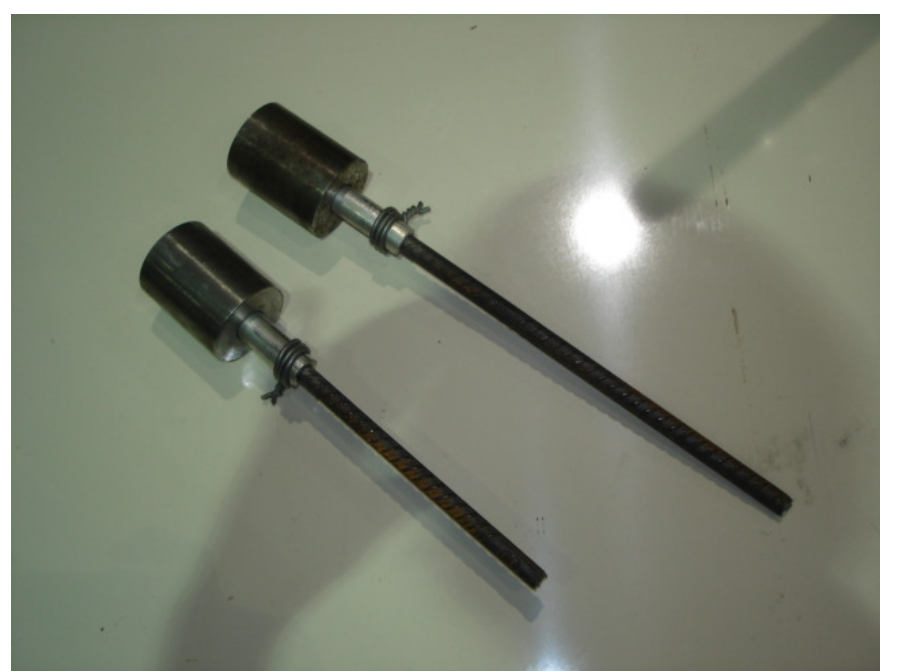

Figura 23 - Corpos-de-prova granalhados, com clavete e alumínio.

\subsubsection{Telas}

Para os corpos-de-prova constituídos por telas, foram adotados os mesmos procedimentos das barras, isto é, corpos-de-prova com $600 \mathrm{~mm}$ de comprimento, granalhados, com sistema de fixação de clavetes e duas semicanas de tubos de alumínio. Foi necessário apenas uma pequena adaptação das barras transversais, as quais foram cortadas rente à barra longitudinal (Figuras 24 e 25), permitindo assim que o corpo-de-prova utilizasse o mesmo sistema de proteção (mangueiras plásticas) para o processo de granalha. 

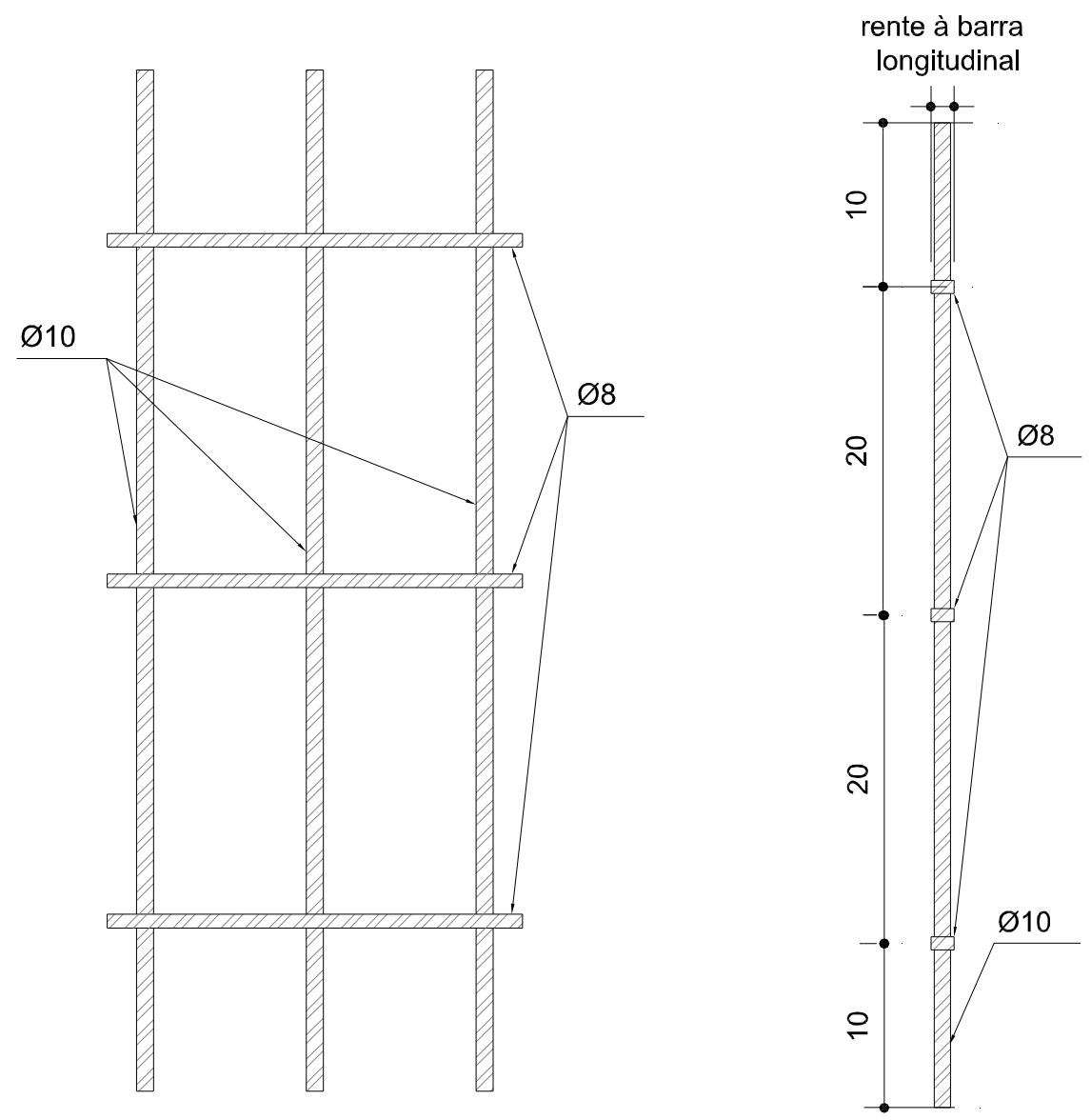

Figura 24 - Exemplo esquemático de corte de tela para confecção do corpo-de-prova.
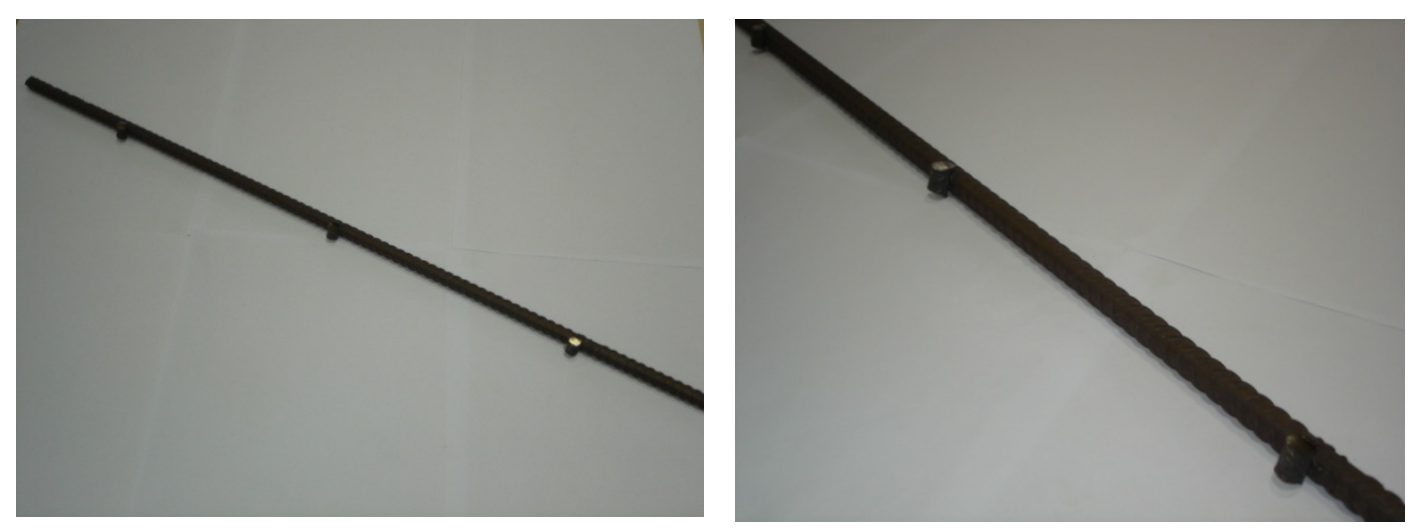

Figura 25 - Corpo-de-prova - telas . 


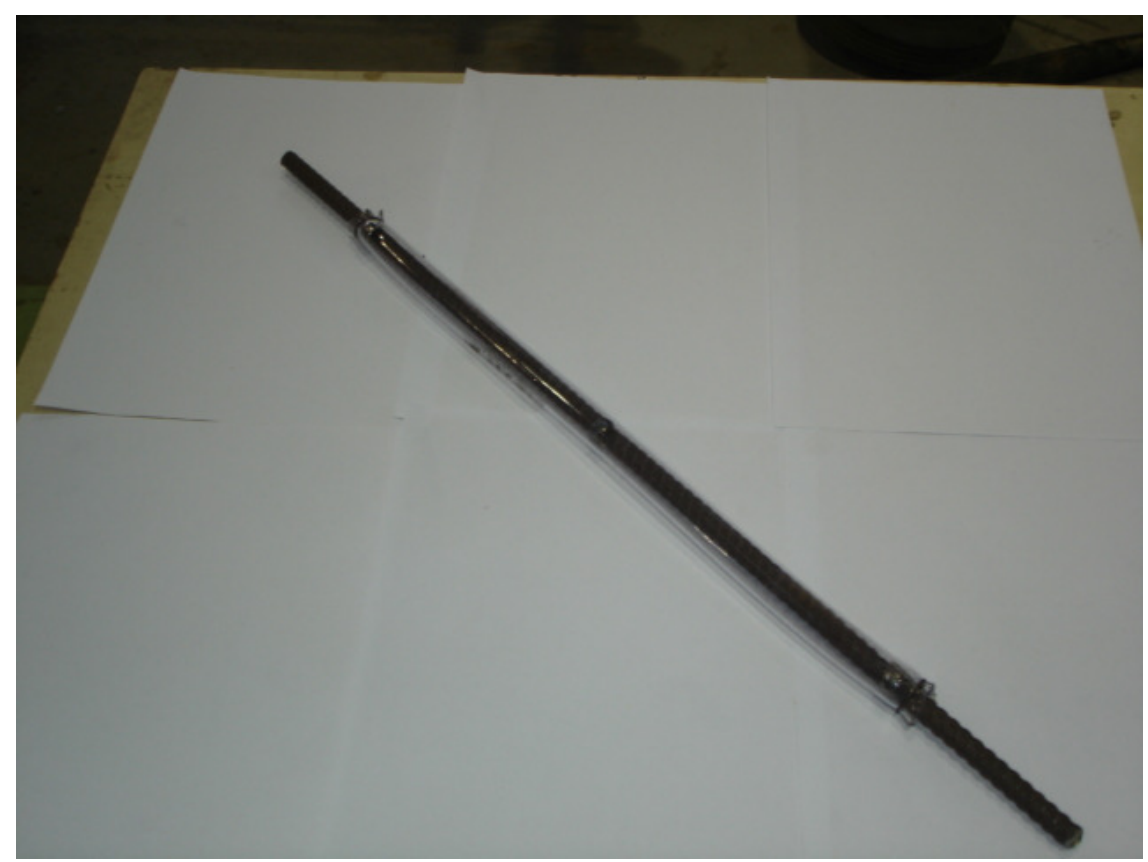

Figura 26 - Corpo-de-prova protegido com mangueira plástica pronto para procedimento de granalha

\subsection{ENSAIOS DE FADIGA EM LAJES}

O Programa de pesquisa consiste na investigação experimental de lajes de concreto armado com telas e barras soldadas, montadas com diversas configurações de armadura transversal, submetidas a ensaios estáticos e dinâmicos.

A finalidade dos ensaios realizados é a verificação do comportamento estrutural à fadiga especialmente das pré-lajes de concreto, armadas com barras de aço e telas soldadas. Para isso foram moldados corpos-de-prova que simulem estes elementos estruturais das pontes, numa escala de 1 para 1,5. As lajes possuem as mesmas propriedades geométricas $1,8 \mathrm{~m}$ de comprimento, $0,5 \mathrm{~m}$ de largura e $0,12 \mathrm{~m}$ de altura .

$\mathrm{O}$ uso desses modelos em escala tem a finalidade de facilitar o manuseio dos corpos-de-prova durante os ensaios. Foi tomado o devido cuidado para se manter as características das peças ensaiadas compatíveis com a das obras que são executadas na escala real, como por exemplo, garantir que a ruptura por flexão acontecesse antes da ruptura por força cortante e que os valores da fadiga também fossem semelhantes aos encontrados na prática. $\mathrm{Na}$ verdade este tamanho é de fato usado em obras menores.

As armações escolhidas para as lajes foram baseadas nas que são utilizadas nas pontes. A partir das armações escolhidas e das dimensões das peças foi calculado, como será mostrado no item 3.6, o ELU de ruptura e fadiga de cada peça, para que fosse possível calcular as forças utilizadas nos ensaios estáticos e dinâmicos. 
Com o intuito de se garantir uma boa amostragem nos resultados para cada grupo foram concretados três lajes, das quais uma será submetida a um ensaio de ruptura, com o objetivo de verificar seu comportamento estrutural e as outras duas peças serão ensaiadas à fadiga.

\subsection{CORPOS-DE-PROVA}

Para a realização dos ensaios dinâmicos foram moldados 20 corpos-deprova em concreto convencional, concretados em duas etapas para simular as lajes executadas com pré-lajes e também em um etapa única de concretagem.

Devido à dimensão dos corpos-de-prova não foi possível curá-los em câmara úmida. A cura foi realizada durante os primeiros sete dias, umedecendo as lajes diariamente e as mantendo envolvidas com uma lona plástica para garantir uma cura satisfatória (Figura 27).

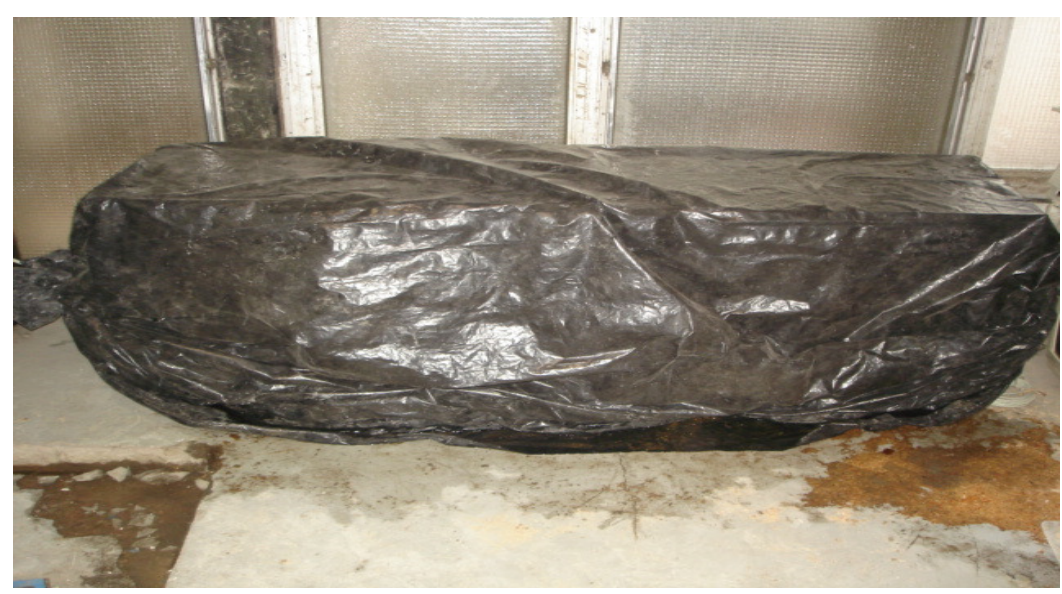

Figura 27 - Lajes envolvidas por lona plástica para a cura adequada

As 20 lajes possuem as mesmas propriedades geométricas $1,8 \mathrm{~m}$ de comprimento, 0,5 m de largura e 0,12 m de altura (Figura 28), variando a armação e se possuem ou não uma pré-laje. Resultaram em 3 grupos (1,2 e 3 ) subdivididos em subgrupos (1 A, 1B, 2 A, 2B, 3 A 3B) cujas características serão descritas no item 3.4.1.

Nas lajes que foram concretadas com pré-laje não houve tratamento algum na região da junta, isto é, após a concretagem da pré-laje não se fez nenhuma intervenção. O intervalo entre a concretagem da pré-laje para a capa foi de 4 dias. 
Devido à impossibilidade de ser realizadas betonadas de grande volume, cada laje foi concretada usando um única betonada, então é natural que os corpos-deprova apresentem uma pequena diferença com relação às propriedades do concreto.

Para que fosse possível se conhecer as propriedades de cada laje. Para cada betonada foram moldados 9 corpos-de-prova, com o objetivo de serem realizados ensaios de caracterização.

Para se obter o traço de um concreto que atingisse uma resistência mínima $30 \mathrm{MPa}$ aos 28 dias, resistência bastante frequente em lajes de pontes, foram realizadas três betonadas experimentais. Baseado na resistência de cada uma das betonadas de teste foi determinado o traço utilizado.

\subsubsection{Descrição dos grupos}

Grupo 1:

Este grupo possui seis lajes subdivididos em 2 subgrupos 1A, 1B com armaduras distintas. A idéia do grupo 1 é a de estudar o comportamento das lajes armadas com barras isoladas.

Subgrupo 1A:

Este subgrupo foi concretado em duas etapas, simulando as lajes de pontes executadas com pré-laje, como ilustrado nos desenhos esquemáticos das Figuras 28 a 31.

A armação longitudinal positiva deste grupo é de $\phi 8 \mathrm{c} / 15$ que resulta em um As longitudinal de $2 \mathrm{~cm}^{2}$, a armadura de distribuição é $\phi 8 \mathrm{c} / 40$ e a armação negativa é de $\phi$ 6,3 c/15 nas duas direções. (Figuras 28 a 31) 


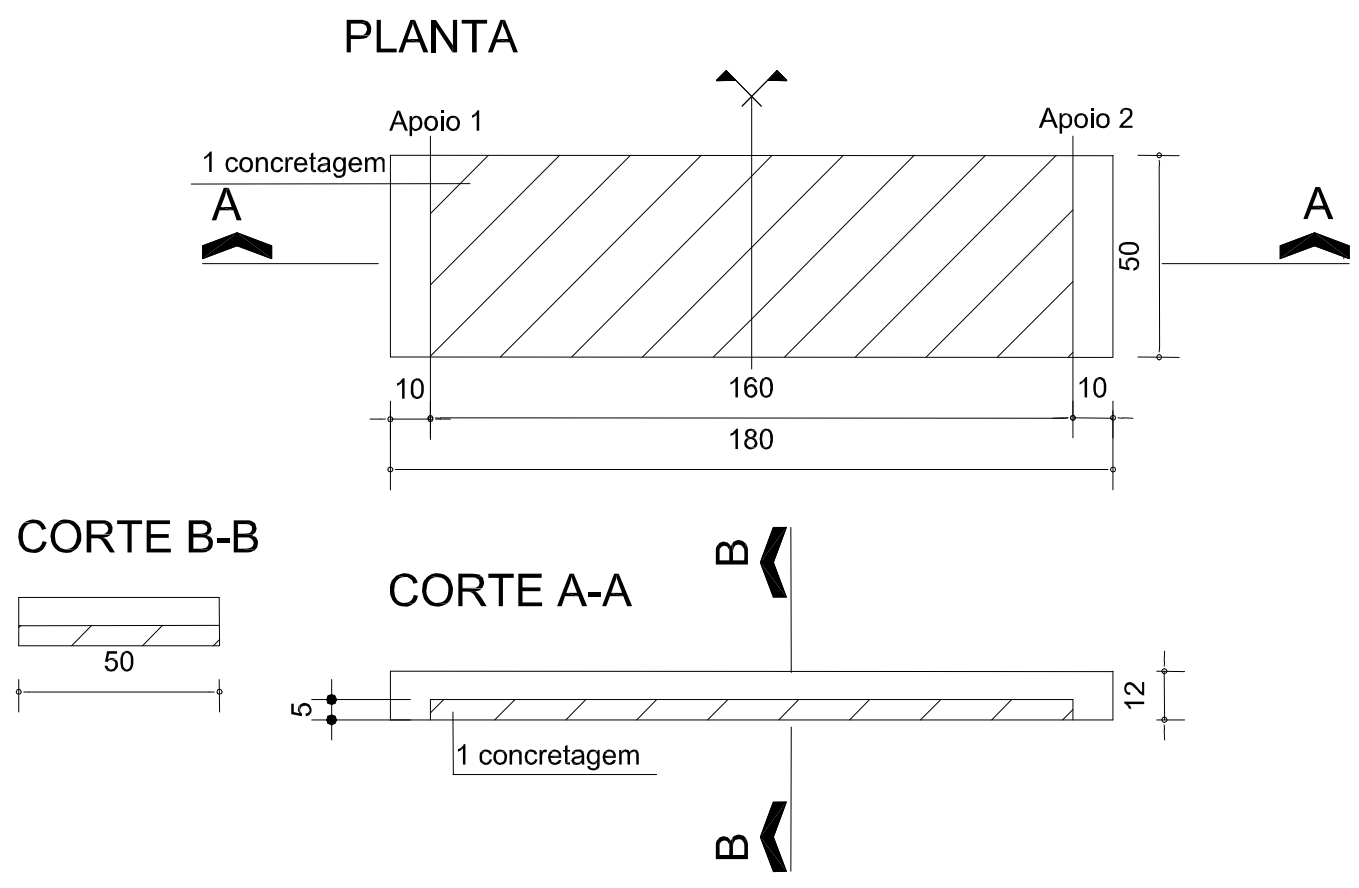

Figura 28 - Desenho esquemático das etapas de concretagem

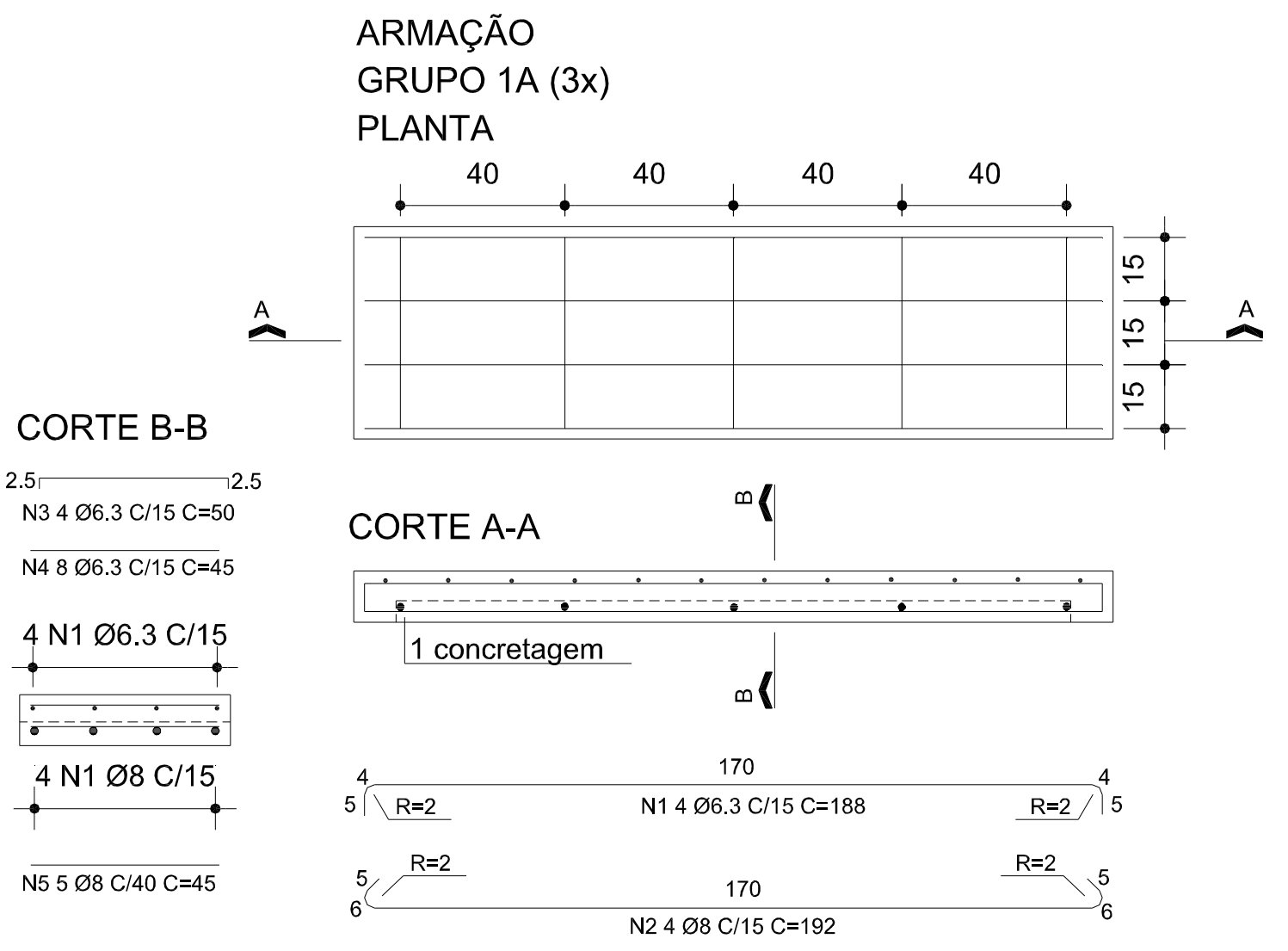

Figura 29- Desenho esquemático das armaduras do subgrupo $1 \mathrm{~A}$ 


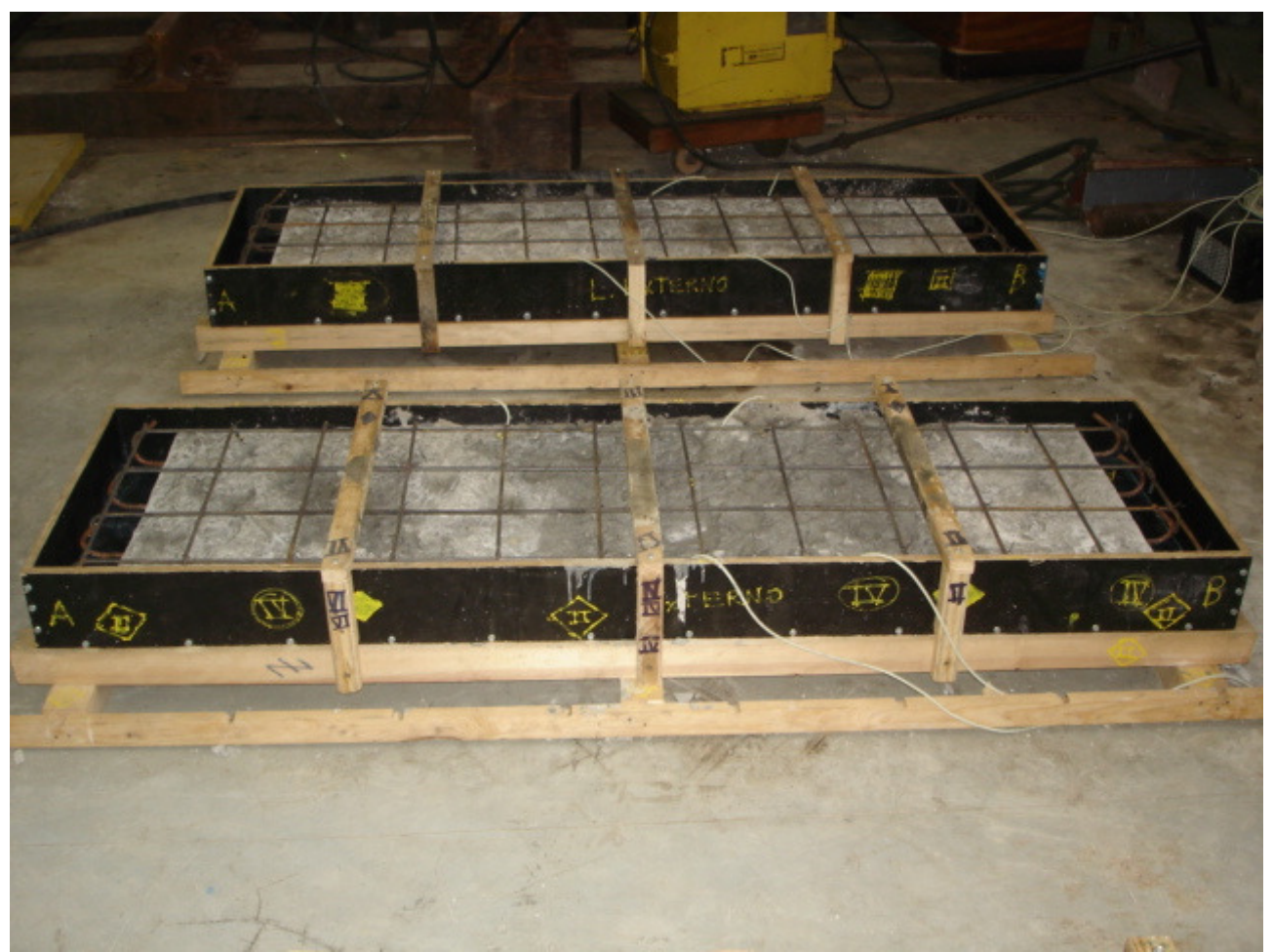

Figura 30 - Foto após a primeira etapa concretagem, com a armadura negativa montada.

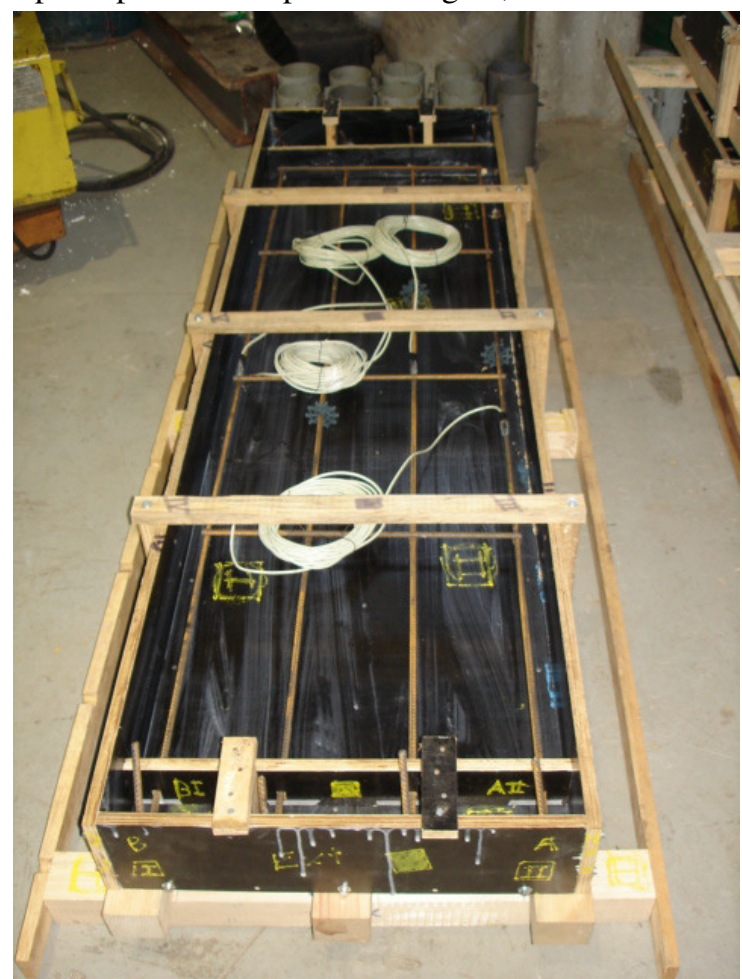

Figura 31 - Armação positiva do subgrupo 1A.

Subgrupo 1 B:

Este grupo foi concretado também duas etapas como ilustrado nos desenhos esquemáticos da Figura 28. A armação positiva principal deste grupo é de $\phi 10 \mathrm{c} / 10 \mathrm{~cm}$ 
que resulta em um As longitudinal de $4 \mathrm{~cm}^{2}$, a armadura de distribuição é $\phi 8 \mathrm{c} / 20 \mathrm{~cm}$ e a armação negativa é de $\phi 6,3 \mathrm{c} / 15 \mathrm{~cm}$ nas duas direções. (Figura 32)

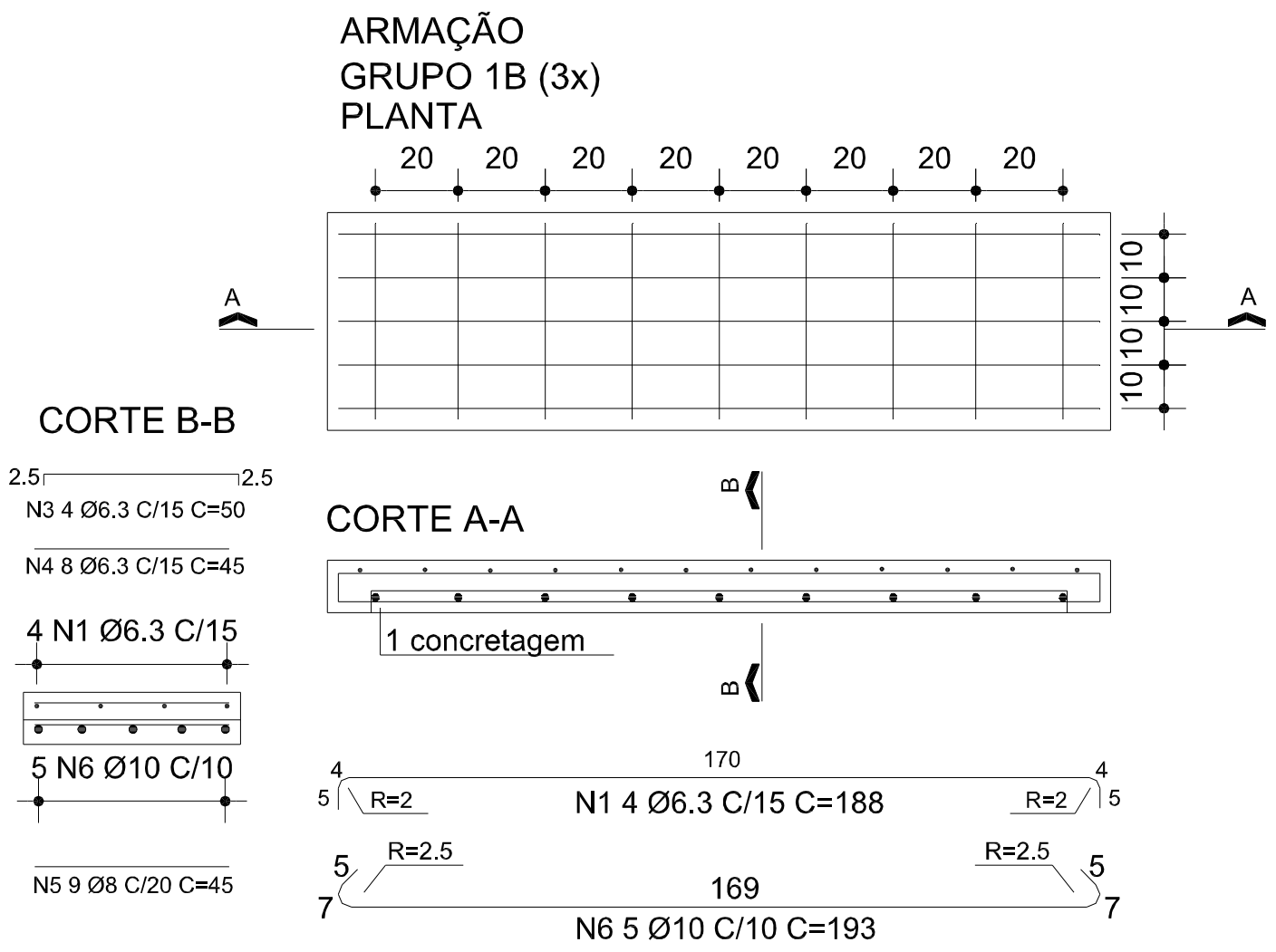

Figura 32 - Desenho esquemático das armaduras do subgrupo 1B

Grupo 2:

Assim como no subgrupos 1A e 1B foram idealizados os subgrupos $2 \mathrm{~A}$ e 2B, a única diferença entre eles é o fato do grupo 2 utilizar tela soldada ao invés de barras isoladas. Deste modo será possível comparar o comportamento estrutural de lajes armadas com barras e telas soldadas.

Subgrupo 2 A:

Este grupo foi concretado também em duas etapas como ilustrado nos desenhos esquemáticos da Figura 28. A armação deste grupo é em tela soldada como ilustra a Figura 33, a armadura deste grupo é a mesma da do subgrupo 1A, ou seja, a armação positiva principal deste grupo é de $\phi 8 \mathrm{c} / 15$ que resulta em um As longitudinal de $2 \mathrm{~cm}^{2}$, a armadura de distribuição é $\phi 8 \mathrm{c} / 40 \mathrm{~cm}$ e a armação negativa é de $\phi 6,3 \mathrm{c} / 15$ $\mathrm{cm}$ em ambas direções. 


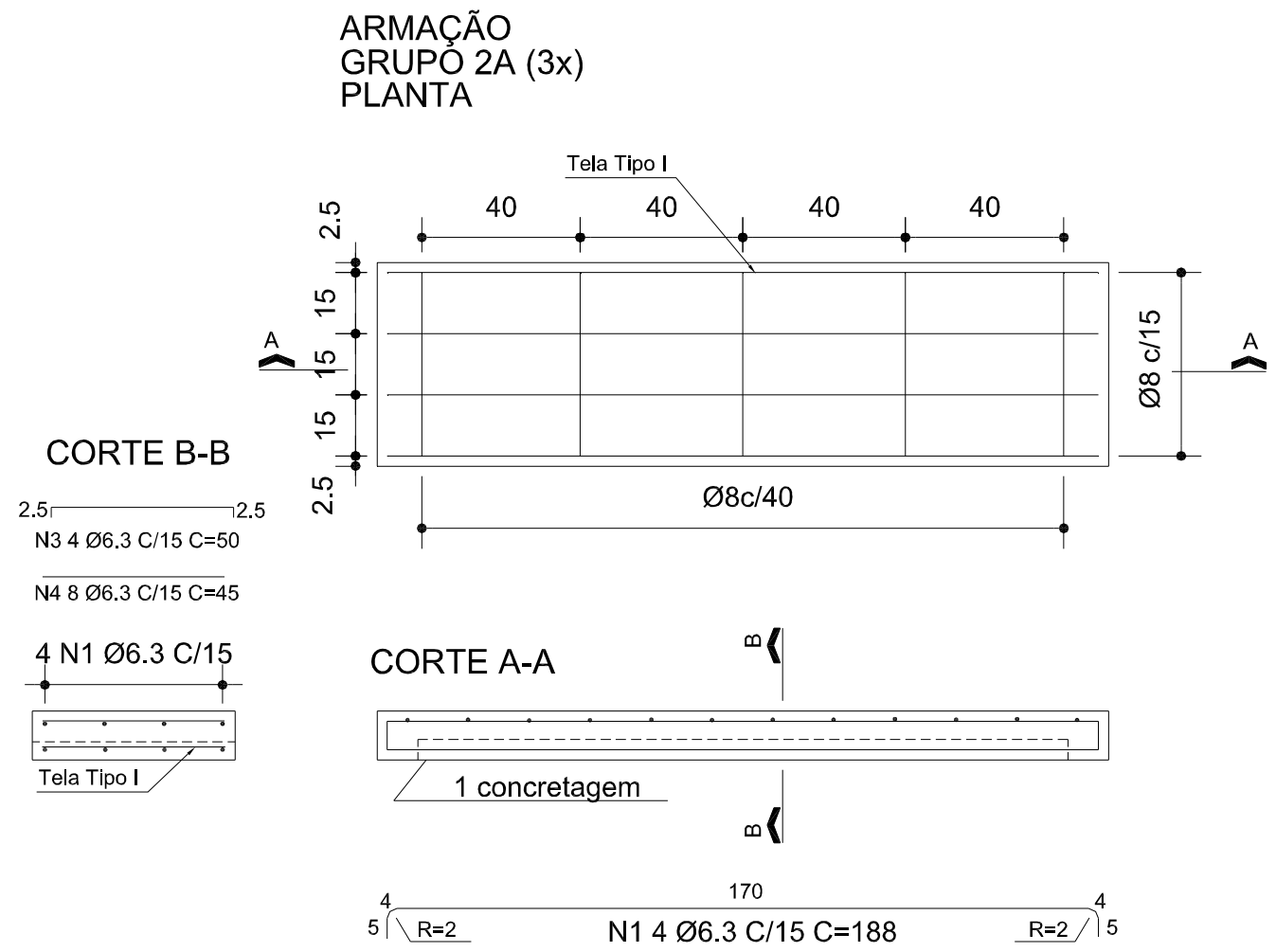

Figura 33 - Desenho esquemático das armaduras do subgrupo 2A.

Subgrupo 2 B:

Este subgrupo foi concretado também duas etapas como ilustrado nos desenhos esquemáticos da Figura 28. A armação deste subgrupo é em tela soldada como ilustra a Figura 34, a armadura deste subgrupo é a mesma da do subgrupo 1B, ou seja, a armação positiva principal deste grupo é de $\phi 10 \mathrm{c} / 10 \mathrm{~cm}$ que resulta em um $\mathrm{A}_{\mathrm{s}}$ longitudinal de $4 \mathrm{~cm}^{2}$, a armadura de distribuição é $\phi 8 \mathrm{c} / 20 \mathrm{~cm}$ e a armação negativa é de $\phi 6,3 \mathrm{c} / 15 \mathrm{~cm}$ nas duas direções. 


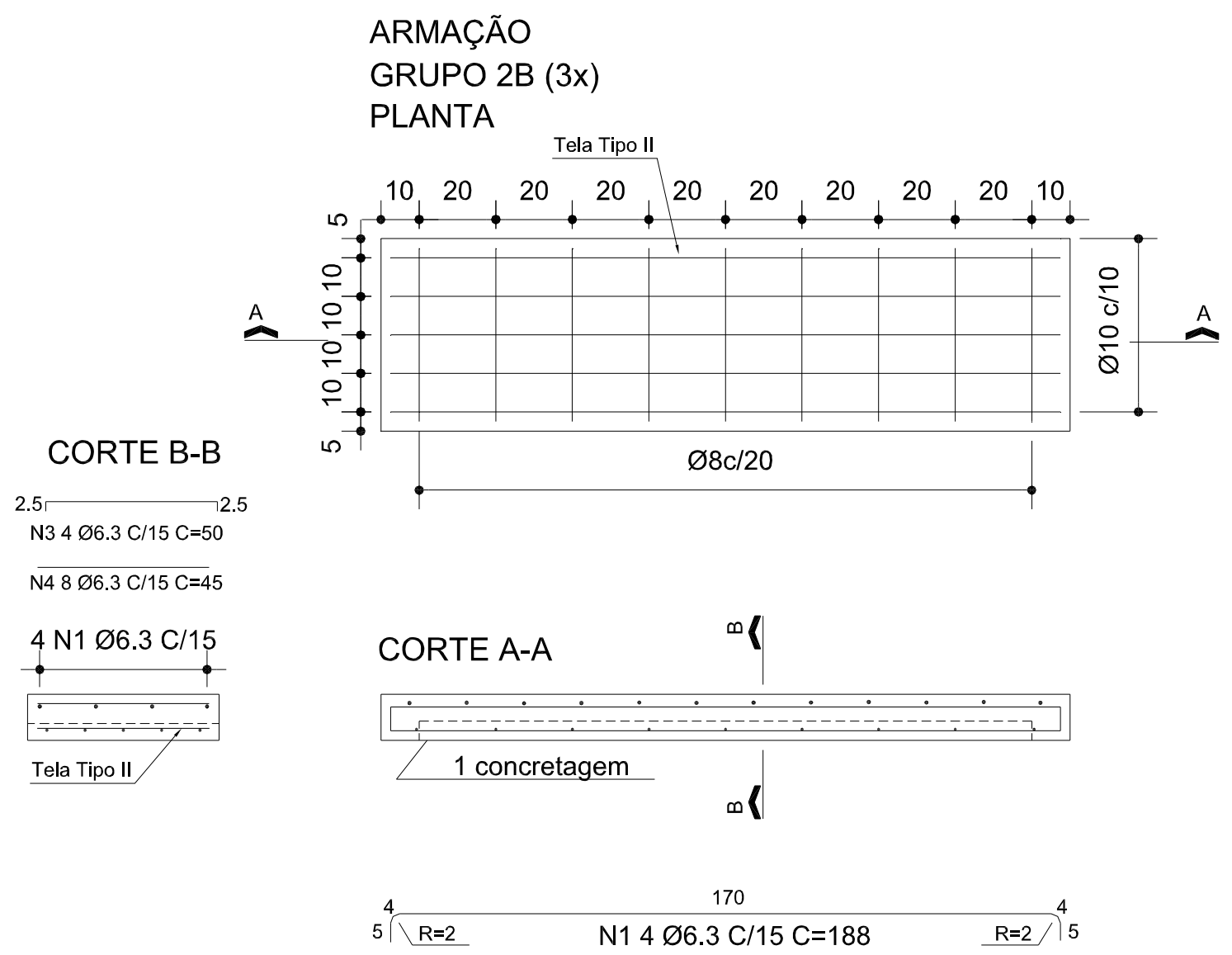

Figura 34 - Desenho esquemático das armaduras do subgrupo 2B.

Subgrupo 3 A:

Este subgrupo foi concretado em uma única etapa como ilustrado no desenhos esquemáticos da Figura 35. A armação deste subgrupo é em tela soldada como ilustra a Figura 35, a armadura deste subgrupo é a mesma da do subgrupo $2 \mathrm{~A}, 2 \mathrm{~cm}^{2}$, na verdade a única diferença entre este grupo e o 2 A é que este grupo foi concretado em uma etapa única, não existindo assim uma pré-laje. 

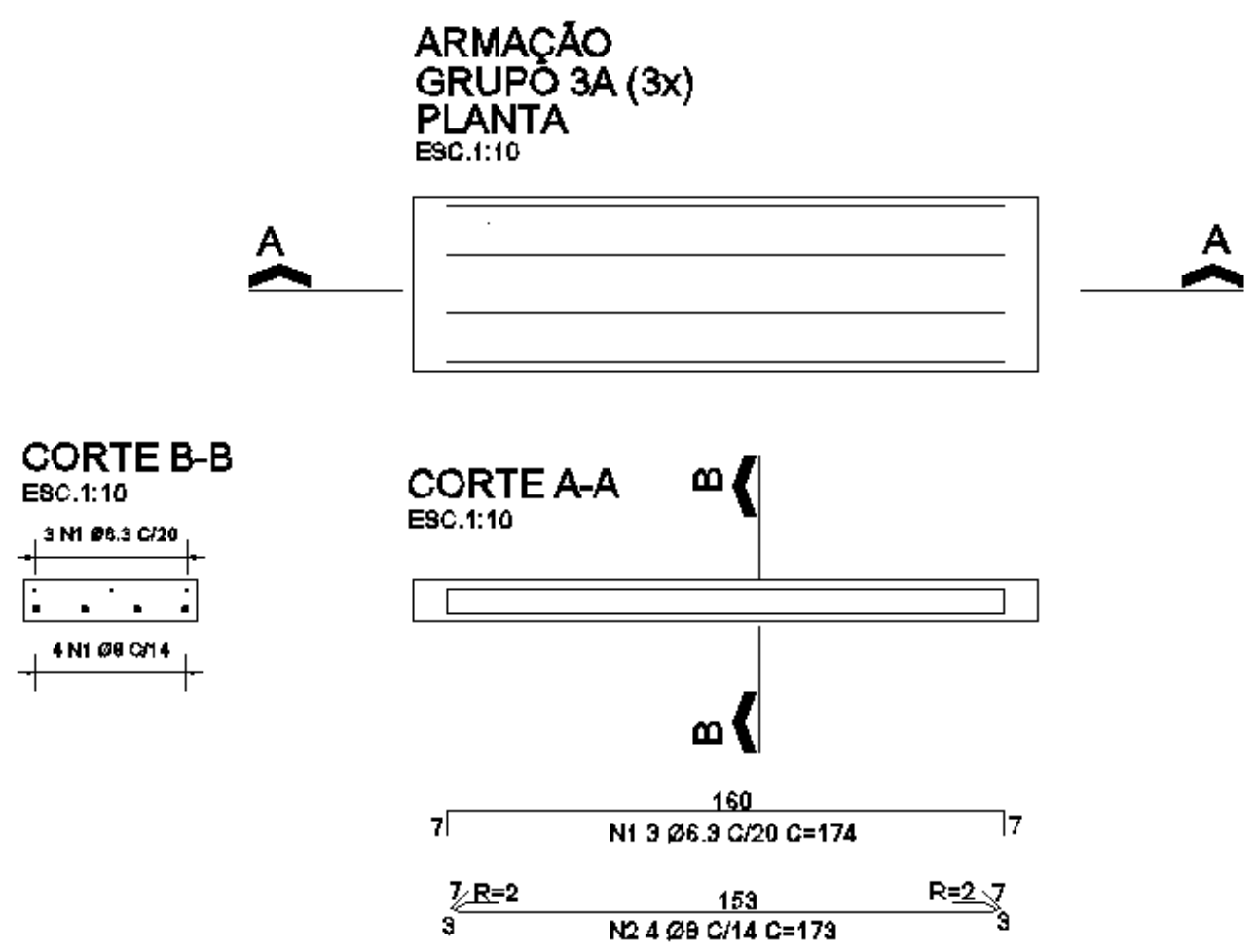

Subgrupo 3 B:

Figura 35 - desenho esquemático do grupo $3 \mathrm{~A}$

Este subgrupo, assim como o $3 \mathrm{~A}$ foi concretado em uma única etapa como ilustrado no desenhos esquemáticos da Figura 36. A armação deste subgrupo é em tela soldada como ilustra a Figura 36, a armadura deste subgrupo é a mesma da do subgrupo 2B, $4 \mathrm{~cm}^{2}$, e assim como no subgrupo $3 \mathrm{~A}$ a diferença dele para o subgrupo $2 \mathrm{~B}$ é a não existência da pré-laje. 


\section{ARMACAO}

GRUPO 3B (3x)

PLANTA

ESC.1:10
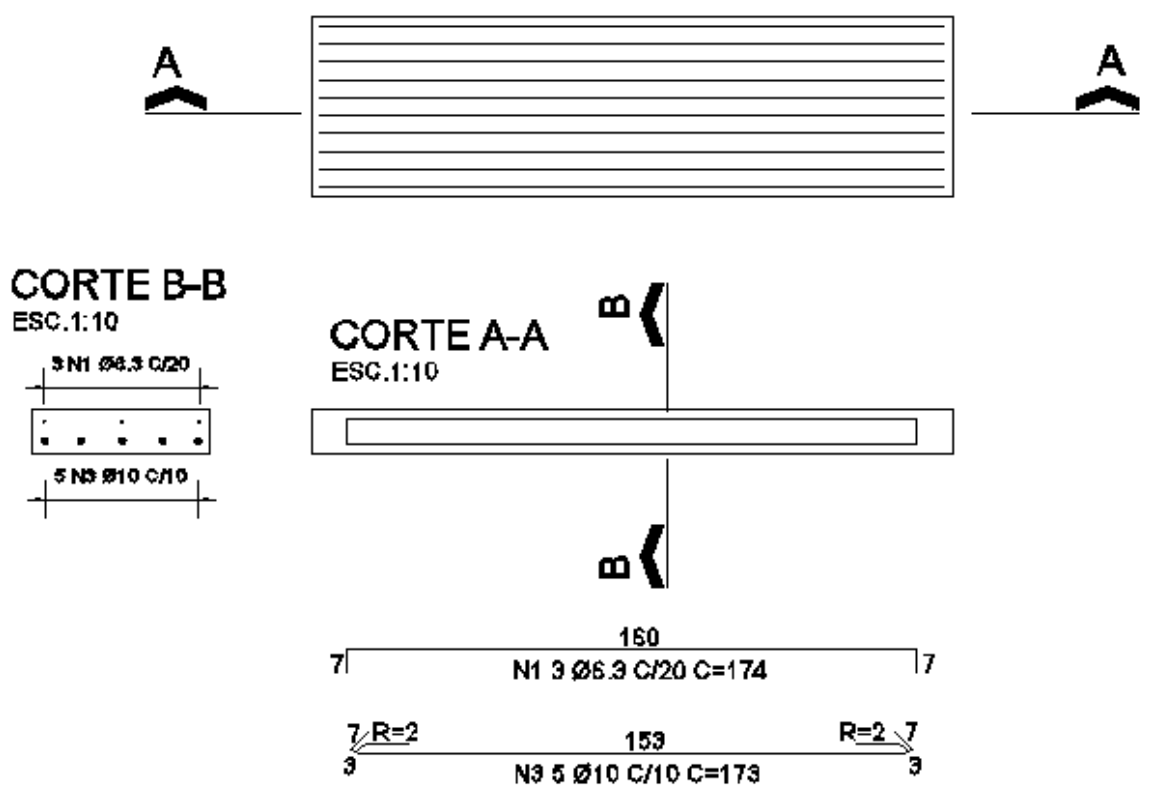

Figura 36 - desenho esquemático do grupo 3 B

A tabela 5 resume os grupos ensaiados:

Tabela 5 - Resumo dos grupos de ensaio.

\begin{tabular}{|c|c|c|c|c|c|c|c|c|}
\hline Grupos & $\begin{array}{l}\text { Dimensões } \\
(\mathrm{m})\end{array}$ & Tipo & Qtd. & Aço & $\begin{array}{c}\text { As } \\
\left(\mathrm{cm}^{2}\right)\end{array}$ & Configuração & Tipo & Ciclos \\
\hline $1 \mathrm{~A}$ & $1,80 \times 0,50 \times 0,12$ & com pré-laje & 3 & CA50 & 2.00 & $\phi 8 \mathrm{c} / 15$ & Barras & $2 \times 10^{6}$ \\
\hline 1B & $1,80 \times 0,50 \times 0,12$ & com pré-laje & 3 & CA50 & 4.00 & $\phi 10 \mathrm{c} / 10$ & Barras & $2 \times 10^{6}$ \\
\hline $2 \mathrm{~A}$ & $1,80 \times 0,50 \times 0,12$ & com pré-laje & 3 & CA50 & 2.00 & $\phi 8 \mathrm{c} / 15 \times \phi 8 \mathrm{c} / 40$ & Telas & $2 \times 10^{6}$ \\
\hline $2 \mathrm{~B}$ & $1,80 \times 0,50 \times 0,12$ & com pré-laje & 3 & CA50 & 4.00 & $\phi 10 \mathrm{c} / 10 \times \phi 8 \mathrm{c} / 20$ & Telas & $2 \times 10^{6}$ \\
\hline $3 \mathrm{~A}$ & $1,80 \times 0,50 \times 0,12$ & maciça & 3 & CA50 & 2.00 & $\phi 8 \mathrm{c} / 15 \times \phi 8 \mathrm{c} / 40$ & Telas & $2 \times 10^{6}$ \\
\hline $3 \mathrm{~B}$ & $1,80 \times 0,50 \times 0,12$ & maciça & 3 & CA50 & 4.00 & $\phi 10 \mathrm{c} / 10 \times \phi 8 \mathrm{c} / 20$ & Telas & $2 \times 10^{6}$ \\
\hline
\end{tabular}

\subsection{ARRANJO DO ENSAIO}

O arranjo estrutural escolhido para os ensaios foi o de laje simplesmente apoiada, submetida a carregamentos cíclicos no meio do vão. Os vínculos da viga serão apoios móveis, que permitem a liberdade de rotação e deslocamentos laterais, evitando assim a introdução de esforços horizontais não previstos nos cálculos. 
O esquema de ensaio é um pórtico, devidamente fixado a uma laje de reação conforme as figuras 37 A 44. Para aplicação dos carregamentos foi utilizado um atuador da BRASVÁLVULAS, acoplado a uma célula de carga, existente no laboratório de Estruturas e Materiais da Escola Politécnica de São Paulo.

PLANTA SUPERIOR

ESC. 1:10

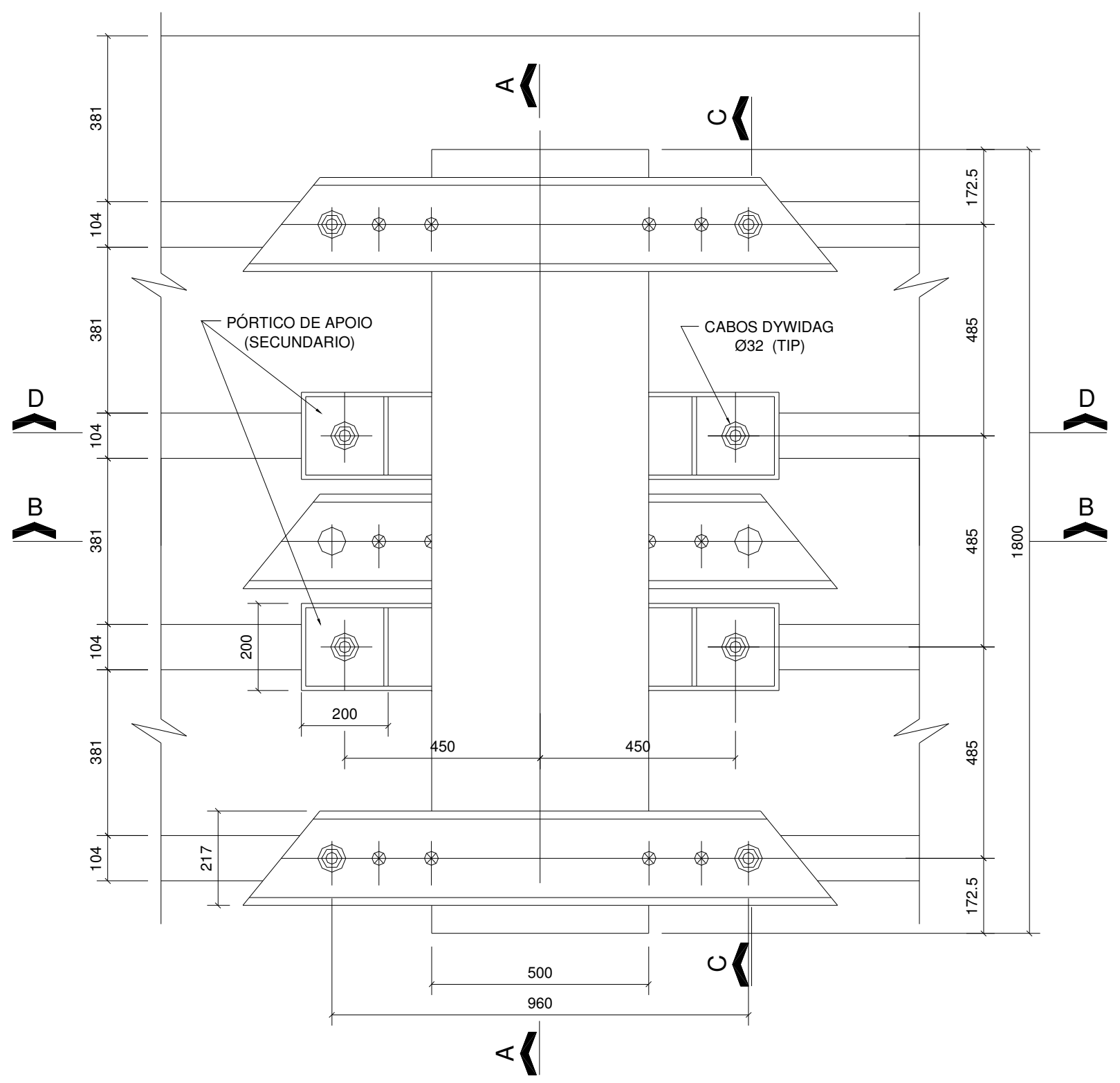

Figura 37 - Planta superior do arranjo do ensaio 


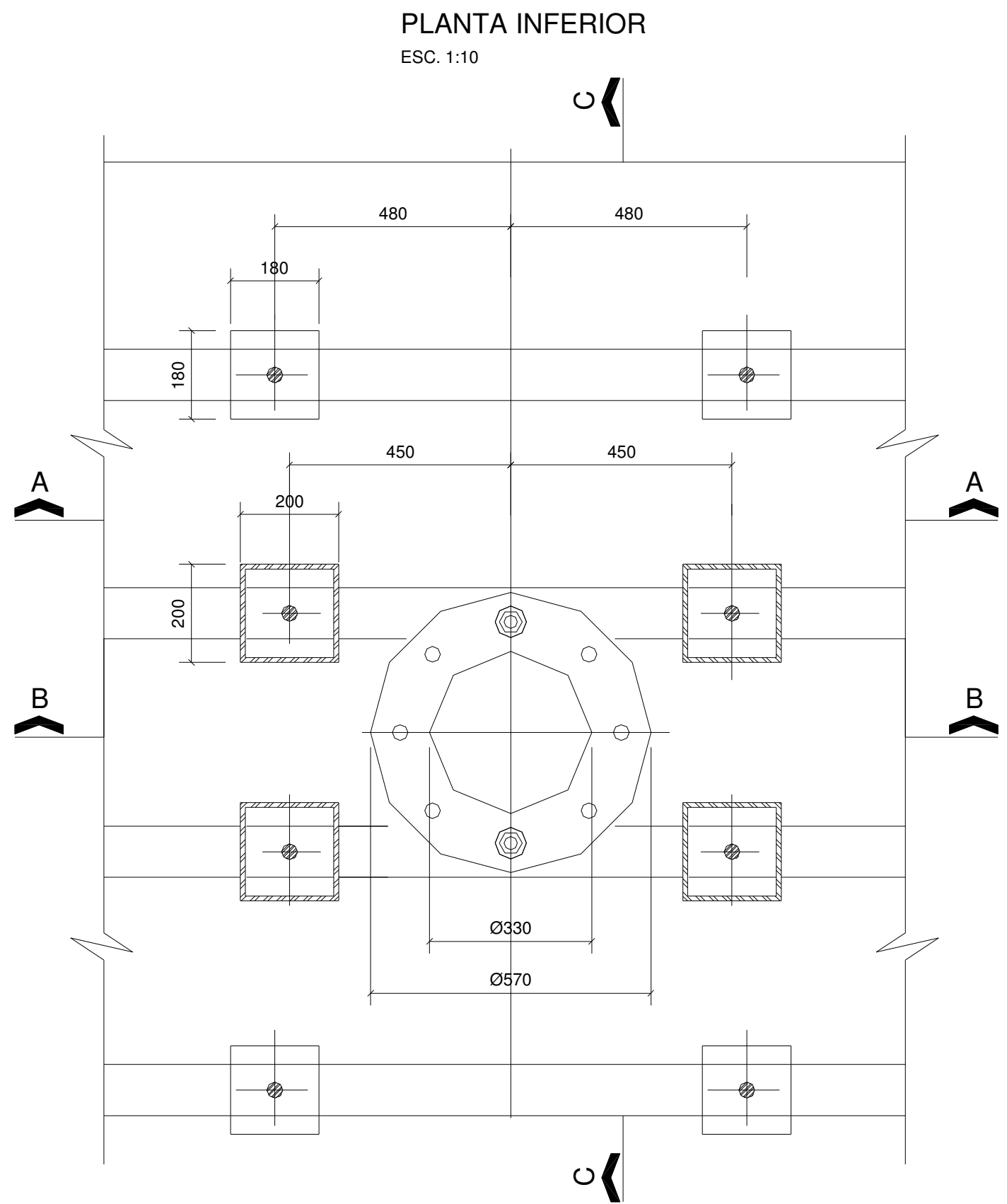

Figura 38 - Planta inferior do arranjo do ensaio 


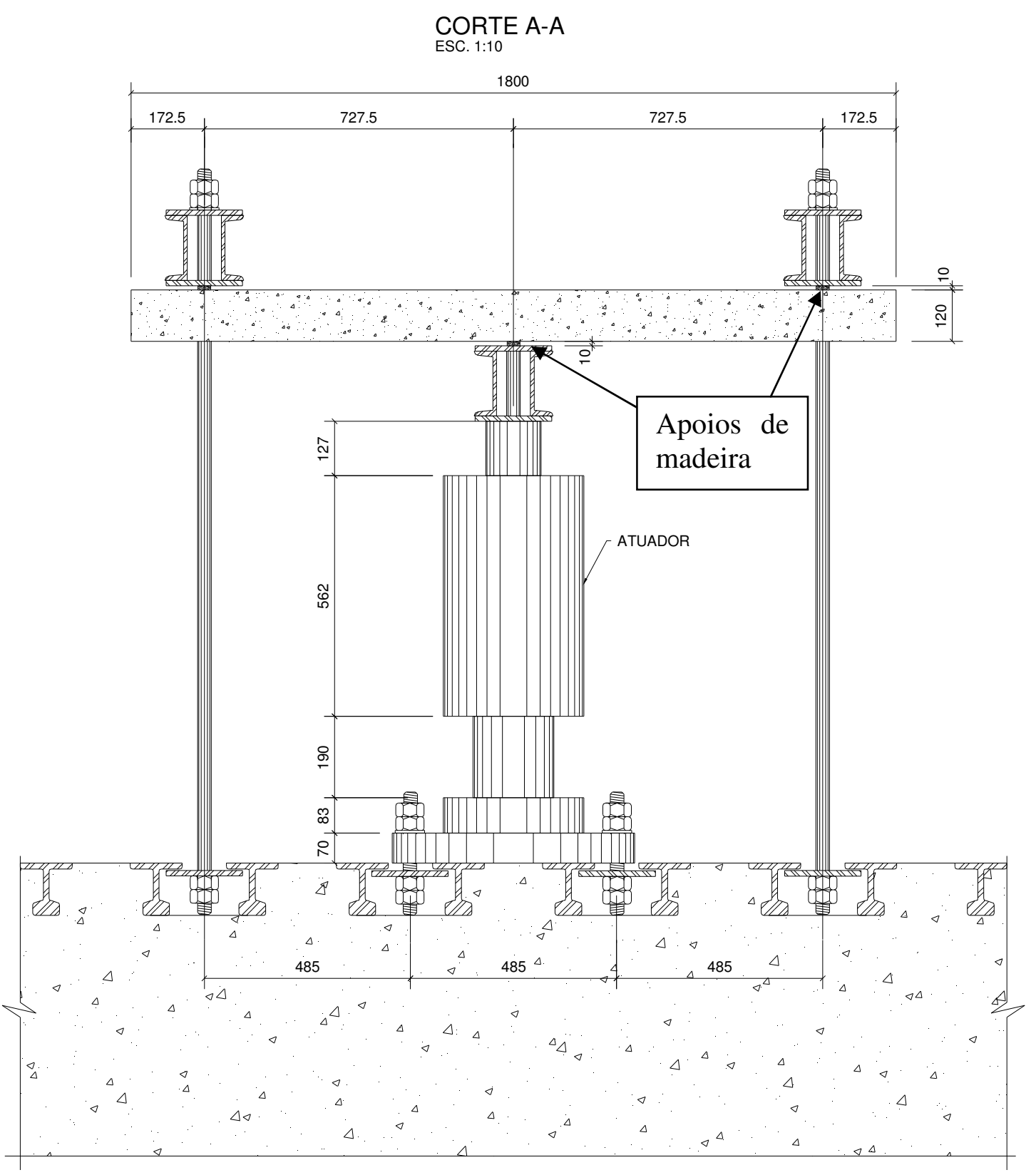

Figura 39 - Corte A-A 
CORTE B-B

ESC. 1:10

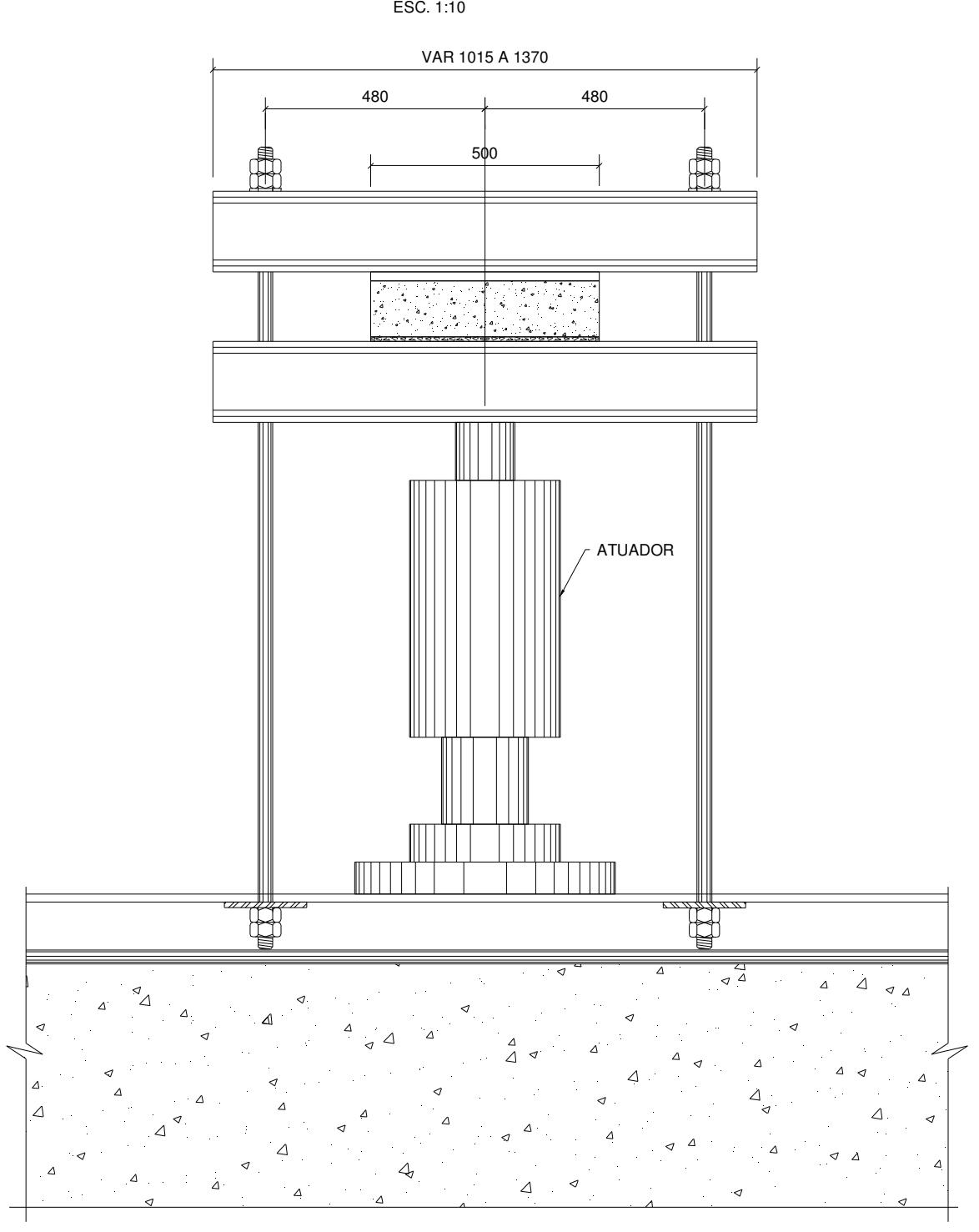

Figura 40 - Corte B-B 
CORTE C-C

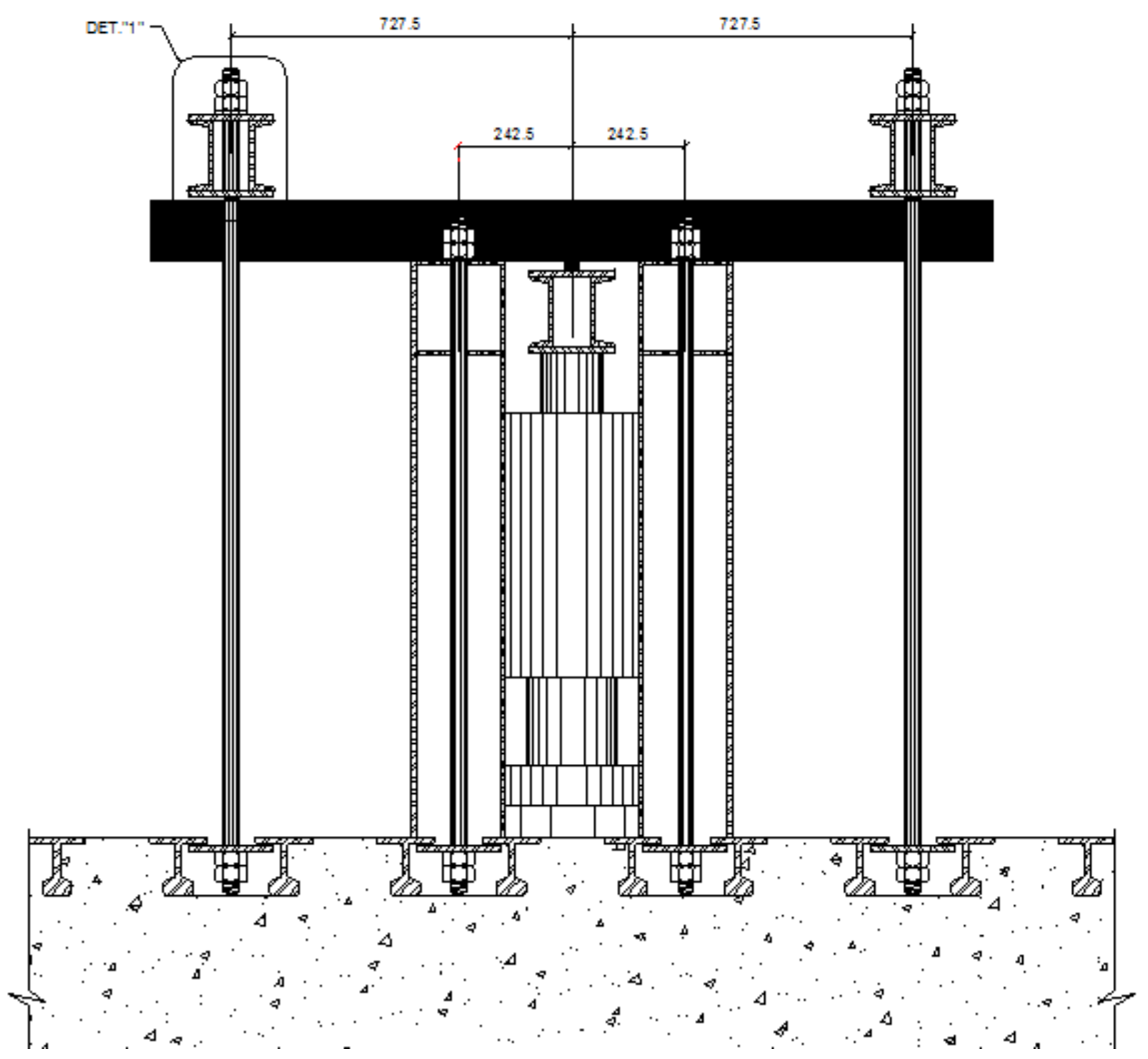

Figura 41 - Corte C-C

DET."1"

ESC. 1:10

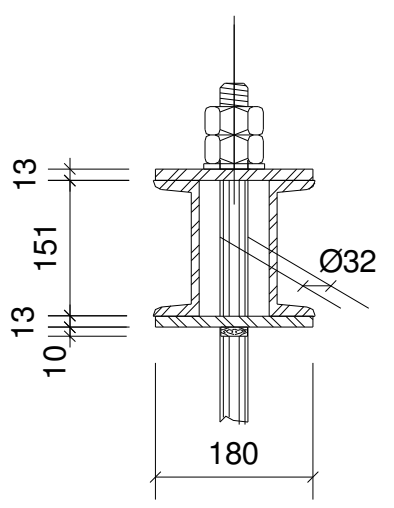

Figura 42 - Detalhe 1 


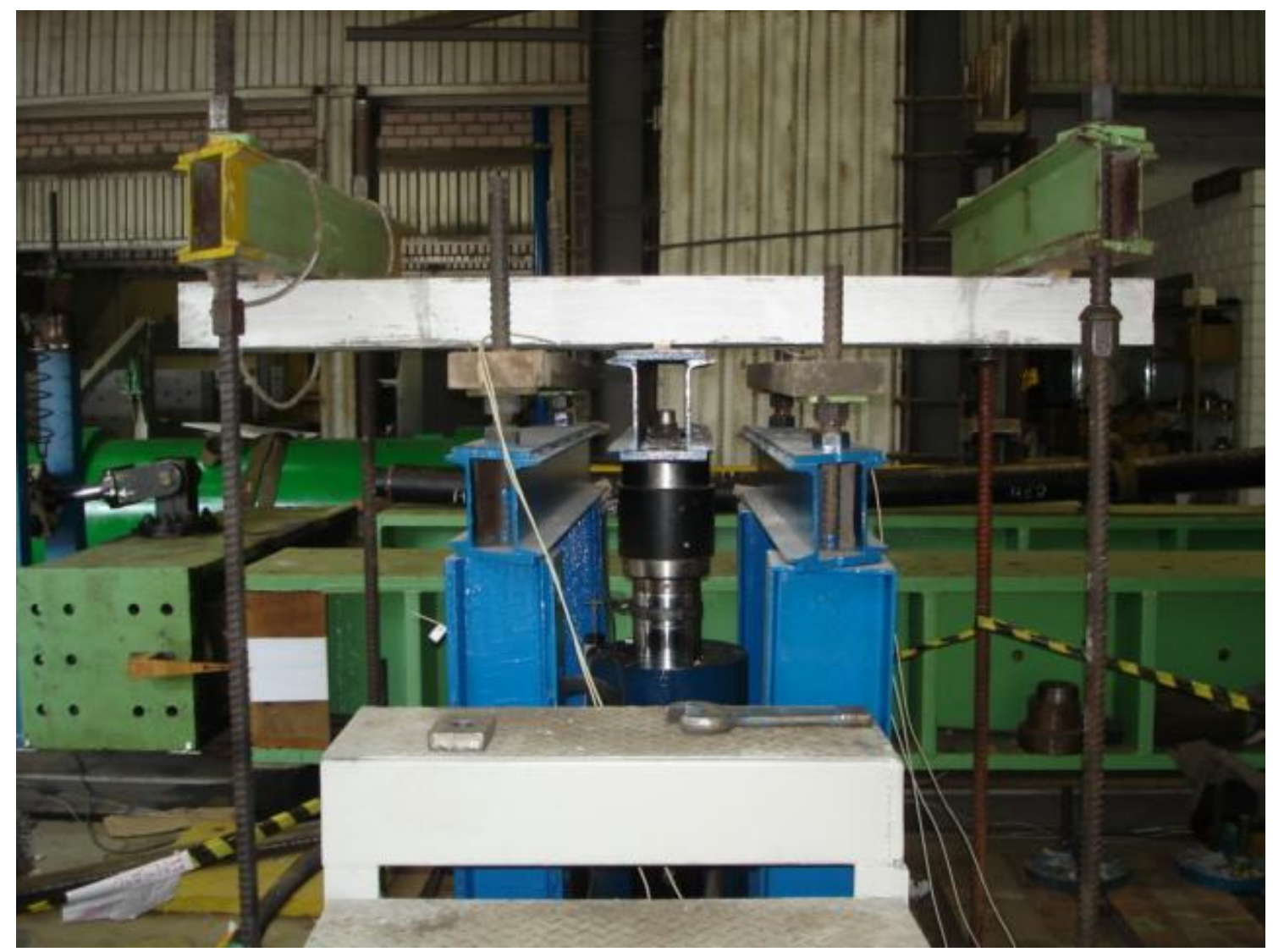

Figura 43 - Pórtico

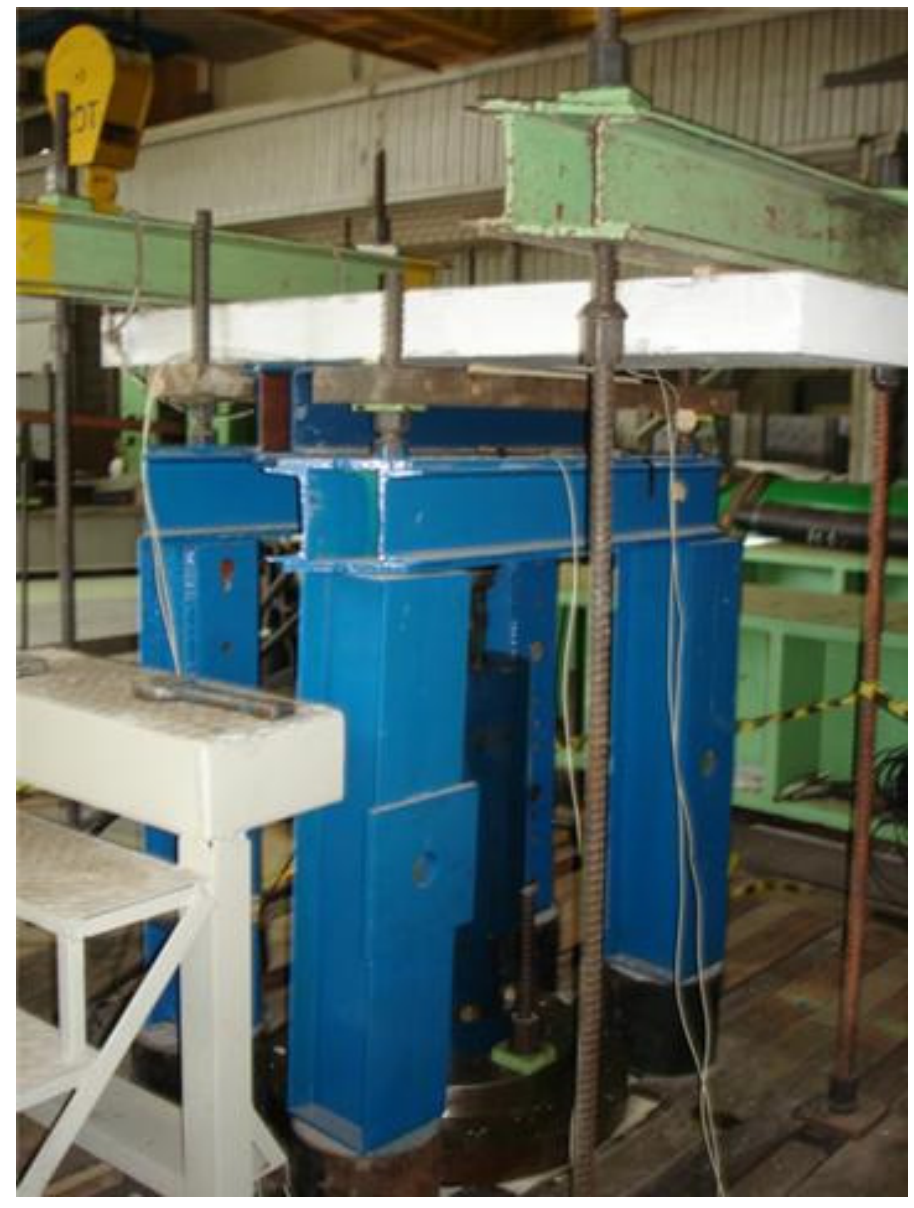

Figura 44 - Pórtico 
O objetivo do ensaio é simular uma estrutura real de laje de ponte, ou seja, uma laje biapoiada. Com o intuito de facilitar a montagem do ensaio (execução laboratorial) o ensaio foi idealizado invertido (rotação de $180^{\circ}$ ), como ilustrado nas figuras de 37 a 44 .

Por este motivo os cálculos apresentados no item 3.6 serão denominados de cálculos para ensaio (Figura 45) e cálculos para a ponte (Figura 46). Este último apresenta os valores do ELU da peça.

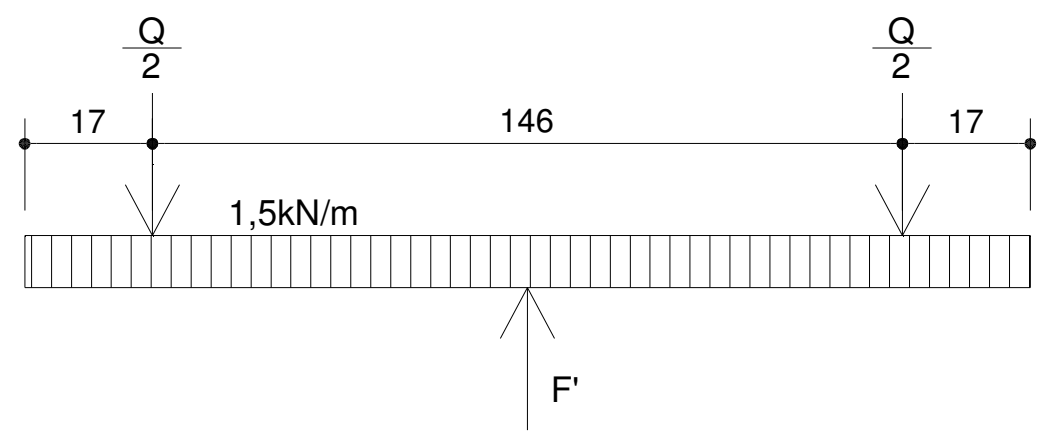

Figura 45 - Esquema estrutural "modelo ensaio".

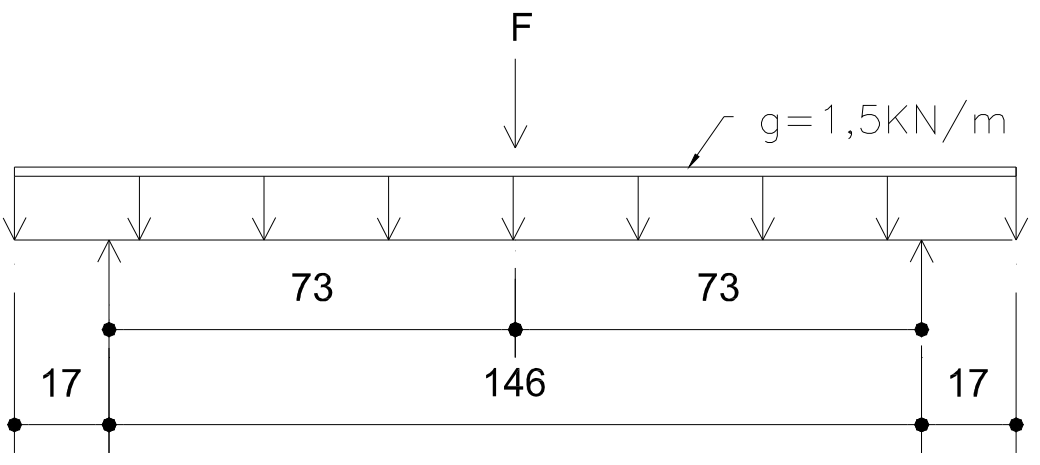

Figura 46 - Esquema estrutural “ponte”.

A única diferença entre o modelo ponte que vai ser calculado pra o modelo de uma ponte real, serão os dois balanços de dezessete centímetros de comprimento existentes, que serão levados em conta nos cálculos, contudo poderá ser observado que sua influência nos valores das forças é desprezível.

No caso do modelo de cálculo para ensaio serão calculadas as forças aplicadas aos corpos-de-prova, com o objetivo de atingir os mesmos esforços que foram calculados para o ELU do modelo ponte. Nos cálculos do modelo ensaio serão levados em conta todas as diferenças causadas pelas condições de apoio do ensaio e pelo fato da estrutura estar invertida em relação às estruturas reais. 


\subsubsection{Instrumentação das lajes}

O comportamento de uma estrutura pode ser determinado pelas e deformações que resultam após a aplicação de certo carregamento. A medição dessas forças e deformações pode ser feita por meio de sensores acoplados a condicionares de sinais e sistemas de aquisição de dados (SABINS,1983).

Os sensores utilizados nesta pesquisa são extensômetros e transdutores de deslocamento (LVDT). Em cada laje foram instalados quatro extensômetros elétricos para a medida da deformação específica. As figuras 47 e 48 ilustram a posição dos extensômetros instalados nas barras das armaduras e nas telas soldadas.

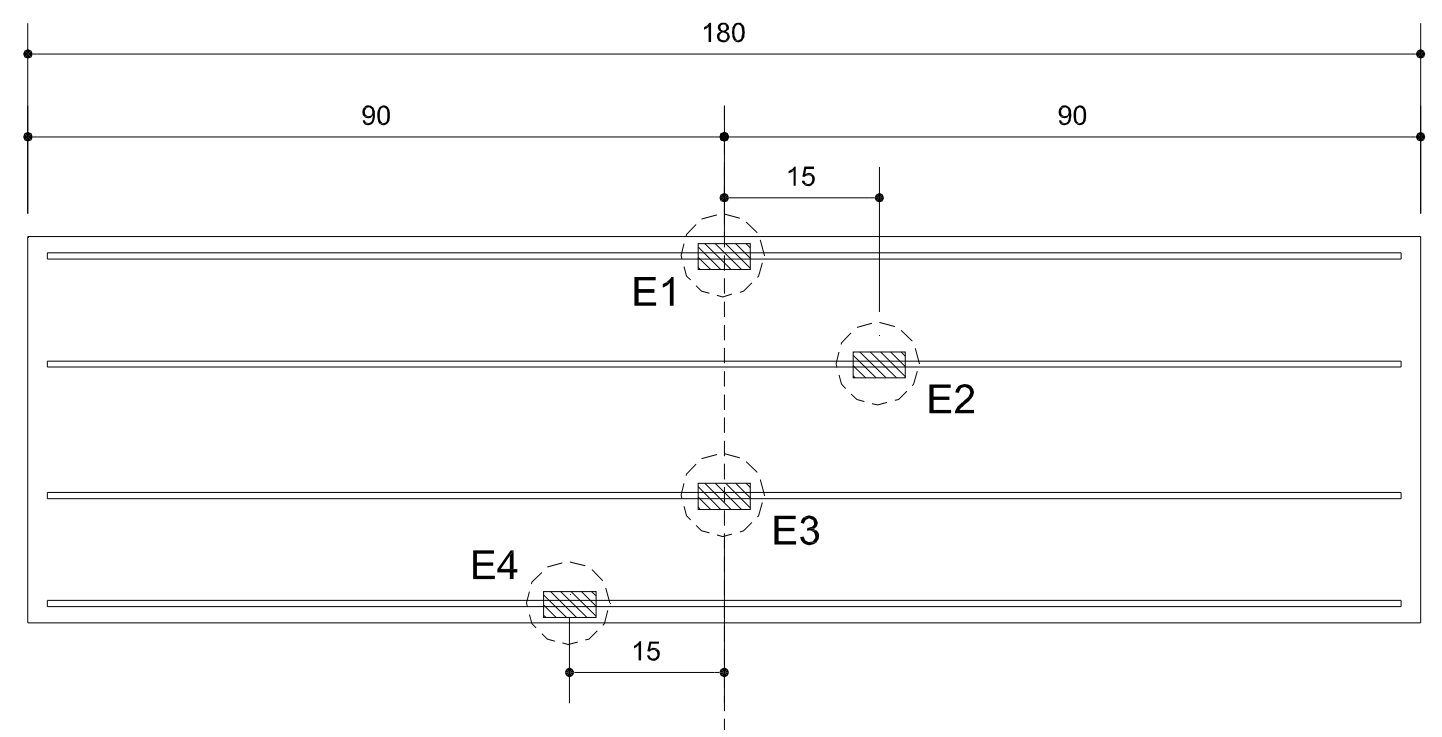

Figura 47 - Posicionamento dos extensômetros na armadura da laje com $A_{s}=2 \mathrm{~cm}^{2}-4$ barras longitudinais.

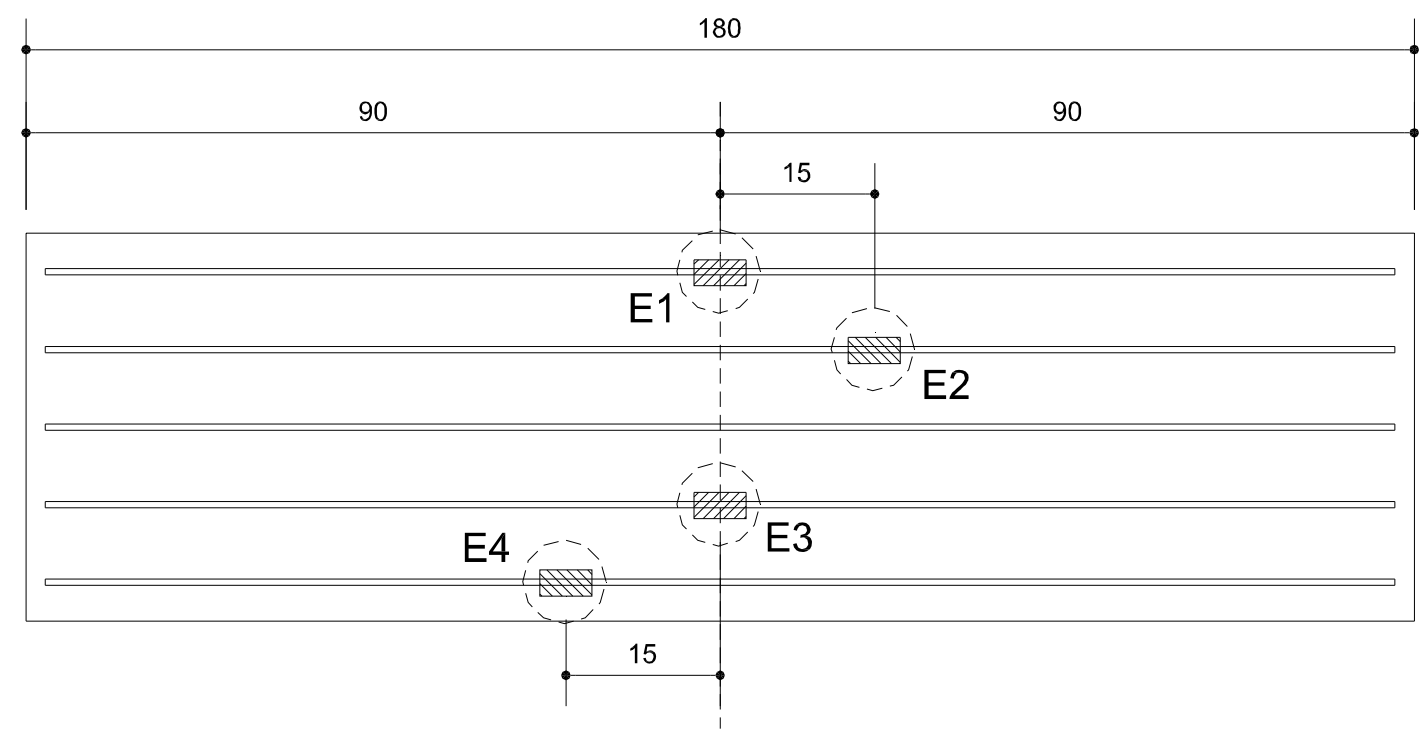

Figura 48 - Posicionamento dos extensômetros na armadura da laje com As= $4 \mathrm{~cm}^{2}-5$ barras longitudinais 
A posição dos extensômetros foi escolhida com o objetivo de acertar o possível local do surgimento de fissuras, pois nesses pontos é onde existirão os maiores valores de tensões. Contudo se isto não acontecer através de equações matemáticas é possível descobrir o valor da tensão uma vez que vão ser obtidas tensões em alguns pontos próximos as fissuras.

Os carregamentos aplicados ao ensaio foram medidos através de uma célula de carga disposta no centro da laje.

Os sinais emitidos pelos sensores durante os ensaios foram registrados em um sistema digital de aquisição de dados (ADS, da LYNX), após o devido tratamento para a geração de gráficos, serviram para análise dos resultados obtidos.

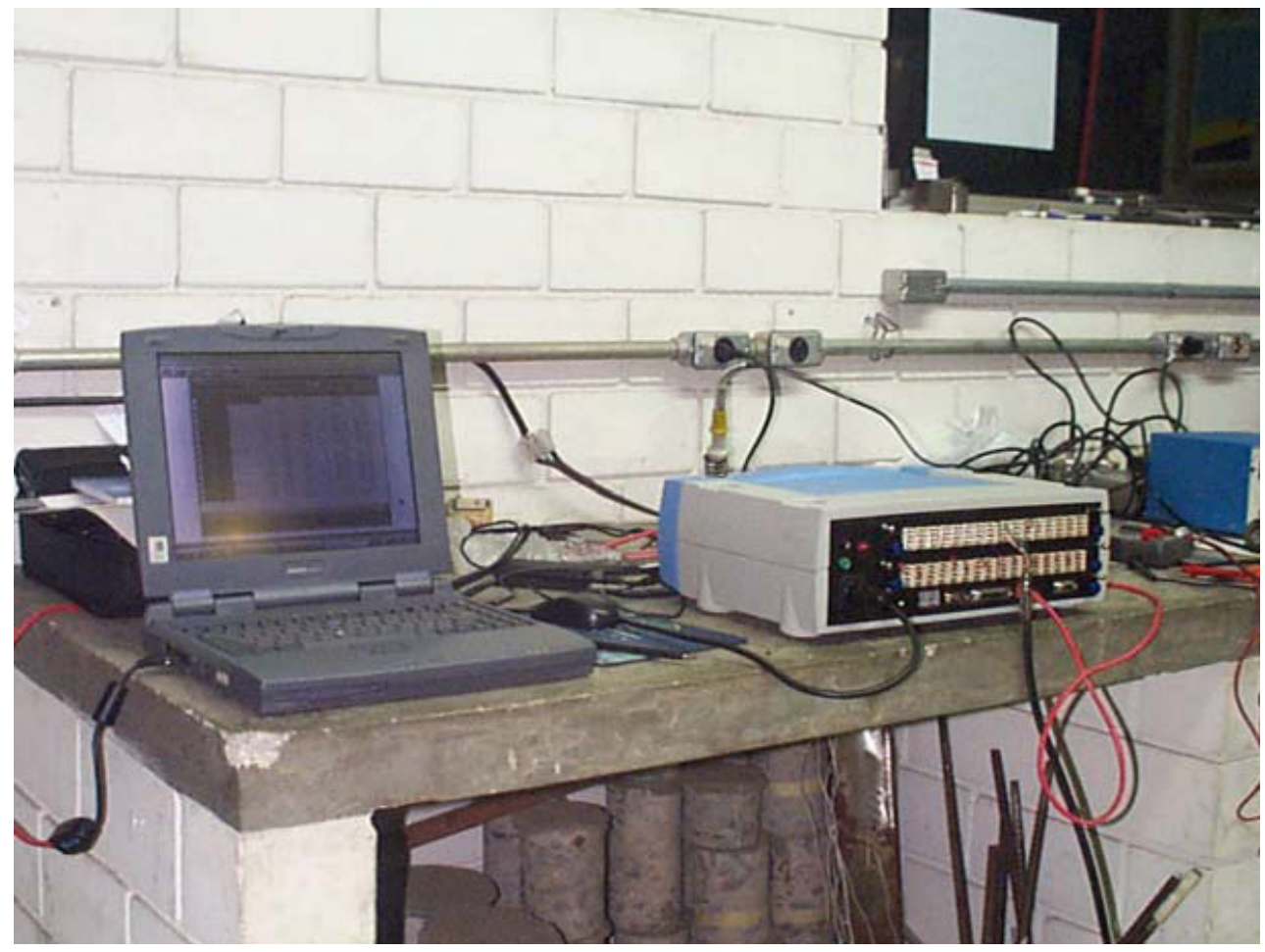

Figura 49 - Sistema de aquisição de dados

\subsection{DIMENSIONAMENTO DOS CORPOS-DE-PROVA}

\subsubsection{Dimensionamento para o ELU de ruptura}

Para o cálculo dos carregamentos do ensaio de ruptura serão apresentados os cálculos para o esquema "ponte" e o esquema ensaio.

Para o cálculo das forças a serem aplicadas nos corpos-de-provas durante os ensaios. Serão utilizados os ELU calculados usando como base o modelo ponte. Mas 
serão utilizados os valores das forças obtidas através do modelo ensaio para o carregamento que será aplicado às lajes, como será demonstrado mais adiante neste item.

Para o dimensionamento do ELU de ruptura da peça foram retirados todos os coeficientes, sendo possível, desta forma, se chegar à ruptura da peça através da força estimada. Para o cálculo utilizaram-se os valores de resistência à compressão do concreto de $30 \mathrm{MPa}$ e para a resistência ao escoamento do aço foi utlizado $\mathrm{f}_{\mathrm{y}}=500 \mathrm{MPa}$ e módulo de elasticidade de $210 \mathrm{GPa}$. Os cálculos serão corrigidos para os valores exatos quando os ensaios de caracterização do concreto e do aço forem realizados.

\section{Dimensionamento à flexão}

1) Esquema Ponte:

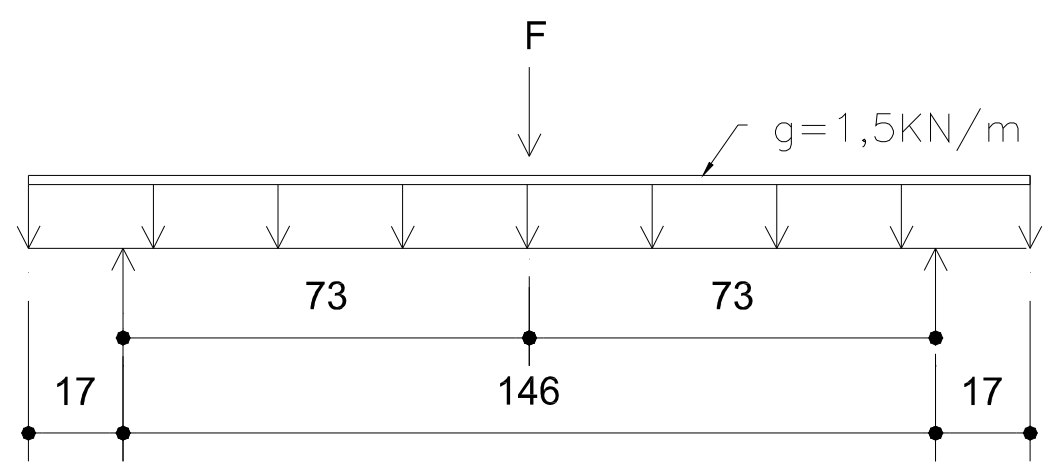

Figura 50 - Esquema estrutural "ponte".

Supondo-se que a peça esteja no domínio 2:

$$
\begin{aligned}
& R_{c d}=R_{s d} \\
& 0,85 \times f_{c d} \times 0,8 \times x \times b w=f_{y d} \times A_{s}
\end{aligned}
$$

Retirando-se todos os coeficientes parciais de segurança, uma vez que estamos estimando a carga última, temos:

$$
f_{c} \times 0,8 \times x \times b w=f_{y} \times A_{s}
$$


$30000 \times 0,8 \times x \times 0,5=50 \times 4$

$x=0,01667 m<0,259 d-$ hipótese confirmada

$M_{u, M}=R_{c}(d-0,4 x)$

$M_{u, M}=0,8 \times 0,01667 \times 30000 \times 0,5 \times(0,095-0,4 \times 0,01667)$

$M_{u, M}=17,67 \mathrm{kNm}$

$$
M_{u, M}=17,67 \mathrm{kNm}
$$

- Momento devido à carga $\mathrm{P}$ :

$M_{1 / 2 v \tilde{a} o}=\frac{F}{2} \times 0,73=0,365 F$

$M_{1 / 2 v \tilde{a} o}=M_{u, M}$

$0,365 F=17,67 \mathrm{kNm}$

$F=48,41 k N$

$F_{u, M}=48,41 k N$

Momento devido ao peso próprio

$g=0,12 \times 0,5 \times 25=1,5 \mathrm{kN} / \mathrm{m}$

$M_{1 / 2 \text { vão }}=1,35 \times 0,73-1,5 \times 0,9 \times 0,45$

$M_{\frac{1}{2} \text { vão }}=0,378 \mathrm{kNm}$

Momento aplicado a peça para a ruptura

$$
M q=17,67-0,378=17,28 \mathrm{kNm}
$$

Assim o valor da força de ruptura F será dado por:

$$
F=\frac{17,28}{0,365}=47,37 k N
$$


2) Esquema Ensaio

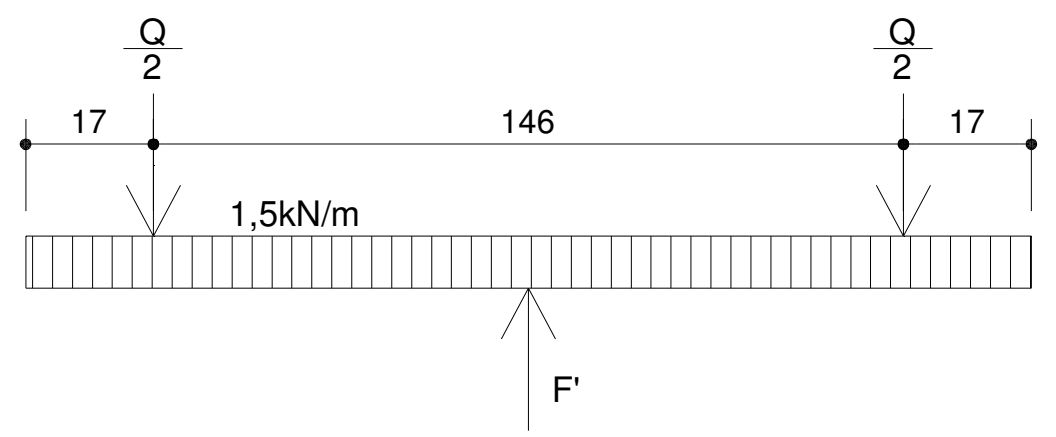

Figura 51 - Esquema estrutural "modelo ensaio".

$$
\begin{aligned}
& P=1,8 \times 0,12 \times 0,50 \times 25=2,7 \mathrm{kN} \\
& F^{\prime}=P+F \\
& M_{u, M}=17,67 \mathrm{kNm} \\
& M g=\frac{1,5 \times 0,9 \times 0,9}{2}=0,608 \mathrm{kNm} \\
& M q=17,67-0,608=17,06 \mathrm{kNm} \\
& F=46,75 \mathrm{KN} \\
& F^{\prime}=46,75+2,7=49,45 \mathrm{kN}
\end{aligned}
$$

\section{Verificação ao Cisalhamento - Modelo de Cálculo I}

$V_{s d} \leq V_{R d 1}$, onde:

$V_{R d 1}=\left\lfloor\tau_{R d} \times k \times\left(1,2+40 \rho_{1}\right)+0,15 \sigma_{c p}\right\rfloor \times b w \times d \quad$ e $\tau_{R d}=0,25 f_{c t d}$

$f_{c t d}=\frac{f_{c t k}, \text { inf }}{\gamma_{c}} \times \rho_{1}=\frac{A_{s 1}}{b w d} \leq 0,02$

$k=|(1,6-d)| \geq|1|$, com $d$ em $m$

Novamente, sem considerar os coeficientes parciais de segurança temos:

$$
\begin{aligned}
\tau_{R k} & =0,25 f_{c t k}=0,25 f_{c t m}, \text { inf }=0,25 \times 0,3 \times f_{c t}^{\frac{2}{3}}=0,075 \times 30^{\frac{2}{3}} \mathrm{MPa} \\
\rho_{1} & =\frac{4}{50 \times 9,5}=0,00842<0,02 \\
V_{R 1} & =0,075 \times 30^{\frac{2}{3}} \times|1,6-0,095| \times(1,2+40 \times 0,00842) \times 50 \times 9,5 \times 0,1 \\
V_{R 1} & =79,5551 \mathrm{kN}
\end{aligned}
$$




$$
\begin{aligned}
& F_{u, V}=79,56 \mathrm{kN} \\
& F_{u, V}=2 \times 79,56=159,12 \mathrm{kN}
\end{aligned}
$$

Assim, conclui-se que não há risco de ruptura por força cortante.

\section{Cálculo do Momento de Fissuração}

Segundo a NBR 6118, "nos estados limites de serviço as estruturas trabalham parcialmente no estádio I e parcialmente no estádio II. A separação entre essas duas partes é definida pelo momento de fissuração. "Sendo assim, o momento de fissuração pode ser calculado pela seguinte expressão de forma aproximada:

$$
M_{c r}=\frac{\alpha \times f_{c t} \times I_{C}}{y_{t}},
$$

sendo:

$\alpha=1,5$ para seções retangulares;

Onde:

$\alpha$ é o fator que correlaciona aproximadamente a resistência à tração na flexão com a resistência à tração direta;

$y_{t}$ é a distância do centro de gravidade da seção à fibra mais tracionada;

$I_{c}$ é o momento de inércia da seção bruta de concreto;

$f_{c t}$ é a resistência à tração direta do concreto, calculada segundo a equação:

$$
f_{c t}=f_{c t k, \text { inf }}=0,7 f_{c t m}
$$

Retirando-se o coeficiente 0,7 , tem-se:

$$
f_{c t}=f_{c t k, \text { inf }}=0,3 f_{c t k} \frac{2}{3}
$$

E sendo $\alpha=1,5$, tem-se:

$$
\begin{aligned}
& M_{c r}=1,5 \times \frac{0,3 \times f_{c k}{ }^{\frac{2}{3}} \times 10 \times b w}{\frac{h}{2}} \times \frac{h^{3}}{12}=1,5 \times 0,3 \times 30^{\frac{2}{3}} \times 10 \times 50 \times 12^{2} / 6 \\
& M_{c r}=5,21 \mathrm{kNm}
\end{aligned}
$$$$
F_{c r}=\frac{5,21}{0,365}=14,27 \mathrm{kN}
$$

Assim, a carga de fissuração é $F_{c r}=14,27 k N$

\subsubsection{Dimensionamento para o ELU de fadiga}

Para o calculo do ELU de fadiga foi simulado um projeto completo de laje de ponte, exigindo-se da peça a mesma segurança de uma ponte seja no ELU seja no ELU de 
fadiga. Assim, a partir da seção transversal da peça e sua armadura, introduzindo todos os fatores parciais de segurança das normas NBR-6118 e 8681, foi calculada a máxima carga característica aplicável à peça, além do seu peso próprio. Conforme recomenda a NBR 8681, a carga a utilizada na verificação da fadiga de lajes deve usar o coeficiente de carga freqüente para fadiga $\Psi_{1}=0,8$.

O esquema estático utilizado para o cálculo do $M_{u, M}$ foi o esquema "ponte" indicado na figura 50.

\section{Dimensionamento à flexão}

Equação do momento:

Devido à carga $F$ :

$$
\begin{aligned}
& M_{\frac{1 / 2 \text { vão }}{2}}=\frac{F}{2} \times 0,73 \\
& M_{\frac{1 / 2 \text { vão }}{}=0,365 F \times k N m}
\end{aligned}
$$

Recalculando o subgrupo 1B, utilizando agora os coeficientes de segurança e majoração:

Supondo-se domínio 2:

$$
\begin{aligned}
& R_{c d}=R_{s d} \\
& 0,85 \times f_{c d} \times 0,8 \times x \times b w=\sigma_{s i} \times A_{s i} \\
& 0,85 \times \frac{30000}{1,4} \times 0,8 \times x \times 0,5=\frac{50 \times 4}{1,15} \\
& x=0,0239 m<0,259 \times 0,095=0,024605 \therefore o k \text { Hipótese confirmada } \\
& M_{R d}=R_{c}(d-0,4 x) \\
& \left.M_{R d}=0,85 \times \frac{30000}{1,4} \times 0,8 \times 0,0239 \times 0,5 \times(0,095-0,4 \times 0,0239)\right) \\
& M_{R d}=14,861 \mathrm{kNm}
\end{aligned}
$$

Sendo:

$$
\begin{aligned}
& M_{r d}=M_{s d} ; \\
& M_{s d}=1,35 M_{g}+1,50 M_{q} ;
\end{aligned}
$$

Para o cálculo do momento devido ao peso próprio foi utilizado o esquema ensaio, como ilustra a figura 51: 
Para este esquema:

$M_{g}=0,378 \mathrm{kNm}$

Então:

$M_{r d}=M_{s d}$

$M_{q}=\frac{14,861-1,35 \times 0,378}{1,5}=9,57 \mathrm{kNm}$

Para a verificação da fadiga nas estruturas, a NBR 6118:2003 prescreve a seguinte combinação frequente de ações:

Combinação freqüente:

$M_{\text {Fad }}=M_{g}+\psi_{1} \times M_{q} \quad \operatorname{com} \psi_{1}=0,8$

$M_{\text {Fad }}=0,378+0,8 \times 9,57=8,03 \mathrm{kNm}$

Cálculo da posição da linha neutra, x, para o estádio II:

$\mathrm{x}: 50 \frac{x^{2}}{2}=4(9,5-x) 7$

$25 x^{2}-266+28 x=0$

$x=2,7496 \mathrm{~cm}$

$I_{I I}=\frac{50(2,7496)^{3}}{3}+7 \times 4(9,5-2,7496)^{2}=1622,365 \mathrm{~cm}^{4}$

Cálculo da tensões no estádio II:

$$
\begin{aligned}
& \sigma_{s} \min =\frac{37,8}{1622,365}(9,5-2,7496) 7=1,10 \mathrm{kN} / \mathrm{cm}^{2}=11,0 \mathrm{MPa} \\
& \sigma_{s} \max =\frac{803}{1622,365}(9,5-2,7496) 7=23,38 \mathrm{KN} / \mathrm{cm}^{2}=233,80 \mathrm{MPa} \\
& \Delta \sigma_{s}=233,8-11,00=222,8 \mathrm{MPa}
\end{aligned}
$$


Para o esquema ensaio, será mantida a mesma variação de tensões e será adotada uma carga mínima de ensaio de $F=5 k N$, com o objetivo de minimizar as vibrações.

Com $F_{\text {min }}=5 k N$, tem-se:

$M_{\text {min }}=0,608+0,365 \times(5-2,7)=1,45 \mathrm{kNm}$

Sendo $x=2,7496 \mathrm{~cm}$ e $I_{I I}=1622,365 \mathrm{~cm}^{4}$ calculados anteriormente, a tensão mínima será dada por:

$\sigma_{s \min }=\frac{145}{1622,365}(9,5-2,7496) 7=4,22 \mathrm{kN} / \mathrm{cm}^{2}=42,20 \mathrm{MPa}$

Sendo a variação de tensão do esquema ponte $\Delta \sigma_{s}=222,8 M P a$, o valor da tensão máxima será dado por:

$$
\sigma_{s, \max }=42,20+222,8=265 \mathrm{MPa}
$$

Sendo:

$$
\begin{aligned}
& \sigma_{s \text { max }}=\frac{M_{\text {maxx }}}{1622,365}(9,5-2,7496) 7, \text { então: } \\
& 26,5=\frac{M_{\text {máx }}}{1622,365}(9,5-2,7496) 7 \\
& M_{\text {máx }}=909,84 \mathrm{KNcm} \\
& 9,09=0,608+0,365 \times\left(F_{\text {máx }}-2,7\right) \\
& F_{\text {máx }}=25,93 \mathrm{kN}
\end{aligned}
$$

Tabela 6 - Dimensionamento à flexão

\begin{tabular}{c|ccc}
\hline Lajes dos & $M_{r k}(K N m)$ & $F_{u, M}(K N)$ & $F_{u, M}^{\prime}(K N)$ \\
\cline { 2 - 4 } Grupos $2 \mathrm{~cm}^{2}$ & 9,17 & 24,1 & 26,2 \\
\hline
\end{tabular}

Tabela 7 - Dimensionamento à fadiga

\begin{tabular}{c|ccccccc}
\hline Lajes dos & $M_{r d}(K N m)$ & $M_{q}(K N m)$ & $M_{\text {fad }}(K N m)$ & $\sigma_{\text {Máx }}(M P a)$ & $\sigma_{\text {Min }}(M P a)$ & $\begin{array}{c}F_{\text {Máx }} \\
(K N)\end{array}$ & $M_{\text {máx }}(K N m)$ \\
\cline { 2 - 8 } Grupos 2 $\mathrm{cm}^{2}$ & 7,85 & 4,9 & 4,3 & 304 & 82,2 & 15,72 & 5,36 \\
\hline
\end{tabular}




\subsection{ENSAIOS DE RUPTURA}

\subsubsection{Descrição do ensaio}

O esquema de ensaio será montado em um pórtico metálico, devidamente fixado em uma laje de reação, conforme já ilustrado anteriormente. (Figuras 37 a 44)

Inicialmente serão feitos ensaios estáticos até a ruptura, passando pela carga de fissuração, sob controle de deformações, em um corpo-de-prova de cada grupo. O objetivo é verificar o seu comportamento estrutural sob carga estática.

\subsection{ENSAIO DE FADIGA}

\subsubsection{Descrição do ensaio}

Os ensaios dinâmicos vão constar de três etapas, a primeira etapa consistirá apenas na aplicação de uma carga vertical estática, sob carga controlada, com a finalidade de fissurar a pré-laje e assim mobilizar o esquema estrutural biela-tirante, a carga de fissuração foi calculada usando o momento de fissuração da peça de acordo com a NBR-6118:2003. Esse procedimento representa uma situação provável em que o peso próprio da ponte e dos veículos que passam sobre a laje provocam solicitações capazes de fissurar a laje.

Na segunda etapa, aplicar-se-á o carregamento cíclico, com frequiência de 6 $\mathrm{Hz}$, até $2 \times 10^{6}$ ciclos, sob carga controlada.

De acordo com a NBR 7480: "Barras e fios de aço destinados a armaduras para concreto armado", a freqüência utilizada para estes ensaios pode variar entre 4 e 6 $\mathrm{Hz}$, por isso a escolha de $6 \mathrm{~Hz}$ para a execução do ensaio.

A terceira etapa consiste após a aplicação dos $2 \times 10^{6}$ ciclos, se realizar ensaio de ruptura estática para se avaliar o dano causado pelos carregamentos cíclicos. Aqui mais uma vez sob deformação controlada

A finalidade dos ensaios de fadiga desta pesquisa é estudar o comportamento estrutural das lajes armadas com telas soldadas e barras isoladas, vendo até que ponto a solda influencia a resistência. 


\subsection{ENSAIOS DE CARACTERIZAÇÃO DOS MATERIAIS}

\subsubsection{Concreto}

Os concretos utilizados nas lajes dos ensaios foram confeccionados no Laboratório de estruturas e materiais.

Para cada laje concretada foram moldados oito corpos-de-prova para ensaios de caracterização do material.

Os ensaios de ruptura por compressão e ruptura por compressão diametral, do concreto, bem como a determinação do módulo de elasticidade, foram feitos segundo as seguintes Normas brasileiras:

a) NBR 5739 - Concreto - Ensaios de compressão de corpos-de-prova cilíndricos julho 1994;

b) NBR 7222 - Concreto - Argamassa e concreto - Determinação da resistência à tração por compressão diametral de corpos-de-prova cilíndricos - Março 1994;

c) NBR 8522 - Concreto - Determinação do módulo de deformação Estática e Diagrama - Tensão Deformação - Maio 1984.

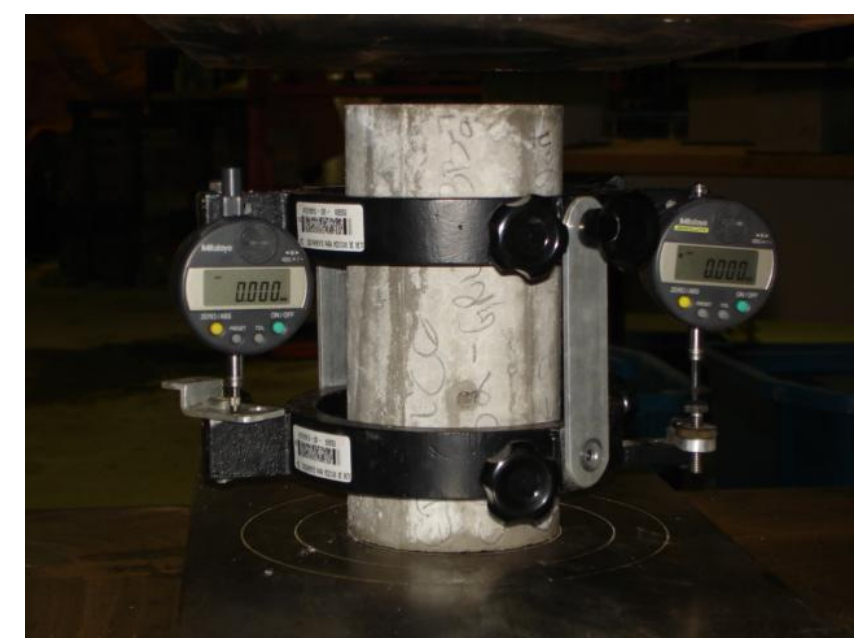

Figura 52- Corpo-de-prova do ensaio de módulo de elasticidade

A resistência à compressão foi determinada aos sete dias e também no dia da ocasião do ensaio da laje, enquanto a resistência a tração e módulo de elasticidade foram determinados apenas no dia da ocasião do ensaio da laje. 
Os resultados dos ensaios de caracterização realizados estão apresentados nas tabelas abaixo. Para a confecção dos corpos de prova para os ensaios de compressão e de modulo de elasticidade foi utilizado o concreto da capa e para os ensaios de tração foi utilizado o da pré-laje.

Tabela 8 - Ensaio de caracterização

\begin{tabular}{c|ccc}
\hline Grupo 1A & $f c(\mathrm{MPa})$ & $f c t(\mathrm{MPa})$ & $E(\mathrm{GPa})$ \\
\hline laje1 & 52 & 3,47 & 36,4 \\
laje2 & 49 & 3,05 & 35,9 \\
laje3 & 48 & 3,1 & 34,2 \\
\hline
\end{tabular}

Tabela 10 - Ensaio de caracterização

\begin{tabular}{c|ccc}
\hline Grupo 2A & $f c(\mathrm{MPa})$ & $f c t(\mathrm{MPa})$ & $E(\mathrm{GPa})$ \\
\hline laje1 & 44 & 3,96 & 36,7 \\
laje2 & 47 & 3,7 & 33,7 \\
laje3 & 42 & 3,87 & 39,4 \\
\hline
\end{tabular}

Tabela 12 - Ensaio de caracterização

\begin{tabular}{c|ccc}
\hline Grupo 3A & $f c(M P a)$ & $f c t(M P a)$ & $E(G P a)$ \\
\hline laje1 & 48 & 3,83 & 37,4 \\
laje2 & 52 & 4,1 & 34 \\
laje3 & 50 & 4,22 & 39,7 \\
\hline
\end{tabular}

Tabela 9 - Ensaio de caracterização

\begin{tabular}{c|ccc}
\hline Grupo $1 B$ & $f_{c}(\mathrm{MPa})$ & $f_{c t}(\mathrm{MPa})$ & $E(\mathrm{GPa})$ \\
\hline laje1 & 50 & 4,24 & 42,7 \\
laje2 & 50 & 4,34 & 35,4 \\
laje3 & 43 & 4,24 & 38,2 \\
laje4 & 44 & 4,01 & 38,6 \\
\hline
\end{tabular}

Tabela 11 - Ensaio de caracterização

\begin{tabular}{c|ccc}
\hline Grupo $2 B$ & $f_{c}(\mathrm{MPa})$ & $f_{c t}(\mathrm{MPa})$ & $E(\mathrm{GPa})$ \\
\hline laje1 & 43 & 4,22 & 33,7 \\
laje2 & 50 & 4,12 & 33,4 \\
laje3 & 49 & 4,57 & 33,6 \\
\hline
\end{tabular}

Tabela 13 - Ensaio de caracterização

\begin{tabular}{c|ccc}
\hline Grupo $3 B$ & $f c(M P a)$ & $f c t(M P a)$ & $E(G P a)$ \\
\hline laje1 & 44 & 2,92 & 34 \\
laje2 & 40 & 4,13 & 33,2 \\
laje3 & 39 & 4,04 & 31,5 \\
\hline
\end{tabular}

Os ensaios de caracterização realizados para a determinação da resistência à tração direta do concreto foram ensaios indiretos. Então deve ser feita uma correlação com resultado obtido no ensaio indireto para se obter o valor da resistência à tração direta do concreto. De acordo com a NR6118-2003 a resistência à tração direta do concreto é 0,9 do valor obtido através dos ensaios indiretos.

Os ensaios de caracterização das lajes foram realizados no mesmo dia da ruptura estática das lajes. Estes ensaios de caracterização ocorreram em média quando as lajes tinham 90 dias de idade, então é natural que o $f c$ esteja acima dos $30 \mathrm{MPa}$ desejados inicialmente, uma vez que o valor esperado era quando as lajes estivessem com 28 dias de idade. 
Para que fosse possível conhecer com maior precisão as propriedades das peças aos 28 dias, os corpos-de-prova das lajes do grupo 3B foram ensaiados aos 28 dias.

\subsubsection{Aço das armaduras}

As barras de aço utilizadas nas lajes cumprem todas as especificações da NBR 7480:1996. Os ensaios de tração realizados nas barras foram feitos segundo a Norma brasileira NBR6152 - Materiais metálicos - Determinação das propriedades mecânicas à tração - Outubro 1992.

Os gráficos das figuras 53 e 54 ilustram o comportamento das barras nos ensaios de tração. De acordo com os ensaios realizados foi possível perceber que para aços de mesmo diâmetro a dispersão dos resultados foi pequena, por este motivo o valor médio é representativo. A área efetiva das barras $\left(A s, e f \quad \mathrm{~cm}^{2}\right)$ foi determinada experimentalmente. Na tabela 14 encontram-se os valores das propriedades dos aços utilizados nas lajes desta pesquisa.

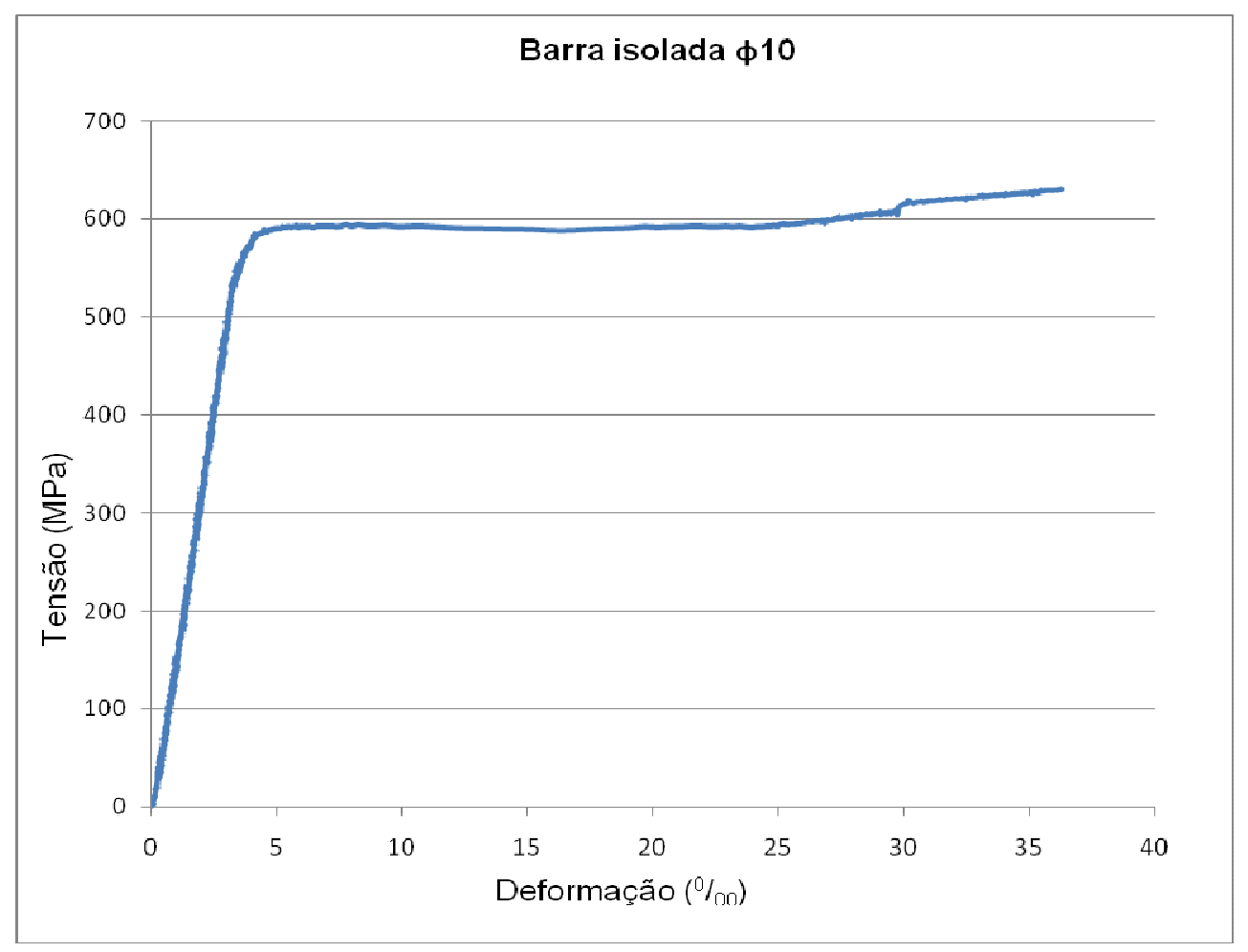

Figura 53- Ensaio de tração de barras 


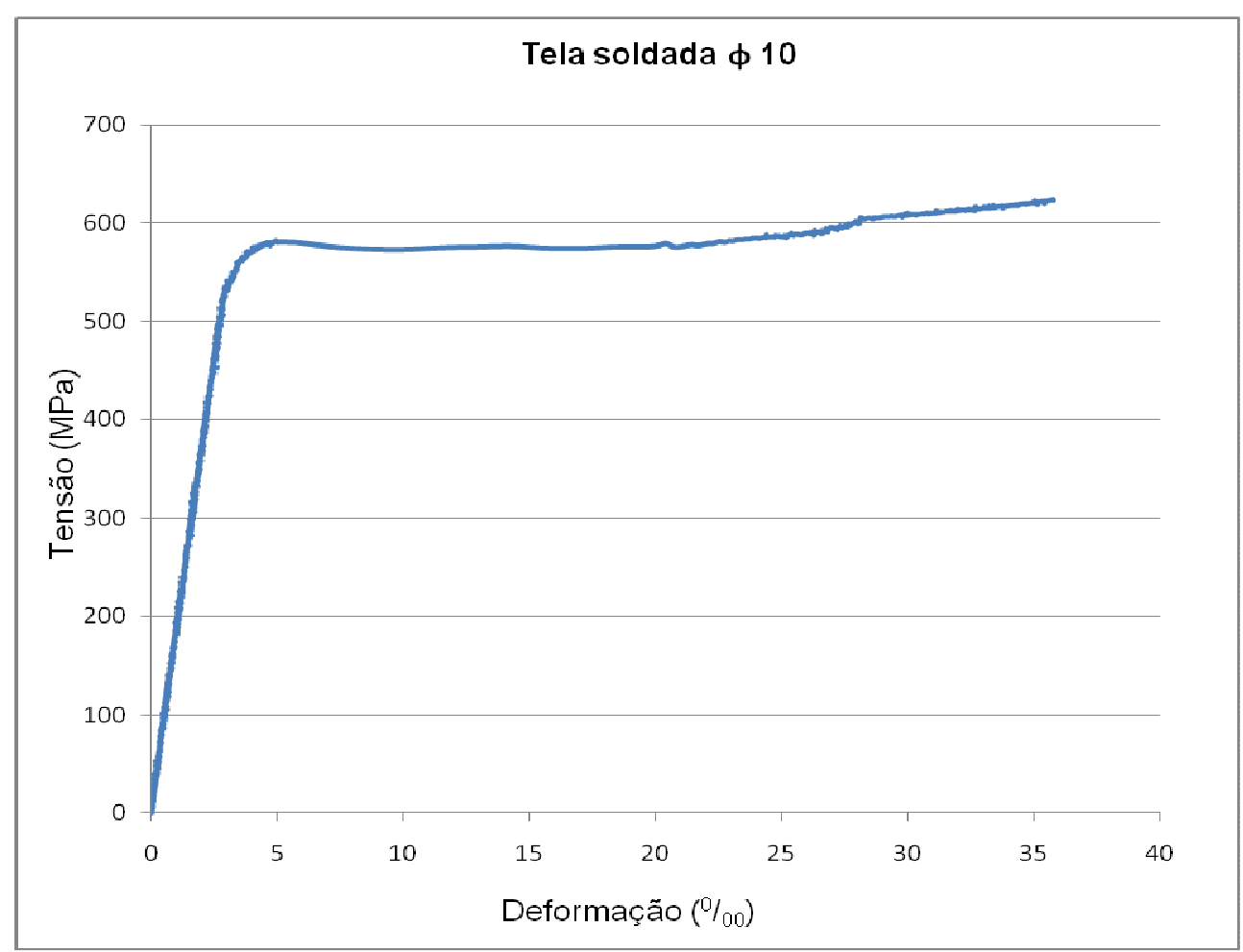

Figura 54- Ensaio de tração de barras

\begin{tabular}{c|cccc}
\multicolumn{5}{c}{ Tabela 14- Resultados dos ensaios de tração } \\
\hline & $\phi(\mathrm{mm})$ & As,ef $(\mathrm{cm} 2)$ & fy(MPa) & E(GPa) \\
\hline Telas & 8 & 0,5 & 600 & 198,80 \\
Telas & 10 & 0,8 & 583 & 211,70 \\
Barras & 8 & 0,5 & 603 & 198,80 \\
Barras & 10 & 0,8 & 592 & 191,10 \\
\hline
\end{tabular}

De acordo com os resultados dos ensaios de caracterização foi possível perceber uma pequena diferença dos resultados obtidos com os utilizados no cálculo dos carregamentos. Como se pode observar na tabela 12 do subgrupo $3 \mathrm{~b}$ o $f c$ atingido pelas lajes aos 28 dias foi em média $41 \mathrm{MPa}$, valor superior aos $30 \mathrm{MPa}$ desejados no inicio da pesquisa. Contudo para os casos estudados a linha neutra não atingiu profundidade superior a 2,5 cm. Então é natural que a influência desta diferença de resistência à compressão não altera de forma significativa os carregamentos aplicados nas lajes e nos resultados obtidos. 
Para ilustrar o exposto no parágrafo anterior será apresentado abaixo nas tabelas de 15 a 18 o resumo dos cálculos realizados no item 3.6 deste trabalho e as tabelas 19 e 20 com os cálculos refeitos com o valor do $f_{c}$ obtido para a laje 1 do grupo 1 A que de todas as lajes foi a que atingiu o maior $f_{c}$, e por isto trará a maior variação no resultado.

Tabela 15 - Dimensionamento à flexão

\begin{tabular}{c|ccc}
\hline Lajes dos & $\boldsymbol{M}_{\boldsymbol{r} \boldsymbol{k}}(\mathbf{K N m})$ & $\boldsymbol{F}_{\boldsymbol{u}, \boldsymbol{M}}(\boldsymbol{K N})$ & $\boldsymbol{F}^{\prime}{ }_{\boldsymbol{u}, \boldsymbol{M}}(\boldsymbol{K N})$ \\
\cline { 2 - 4 } Grupos $2 \mathrm{~cm}^{2}$ & & & \\
& 9,17 & 24,1 & 26,2 \\
\hline
\end{tabular}

Tabela 16 - Dimensionamento à fadiga

\begin{tabular}{|c|c|c|c|c|c|c|c|}
\hline \multirow{2}{*}{$\begin{array}{c}\text { Lajes dos } \\
\text { Grupos } 2 \mathrm{~cm}^{2}\end{array}$} & $M_{r d}(K N m)$ & $M_{q}(K N m)$ & $M_{f a d}(K N m)$ & $\sigma_{M a ́ x}(M P a)$ & $\sigma_{M i n}(M P a)$ & $\begin{array}{l}F_{\text {Máx }} \\
(K N)\end{array}$ & $M_{m a ́ x}(K N m)$ \\
\hline & 7,85 & 4,9 & 4,3 & 304 & 82,2 & 15,72 & 5,36 \\
\hline
\end{tabular}

Tabela 17 - Dimensionamento à flexão

\begin{tabular}{c|ccc}
\hline Lajes dos & $\boldsymbol{M}_{\boldsymbol{r k}}(\mathbf{K N m})$ & $\boldsymbol{F}_{\boldsymbol{u}, \boldsymbol{M}}(\mathbf{K N})$ & $\boldsymbol{F}^{\prime}{ }_{\boldsymbol{u}, \boldsymbol{M}}(\mathbf{K N})$ \\
\cline { 2 - 4 } Grupos $4 \mathrm{~cm}^{2}$ & & & \\
& 17,7 & 47,4 & 49,4 \\
\hline
\end{tabular}

Tabela 18 - Dimensionamento à fadiga

\begin{tabular}{|c|c|c|c|c|c|c|c|}
\hline \multirow{3}{*}{$\begin{array}{c}\text { Lajes dos } \\
\text { Grupos } 4 \mathrm{~cm}^{2}\end{array}$} & $M_{r d}(K N m)$ & $M_{q}(K N m)$ & $M_{f a d}(K N m)$ & $\sigma_{M a ́ x}(M P a)$ & $\sigma_{\text {Min }}(M P a)$ & $\begin{array}{l}F_{\text {Máx }} \\
(\boldsymbol{K N})\end{array}$ & $M_{m a ́ x}(K N m)$ \\
\hline & & & & & & & \\
\hline & 14,9 & 9,6 & 8 & 265,2 & 42,2 & 26 & 910 \\
\hline
\end{tabular}

Tabela 19 - Dimensionamento à flexão

\begin{tabular}{c|ccc}
\hline Grupo 1A & $\boldsymbol{M}_{\boldsymbol{r} \boldsymbol{k}}(\boldsymbol{K N m})$ & $\boldsymbol{F}_{\boldsymbol{u}, \boldsymbol{M}}(\boldsymbol{K N})$ & $\boldsymbol{F}^{\prime}{ }_{\boldsymbol{u}, \boldsymbol{M}}(\boldsymbol{K N})$ \\
\hline laje1 & 9,3 & 24,5 & 26,5 \\
\hline
\end{tabular}

Tabela 20 - Dimensionamento à fadiga

\begin{tabular}{c|ccccccc}
\hline Grupo 1A & $\boldsymbol{M}_{\boldsymbol{r d}}(\mathbf{K N m})$ & $\boldsymbol{M}_{\boldsymbol{q}}(\boldsymbol{K N m})$ & $\boldsymbol{M}_{\text {fad }}(\boldsymbol{K N m})$ & $\boldsymbol{\sigma}_{\text {Máx }}(\boldsymbol{M P a})$ & $\boldsymbol{\sigma}_{\text {Min }}(\mathbf{M P a})$ & $\begin{array}{c}\boldsymbol{F}_{\text {Máx }} \\
(\boldsymbol{K N})\end{array}$ & $\boldsymbol{M}_{\text {máx }}(\boldsymbol{K N m})$ \\
\hline laje1 & 8 & 5 & 4,4 & 309,3 & 82,2 & 15,98 & 5,46 \\
\hline
\end{tabular}


Como se pode se observar a diferença em relação a variação do $f_{c}$, alterou o valor das forças aplicadas em $2 \%$, confirmando a baixa influência da variação do $f_{c}$ nos resultados obtidos.

Nas tabelas 21 a 28 serão apresentados os valores calculados para cada subgrupo do ensaio e das propriedades do aço de acordo com os ensaios de tração realizados. Como já foi observado que o $f_{c}$ não altera de maneira significativa os resultados, então para cada subgrupo serão apresentados os cálculos baseados na laje com maior $f_{c}$ de cada subgrupo. Como os aços utilizados nas lajes do grupo $2 \mathrm{~A}$ e $3 \mathrm{~A}$, 2B e 3B possuem as mesmas propriedades, essas lajes serão analisadas simultaneamente, como se pode observar nas tabelas abaixo.

Tabela 21 - Dimensionamento à flexão

\begin{tabular}{c|ccc}
\hline Grupo 1A & $M_{r k}(K N m)$ & $F_{u, M}(K N)$ & $F_{u, M}^{\prime}(K N)$ \\
\cline { 2 - 4 } & 11,18 & 29,58 & 31,66 \\
\hline
\end{tabular}

Tabela 22 - Dimensionamento à fadiga

\begin{tabular}{c|ccccc}
\hline Grupo 1A & $M_{r d}(K N m)$ & $M_{q}(K N m)$ & $M_{\text {fad }}(K N m)$ & $F_{\text {Máx }}(K N)$ & $M_{\text {máx }}(K N m)$ \\
\cline { 2 - 6 } & 9,61 & 6,07 & 5,23 & 18,31 & 6,31 \\
\hline
\end{tabular}

Tabela 23 - Dimensionamento à flexão

\begin{tabular}{c|ccc}
\hline Grupo $1 B$ & $M_{r k}(K N m)$ & $F_{u, M}(K N)$ & $F_{u, M}^{\prime}(K N)$ \\
\cline { 2 - 4 } & 21,37 & 57,52 & 59,6 \\
\hline
\end{tabular}

Tabela 24 - Dimensionamento à fadiga

\begin{tabular}{c|ccccc}
\hline Grupo $1 B$ & $M_{r d}(K N m)$ & $M_{q}(K N m)$ & $M_{\text {fad }}(K N m)$ & $F_{\text {Máx }}(K N)$ & $M_{\text {máx }}(K N m)$ \\
\cline { 2 - 6 } & 18,2 & 11,8 & 9,8 & 30,8 & 10,9 \\
\hline
\end{tabular}

Tabela 25 - Dimensionamento à flexão

\begin{tabular}{|c|c|c|c|c|c|}
\hline \multirow[t]{2}{*}{ Grupos $2 A / 3 A$} & $M_{r k}(K N m)$ & $F_{u, M}(K N)$ & $F_{u, M}^{\prime}(K N)$ & & \\
\hline & 11,12 & 29,4 & 31,50 & & \\
\hline \multicolumn{6}{|c|}{ Tabela 26 - Dimensionamento à fadiga } \\
\hline \multirow[t]{2}{*}{ Grupos $2 A / 3 A$} & $M_{r d}(K N m)$ & $M_{q}(K N m)$ & $M_{f a d}(K N m)$ & $\begin{array}{l}F_{\text {Máx }} \\
(K N)\end{array}$ & $M_{\text {máx }}(K N m)$ \\
\hline & 9,56 & 6,0 & 5,2 & 18,24 & 6,28 \\
\hline
\end{tabular}

Tabela 27 - Dimensionamento à flexão

\begin{tabular}{c|ccc}
\hline Grupos $2 B / 3 B$ & $M_{r k}(K N m)$ & $F_{u, M}(K N)$ & $F_{u, M}^{\prime}(K N)$ \\
\cline { 2 - 4 } & 21,1 & 56,7 & 58,8 \\
\hline
\end{tabular}


Tabela 28 - Dimensionamento à fadiga

\begin{tabular}{c|ccccc}
\hline Grupos 2B/3B & $M_{r d}(K N m)$ & $M_{q}(K N m)$ & $M_{\text {fad }}(K N m)$ & $\begin{array}{c}F_{\text {Máx }} \\
(K N)\end{array}$ & $M_{\text {máx }}(K N m)$ \\
\cline { 2 - 6 } & 17,9 & 11,6 & 9,7 & 30,43 & 10,7 \\
\hline
\end{tabular}

Comparando os resultados expostos nas tabelas 20 a 27 com as tabelas 15 a 18. É possível perceber que a diferença entre os carregamentos que deveriam ser aplicados nas lajes com os que de fato foram aplicados, de fato é uma diferença significativa chegando a aproximadamente $20 \%$ para as cargas de ruptura e de $15 \%$ para os carregamentos de fadiga.

Para o caso dos ensaios de ruptura apesar dos carregamentos terem sido $20 \%$ inferiores, isto não altera os resultados, uma vez que como nos ensaios de ruptura o desempenho da peça estava sendo medido pelos extensômetros e em todas as lajes foram aplicados carregamentos que ultrapassaram o valor da ruptura calculada baseada nos ensaios de caracterização do material, então pode se afirmar que os ensaios não foram afetados por essa alteração.

Para o caso do ensaios de fadiga, a flutuação de tensão sempre era confirmada através das deformações medidas pelos extensômetros durante os ensaios. Deste modo quando não se estava obtendo as flutuações de tensões desejadas as forças eram ajustadas de modo a obtê-las. As flutuações de tensões de fato aplicadas a cada grupo serão apresentadas no item 4.2.2 deste trabalho onde será feita a análise dos ensaios dinâmicos. 


\section{RESULTADOS E ANÁLISES DOS RESULTADOS}

\subsection{ENSAIO DE BARRA AO AR}

Nas tabelas abaixo são apresentados as flutuações de tensão aplicadas às barras e às telas e o respectivo número de ciclos até a ruptura:

Tabela 29 - Resultados obtidos para os grupos 1,2 e 3; barras isoladas.

\begin{tabular}{|c|c|c|c|c|c|c|}
\hline \multirow{9}{*}{ 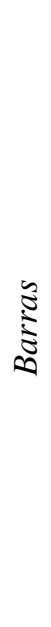 } & \multirow{2}{*}{\multicolumn{2}{|c|}{$\begin{array}{c}\text { Grupo } 1 \\
\Delta \sigma=364 \mathrm{MPa}\end{array}$}} & \multicolumn{2}{|c|}{ Grupo 2} & \multicolumn{2}{|r|}{ Grupo 3} \\
\hline & & & & $50 \mathrm{MPa}$ & & $\sigma=198 \mathrm{MPa}$ \\
\hline & $\mathrm{CP}$ & $\mathbf{N}$ & $\mathrm{CP}$ & $\mathbf{N}$ & $\mathrm{CP}$ & $\mathbf{N}$ \\
\hline & 1 & 245180 & 7 & 940029 & 13 & 2220652 \\
\hline & 2 & 195600 & 8 & 823040 & 14 & 1351284 \\
\hline & 3 & 213600 & 9 & 665009 & 15 & 6000000 s/rup. \\
\hline & 4 & 276750 & 10 & 744114 & 16 & $6000000 \mathrm{~s} / \mathrm{rup}$. \\
\hline & 5 & 233100 & 11 & 656000 & 17 & 6000000 s/rup. \\
\hline & 6 & 288100 & 12 & 638876 & 18 & $6000000 \mathrm{~s} / \mathrm{rup}$. \\
\hline
\end{tabular}

Tabela 30 - Resultados obtidos para o grupo 4,5 e 6; telas soldadas.

\begin{tabular}{|c|c|c|c|c|c|c|}
\hline \multirow{9}{*}{$\frac{\hat{s}}{v}$} & \multirow{2}{*}{\multicolumn{2}{|c|}{$\begin{array}{c}\text { Grupo } 4 \\
\Delta \sigma=364 \mathrm{MPa}\end{array}$}} & \multicolumn{2}{|c|}{ Grupo 5} & \multicolumn{2}{|c|}{ Grupo 6} \\
\hline & & & & $50 \mathrm{MPa}$ & & $8 \mathrm{MPa}$ \\
\hline & $\mathrm{CP}$ & $\mathbf{N}$ & $\mathrm{CP}$ & $\mathbf{N}$ & $\mathrm{CP}$ & $\mathbf{N}$ \\
\hline & 19 & 108508 & 25 & 215064 & 31 & 369684 \\
\hline & 20 & 113681 & 26 & 124708 & 32 & 419658 \\
\hline & 21 & 95182 & 27 & 346370 & 33 & 227930 \\
\hline & 22 & 77820 & 28 & 188782 & 34 & 353794 \\
\hline & 23 & 85513 & 29 & 139350 & 35 & 351362 \\
\hline & 24 & 77361 & 30 & 191052 & 36 & 310800 \\
\hline
\end{tabular}

Para que fosse possível analisar os dados inicialmente foram calculados, para cada grupo de flutuação de tensão, a média $\mathrm{N}_{\mathrm{m}}$ e o desvio padrão $\mathrm{S}$. Com o intuito de se avaliar a variabilidade dos resultados obtidos, utilizou-se o parâmetro adimensional " $n$ ", que mede a dispersão dos dados. Estes resultados estão ilustrados nas tabelas 31 e 32 . 
Tabela 31 - Resultados obtidos para os grupos 1 e 2.

\begin{tabular}{cccccc}
\hline \multicolumn{5}{c}{ Grupo 1 (Barras Isoladas) - Ds $=\mathbf{3 6 4} \mathbf{M P a}$} \\
$\mathbf{C P}$ & $\mathbf{N}$ & MÉDIA $\left(\mathbf{N}_{\mathbf{m}}\right)$ & DESVIO PADRÃO N & $\mathbf{n = N} / \mathbf{N}_{\mathbf{m}}$ & DESVIO PADRÃo n \\
1 & 245180 & 242055 & 35726 & 1,013 & 0,148 \\
2 & 195600 & & & 0,808 & \\
3 & 213600 & & & 0,882 & \\
4 & 276750 & & & 1,143 & \\
5 & 233100 & & 0,963 & \\
6 & 288100 & & 1,190 &
\end{tabular}

Grupo 2 (Barras Isoladas) - Ds $=250 \mathrm{MPa}$

$\begin{array}{ccc}\mathbf{C P} & \mathbf{N} & \text { MEDIA }\left(\mathbf{N}_{\mathbf{m}}\right) \\ 7 & 940029 & 744511 \\ 8 & 823040 & \\ 9 & 665009 & \\ 10 & 744114 & \\ 11 & 656000 & \\ 12 & 638876 & \end{array}$

DESVIO PADRÃO $\mathbf{N} \quad \mathbf{n}=\mathbf{N} / \mathbf{N}_{\mathbf{m}}$

DESVIO PADRÃO n

Média Desvio Padrão n (Grupos 1 e 2)

0,153

0,159

1,105

0,893

0,999

0,881

0,858

*Grupo 3 será analisado separadamente devido a complexidade de seus resultados

\begin{tabular}{|c|c|c|c|c|c|}
\hline \multicolumn{6}{|c|}{ Tabela 32 - Resultados obtidos para os grupos 4,5 e 6.} \\
\hline \multicolumn{6}{|c|}{ Grupo 4 (Telas Soldadas) $-\Delta \sigma=364 \mathrm{MPa}$} \\
\hline $\mathbf{C P}$ & $\mathbf{N}$ & MÉDIA $\left(\mathbf{N}_{\mathbf{m}}\right)$ & DESVIO PADRÃO N & $\mathbf{n}=\mathbf{N} / \mathbf{N}_{\mathbf{m}}$ & DESVIO PADRÃO n \\
\hline 19 & 108508 & 93011 & 15518 & 1,167 & 0,167 \\
\hline 20 & 113681 & & & 1,222 & \\
\hline 21 & 95182 & & & 1,023 & \\
\hline 22 & 77820 & & & 0,837 & \\
\hline 23 & 85513 & & & 0,919 & \\
\hline 24 & 77361 & & & 0,832 & \\
\hline \multicolumn{6}{|c|}{ Grupo 5 (Telas Soldadas) $-\Delta \sigma=250 \mathrm{MPa}$} \\
\hline $\mathbf{C P}$ & $\mathbf{N}$ & MÉDIA $\left(\mathbf{N}_{\mathbf{m}}\right)$ & DESVIO PADRÃO N & $\mathbf{n}=\mathbf{N} / \mathbf{N}_{\mathbf{m}}$ & DESVIO PADRÃO n \\
\hline 25 & 215064 & 200888 & 78993 & 1,071 & 0,393 \\
\hline 26 & 124708 & & & 0,621 & \\
\hline 27 & 346370 & & & 1,724 & \\
\hline 28 & 188782 & & & 0,940 & \\
\hline 29 & 139350 & & & 0,694 & \\
\hline 30 & 191052 & & & 0,951 & \\
\hline \multicolumn{6}{|c|}{ Grupo 6 (Telas Soldadas) - $\Delta \sigma=198 \mathrm{MPa}$} \\
\hline $\mathbf{C P}$ & $\mathbf{N}$ & MÉDIA ( $\left.\mathbf{N}_{\mathbf{m}}\right)$ & DESVIO PADRÃO N & $\mathbf{n}=\mathbf{N} / \mathbf{N}_{\mathbf{m}}$ & DESVIO PADRÃO n \\
\hline 31 & 369684 & 338871 & 64731 & 1,091 & 0,191 \\
\hline 32 & 419658 & & & 1,238 & \\
\hline 33 & 227930 & & & 0,673 & \\
\hline 34 & 353794 & & & 1,044 & \\
\hline 35 & 351362 & & & 1,037 & \\
\hline 36 & 310800 & & & 0,917 & \\
\hline \multicolumn{5}{|c|}{ Média Desvio Padrão n (Grupos 4, 5 e 6 ) } & 0,250 \\
\hline
\end{tabular}


Observando-se os resultados calculados, nota-se que a variabilidade do fenômeno da fadiga de barras isoladas independe da flutuação de tensão aplicada, visto que o desvio padrão do n calculado para os grupos 1 e 2 são semelhantes. Já para as telas, grupos 4, 5 e 6, percebe-se que a variabilidade aumentou em relação às barras e de forma muito importante no grupo 5. Os resultados obtidos para o grupo 3 apresentam maior complexidade e por isso serão discutidos posteriormente.

Analisando-se os ensaios realizados em barras isoladas (grupos 1 e 2), apesar de se ter dois conjuntos de barras com flutuações de tensões diferentes, concluise que estes dois grupos podem ser agrupados em um único grupo, no que diz respeito à variabilidade e conseqüente determinação do número de ciclos característico de cada ponto da Curva de Wöhler. Isto é o coeficiente de variação utilizado será o mesmo para o cálculo do Nk tanto para o grupo 1 quanto para o grupo 2 .

No que diz respeito aos conjuntos 4,5 e 6 , admitiu-se que a maior variabilidade do grupo 5 não é propriedade desse nível de flutuação mas do processo de soldagem em si e por isso os três grupos devem ser estudados em conjunto. Ou seja , para o caso das telas soldadas será usado o mesmo coeficiente de variação nos três grupos.

É importante salientar que as barras e as telas devem ser sempre analisadas separadamente, visto que elas apresentam variabilidades significativamente diferentes, devido às soldas existentes nas telas, a qual é um fator determinante na resistência à fadiga.

As figuras 55 e 56 ilustram os gráficos de distribuição normal dos resultados obtidos para a barras isoladas e telas soldadas:

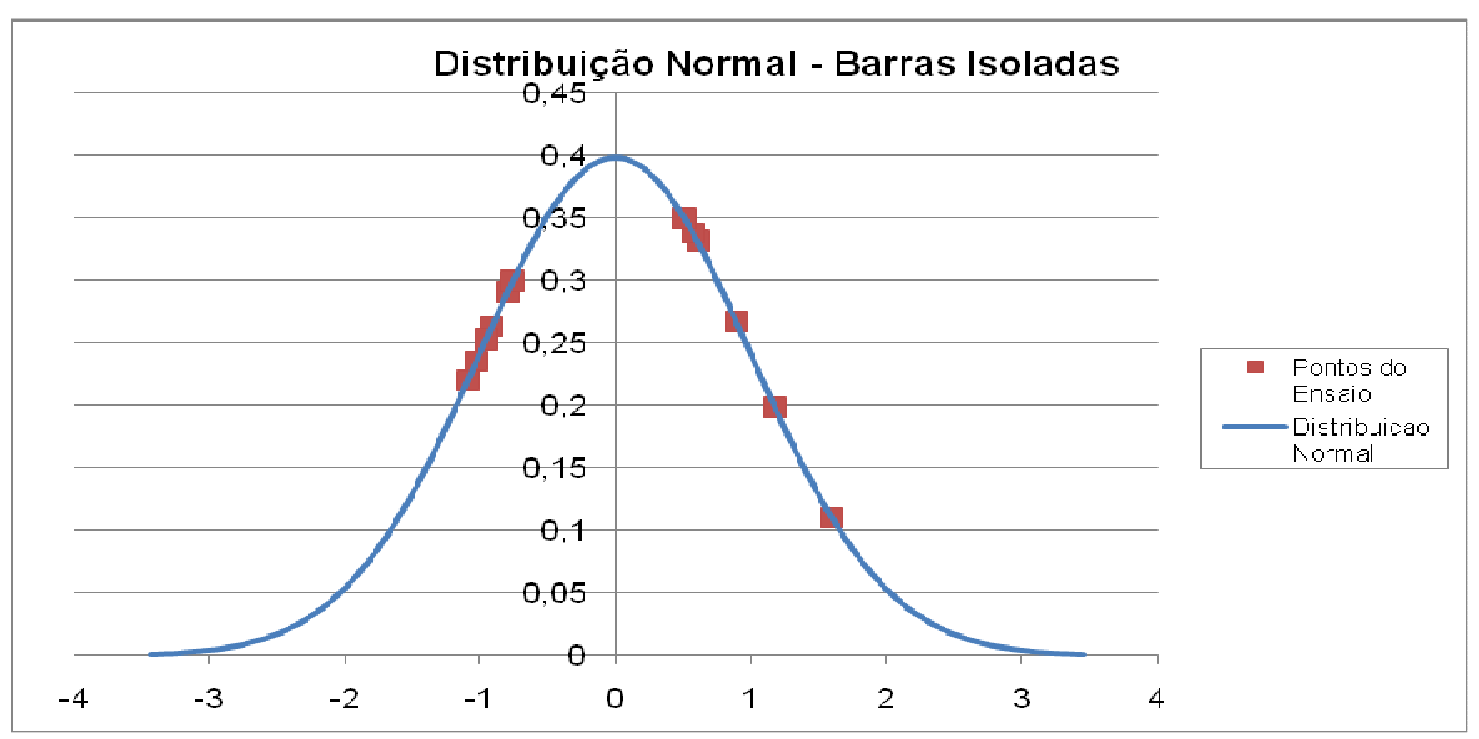

Figura 55 - Distribuição Normal para Barras Isoladas. 


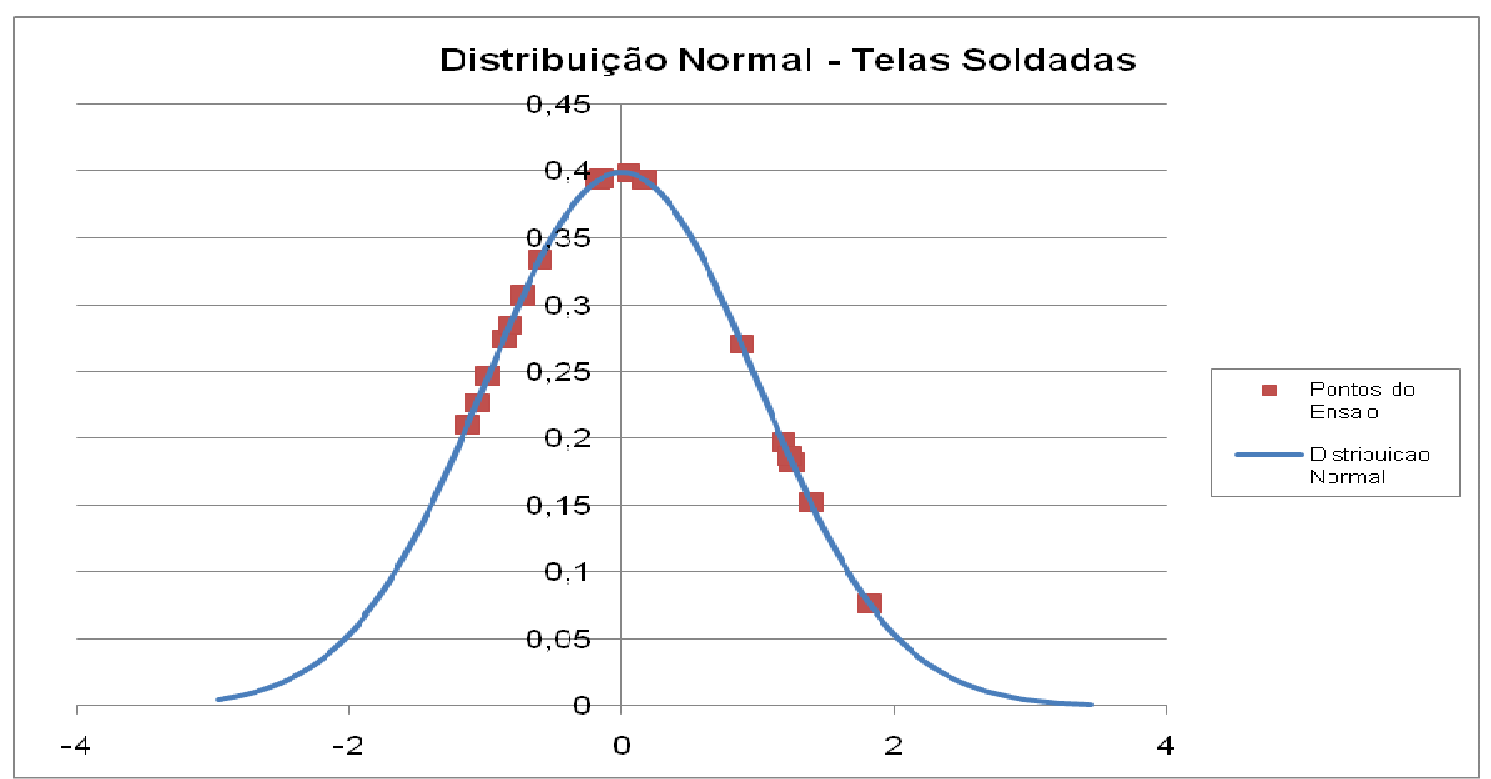

Figura 56 - Distribuição Normal para Telas Soldadas.

Para a determinação de cada um dos três pontos da curva de Wholer, tanto para as barras quanto para as telas, foi utilizada a equação 4.1 para a obtenção do valor característico $\mathrm{Nk}$, com $95 \%$ de confiança, de cada flutuação de tensão :

$$
N_{K}=N_{m}-1,64 \times c v \times N_{m}
$$

Onde:

$N_{k}=$ Valor característico do número de ciclos para dada flutuação.

$\mathrm{N}_{\mathrm{m}}=$ Média do número de ciclos para dada flutuação (ver tabela 31).

cv = Coeficiente de Variação, desvio padrão do número adimensional "n".

Com o objetivo de estimar com mais precisão a variabilidade dos resultados, foi calculado um coeficiente de variação $\mathrm{Cv}$ para as barras através dos grupos 1 e 2, e para as telas através dos grupos 4,5,e 6, conforme descrito anteriormente. A tabela 33 resume os valores de $\mathrm{N}_{\mathrm{m}}$ e $\mathrm{Cv}$ para os grupos.

\begin{tabular}{ccc} 
Tabela $33-$ Valores de "N & $\mathrm{N}_{\mathrm{m}}$ "e "cv" para os divers \\
\cline { 2 - 3 } Grupo & $\mathbf{N}_{\mathbf{m}}$ & $\mathbf{C v}$ \\
1 & 242055 & 0,153 \\
2 & 744511 & 0,153 \\
3 & - & - \\
4 & 93011 & 0,250 \\
5 & 183562 & 0,250 \\
6 & 338871 & 0,250 \\
\hline
\end{tabular}


Os resultados de $\mathrm{N}_{\mathrm{k}}$ obtidos estão descritos na tabela 33:

Tabela 34 - Valores de " $\mathrm{N}_{\mathrm{k}}$ " para os diversos grupos.

\begin{tabular}{cc}
\hline Grupo & $\mathbf{N}_{\mathbf{k}}$ \\
1 & 205020 \\
2 & 630600 \\
3 & - \\
4 & 66967 \\
5 & 132164 \\
6 & 199934 \\
\hline
\end{tabular}

No que diz respeito ao grupo 3, verifica-se que, embora alguns resultados sejam excepcionais, com as barras suportando mais de 6 milhões de ciclos sem mostrar sinais de fadiga, outras romperam com flutuação da ordem de 2 milhões, ou mesmo menos. Entendemos que nesse nível de flutuação, onde os ensaios são muito demorados e caros, precisamos de mais ensaios para concluir.

Os formatos das curvas de Wöhler para as barras isoladas e telas soldadas estão representados na figuras abaixo:

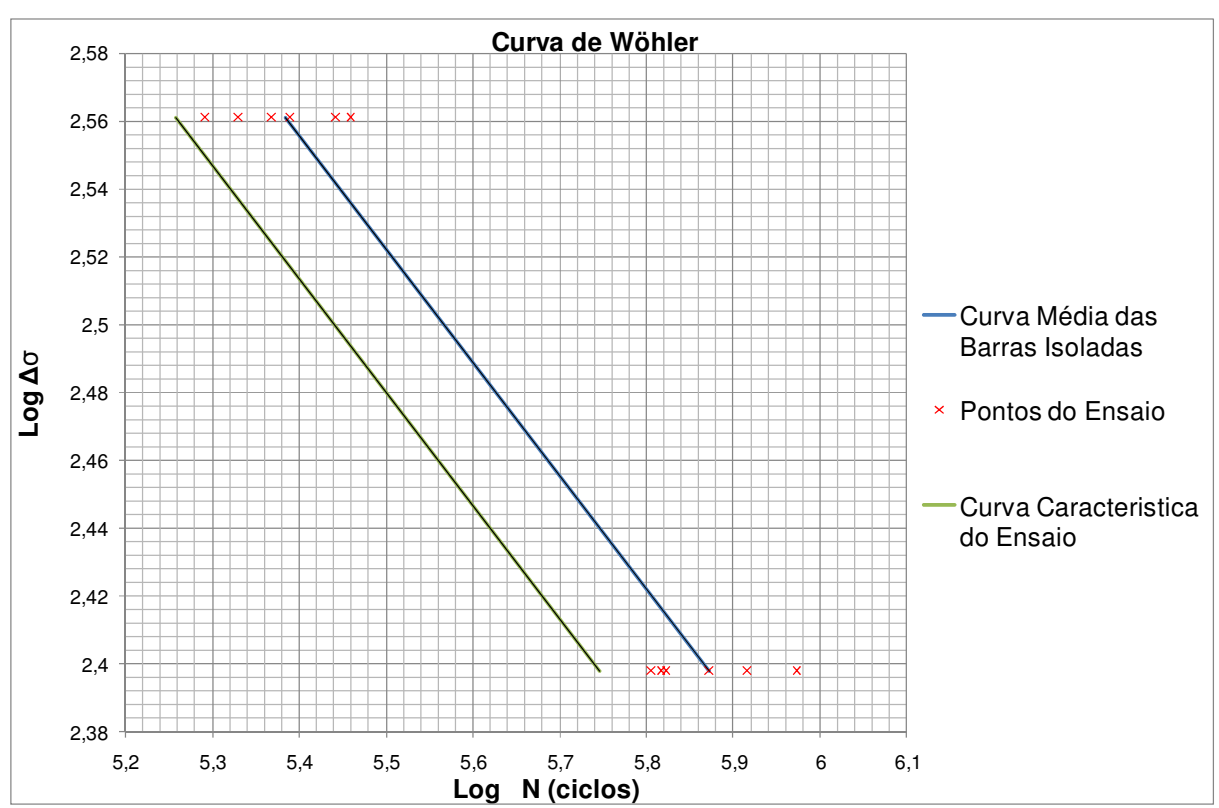

Figura 57 - Curvas de Wöhler para barras isoladas. 


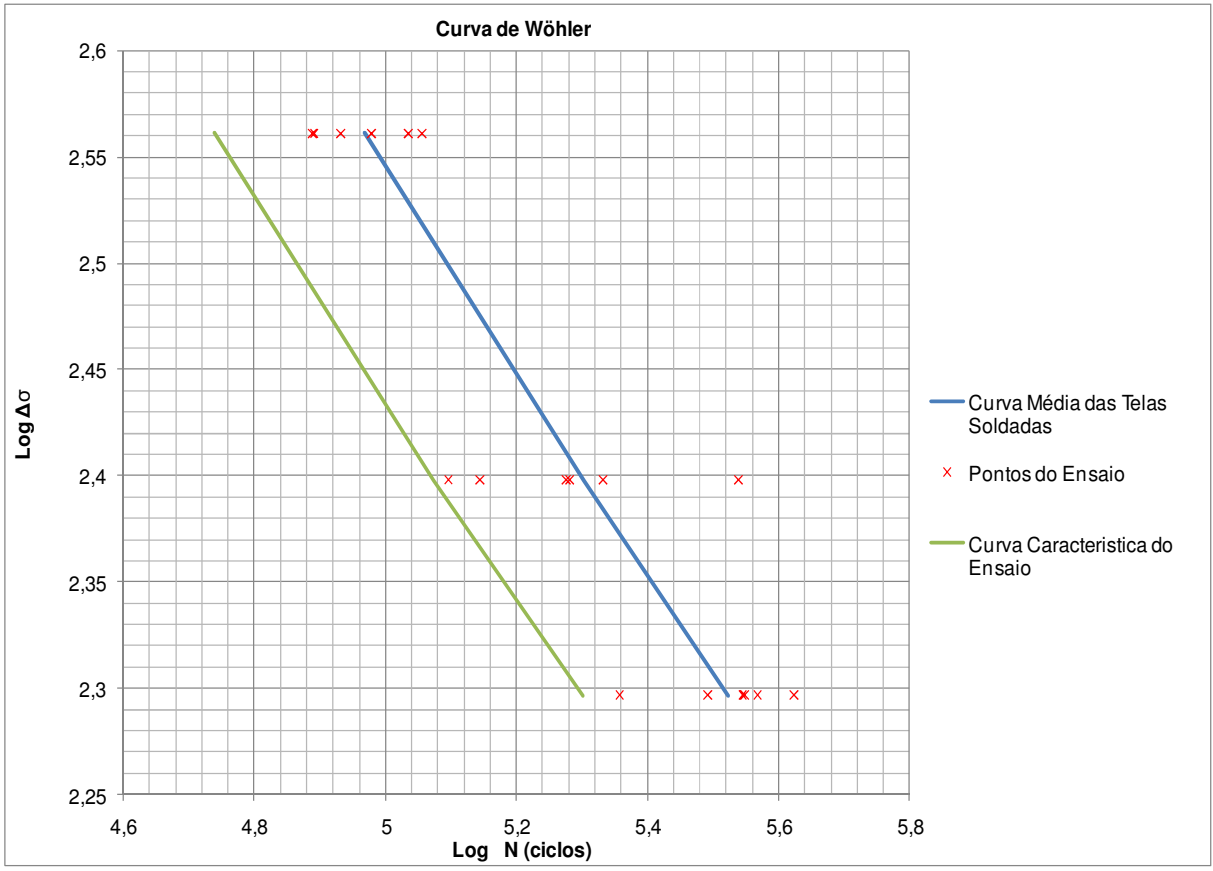

Figura 58 - Curvas de Wöhler para Telas Soldadas.

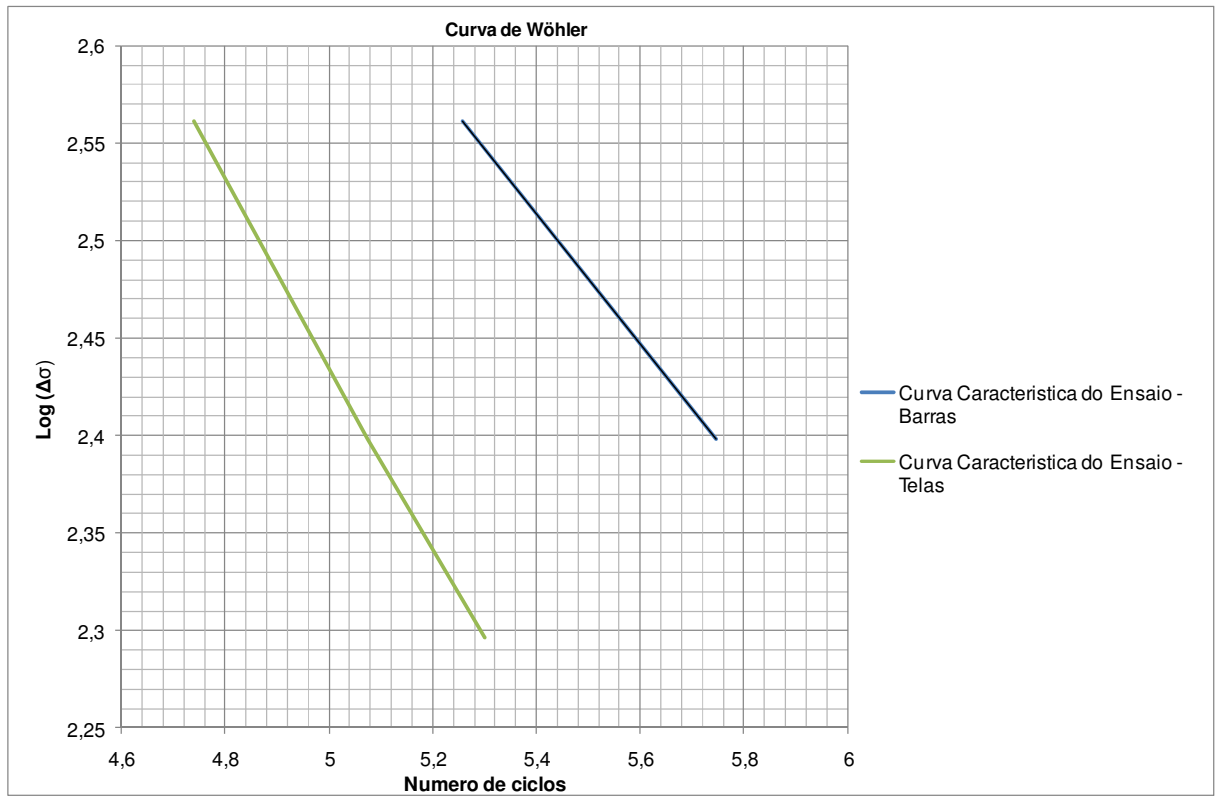

Figura 59- Curvas de Wöhler para Barras Isoladas e Telas Soldadas.

Nas figuras abaixo estão apresentados as comparações entre as curvas de Wöhler da NBR 6118 - 2003, que é a mesma adotada pelo CEB-FIP Model Code 1990 (1991), com as curvas características dos ensaios. 


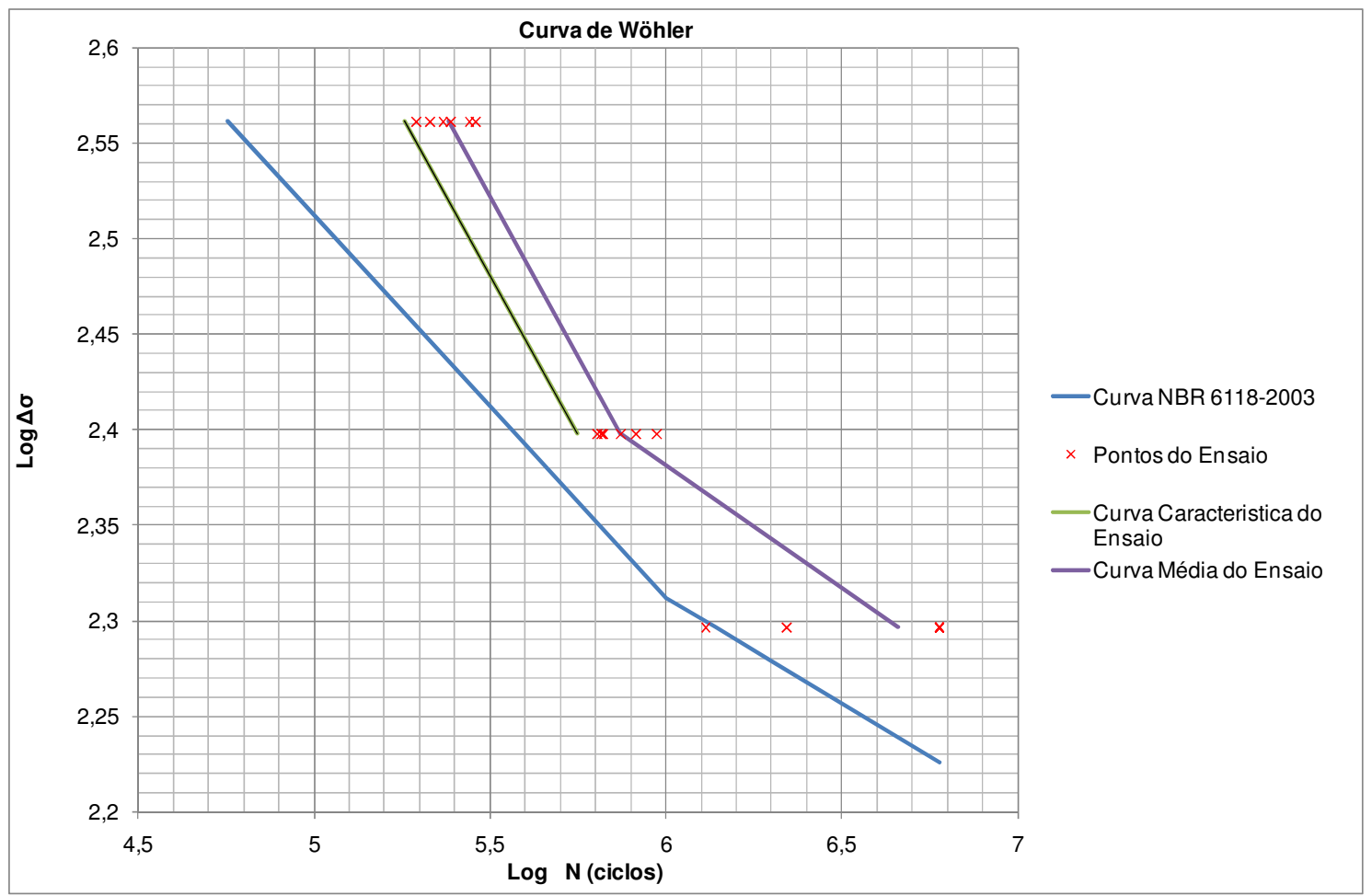

Figura 60 - Comparação entre as Curvas de Wöhler das Barras Isoladas.

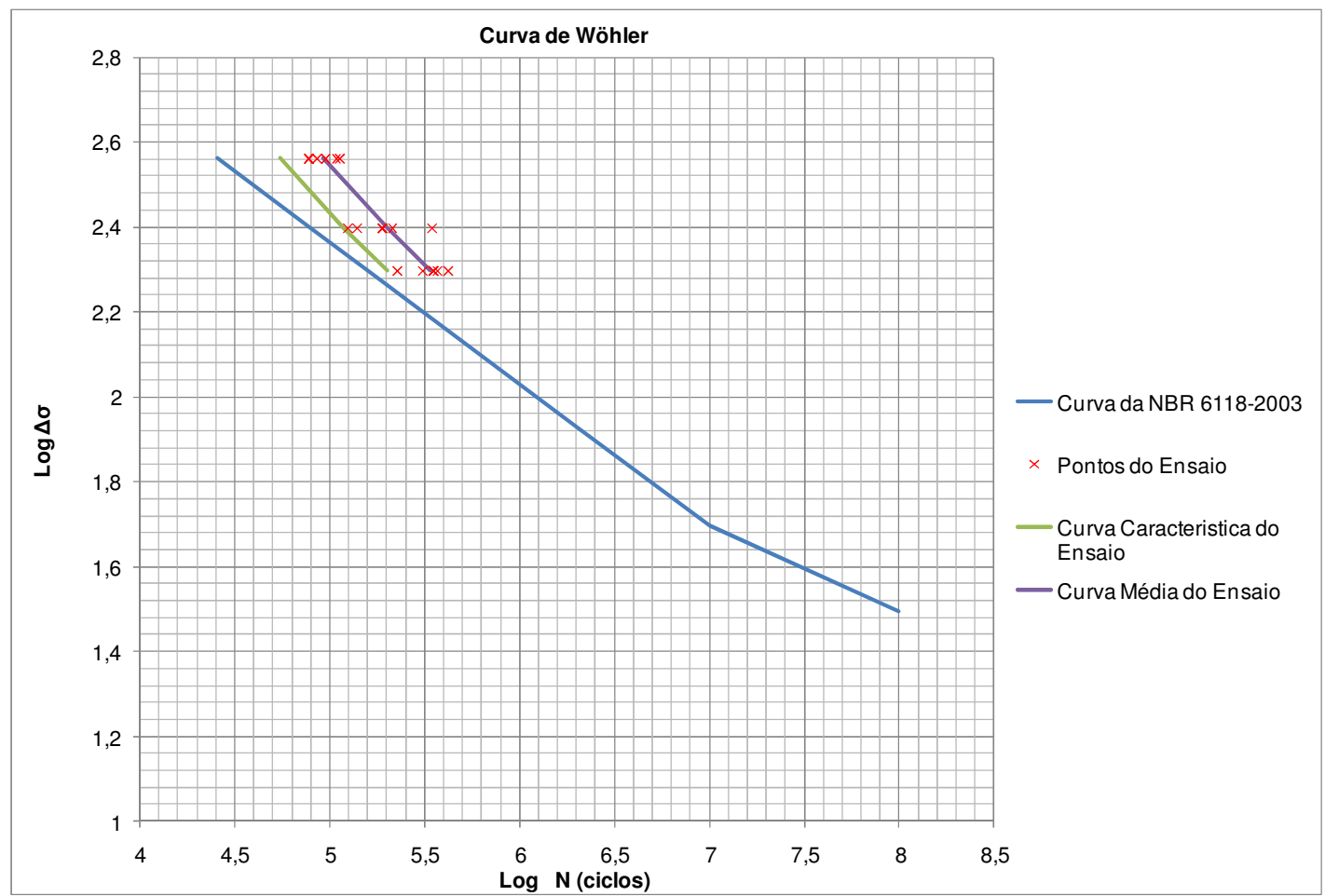

Figura 61- Comparação entre Curvas de Wöhler das Telas Soldadas.

Nas figuras 60 e 61 foram plotadas as curvas médias dos ensaios. Pois é provável que as armaduras apresentem um desempenho semelhante a esse quando mergulhadas no concreto. Uma vez que quando todas as barras estão juntas as barras tendem a trabalhar em conjunto e não isoladamente como no ensaio de barra ao ar. 
Então é natural que a média do conjunto seja um valor bem representativo do comportamento das armaduras.

A seguir será feito um cálculo baseado na equação desta reta média, com o objetivo de saber qual a flutuação de tensão que levaria as barras a ruptura com 2 milhões de ciclos, levando-se em conta o comportamento médio mencionado anteriormente.

Dos resultados dos ensaios realizados nas barras isoladas é possível saber que os pontos que definem o segundo trecho da reta média são :

$$
\text { Pontos } \rightarrow(n \text { ciclos }, \Delta \sigma)
$$

$(744511,250)$

$(4583333,198)$

Cálculo da equação da reta:

$$
\begin{aligned}
& 250=744511 a+b \\
& 198=4583333 a+b
\end{aligned}
$$

Resolvendo o sistema de equações :

$y=0,000013503 \cdot x+260,05$

Para se obter uma provável ruptura por fadiga com 2 milhões de ciclos a flutuação de tensão a ser aplicada nas lajes com barras isoladas é de $233 \mathrm{MPa}$.

Da observação dos resultados obtidos nos ensaios foi possível concluir:

a) Comparando-se os resultados obtidos nos grupos 1, 2 e 3 com os resultados esperados calculados pelas equações do CEB-FIP Model Code 1990 (1991) é possível perceber um desempenho à fadiga melhor dos aços brasileiros do que os europeus, considerados na publicação do FIB.

b) Comparando esses mesmos resultados com a curva de Wholer da NBR6118, verifica-se que a norma está do lado seguro.

c) Nos ensaios realizados nas telas soldadas foi possível perceber uma grande perda de resistência à fadiga quando comparada com a resistência das barras isoladas e um aumento da variabilidade. Isto se deve, provavelmente, ao processo de soldagem, que gera uma alteração de forma e composição localizadas e, por conseqüência, uma 
concentração de tensões, acelerando assim o processo de fadiga das telas soldadas. O aumento da variabilidade deve decorrer da variabilidade dessas alterações.

d) Com relação aos resultados dos ensaios do grupo 3 (barras isoladas), devido à pequena quantidade de amostras e uma grande dispersão nos resultados, não é possível tirar conclusões confiáveis a respeito do comportamento do aço quando submetido a flutuações de tensão dessa ordem de grandeza.

\subsection{ENSAIO DAS LAJES}

\subsubsection{Considerações preliminares}

Antes da análise dos resultados dos ensaios, serão apresentados os imprevistos e problemas ocorridos durante os ensaios e as soluções adotadas para contorná-los.

Nos primeiros ensaios realizados, ou seja, os do grupo 1A e algumas lajes do 1B foi percebida uma incapacidade dos extensômetros realizarem a medição das deformações até o final dos ensaios, isto se deve ao fato deles estarem posicionados em uma zona de altas tensões.

Para que fosse possível identificar a causa da incapacidade dos extensomêtros, foi feita uma inspeção nessas lajes, figura 62 mostra uma parte de uma peça inspecionada.

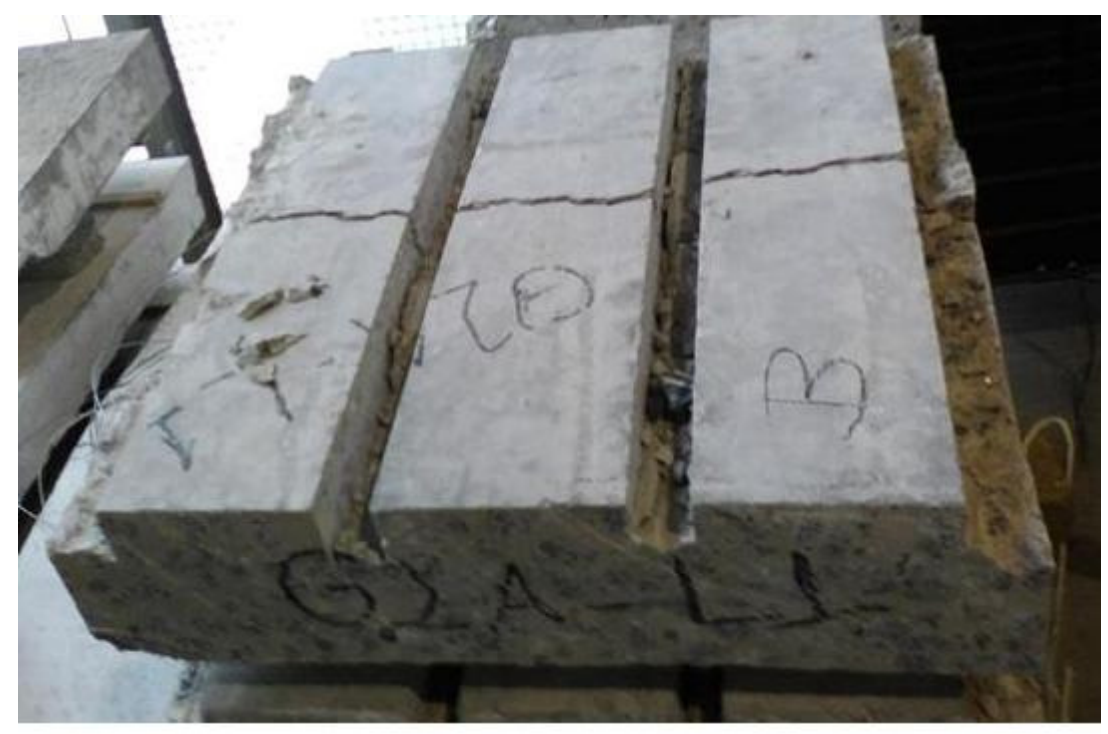

Figura 62 - Parte laje1 do grupo 1 A que foi inspecionada

Através da inspeção concluiu-se que à medida que as solicitações aumentavam pelo fato dos extensômetros estarem também em contato com concreto 
eles descolavam da armadura, ficando aderidos ao concreto. Então é natural que as medidas de deformações aferidas não eram correspondentes às deformações das armaduras.

Uma vez que todas as lajes a serem ensaiadas já haviam sido concretadas a solução encontrada para o problema foi fazer uma abertura na laje para que uma das barras fosse instrumentada novamente, deixando o extensômetro exposto ao ar, evitando assim o contato com o concreto (figura 63 e 64). Como a região onde foi feita a abertura é uma zona tracionada esta retirada de concreto não afeta a capacidade resistente da peça.

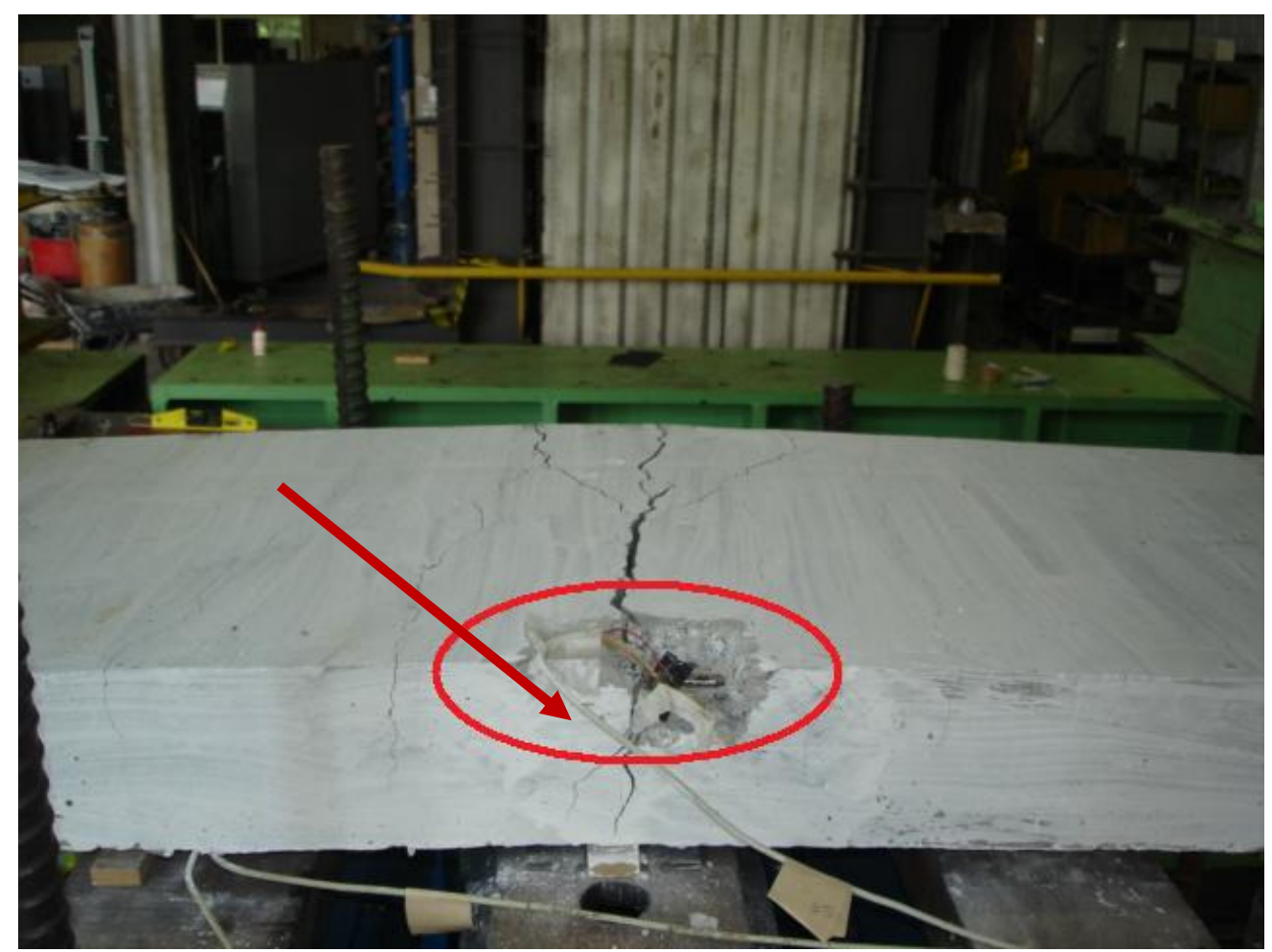

Figura 63 - abertura na laje evitando o contato do extensômetro com o concreto

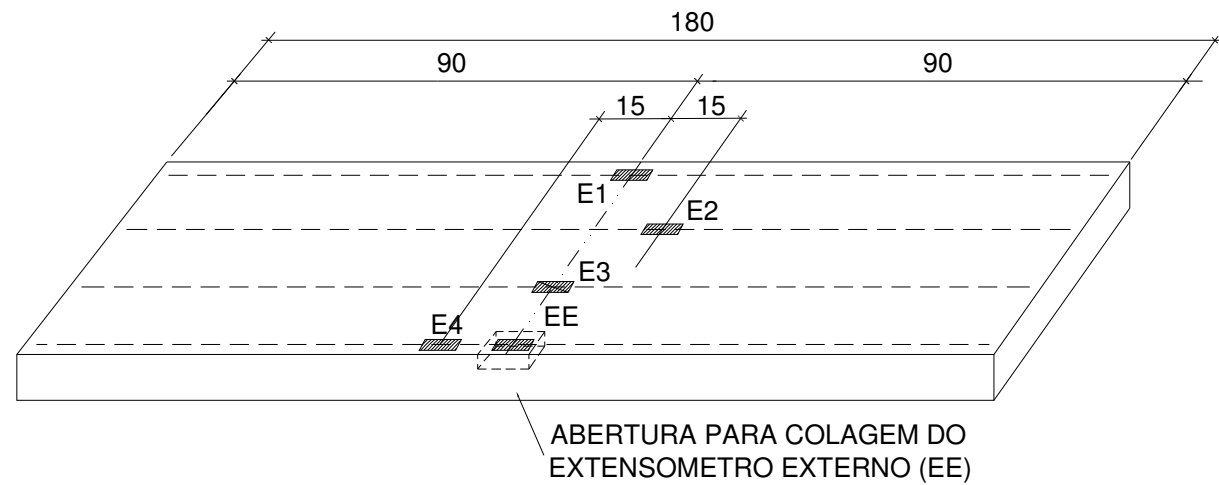

Figura 64 - Esquema do posicionamento do extensômetro externo 
$\mathrm{Na}$ época dos ensaios das lajes do grupo 2B e da laje 3 do $1 \mathrm{~B}$ aconteceram no Laboratório de Estruturas e Materiais sucessivas quedas e/ou picos de energia, ocasionando um descontrole no sistema de ensaio. Por este motivo a laje 1 foi perdida durante o ensaio dinâmico e as lajes 2 e 3 foram perdidas após o termino do ensaio dinâmico, mas antes da realização ensaio estático. Portanto apenas não serão apresentados os resultados dos ensaios estáticos das lajes do grupo $2 \mathrm{~B}$ e da laje 3 do grupo 1B.

Devido aos problemas ocorridos com as lajes do grupo 2B, não existiriam lajes com a mesma taxa de armadura do grupo $1 \mathrm{~B}$, armadas com telas soldadas para que se fizessem comparações dos ensaios estáticos. Contudo esta pesquisa teve uma grande parte dos ensaios compartilhados com a pesquisa de mestrado da alunos Edielce Caixeta e Paulo Cavalvanti. Por isto neste momento do trabalho serão utilizadas as lajes dos subgrupos 3 A e 3 B em algumas análises dos ensaios estáticos.

De acordo com as conclusões da pesquisa dos alunos citados anteriormente a presença ou não da pré-laje não afeta a capacidade resistente das lajes, então é natural que o desempenho das lajes do grupo 2 sejam semelhantes as do grupo 3. Não havendo problema em comparar as lajes com pré-laje com as sem a pré-laje.

O problema de falta e ou picos de energia já havia sido previsto antes do início dos ensaios, por este motivo tanto o sistema de aquisição quanto o de controle estavam conectados a rede elétrica através de no breaks, para evitar este tipo de problema.

Após a concretagem de todas as lajes foi percebida uma inversão das alturas da pré-laje e da capa, por um equivoco na montagem das formas. Assim sendo a pré-laje possui $7 \mathrm{~cm}$ ao invés de $5 \mathrm{~cm}$ e a capa possui $5 \mathrm{~cm}$ ao invés de $7 \mathrm{~cm}$. Conforme pode ser observado na figura 65 abaixo. 


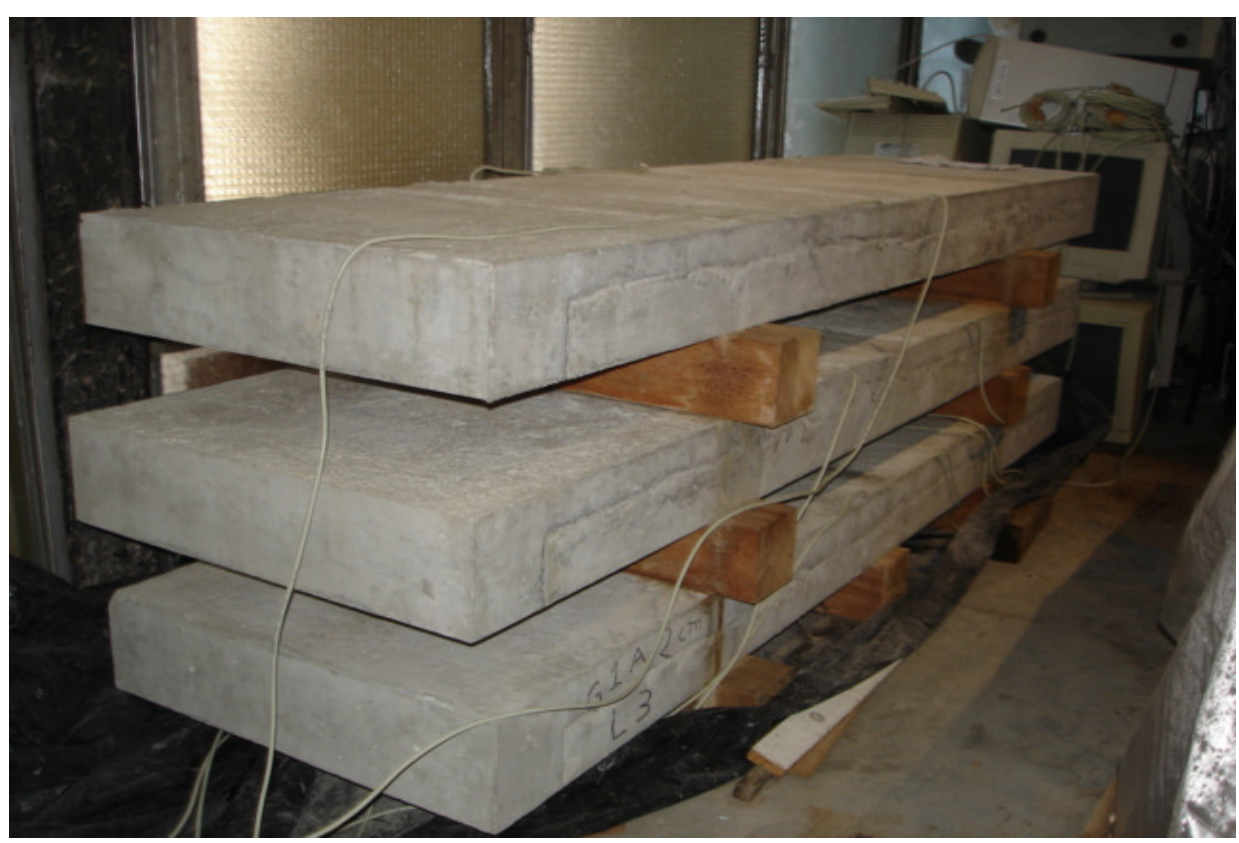

Figura 65 - Lajes instrumentadas

Contudo esta inversão não ocasiona nenhum problema, uma vez que tanto de uma forma como de outra a linha neutra permanece acima da região de contato entre a capa e a pré-laje. Também é importante salientar que nos ensaios realizados não houve surgimento de nenhuma fissura na região de contato entre os concretos de idades diferentes.

\subsubsection{Ensaios de ruptura estática}

Os gráficos de ruptura apresentados nos itens que se seguem, não têm início no ponto zero x zero. Uma vez que os ensaios foram realizados com uma rotação de $180^{\circ}$, então o atuador sempre estava suportando o peso da laje mais os perfis, que têm um peso aproximado de $3 \mathrm{KN}$. Então por este motivo os gráficos apresentados a seguir possuem origem no ponto $(3,0)$.

\subsubsection{Análise do individual do comportamento das lajes no ensaio estático}

As figuras de 66 a 68 apresentados a seguir são os gráficos dos ensaios de ruptura efetuados nas 3 lajes do Subgrupo 1 A . A laje 1 foi apenas ensaiada estaticamente enquanto as lajes 2 e 3 foram ensaiadas estaticamente após a realização do ensaio dinâmico, descrito no item 3.3 deste trabalho. 


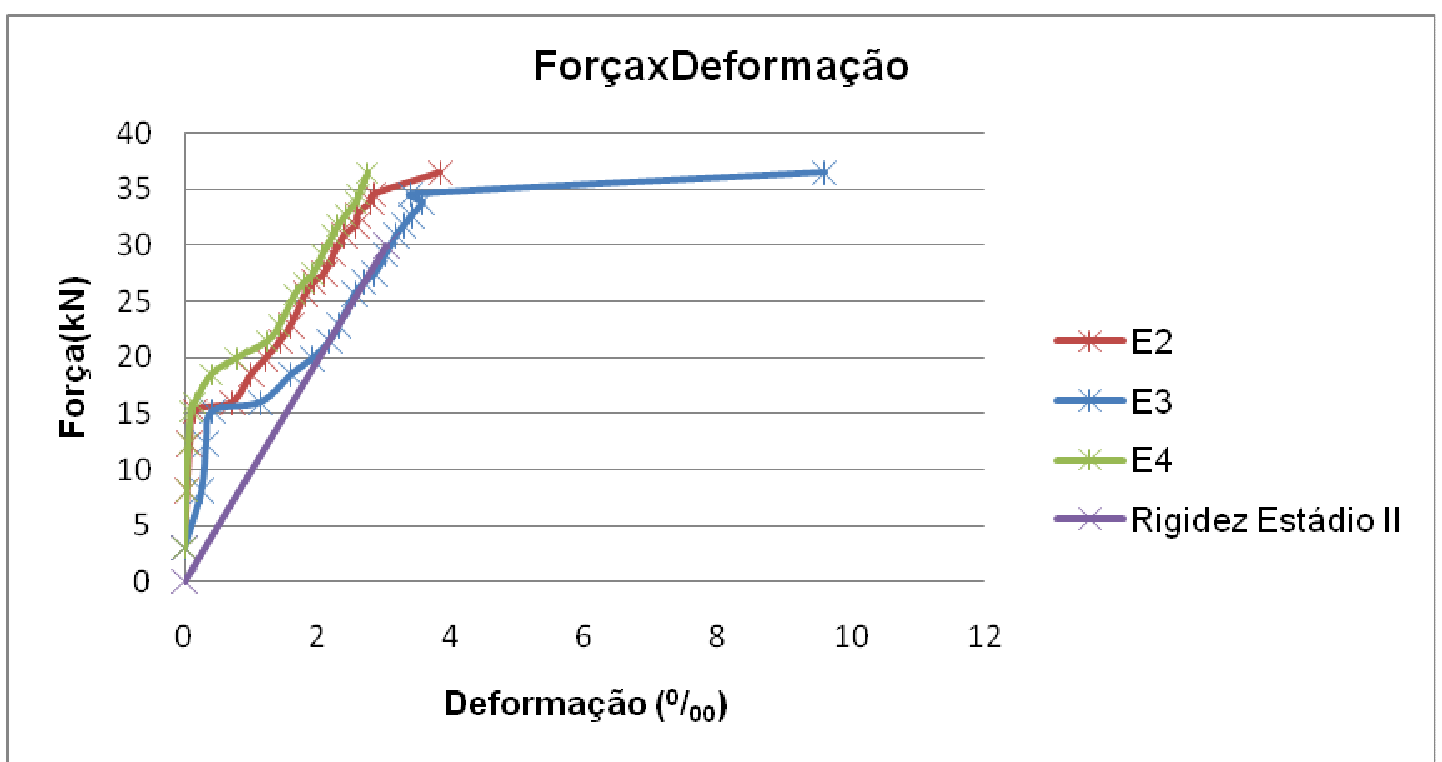

Figura 66 - Gráfico do ensaio de ruptura da laje 1

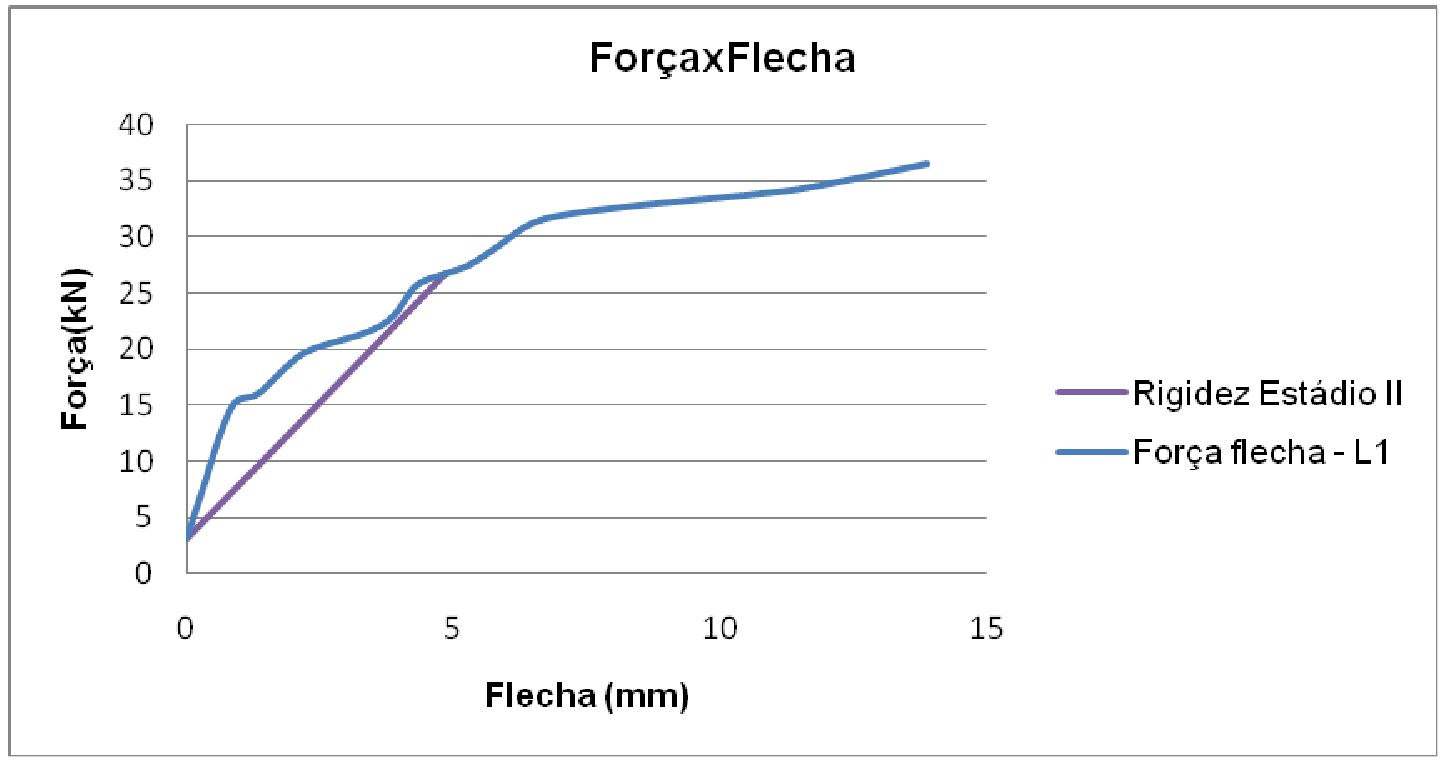

Figura 67 - Gráfico força x deslocamento do ensaio de ruptura da laje 1 


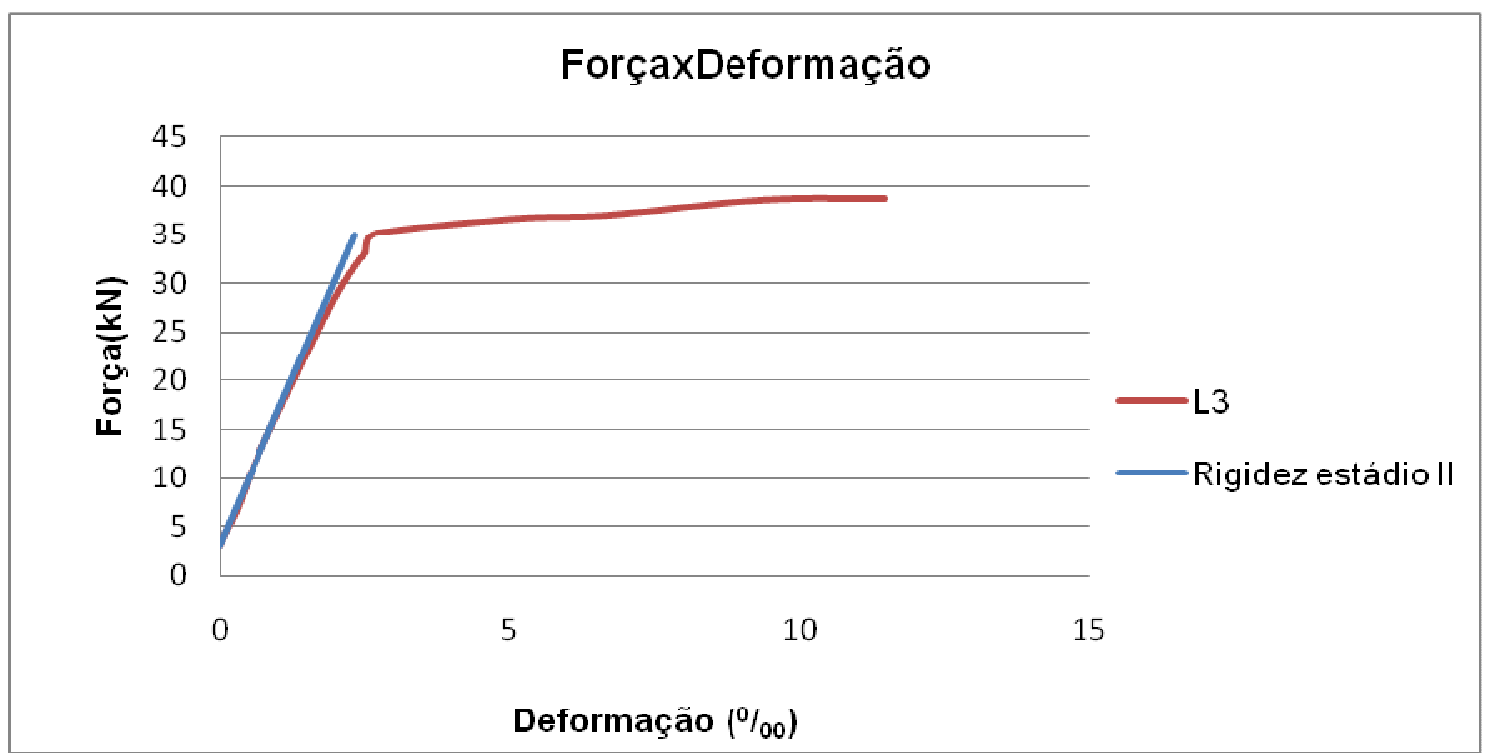

Figura 68 - Gráfico do ensaio de ruptura da laje 3

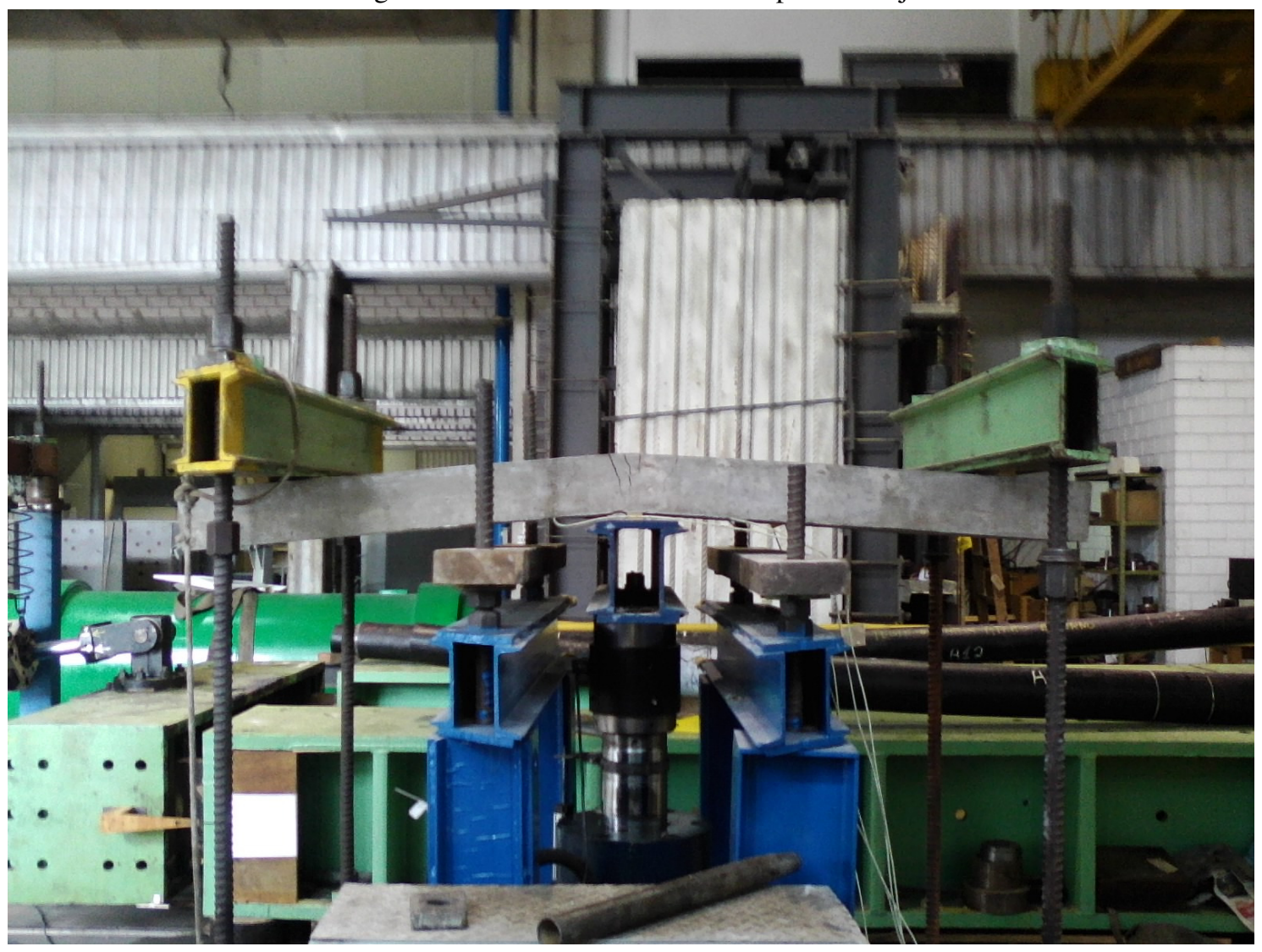

Figura 69 - laje sendo ensaiada a ruptura 


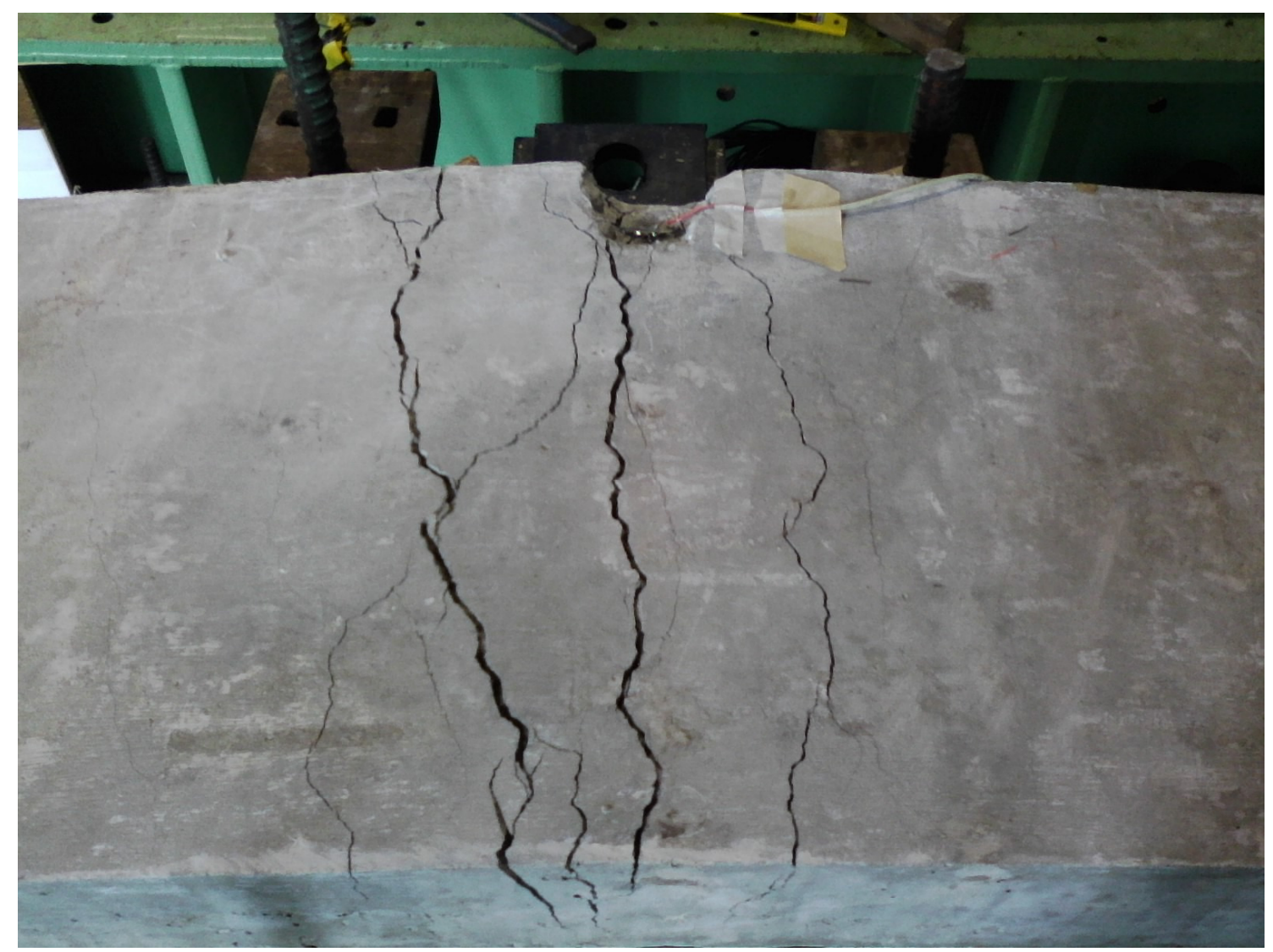

Figura 70 - Vista superior da laje após a o ensaio de ruptura

Na figura 66 é possível perceber claramente a passagem da peça pelos 3 estádios de solicitação. Em roxo é mostrada a reta da rigidez utilizada para calcular os valores experimentais, mostrados nas tabelas 36 a 40.

Na figura 67 é possível perceber também a passagem pelos 3 estádios de solicitação, contudo neste gráfico é possível perceber que a rigidez do estádio II leva em conta a contribuição entre fissuras, fenômeno que não aparece no gráfico força deformação ilustrado pela figura 66. Mais uma vez em roxo é mostrada a reta da rigidez utilizada para calcular os valores experimentais, mostrados nas tabelas 29 a 33 .

Como as lajes 2 e 3 foram fissuradas anteriormente para a execução do ensaio dinâmico, então é natural que na figura 68 o gráfico não apresente o comportamento do estádio I uma vez que ela já estava fissurada. Em azul é mostrada a reta da rigidez utilizada para calcular os valores experimentais, mostrados nas tabelas 29 a 33.

A seguir serão demonstrados os cálculos do momento de fissuração, do módulo de elasticidade e rigidez no estádio II de forma teórica acordo com as equações da NBR6118-2003 e comparados com os valores obtidos através do ensaio. 
Para a laje 1 temos do grupo $1 \mathrm{~A}$ :

Cálculos de acordo com a NBR6118-2003:

$F C=52,47 M P Q \quad E S=210 G P a \quad A s=2 \mathrm{~cm}^{2}$

$E C S=0,85 \times 5600 \times \sqrt{F C} \quad E C s=34,48 G P a$

Cálculo da profundidade da linha neutra:

$$
\begin{aligned}
& b x \times \frac{x}{2}=A_{s} \times(d-x) \alpha \quad \alpha=6,09 \\
& 50 \frac{x^{2}}{2}=2(9,5-x) 6,09 \\
& 25 x^{2}-115,72+12,18 x=0 \\
& x=1,92 \mathrm{~cm}
\end{aligned}
$$

Cálculo da rigidez no estádio II puro:

$$
\begin{aligned}
& I_{I I}=\frac{b x^{2}}{3}+\alpha \times A_{s}(d-x)^{2} \\
& I_{I I}=\frac{50 \times 1,92^{3}}{3}+6,09 \times 2(9,5-1,92)^{2} \\
& I_{I I}=817,84 \mathrm{~cm}^{4}
\end{aligned}
$$

Cálculo da rigidez no estádio com contribuição entre fissuras:

Equação de Branson:

$\mathrm{I}_{\varepsilon}=\mathrm{I}_{0}\left(\frac{M c r}{M m a ́ x}\right)^{3}+\left(1-\left(\frac{M c r}{M m a ́ x}\right)^{3}\right)_{11}$

Cálculo do momento de fissuração:

$$
\begin{aligned}
& M_{c r}=\frac{\alpha \times f_{c t} \times I_{C}}{Y_{t}} \\
& M_{c r}=\frac{1,5 \times 3,47 \times 7200}{6000}=6,25 \mathrm{KNm}
\end{aligned}
$$

$M m a ́ x=9,16 K N m$ 
$I_{s}=7200\left(\frac{6,25}{9,16}\right)^{3}+\left(1-\left(\frac{6,25}{9,16}\right)^{3}\right) 817,84=2845 \mathrm{~cm}^{4}$

Cálculos de acordo com os gráficos dos ensaios de ruptura:

O módulo de elasticidade do concreto e do aço utilizados foram os obtidos através do ensaio dos ensaios de caracterização.

$$
E c s=31 G P a \quad E s=198,80 G P a
$$

Cálculo da profundidade da linha neutra:

$$
\begin{gathered}
b x \times \frac{x}{2}=A_{s} \times(d-x) \alpha \quad \alpha=6,41 \\
50 \frac{x^{2}}{2}=2(9,5-x) 6,41 \\
25 x^{2}-122,10+12,85 x=0 \\
x=1,97 \mathrm{~cm}
\end{gathered}
$$

Cálculo da rigidez no estádio II puro:

$$
\begin{gathered}
\sigma_{s}=\frac{M}{I_{I I}}(d-x) \alpha \\
\sigma_{s}=E_{s} \times \mathcal{E}
\end{gathered}
$$

Substituindo (4.2) em (4.3) :

$$
I_{I I}=\frac{M}{E_{s} \times \varepsilon}(d-x) \alpha
$$

Onde $\mathrm{M}$ é o momento aplicado a peça em um ponto do estádio II e $\varepsilon$ a deformação correspondente. $\mathrm{O}$ valor do momento e da deformação foram retiradas do gráfico força $\mathrm{x}$ deformação obtidos no ensaio de ruptura de cada laje.

$$
\begin{gathered}
M=0,608+0,365 \times(F-2,7) \\
F=22,9 K N \quad \varepsilon=1,388 \% \\
M=0,608+0,365 \times(22,9-2,7) \\
M=7,97 K N m \\
I_{I I}=\frac{7,97}{198,8 \times 2,046} \times(9,5-1,97) \times 6,41 \times 1000
\end{gathered}
$$




$$
I_{I I}=949 \mathrm{~cm}^{4}
$$

Cálculo da rigidez no estádio com contribuição entre fissuras:

Equação de Branson:

$\mathrm{I}_{\mathbb{*}}=\mathrm{I}_{0}\left(\frac{M c r}{M \max }\right)^{3}+\left(1-\left(\frac{M c r}{M \max }\right)^{3}\right) I_{11}$

Momento de fissuração obtido graficamente:

$\mathrm{Mcr}=5,53 \mathrm{KNm}$

Mmáx $=9,16 K N m$

O momento máximo a ser utilizado na equação de branson é o corresponde a uma carga freqüente, contudo para o caso das lajes armadas com $2 \mathrm{~cm}^{2}$ este momento é muito próximo da carga de fissuração. Por isto para o caso dessas lajes foi utilizado o momento último da peça comparado com uma carga de 26 Kn que é uma carga próxima à da ruptura da peça.

No caso das lajes armadas com $4 \mathrm{~cm}^{2}$ não se teve este problema e carga utilizada foi a carga de $30 \mathrm{KN}$, e por isto espera-se que os valores dos subgrupos "B" apresentem menores dispersões que as dos subgrupos "A".

$$
I_{e}=7200 \times\left\langle\frac{5,53}{9,16}\right\rangle^{3}+\left(1-\frac{5,53}{9,16}\right)^{3} \times 949=2362 \mathrm{~cm}^{4}
$$

Por fim a inércia da do estádio II com contribuição entre fissuras calculada pelo gráfico força x deslocamento.

$f=\frac{P \times l^{3}}{48 E I}$

Usando uma carga entre o momento Máximo e o momento de fissuração que representa a carga pré estabelecida próxima da ruptura .

$\mathrm{P}=26 \mathrm{KN}$ e flecha $=4 \mathrm{~cm}$

$$
I_{e}=\frac{26 \times 1,46^{3}}{48 \times 31 \times 4} \times 10^{5}=1367 \mathrm{~cm}^{4}
$$


Nas tabelas abaixo se encontra um resumo dos valores obtidos para cálculos realizados de maneira análoga para as lajes dos outros grupos. Para facilitar nas tabelas as lajes cujos nomes estiveram em azul foram as lajes que não foram ensaiadas dinamicamente.

A análise da contribuição entre fissuras foi realizada apenas para as lajes que não foram ensaiadas dinamicamente. Uma vez que a análise do comportamento da contribuição entre fissuras das peças após os ensaios dinâmicos são bastante complexas e não estão no escopo desta pesquisa.

Tabela 35 - Resumo dos cálculos

\begin{tabular}{|c|c|c|c|c|}
\hline $\begin{array}{c}\text { Grupo } \\
1 \mathrm{~A}\end{array}$ & Parâmetros & Experimental & Numérico & Comparação(\%) \\
\hline \multirow{5}{*}{. } & $\mathrm{I}_{\mathrm{II}}\left(\mathrm{cm}^{4}\right)$ & 949 & 856 & 9,80 \\
\hline & $\mathrm{I}_{\mathrm{e}}\left(\mathrm{cm}^{4}\right)$ & 2363 & 2290 & 3,09 \\
\hline & $\mathrm{I}_{\mathrm{e}(\text { grafico })}\left(\mathrm{cm}^{4}\right)$ & 1367 & 2290 & $-67,52$ \\
\hline & Ecs & 31 & 34 & $-9,68$ \\
\hline & ES & 198,8 & 210 & $-5,63$ \\
\hline \multirow{5}{*}{. } & $\mathrm{I}_{\mathrm{II}}\left(\mathrm{cm}^{4}\right)$ & 1683 & 882 & 47,59 \\
\hline & $\mathrm{I}_{\mathrm{e}}\left(\mathrm{cm}^{4}\right)$ & 2930 & 2310 & 21,16 \\
\hline & $\mathrm{I}_{\mathrm{e} \text { (grafico) }}\left(\mathrm{cm}^{4}\right)$ & $\mathrm{x}$ & $\mathrm{x}$ & $x$ \\
\hline & Ecs & 31 & 33 & $-6,45$ \\
\hline & ES & 198,8 & 210 & $-5,63$ \\
\hline \multirow{5}{*}{ 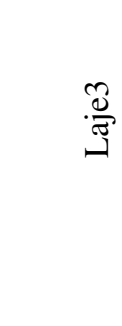 } & $\mathrm{I}_{\mathrm{II}}\left(\mathrm{cm}^{4}\right)$ & 1025 & 890 & 13,17 \\
\hline & $\mathrm{I}_{\mathrm{e}}\left(\mathrm{cm}^{4}\right)$ & 2421 & 2317 & 4,30 \\
\hline & $\mathrm{I}_{\mathrm{e} \text { (grafico) }}\left(\mathrm{cm}^{4}\right)$ & $\mathrm{x}$ & $\mathrm{x}$ & $\mathrm{x}$ \\
\hline & Ecs & 29 & 33 & $-13,79$ \\
\hline & $\mathrm{ES}$ & 198,8 & 210 & $-5,63$ \\
\hline
\end{tabular}

*em azul a laje que não foi submetida a ensaio dinâmico 
Tabela 36 - Resumo dos cálculos

\begin{tabular}{|c|c|c|c|c|}
\hline $\begin{array}{c}\text { Grupo } \\
3 \mathrm{~A}\end{array}$ & Parâmetros & Experimental & Numérico & Comparação(\%) \\
\hline \multirow{5}{*}{ 岇 } & $\mathrm{I}_{\mathrm{II}}\left(\mathrm{cm}^{4}\right)$ & 960 & 882 & 8,13 \\
\hline & $\mathrm{I}_{\mathrm{e}}\left(\mathrm{cm}^{4}\right)$ & 2371 & 2310 & 2,57 \\
\hline & $\mathrm{I}_{\mathrm{e} \text { (grafico) }}\left(\mathrm{cm}^{4}\right)$ & $\mathrm{x}$ & $\mathrm{x}$ & $\mathrm{x}$ \\
\hline & Ecs & 31 & 33 & $-6,45$ \\
\hline & ES & 198,8 & 210 & $-5,63$ \\
\hline \multirow{5}{*}{ 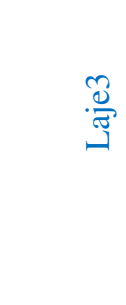 } & $\mathrm{I}_{\mathrm{II}}\left(\mathrm{cm}^{4}\right)$ & 1059 & 890 & 15,96 \\
\hline & $\mathrm{I}_{\mathrm{e}}\left(\mathrm{cm}^{4}\right)$ & 2448 & 2317 & 5,35 \\
\hline & $\mathrm{I}_{\mathrm{e} \text { (grafico) }}\left(\mathrm{cm}^{4}\right)$ & 1768 & 2317 & $-31,05$ \\
\hline & Ecs & 29 & 33 & $-13,79$ \\
\hline & ES & 198,8 & 210 & $-5,63$ \\
\hline
\end{tabular}

*em azul a laje que não foi submetida a ensaio dinâmico

Tabela 37 - Resumo dos cálculos

\begin{tabular}{|c|c|c|c|c|}
\hline $\begin{array}{c}\text { Grupo } \\
3 \mathrm{~A}\end{array}$ & Parâmetros & Experimental & Numérico & Comparação(\%) \\
\hline \multirow{5}{*}{. } & $\mathrm{I}_{\mathrm{II}}\left(\mathrm{cm}^{4}\right)$ & 666 & 890 & $-33,63$ \\
\hline & $\mathrm{I}_{\mathrm{e}}\left(\mathrm{cm}^{4}\right)$ & 2144 & 2317 & $-8,07$ \\
\hline & $\mathrm{I}_{\mathrm{e} \text { (grafico) }}\left(\mathrm{cm}^{4}\right)$ & $\mathrm{x}$ & $\mathrm{x}$ & $\mathrm{x}$ \\
\hline & Ecs & 32 & 33 & $-3,13$ \\
\hline & ES & 198,8 & 210 & $-5,63$ \\
\hline \multirow{5}{*}{. } & $\mathrm{I}_{\mathrm{II}}\left(\mathrm{cm}^{4}\right)$ & 801 & 859 & $-7,24$ \\
\hline & $\mathrm{I}_{\mathrm{e}}\left(\mathrm{cm}^{4}\right)$ & 2248 & 2293 & $-2,00$ \\
\hline & $\mathrm{I}_{\mathrm{e} \text { (grafico) }}\left(\mathrm{cm}^{4}\right)$ & $\mathrm{x}$ & $\mathrm{x}$ & $\mathrm{x}$ \\
\hline & Ecs & 31 & 34 & $-9,68$ \\
\hline & ES & 198,8 & 210 & $-5,63$ \\
\hline \multirow{5}{*}{ 苂 } & $\mathrm{I}_{\mathrm{II}}\left(\mathrm{cm}^{4}\right)$ & 927 & 874 & 5,72 \\
\hline & $\mathrm{I}_{\mathrm{e}}\left(\mathrm{cm}^{4}\right)$ & 2346 & 2304 & 1,79 \\
\hline & $I_{e \text { (grafico) }}\left(\mathrm{cm}^{4}\right)$ & 1689 & 2304 & $-36,41$ \\
\hline & Ecs & 34 & 34 & 0,00 \\
\hline & ES & 198,8 & 210 & $-5,63$ \\
\hline
\end{tabular}

*em azul a laje que não foi submetida a ensaio dinâmico 
Tabela 38 - Resumo dos cálculos

\begin{tabular}{|c|c|c|c|c|}
\hline $\begin{array}{c}\text { Grupo } \\
1 \mathrm{~B}\end{array}$ & Parâmetros & Experimental & Numérico & Comparação(\%) \\
\hline \multirow{5}{*}{. } & $\mathrm{I}_{\mathrm{II}}\left(\mathrm{cm}^{4}\right)$ & 1523 & 1481 & 2,76 \\
\hline & $\mathrm{I}_{\mathrm{e}}\left(\mathrm{cm}^{4}\right)$ & 2359 & 2322 & 1,57 \\
\hline & $\mathrm{I}_{\mathrm{e} \text { (grafico) }}\left(\mathrm{cm}^{4}\right)$ & $\mathrm{x}$ & $\mathrm{x}$ & $\mathrm{x}$ \\
\hline & Ecs & 36 & 34 & 5,56 \\
\hline & ES & 191,1 & 210 & $-9,89$ \\
\hline \multirow{5}{*}{ 岂 } & $\mathrm{I}_{\mathrm{II}}\left(\mathrm{cm}^{4}\right)$ & 1463 & 1572 & $-7,45$ \\
\hline & $\mathrm{I}_{\mathrm{e}}\left(\mathrm{cm}^{4}\right)$ & 2307 & 2400 & $-4,03$ \\
\hline & $\mathrm{I}_{\mathrm{e} \text { (grafico) }}\left(\mathrm{cm}^{4}\right)$ & $\mathrm{x}$ & $\mathrm{x}$ & $\mathrm{x}$ \\
\hline & Ecs & 32 & 31 & 3,13 \\
\hline & ES & 191,1 & 210 & $-9,89$ \\
\hline \multirow{5}{*}{$\stackrel{\mathscr{U}}{\widetilde{G}}$} & $\mathrm{I}_{\mathrm{II}}\left(\mathrm{cm}^{4}\right)$ & 1437 & 1481 & $-3,06$ \\
\hline & $\mathrm{I}_{\mathrm{e}}\left(\mathrm{cm}^{4}\right)$ & 2741 & 2274 & 17,04 \\
\hline & $\mathrm{I}_{\mathrm{e} \text { (grafico) }}\left(\mathrm{cm}^{4}\right)$ & $\mathrm{x}$ & $\mathrm{x}$ & $\mathrm{x}$ \\
\hline & Ecs & 33 & 34 & $-3,03$ \\
\hline & ES & 191,1 & 210 & $-9,89$ \\
\hline
\end{tabular}

*em azul a laje que não foi submetida a ensaio dinâmico

Tabela 39 - Resumo dos cálculos

\begin{tabular}{|c|c|c|c|c|}
\hline $\begin{array}{c}\text { Grupo } \\
\text { 3B }\end{array}$ & Parâmetros & Experimental & Numérico & Comparação(\%) \\
\hline \multirow{5}{*}{ 岕 } & $\mathrm{I}_{\mathrm{II}}\left(\mathrm{cm}^{4}\right)$ & 1729 & 1558 & 9,89 \\
\hline & $\mathrm{I}_{\mathrm{e}}\left(\mathrm{cm}^{4}\right)$ & 2534 & 2388 & 5,76 \\
\hline & $I_{e \text { (grafico) }}\left(\mathrm{cm}^{4}\right)$ & $\mathrm{x}$ & $\mathrm{X}$ & $\mathrm{x}$ \\
\hline & Ecs & 29 & 32 & $-10,34$ \\
\hline & ES & 211,7 & 210 & 0,80 \\
\hline \multirow{5}{*}{ 旌 } & $\mathrm{I}_{\mathrm{II}}\left(\mathrm{cm}^{4}\right)$ & 1533 & 1618 & $-5,54$ \\
\hline & $\mathrm{I}_{\mathrm{e}}\left(\mathrm{cm}^{4}\right)$ & 2367 & 2439 & $-3,04$ \\
\hline & $\mathrm{I}_{\mathrm{e} \text { (grafico) }}\left(\mathrm{cm}^{4}\right)$ & $\mathrm{x}$ & $\mathrm{X}$ & $\mathrm{x}$ \\
\hline & Ecs & 28 & 30 & $-7,14$ \\
\hline & ES & 211,7 & 210 & 0,80 \\
\hline \multirow{5}{*}{ 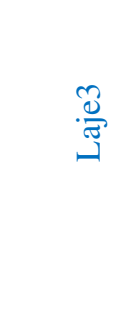 } & $\mathrm{I}_{\mathrm{II}}\left(\mathrm{cm}^{4}\right)$ & 1956 & 1634 & 16,46 \\
\hline & $\mathrm{I}_{\mathrm{e}}\left(\mathrm{cm}^{4}\right)$ & 3142 & 2892 & 7,96 \\
\hline & $\mathrm{I}_{\mathrm{e} \text { (grafico) }}\left(\mathrm{cm}^{4}\right)$ & 2711 & 2892 & $-6,68$ \\
\hline & Ecs & 27 & 30 & $-11,11$ \\
\hline & ES & 211,7 & 210 & 0,80 \\
\hline
\end{tabular}

*em azul a laje que não foi submetida a ensaio dinâmico 
Como é possível observar os valores calculados quando comparado com os valores reais da peça apresentam uma pequena dispersão nos resultados. O único parâmetro que apresenta uma maior dispersão é a inércia do estádio II com a contribuição entre fissuras. Apesar que a variação só é grande para as peças com baixa taxa de armadura $\left(2 \mathrm{~cm}^{2}\right)$, porque o momento de fissuração e a carga de ruptura são muito próximas, prejudicando assim a validade da equação de Branson.

\subsubsection{Análise comparativa dos ensaios estáticos}

A seguir serão apresentados os resultados das lajes separados por grupos com o objetivo de analisar o desempenho das lajes antes e após os ensaios dinâmicos.

Como todas as lajes do subgrupo 1B foram ensaiadas dinamicamente , este subgrupo não fará parte destas análises.

Para que fosse feita uma analise numérica foi escolhido um ponto do gráfico para ser realizada esta análise. Para a escolha do ponto foi fixado um valor de carregamento e analisada as deformações correspondentes ao nível de carga. O Valor do carregamento escolhido foi um ponto acima da carga frequente e abaixo da carga de ruptura.

a) Subgrupo $1 \mathrm{~A}$ :

Na figura 71 está apresentado o gráfico tensão deformação do ensaio realizado nas lajes do subgrupo $1 \mathrm{~A}$, a laje 2 deste subgrupo não fará parte das comparações uma vez apenas um extensomêtro estava aferindo as deformações, e com resultados um pouco exagerados. 


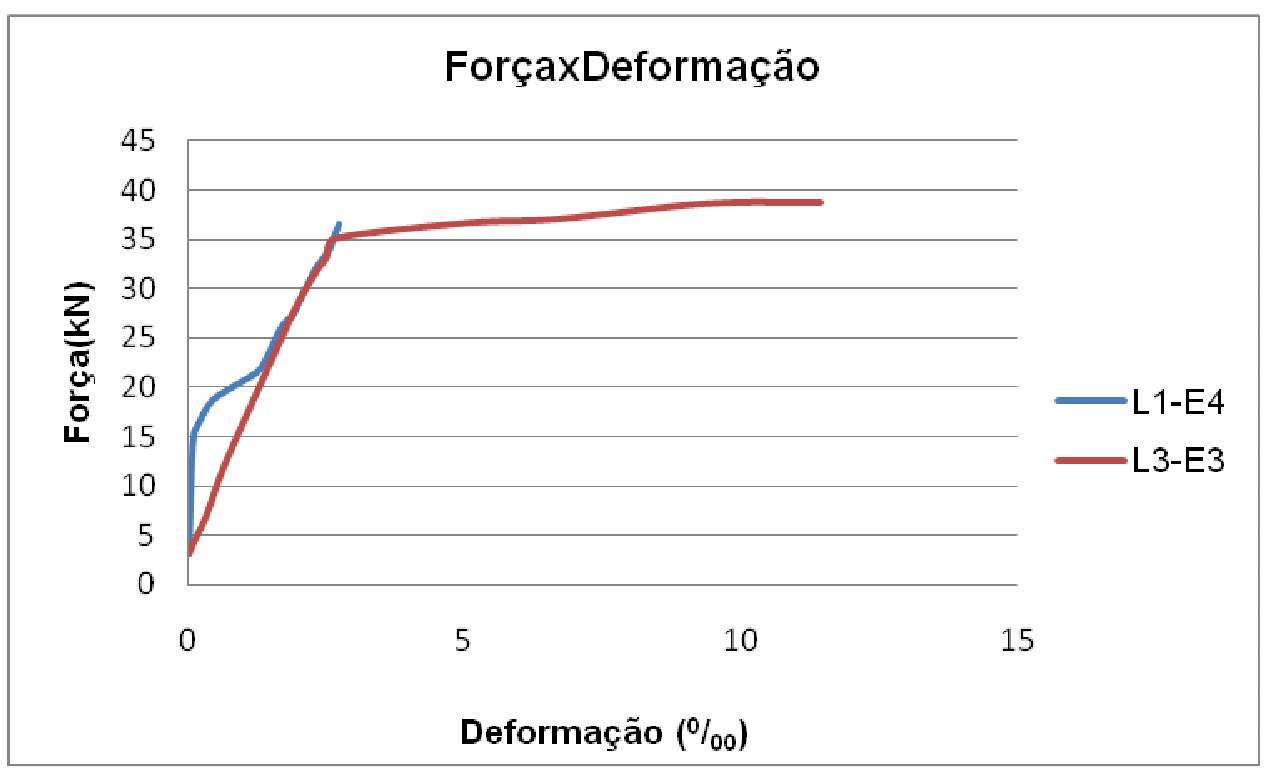

Figura 71 - gráfico do ensaio de ruptura das lajes 1 e 3

Como se pode observas nos gráficos a laje que não sofreu fadiga apresenta um comportamento mais rígido, isto é, para o mesmo nível de carregamento ela apresenta menores deformações que as lajes que foram ensaiadas a fadiga.

Para o carregamento de $26 \mathrm{KN}$ observou-se que a laje 1 apresentou deformação de $1,65 \%$ enquanto a laje $1,77 \%$, o que corresponde a deformações $7 \%$ menores na laje que não foi fadigada quando comparada a laje que sofreu fadiga.

b) Subgrupo $2 \mathrm{~A}$ :

Na figura 72 esta apresentado o gráfico tensão deformação do ensaio realizado nas lajes do subgrupo $2 \mathrm{~A}$.

A laje 1 deste subgrupo não esta apresentada abaixo, pois ela rompeu por fadiga durante o ensaio dinâmico. A laje 1 será analisada com mais detalhes posteriormente neste trabalho. 


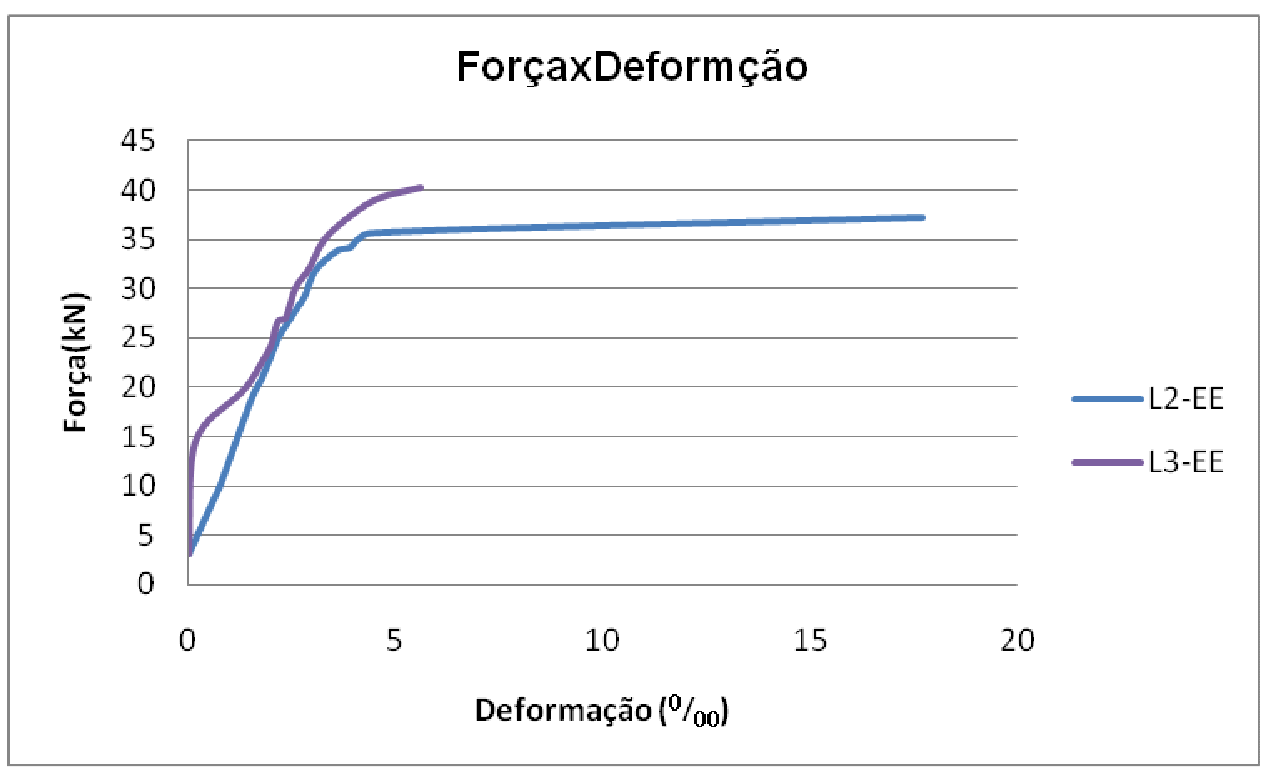

Figura 72 - Gráfico do ensaio de ruptura das lajes 2 e 3

Neste caso assim como no grupo 1A é possível perceber um comportamento semelhante das lajes ensaiadas a fadiga quando comparada com a laje que não foi solicitada ciclicamente.

Para a carga de $26 \mathrm{KN}$ houve um aumento de $11 \%$ nas deformações da laje ensaiada à fadiga com relação à laje que não foi submetida ao carregamento cíclico. Para as duas lajes foram utilizados os extensomêtros externos para a comparação. Para a força de $26 \mathrm{KN}$ os extensomêtros das lajes 2 e 3 mediam respectivamente deformações de $2,39 \%$ e $2,157 \%$. 
c) Subgrupo $3 \mathrm{~A}$ :

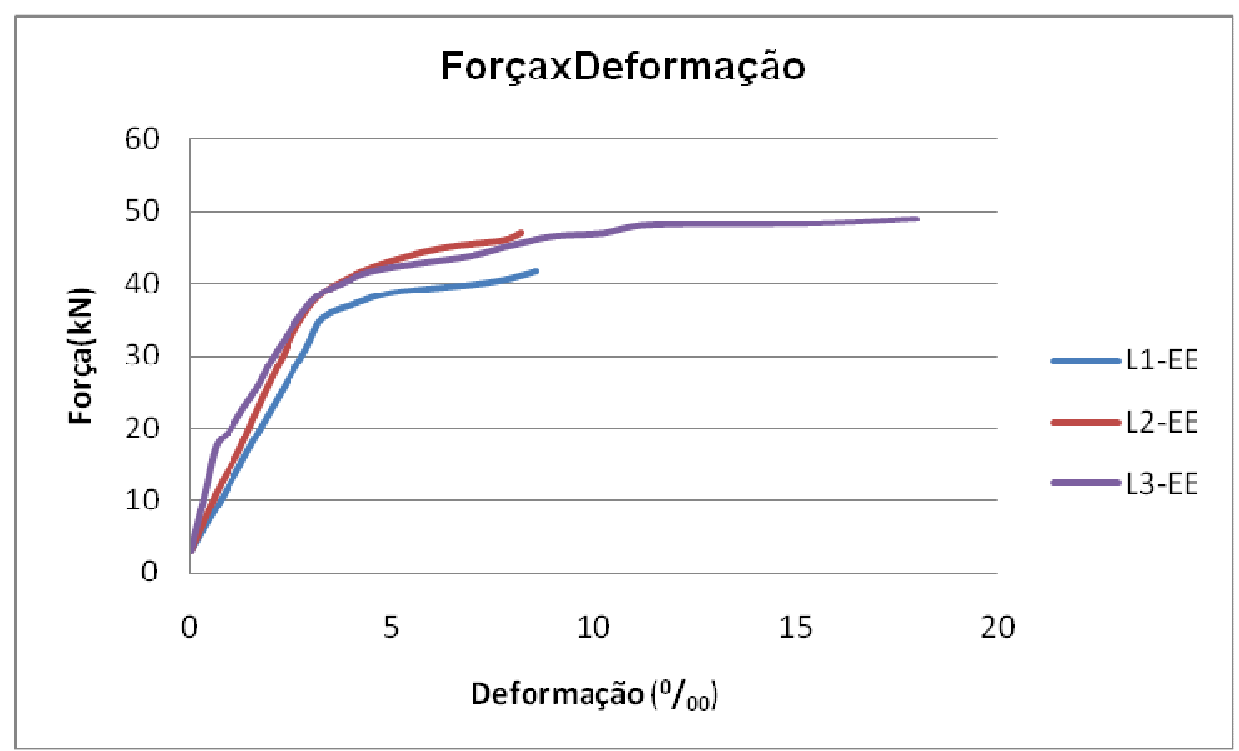

Figura 73 -Gráfico do ensaio de ruptura das lajes 1, 2 e 3

Neste caso, assim como nos subgrupos 1 A e 2 A é possível perceber o mesmo comportamento das lajes ensaiadas a fadiga quando comparada com a laje que não foi solicitada ciclicamente.

Quando comparada a laje $1 \mathrm{com}$ as a lajes 2 e 3, estas duas últimas foram ensaiadas a fadiga, para uma carga de $26 \mathrm{KN}$ houve um aumento de aproximadamente $15 \%$ em relação a laje 2 e $40 \%$ em relação a laje 3 nas deformações. Os extensomêtros das lajes 1,2 e 3 mediam para a força de $26 \mathrm{KN}$ respectivamente $1,65 \%$, 1,90\% $\%$ $2,32 \%$.

O valor obtido para laje 1 acredita-se ser exagerado, comparando-se com os obtidos para as outras lajes, e ainda no ensaio de ruptura da laje 1 apenas um extensomêtro estava funcionando, impedindo uma aferição das deformações mais precisa. 
d) Subgrupo 3B :

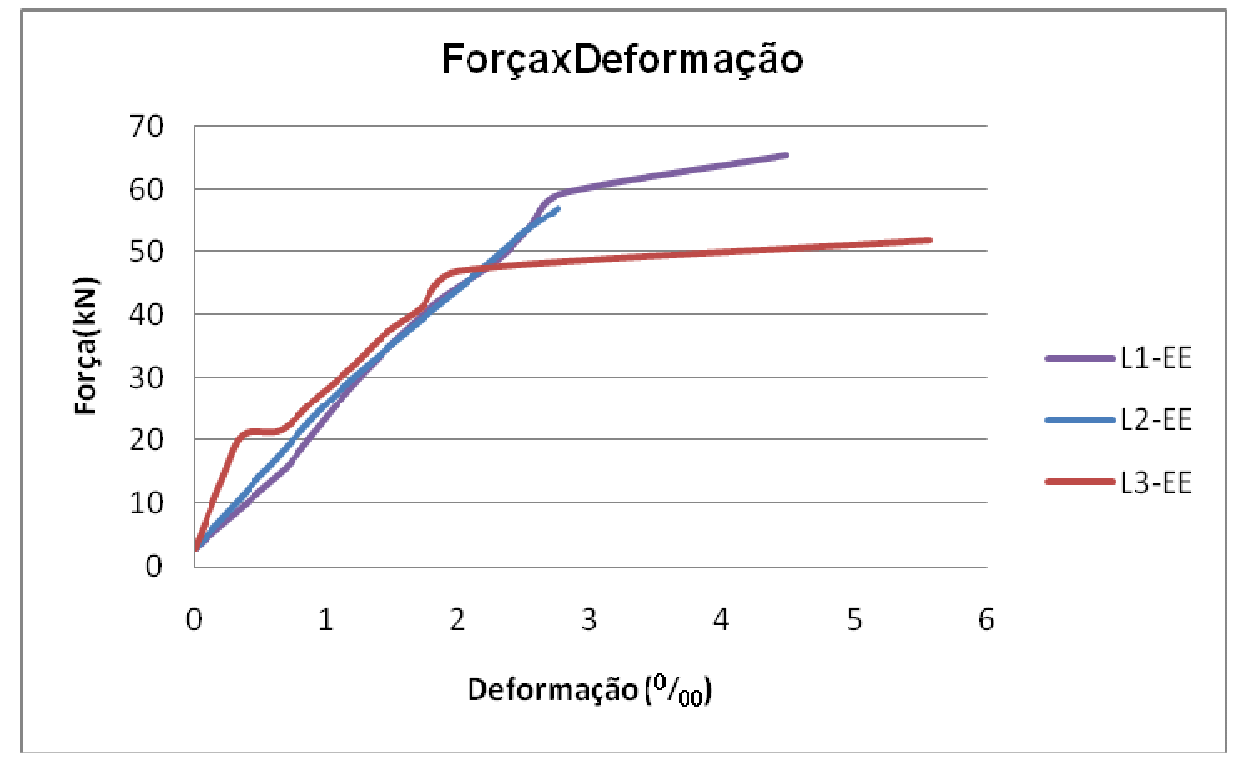

Figura 74 - Gráfico do ensaio de ruptura das lajes 1,2 e 3

Neste caso assim como no grupo 3A é possível perceber um comportamento semelhante das lajes ensaiadas à fadiga quando comparada com a laje que não foi solicitada ciclicamente.

Neste caso houve para a carga de $43 \mathrm{KN}$ houve um aumento médio de $25 \%$ nas deformações das lajes ensaiadas a fadiga com relação à laje que não foi submetida ao carregamento cíclico. As deformações medidas pelos extensômetros externos das lajes 1,2 e 3 eram respectivamente $1,51 \%, 1, .90 \%$ e $1,87 \%$.

4.2.2.3 Análise comparativa do desempenho das lajes armadas com barras isoladas com as de telas soldadas

A seguir serão apresentados os resultados das lajes com o objetivo de analisar o desempenho das lajes armadas com barras e telas soldadas. $\mathrm{Na}$ análise a seguir serão comparadas tanto as lajes com pré-laje quanto as executadas em etapa única, uma vez que de acordo com a pesquisa da aluna Edielce Caixeta a existência ou não da pré-laje não afeta a capacidade resistente das lajes.

Para os casos estudados a seguir a escolha do ponto para a análise numérica foi adotado o mesmo critério do item anterior.

a) Subgrupos $1 \mathrm{~A} 2 \mathrm{~A}$ e $3 \mathrm{~A}$ :

As lajes analisadas neste item foram as lajes dos armadas com $2 \mathrm{~cm}^{2}$ tanto em barras quanto em telas, submetidas apenas ao ensaio estático. 


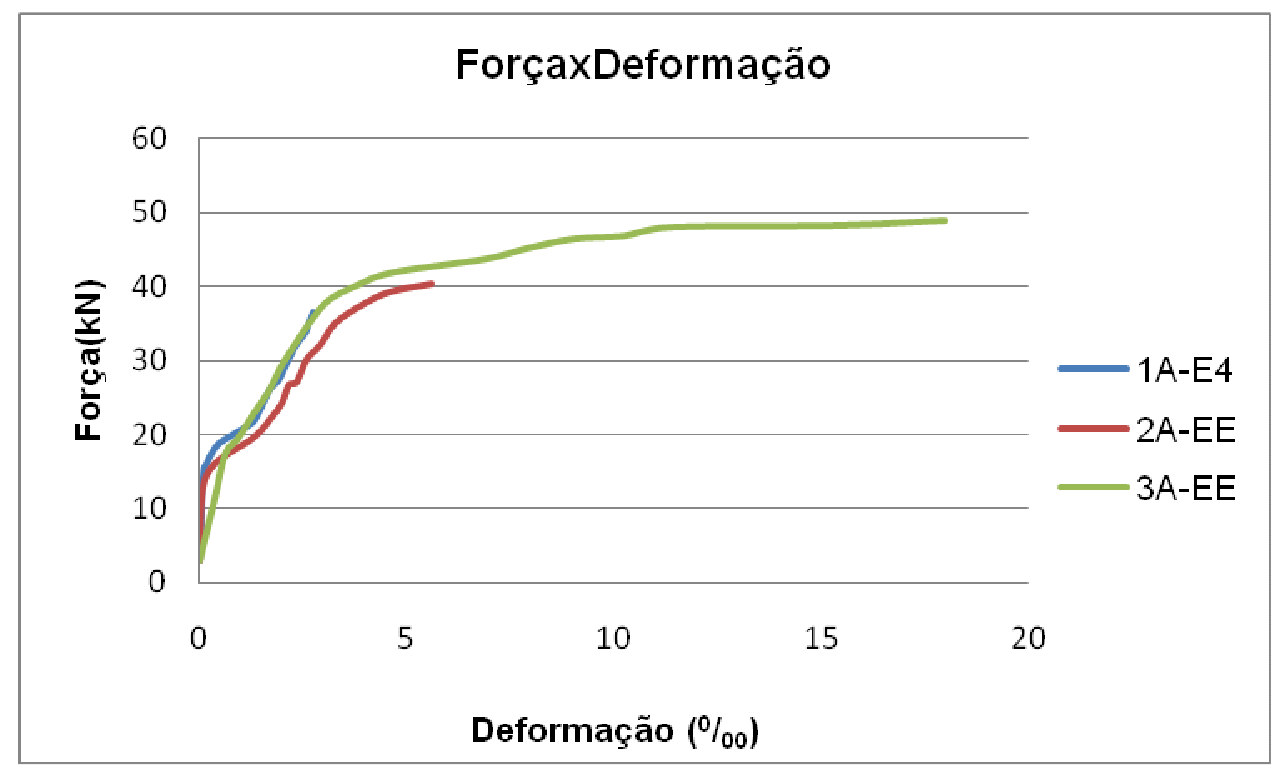

Figura 75 - Gráfico do ensaio de ruptura das peças não fadigadas

Como se pode perceber tanto através do gráfico da figura 90 o comportamento apresentado pelas lajes foi semelhante, o que mostra que quando submetidas apenas a um carregamento estático, não existem diferenças consideráveis na capacidade resistente entre lajes armadas com barras isoladas e telas soldadas.

O resultado deste ensaio é compatível com o comportamento obtido nos ensaios de tração de barras realizados na Dartec e apresentados no item 3.9.2 deste trabalho, uma vez que as forças de ruptura nos ensaios de tração foram semelhantes tanto para as barras quanto para as telas. Apesar de valores próximos, as barras apresentaram resultados ligeiramente melhores que as telas nos ensaios estáticos.

b) Subgrupos $1 \mathrm{~A} 2 \mathrm{~A}$ e $3 \mathrm{~A}$ :

As lajes analisadas neste item foram as lajes dos armadas com $2 \mathrm{~cm}^{2}$ tanto em barras quanto em telas, submetidas ao ensaio estático, após a realização do ensaio de fadiga. 


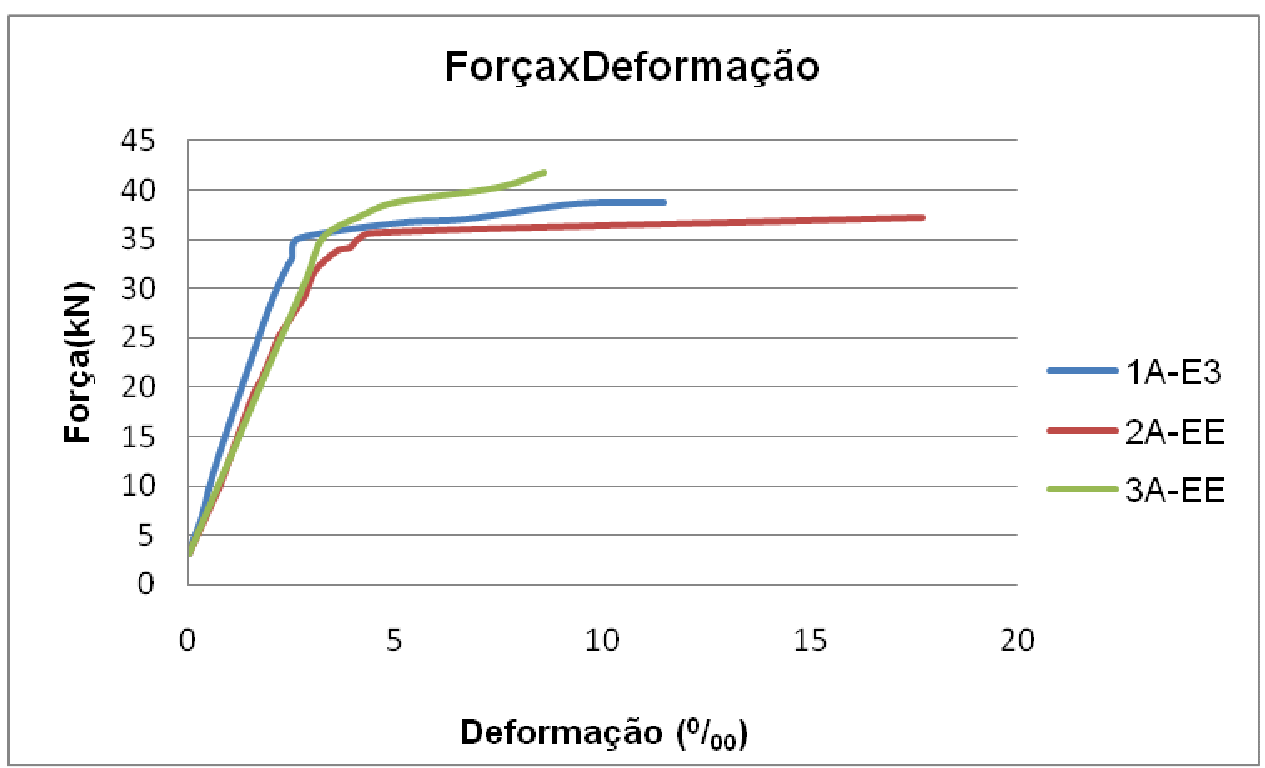

Figura 76 - Gráfico do ensaio de ruptura das peças fadigadas

Como se pode perceber através do gráfico as lajes com barras isoladas apresentaram um comportamento mais rígido que as telas, isto é para um mesmo nível de carregamento as lajes armadas com barras apresentam deformações menores do que as armadas com telas soldadas.

As lajes utilizadas para esta comparação foram no grupo $1 \mathrm{~A}$ foi utilizada a laje 1 , uma vez que a laje 2 os extensômetros não estava fazendo mais aferições, confiáveis das deformações. Para o grupo 2 A só se tinha a laje 2 , uma vez que a laje 1 foi perdida por fadiga. Por fim no grupo 3 A a laje utilizada foi a laje 2 , uma vez que como mencionado anteriormente a laje 1 teve um comportamento um pouco exagerado e ainda possuía apenas 1 extensomêtro fazendo leituras.

c) Subgrupos $1 \mathrm{~B}$ e $3 \mathrm{~B}$ :

As lajes analisadas neste item foram as lajes armadas com $4 \mathrm{~cm}^{2}$ tanto em barras quanto em telas, submetidas ao ensaio estático, após a realização do ensaio de fadiga. 


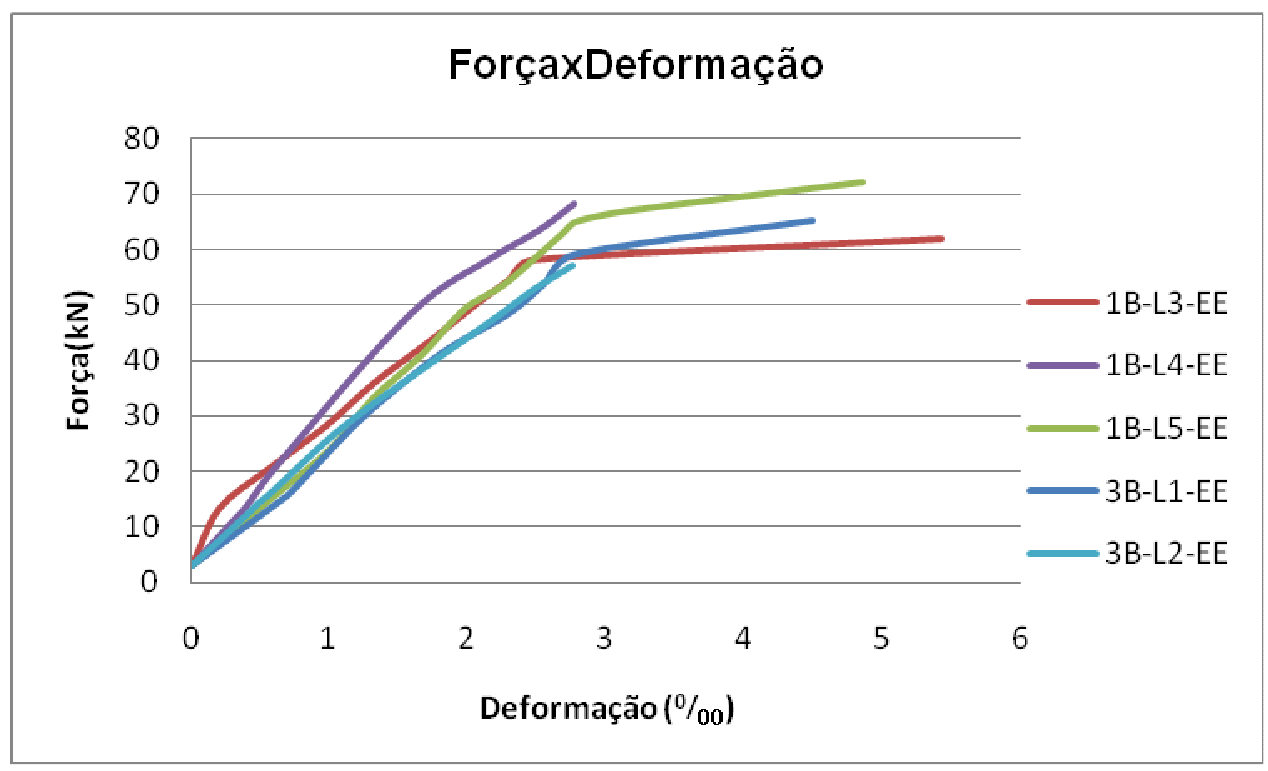

Figura 77 - Gráfico do ensaio ruptura das peças após o ensaio dinâmico

De acordo com o gráfico da figura 77 é possível perceber um comportamento semelhante ao que ocorreu nas lajes do item anterior.

Através dos resultados apresentados neste item é possível concluir que mesmo tendo sido aplicado uma flutuação de tensão $64 \%$ maior nas lajes armadas com barras isoladas. Através dos gráficos é possível perceber um desempenho um pouco melhor das barras em relação às telas. Então é possível afirmar que as lajes armadas telas soldadas tiverem uma dano maior pela fadiga que as lajes armadas com barras isoladas.

Contudo apesar dos danos causados pelos ensaios dinâmicos, quando realizados os ensaios de ruptura estática, tanto as lajes armadas com barras isoladas quanto às armadas com telas soldadas, apresentaram um desempenho superior ao previsto pela NBR6118, mostrando que a norma esta do lado seguro, tanto em relação às telas quanto em relação às barras isoladas.

\subsubsection{Ensaios dinâmicos}

A seguir vão ser descritos e analisados os ensaios dinâmicos realizados nas lajes que, para facilitar a compreensão e as análises, serão divididos de acordo com os subgrupos.

a) Subgrupo $1 \mathrm{~A}$ :

Para este subgrupo foram ensaiadas dinamicamente as lajes 2 e 3. A primeira etapa do ensaio foi a fissuração da laje com o intuito de garantir que a laje 
estivesse estádio II, durante o ensaio dinâmico. Condição que acontece nas lajes de pontes quando em serviço.

O valor da flutuação de tensão aplicada foi calculada de acordo com o item 3.6.2 deste trabalho, o carregamento dinâmico aplicado foi calculado com o objetivo de simular o projeto de uma ponte, exigindo-se da peça a mesma segurança de uma ponte no ELU de fadiga. Assim, a partir da seção transversal da peça e sua armadura, introduzindo todos os fatores parciais de segurança das normas NBR-6118 e 9187, foi calculada a máxima carga característica aplicável à peça, além do seu peso próprio. Conforme recomenda a NBR9187, a carga a utilizar na verificação da fadiga deve ser $80 \%$ dessa carga característica.

Contudo no nosso estudo a verificação da fadiga da armadura foi desprezada, uma vez que a variação de tensão calculada para a combinação freqüente foi de $222 \mathrm{MPa}$ que é superior aos $190 \mathrm{MPa}$ sugeridos como limite pela NBR-61182003.

A seguir serão apresentados gráficos de algumas etapas do ensaio da laje 2. Ao contrário da laje 3 , no inicio do ensaio de fadiga, a laje 2 possuía todos os extensômetros funcionando, por este motivo os gráficos apresentados a seguir dizem respeito ao comportamento da laje 2 . Contudo é importante salientar que as duas lajes tiveram desempenho semelhante. 


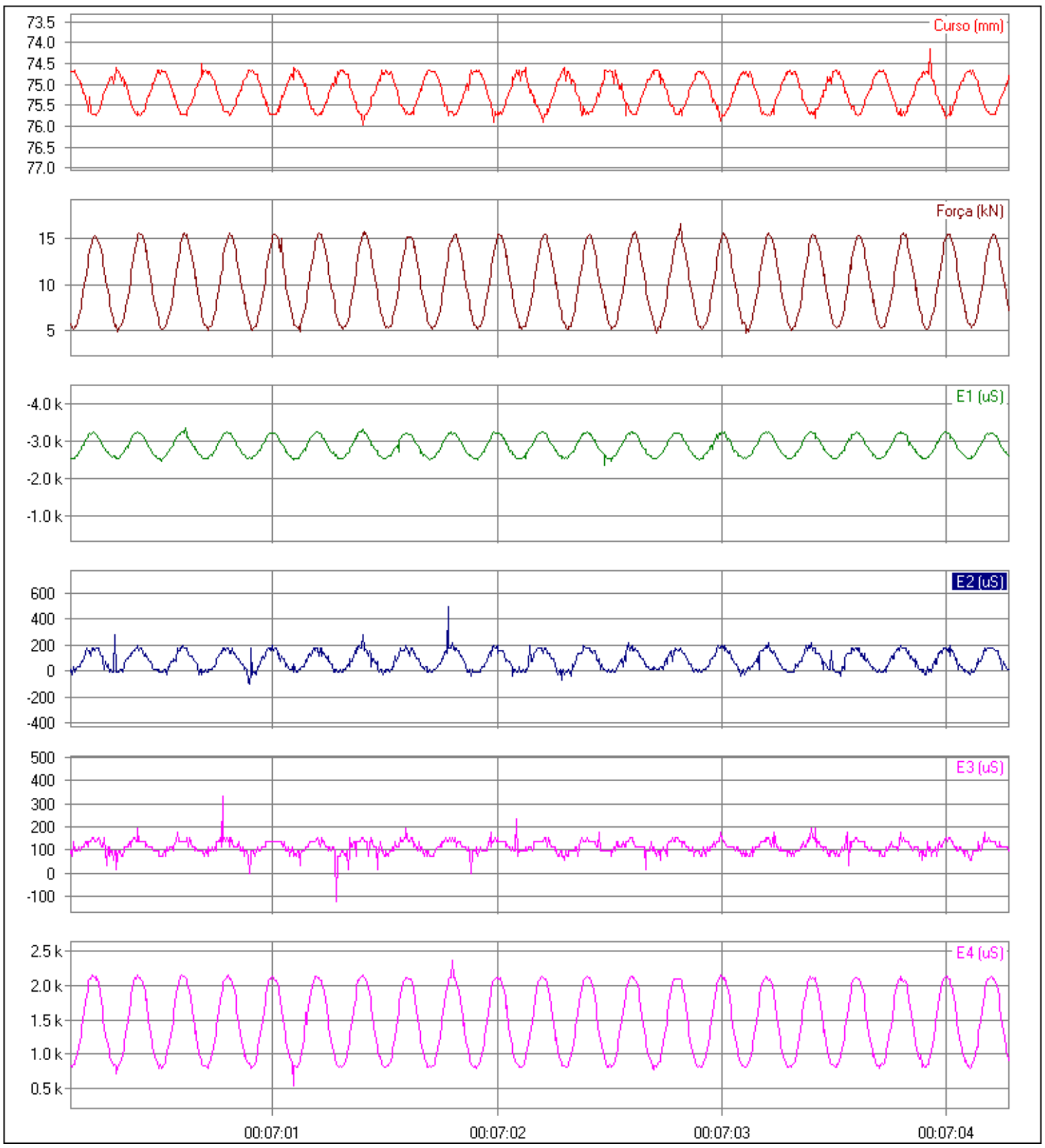

Figura 78 - Comportamento da laje 2 durante os momentos iniciais do ensaio dinâmico 


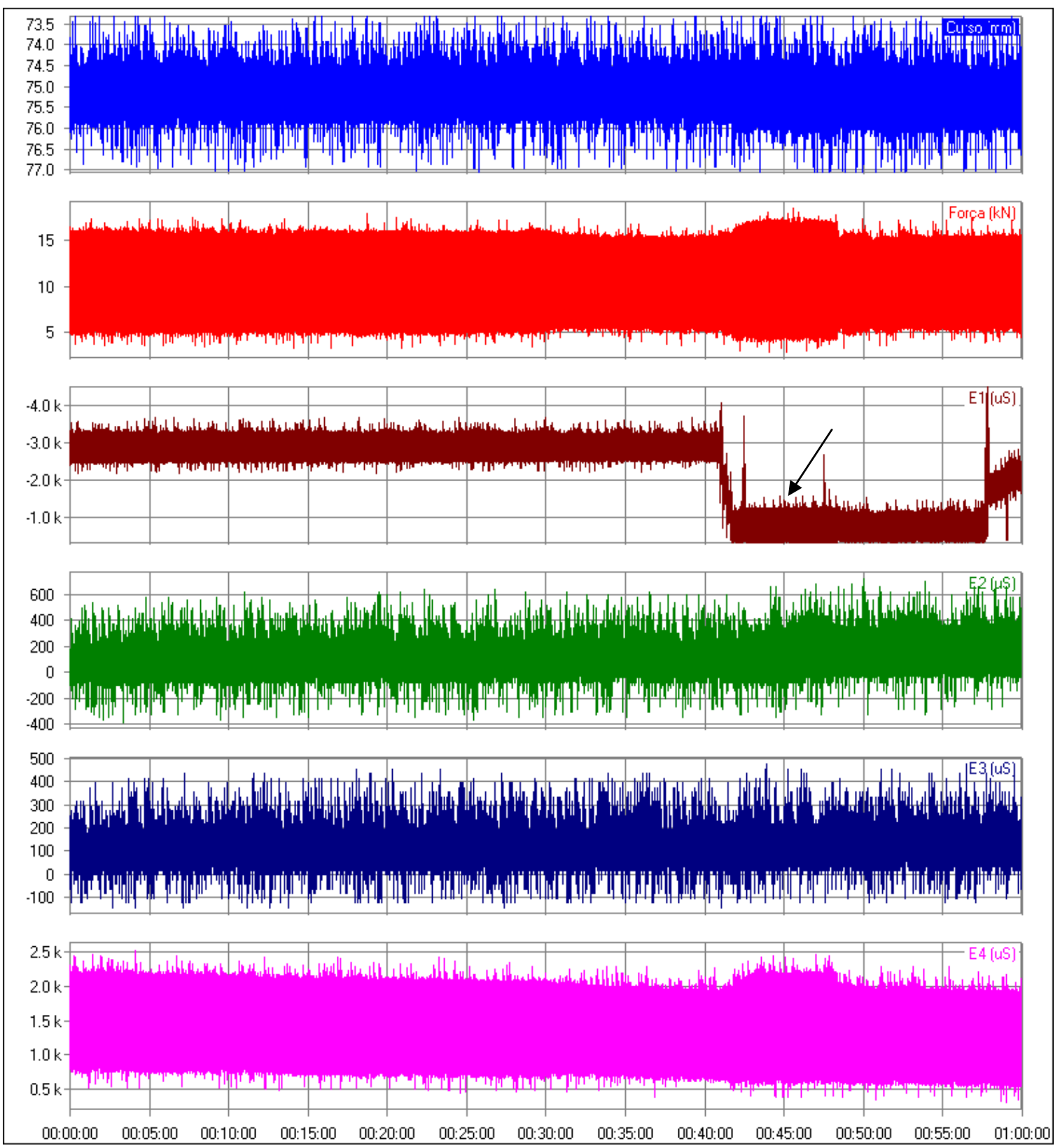

Figura 79 - Comportamento da laje 2 durante a primeira hora do ensaio dinâmico

O gráfico da figura 79 apresentado acima ilustra o comportamento da peça durante a primeira hora de ensaio. Através do gráfico é possível perceber o momento que o E1 deixou de fazer a leitura das deformações. 


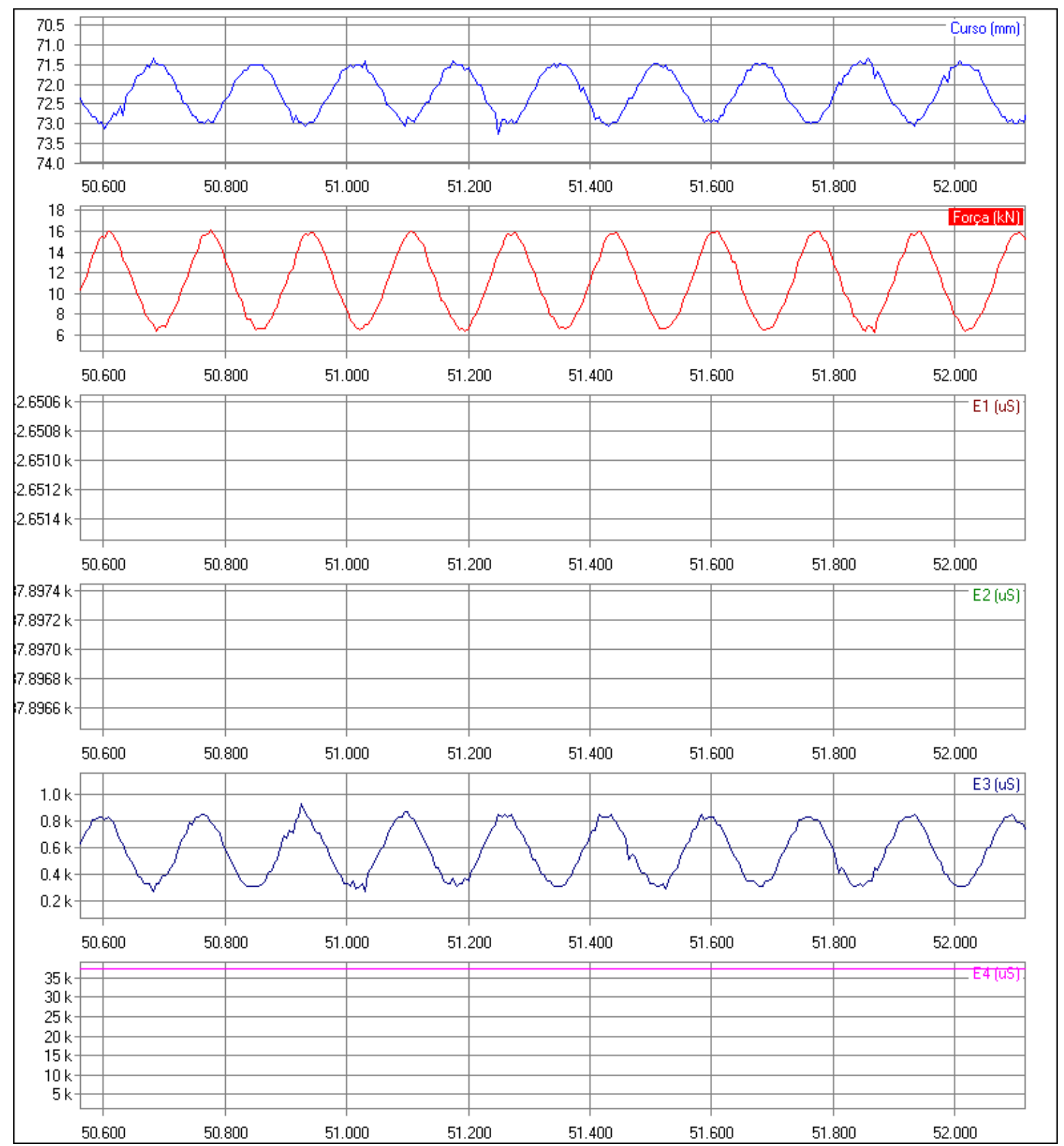

Figura 80 - Comportamento da laje 2 durante a última hora do ensaio dinâmico

Durante o ensaio foi percebido que o pórtico estava vibrando bastante, para evitar este problema foram aumentadas as forças mínima e máxima do ensaio com o objetivo de enrijecer o pórtico, diminuindo assim as vibrações. Como o fator determinante da fadiga é a variação de tensão este aumento não causa nenhuma alteração nos resultados do ensaio.

Nos gráficos das figuras 79 e 80 pode-se ver o comportamento da laje nos momentos iniciais e finais do ensaio respectivamente. Abaixo temos os cálculos para se saber a flutuação de tensão aplicada as barras tanto no início quanto no final do ensaio. 
Início do ensaio

$$
\Delta \sigma=E \varepsilon=198,80 \times(0,001617-0,000390)=244 M P a
$$

Final do ensaio

$$
\Delta \sigma=E \varepsilon=198,80 \times(0,001369-0,000090)=254 M P a
$$

O módulo de elasticidade das barras isoladas foi obtido através dos ensaios de caracterização realizados e a variação das deformações através da leitura dos extensômetros.

Com cálculos feitos de forma análoga, as flutuações iniciais e finais aplicadas na laje 3 foram respectivamente $195 \mathrm{MPa}$ e $197 \mathrm{MPa}$. Vale salientar que para esta laje apenas o extensômetro 3 estava funcionando. Então é natural que se os outros extensômetros estivessem funcionando teriam sido medidos mais valores de deformações. Deste modo com mais valores de deformações provavelmente ficaria provado que a tensão de $222 \mathrm{MPa}$ desejada previamente, teria sido atingida .

\section{b) Subgrupo $2 \mathrm{~A}$}

Neste subgrupo vamos analisar a laje 1 separadamente, uma vez que esta foi a única laje da pesquisa que teve ruptura por fadiga.

Os corpos de prova deste subgrupo possuem as mesmas características do subgrupo $1 \mathrm{~A}$ a única diferença é que o subgrupo 2 A possui armação usando telas soldadas.

Inicialmente não se tinha parâmetros para analisar quão benéfico o concreto seria para o comportamento das telas à fadiga. Por este motivo foi mantida a flutuação de tensão que foi aplicada as lajes armadas com barras isoladas nas armadas com telas soldadas.

A norma recomenda para esta situação que a variação de tensão nas barras não ultrapasse $85 \mathrm{MPa}$, como já mencionado anteriormente. A flutuação aplicada nas barras desta laje foi de $222 \mathrm{Mpa}$.

O gráfico abaixo ilustra o comportamento da laje 1 nos momentos iniciais do ensaio. 


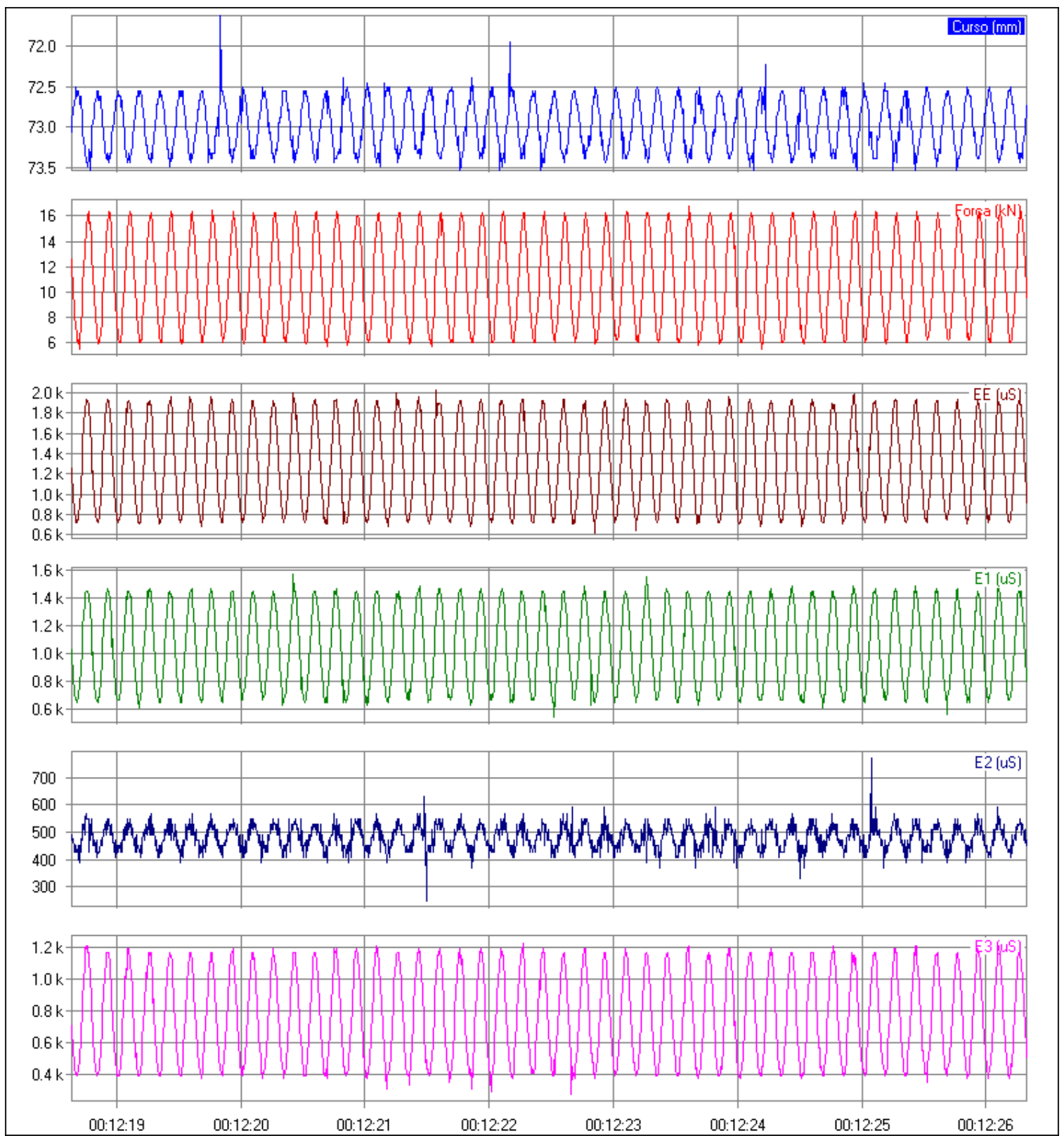

Figura 81 - Comportamento da laje 1 durante os primeiros momentos do ensaio dinâmico

A seguir serão apresentados os cálculos, para que seja possível conhecer a flutuação de tensão aplicada às barras neste momento do ensaio.

$$
\Delta \sigma=E \varepsilon=198800 \times(0,001882-0,000783)=218 \mathrm{MPa}
$$

O módulo de elasticidade das telas soldadas foi obtido através dos ensaios de caracterização realizados e a variação das deformações através da leitura dos extensômetros. 
O gráfico a abaixo mostra o comportamento do ensaio durante a primeira hora, na figura 82 é possível perceber que os 4 extensômetros já haviam perdido a capacidade de efetuar leituras antes do final da primeira hora de ensaio.

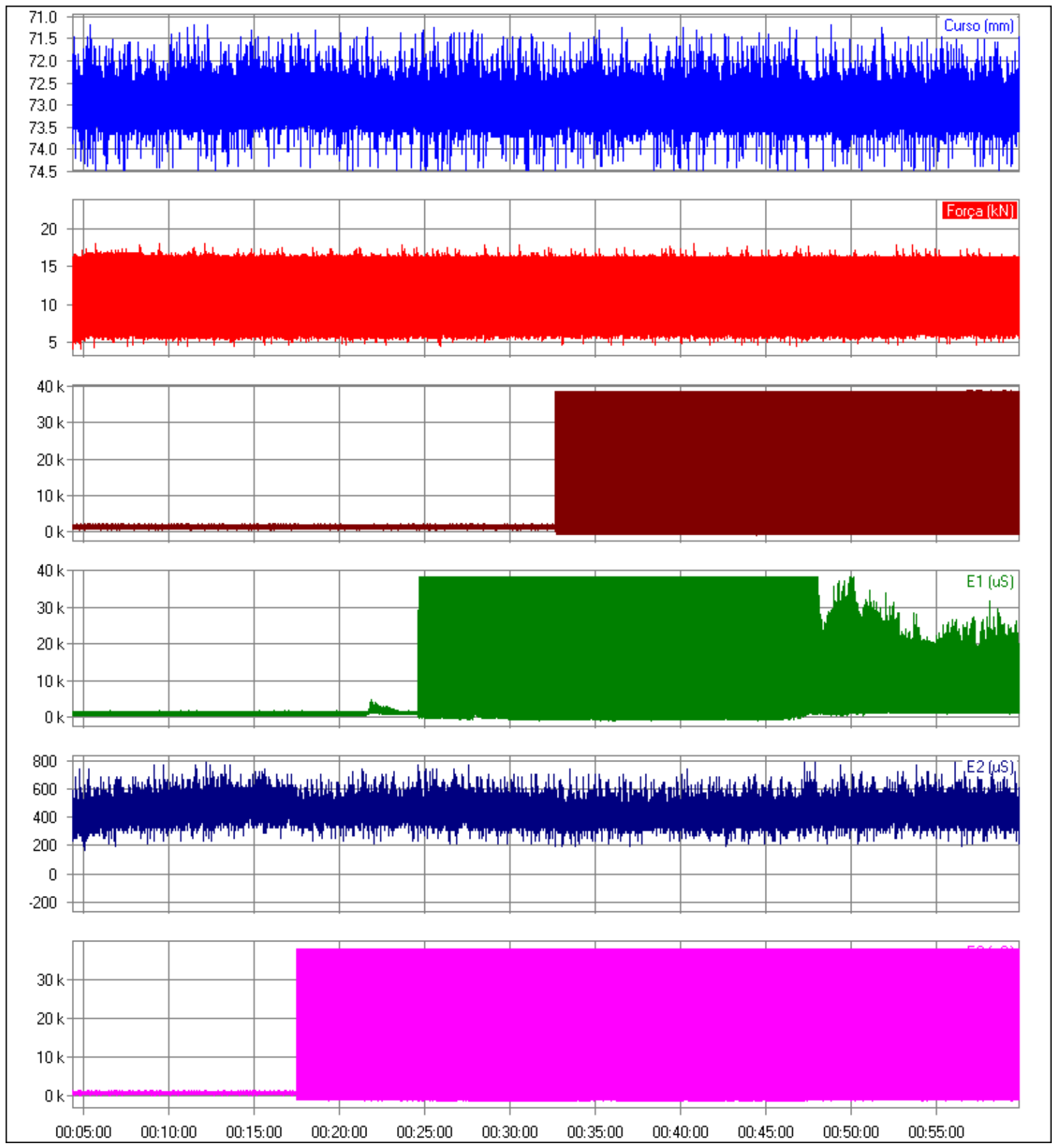

Figura 82 - Comportamento da laje 1 durante a primeira hora do ensaio dinâmico 

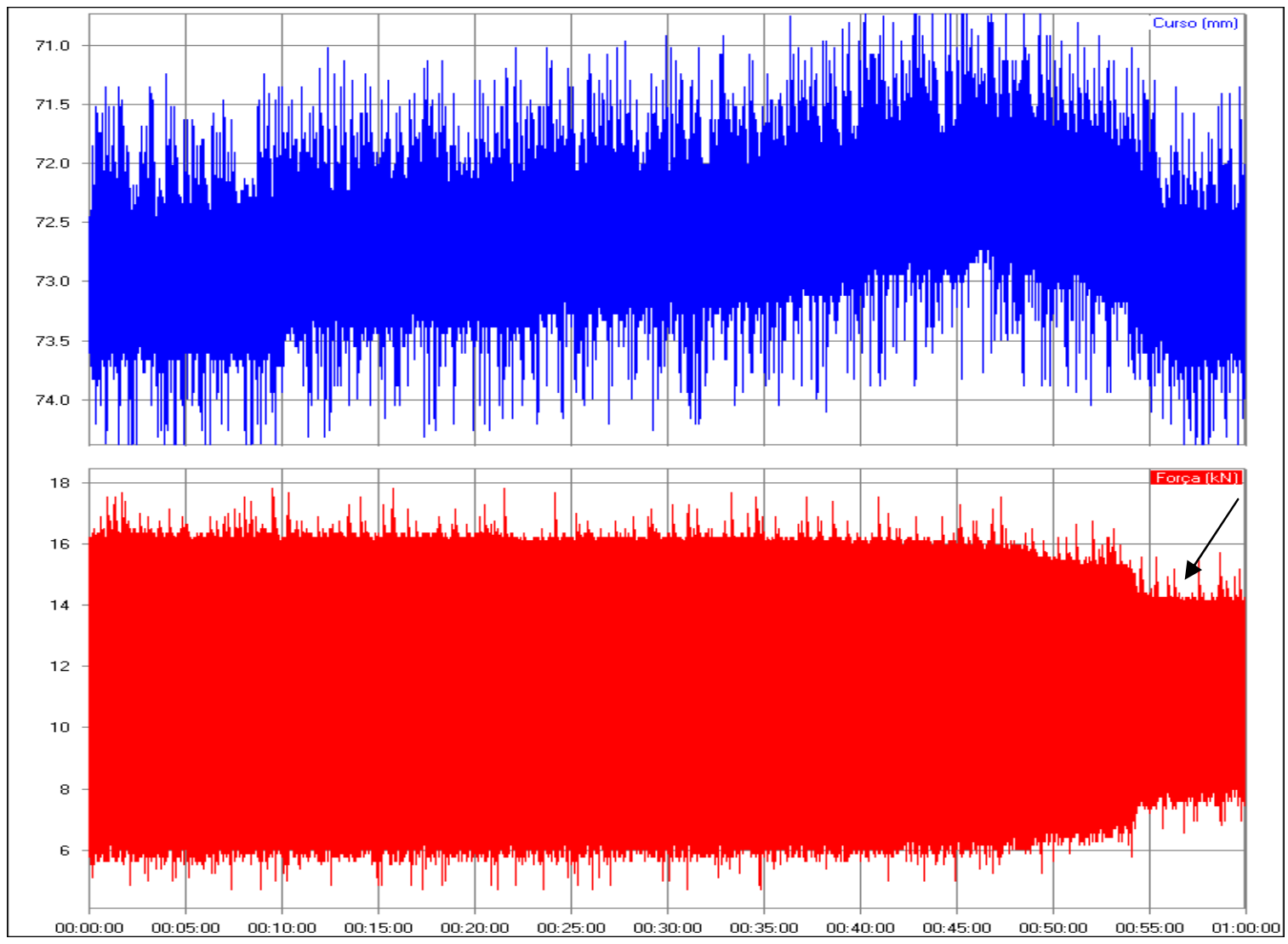

Figura 83 - Comportamento da laje 1 durante a segunda hora do ensaio dinâmico

O gráfico da figura 83 ilustra o comportamento do ensaio na $2^{\mathrm{a}}$ hora. Como se pode perceber, no final da segunda hora houve uma redução involuntária na flutuação do carregamento. Este fato pode ser caracterizado como um defeito do ensaio, uma vez que o ensaio dinâmico era realizado com controle de força. Então é natural que a variação das forças fosse mantida até o final do ensaio. 


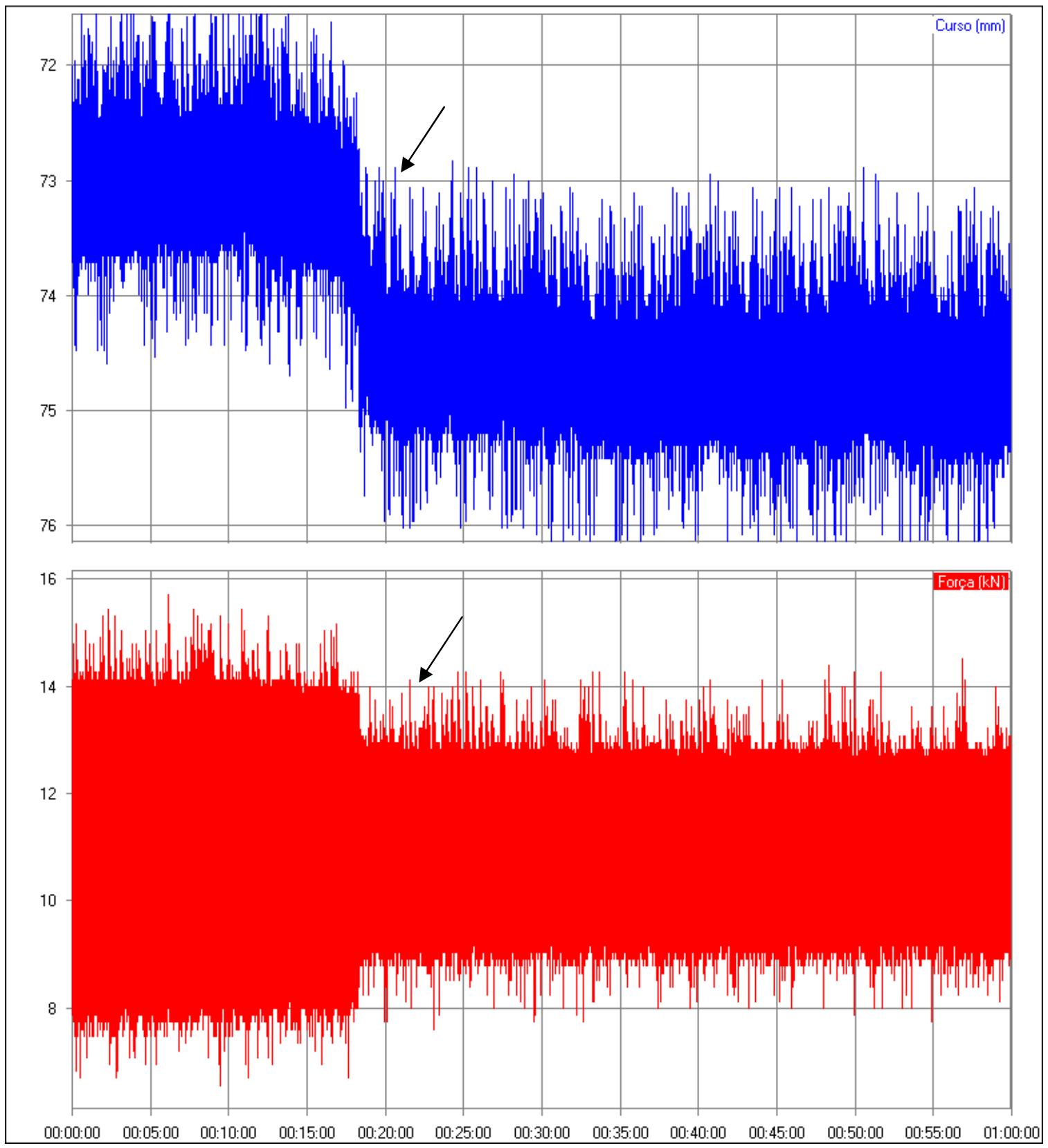

Figura 84 - Comportamento da laje 1 durante a terceira hora do ensaio dinâmico

No gráfico 84 no tempo entre 15 e 20 minutos de ensaio pode ser percebido um aumento do curso do ensaio. Por ser um ensaio de força controlada, isto quer dizer que por algum motivo a laje precisou de um curso maior para manter a variação de forças desejada. Isto se deve a perda de rigidez da laje, provavelmente ocasionada pela perda de uma da barras por fadiga.

Observe que a partir da ruptura da primeira barra mais uma vez houve uma redução da amplitude das forças aplicadas ao ensaio.

Acredita-se que este defeito seja uma conseqüência das flechas na laje estarem bem acima dos valores previstos nos cálculos, e por este motivo a bomba não foi capaz de atingir a vazão necessária para suprir o ensaio. 


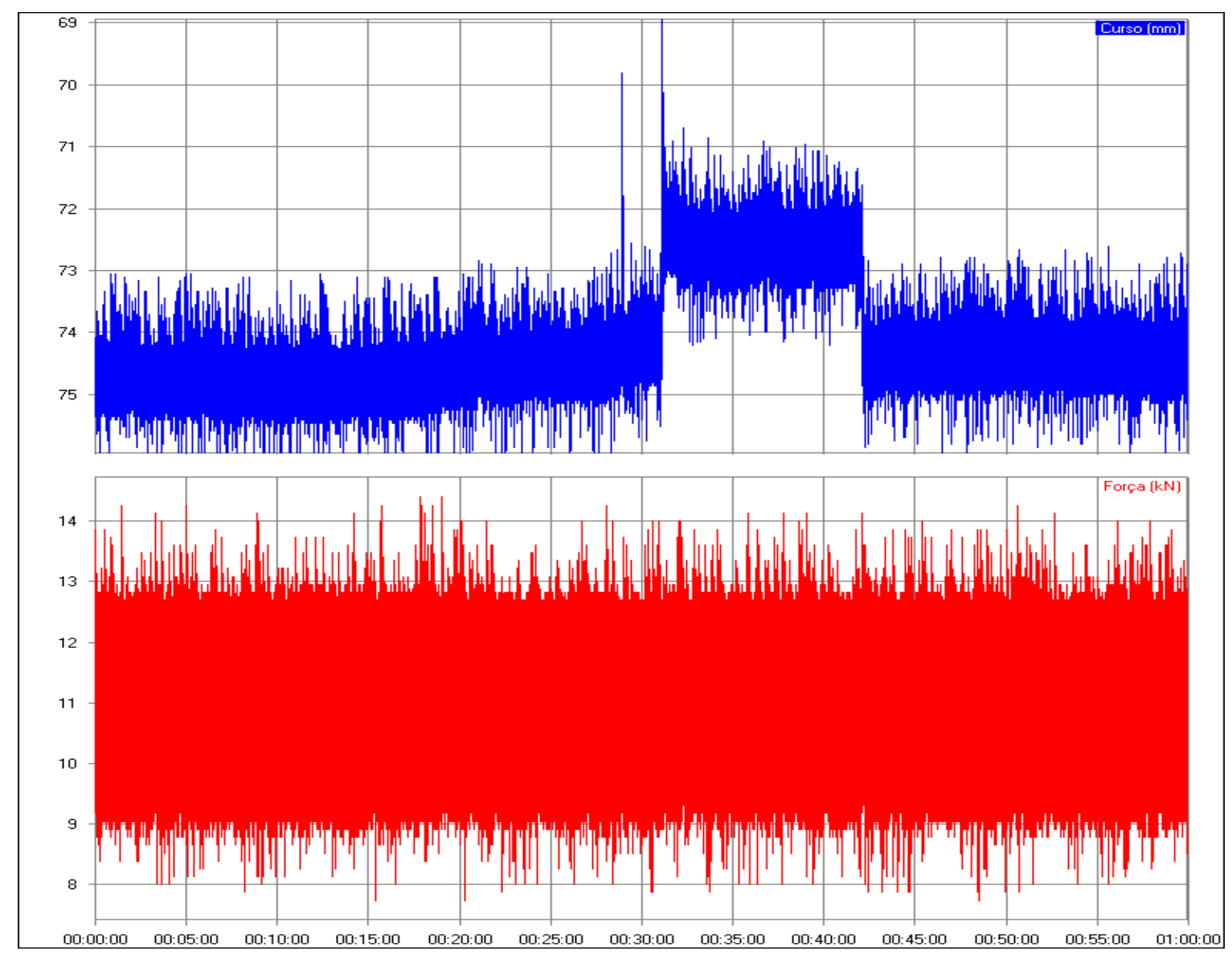

Figura 85 - Comportamento da laje 1 durante a quarta hora do ensaio dinâmico 


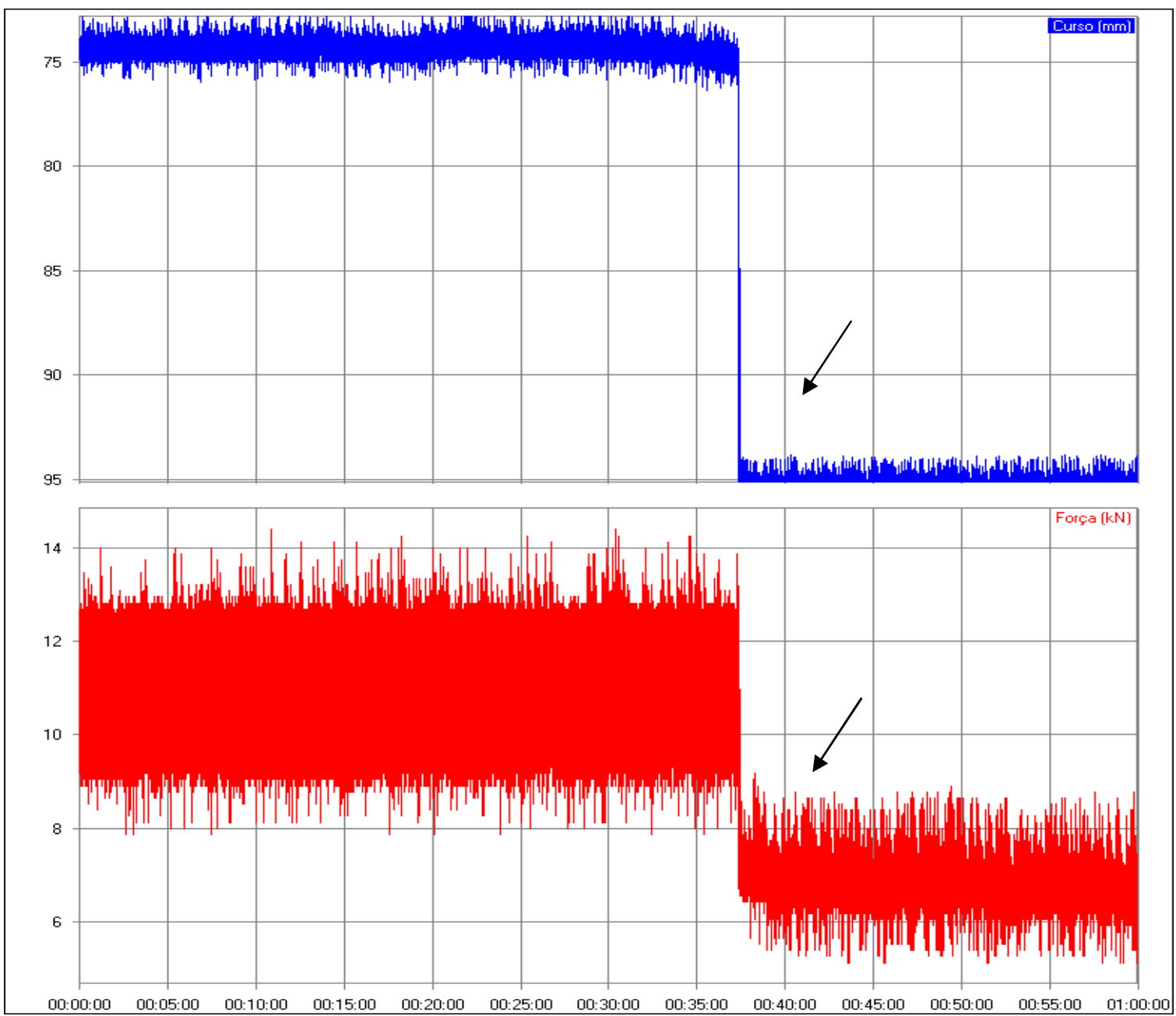

Figura 86 - Comportamento da laje 1 durante a quinta hora do ensaio dinâmico

Os gráficos 85 e 86 mostram respectivamente a quarta e quinta horas do ensaio. Como é possível perceber, na quarta hora o ensaio transcorreu normalmente.

Na quinta hora, com aproximadamente 97200 ciclos o ensaio teve seu fim com o rompimento das barras por fadiga. Como pode ser observado o atuador atingiu o curso máximo e não encontrava nenhuma reação da laje, como pode ser notado no gráfico força $\mathrm{x}$ tempo. A ruptura por fadiga foi confirmada também através de uma análise metalográfica, ilustrada no anexo A. 


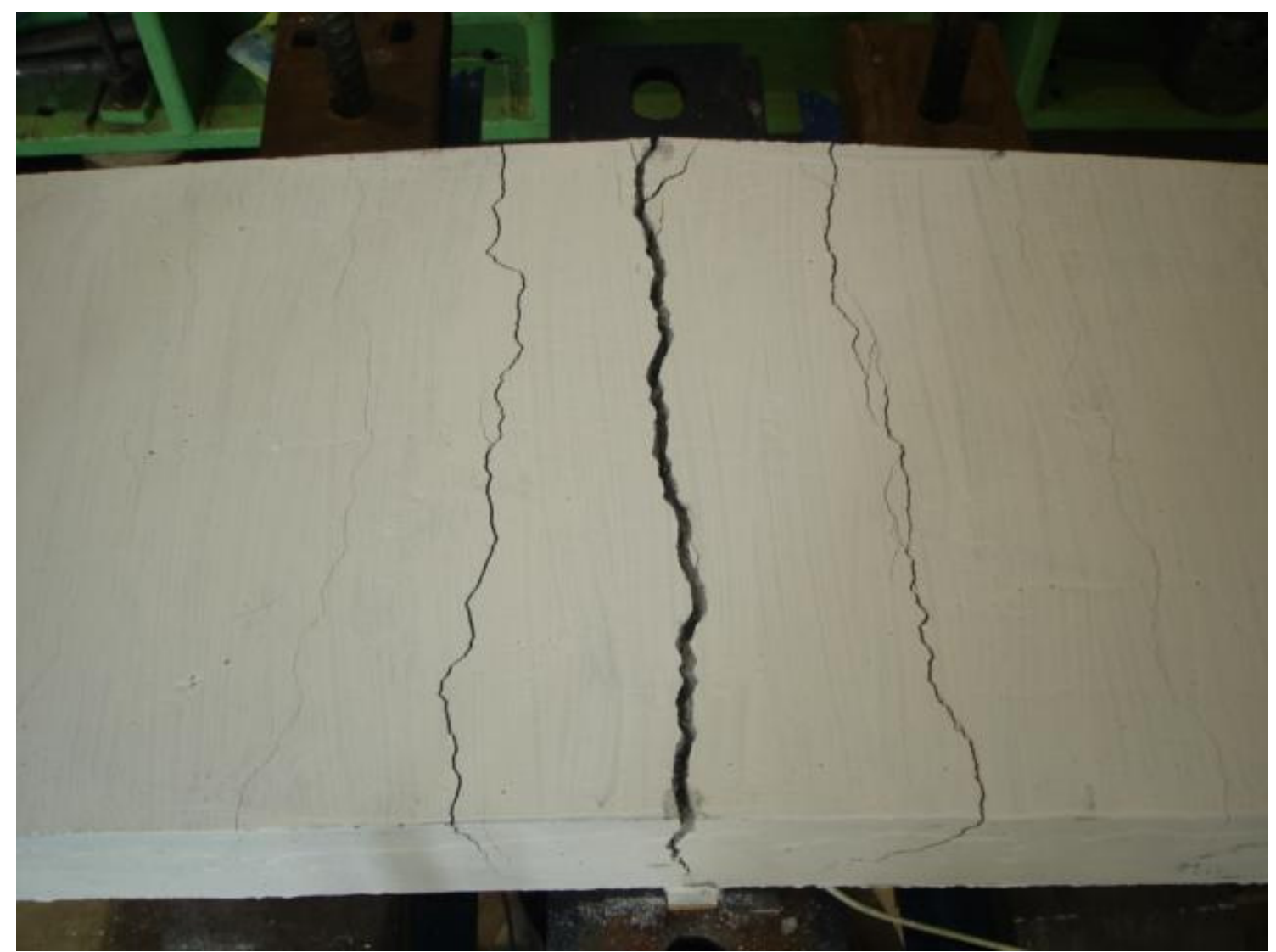

Figura 87 - ruptura por fadiga laje $12 \mathrm{~A}$

Devido a esta ruptura precoce da laje 1 , foi tomada a decisão de diminuir a flutuação de tensão para as lajes armadas com tela soldada, uma vez que uma nova ruptura com 100 mil ciclos não iria trazer nenhuma informação relevante . Então baseados nos ensaios de barra ao ar foi calculada uma flutuação de tensão para a qual a peça provavelmente suportaria os 2 milhões de ciclos desejados, a flutuação escolhida foi a de $135 \mathrm{MPa}$.

O defeito constatado neste ensaio apenas prolongou a vida útil da laje não afetando as conclusões a respeito do mesmo. Uma vez que ficou claro que para esta flutuação de tensão a laje teve uma ruptura com uma pequena quantidade de ciclos.

A monitoração dos ensaios de fadiga estava sendo feita aproximadamente a cada 10 horas, como o defeito aconteceu ao término da primeira hora e a laje rompeu na quinta hora. Não foi possível perceber o defeito a tempo de repará-lo. Uma vez que a solução para o defeito era simplesmente diminuir a frequência do ensaio, tão logo que fosse notada a diminuição na amplitude das forças.

A laje 2 faz parte do grupo de telas soldadas que foi utilizada a flutuação de 135 Mpa. Abaixo serão apresentados os gráficos referentes ao ensaio da laje 2. 


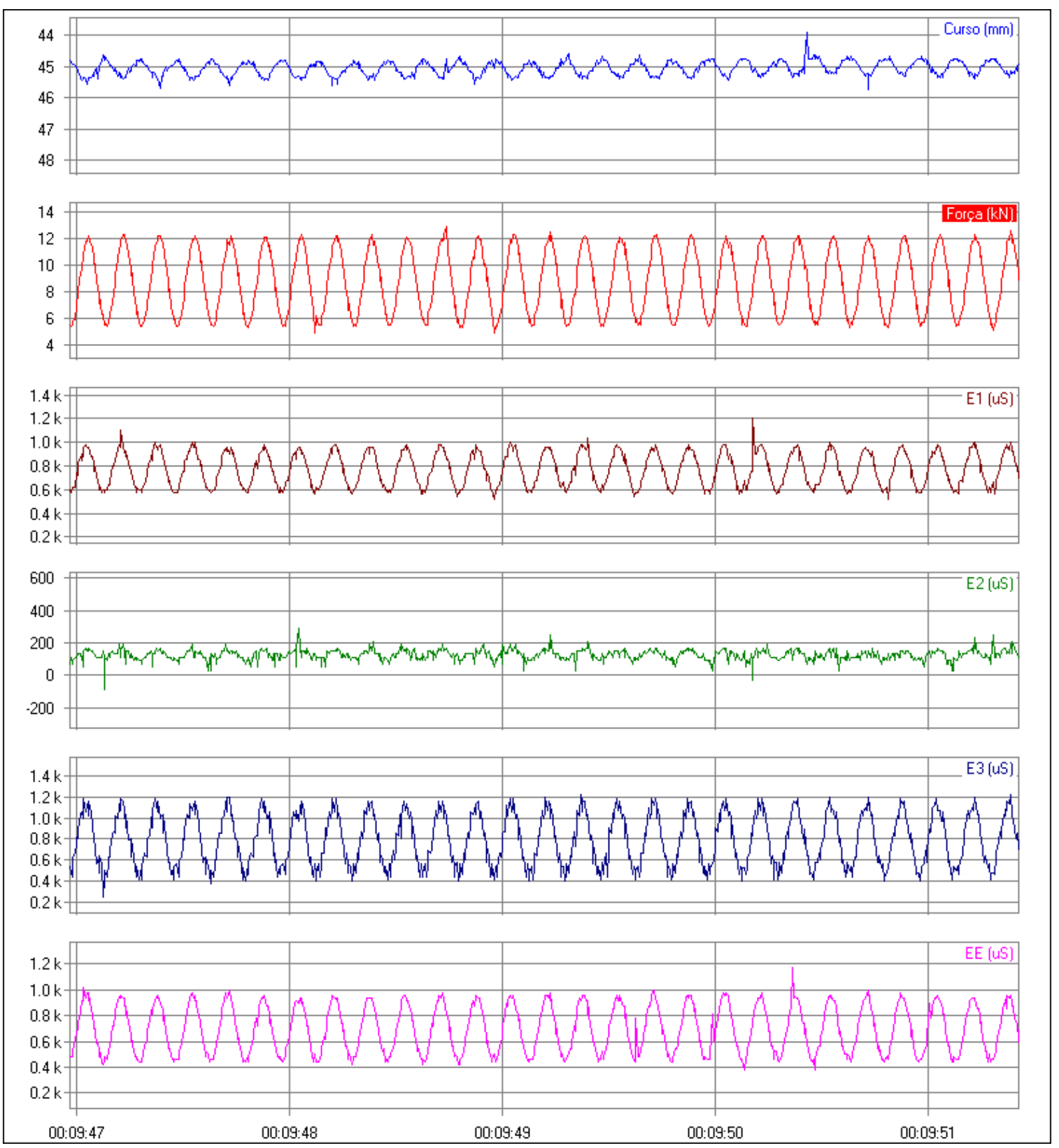

Figura 88 - Comportamento da laje 2 durante os primeiros instantes do ensaio dinâmico 


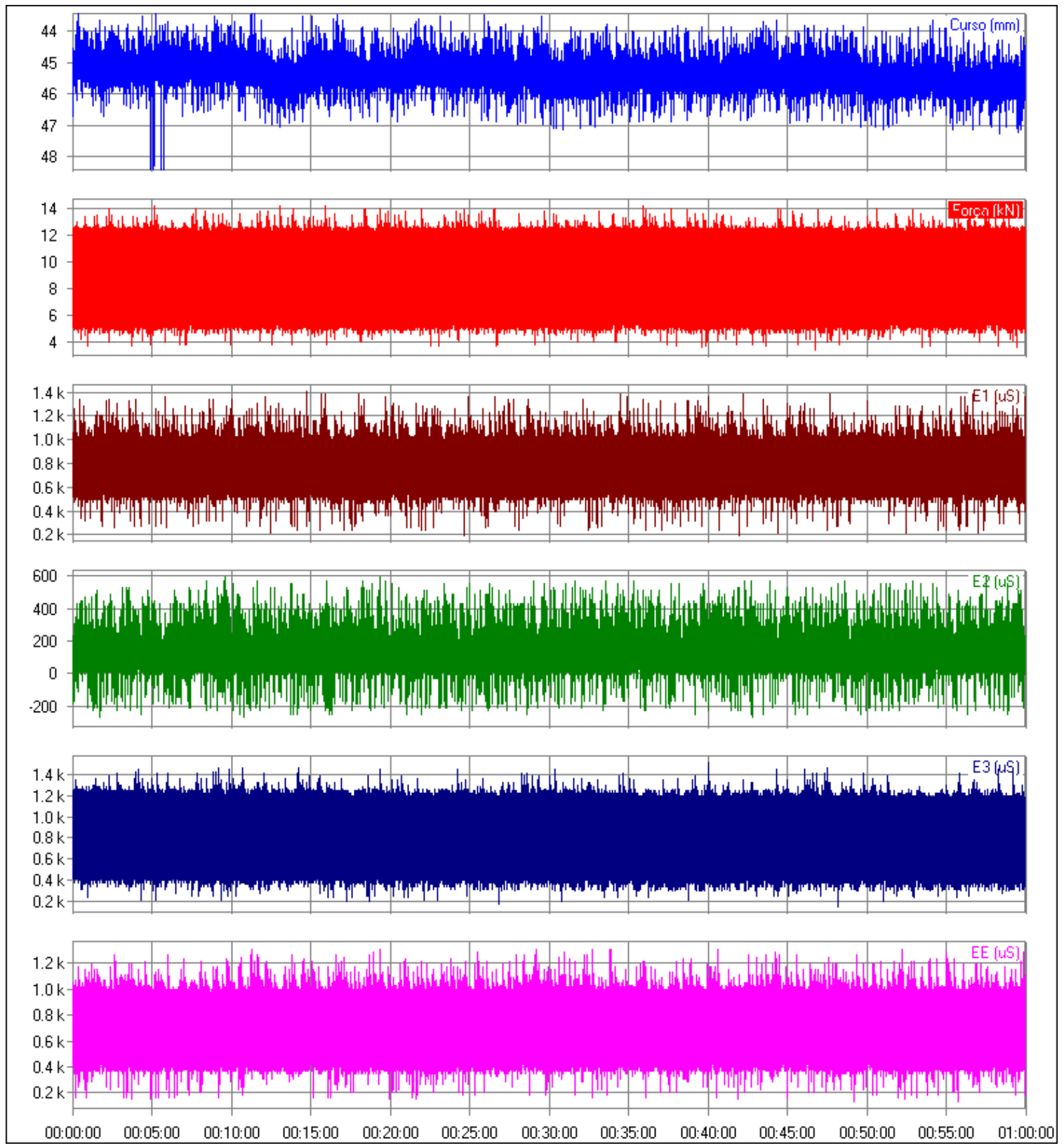

Figura 89 - Comportamento da laje 2 durante a primeira hora do ensaio dinâmico

No gráfico acima se pode ver o comportamento da laje nos momentos iniciais do ensaio. Usando o mesmo critério adotado para a laje 1 do grupo 2 A foi calculada flutuação de tensão aplicada às barras no inicio e no final do ensaio.

Flutuação no início do ensaio:

$$
\Delta \sigma=E \varepsilon=198,8 \times(1,259-0,404)=170 \mathrm{MPa}
$$

Flutuação no final do ensaio:

$$
\Delta \sigma=E \varepsilon=198,8 \times(1,309-0,454)=170 M P a
$$


Como se pode observar a flutuação de tensão aplicada na laje 2 foi em torno de $170 \mathrm{Mpa}$ durante todo o ensaio, acima dos $135 \mathrm{MPa}$ previstos inicialmente. E mesmo assim não houve ruptura por fadiga desta laje.

c) Subgrupo 1B :

Para as lajes do subgrupo 1B armadas com barras isoladas e com uma taxa de armadura maior que as lajes do grupo $1 \mathrm{~A}$. Foi mantida a flutuação de $222 \mathrm{Mpa}$, contudo para este grupo houve necessidade de redução da frequiência do ensaio de $6 \mathrm{~Hz}$ para $4,5 \mathrm{~Hz}$.

A redução da frequiência se fez necessária porque a bomba utilizada para o ensaio não foi capaz de atingir a vazão necessária para garantir a amplitude de forças que conduzisse a flutuação de tensão desejada.

Para este grupo excepcionalmente foram concretadas 5 lajes ao invés de três, porque uma das lajes foi perdida devido aos picos e/ou quedas de energia e a outra foi ciclada com uma flutuação de tensão abaixo do previsto. Contudo nas análises serão estudadas as lajes de 1 a 4 , isto é, a laje 5 que foi ensaiada com freqüência abaixo do normal não será analisada uma vez que não traz informações relevantes.

A laje 3 deste grupo foi perdida durante o ensaio devido um descontrole do sistema do ensaio,que levou o curso do atuador ao Máximo. Para que fosse comprovado que não houve ruptura por fadiga as barras desta laje foram enviadas para a análise metalográfica e não foi constada a ruptura por fadiga, o que comprova a tese que o ensaio foi realmente perdido por uma causa externa.

O gráfico da figura 77 ilustra o momento em que ocorre o descontrole e curso vai até o máximo rompendo a laje. No inicio do ensaio o extensomêtro que estava efetuando medidas confiáveis estava medindo uma flutuação de $210 \mathrm{MPa}$ valor próximo aos $222 \mathrm{MPa}$ desejados, no momento da ruptura não havia mais extensômetros efetuando leituras, por isto na figura 90 só estão ilustrados a força e o curso em função do tempo. 


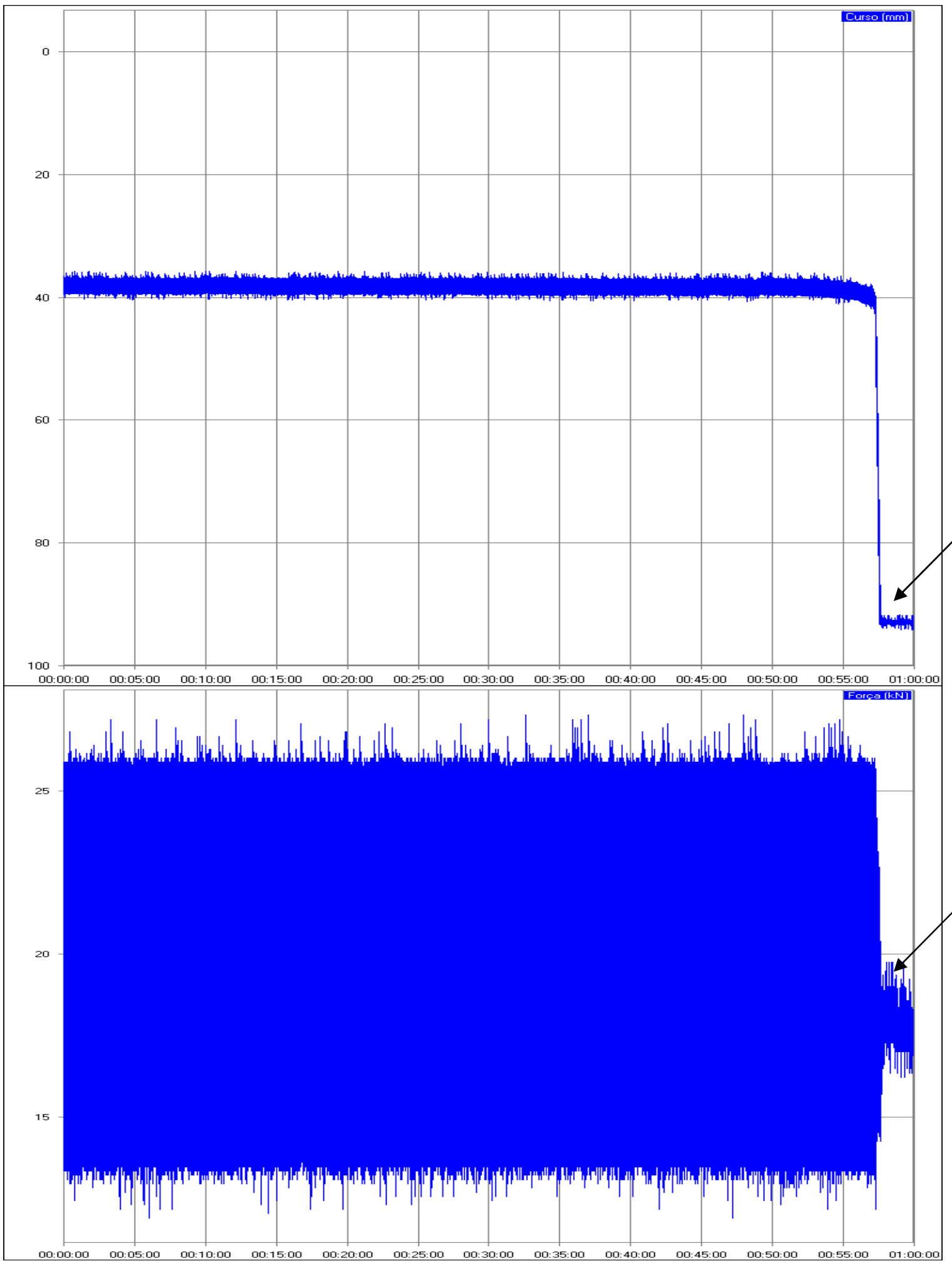

Figura 90 - Comportamento da laje 3 no momento da ruptura aproximadamente 1,6 milhões de ciclos.

As lajes do grupo 1,2 e 4 deste grupo apresentaram o comportamento esperado suportando a flutuação de tensão de $222 \mathrm{MPa}$ prevista. 


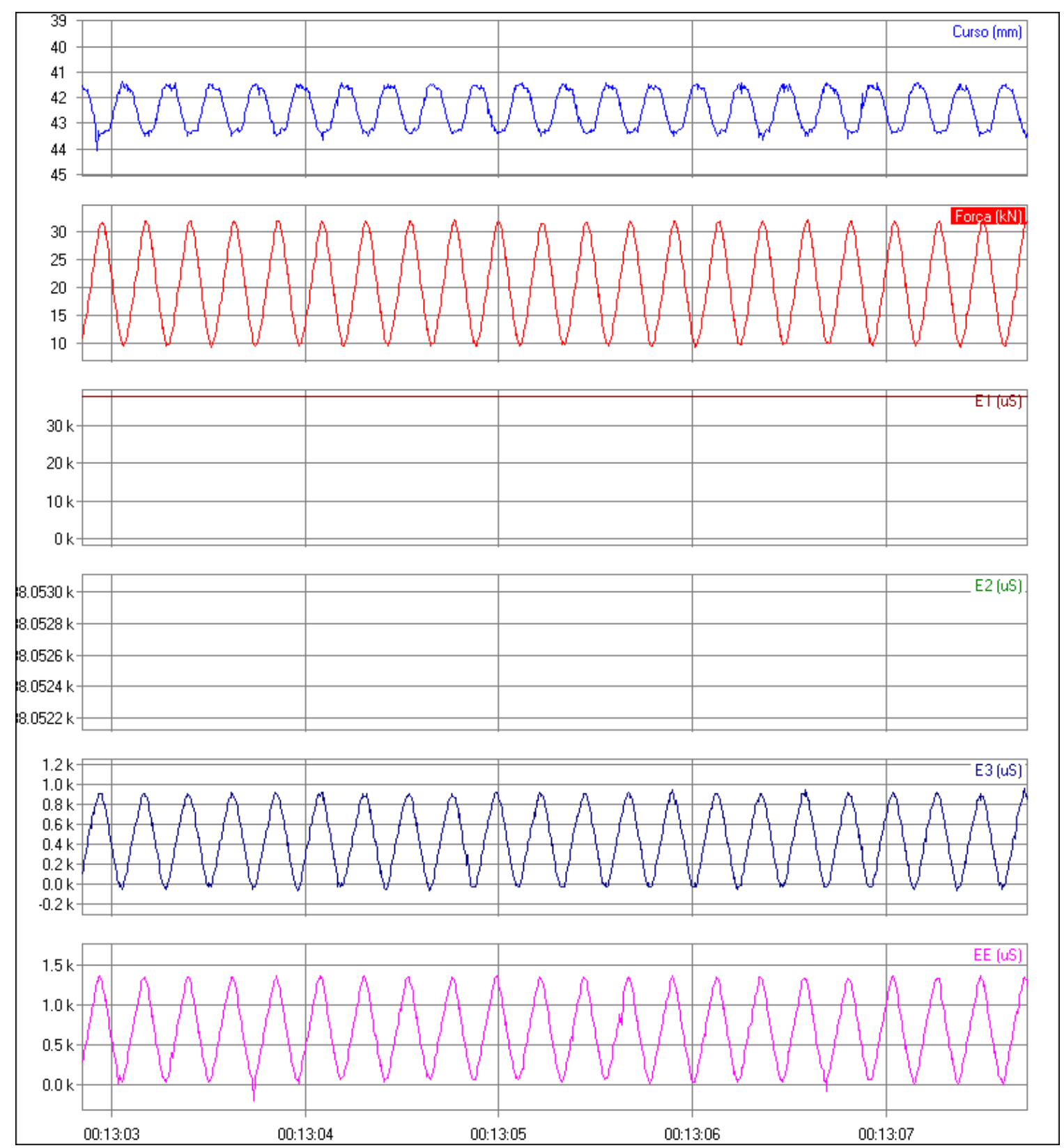

Figura 91 - Comportamento da laje 2 durante a primeira hora do ensaio dinâmico 


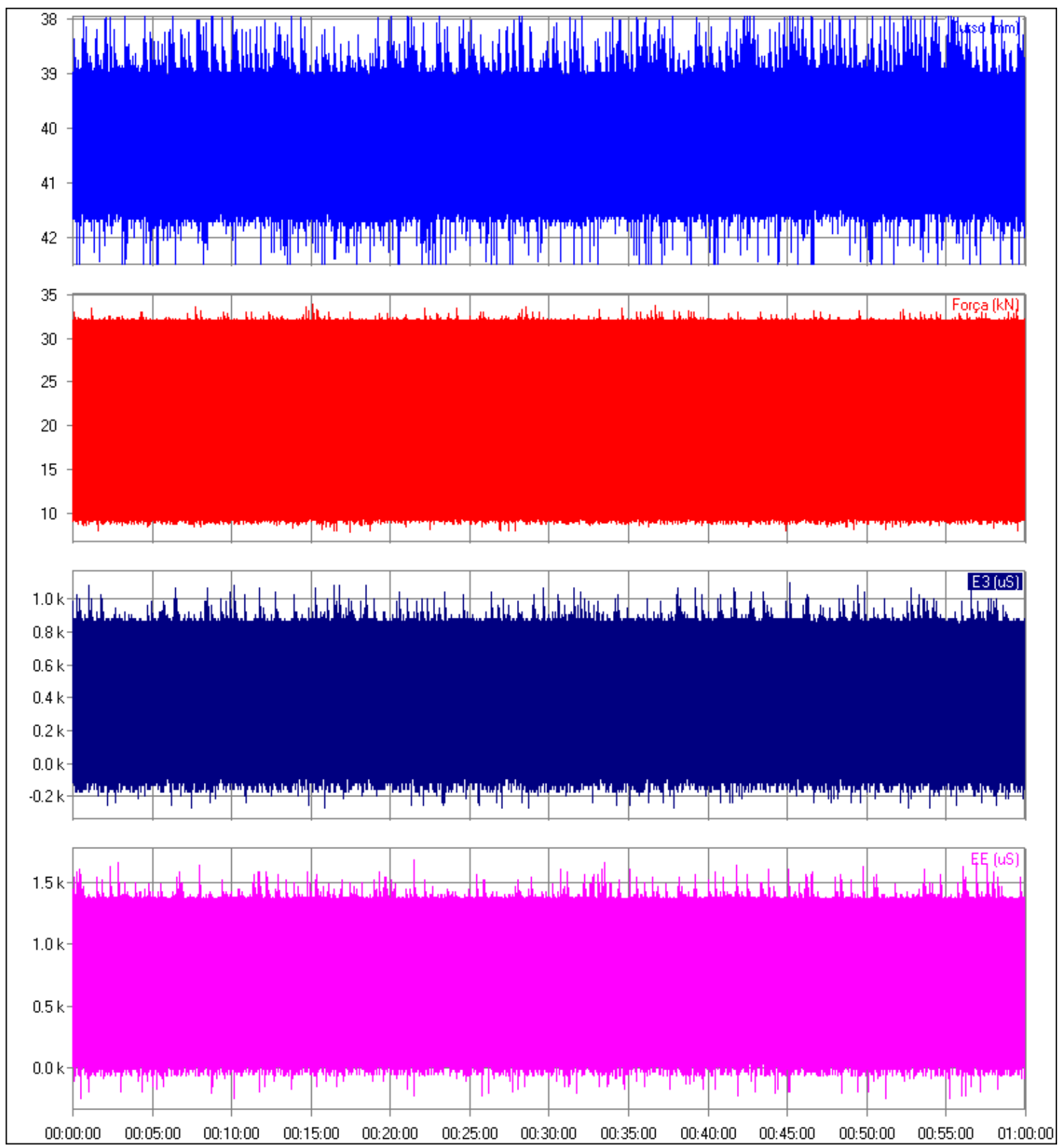

Figura 92 - Comportamento da laje 2 durante a última hora do ensaio dinâmico

Na tabela 40 têm-se os valores das flutuações de tensão no início e no final do ensaio de cada laje.

Tabela 40- Flutuação de tensão

\begin{tabular}{c|cc}
\hline Grupo 1B & $\Delta \sigma_{\text {início }}(\mathrm{MPa})$ & $\Delta \sigma_{\text {final }}(\mathrm{MPa})$ \\
\hline laje1 & 214 & 250 \\
laje2 & 200 & 203 \\
laje4 & 174 & 190 \\
\hline
\end{tabular}


Como se pode observar a laje 1 foi ciclada acima dos $222 \mathrm{MPa}$, a laje 2 foi ciclada abaixo dos $222 \mathrm{MPa}$ mas acima dos $190 \mathrm{MPa}$ estipulados pela norma brasileira e por fim a laje 4 foi ciclada próxima dos $190 \mathrm{MPa}$.

Esta variação abaixo dos $222 \mathrm{MPa}$ não foi proposital. Neste momento da pesquisa ainda não haviam sido realizados os ensaios de caracterização das barras isoladas de $10 \mathrm{~mm}$ de diâmetro, e por isso para estes ensaios foi levado em conta o modulo de elasticidade do aço $210 \mathrm{GPa}$, deste modo nenhuma laje teria tido flutuação menor que $205 \mathrm{MPa}$.

d) Subgrupo 2B

Para as lajes do subgrupo $2 \mathrm{~B}$ armadas com telas soldadas com uma taxa de armadura superior que as lajes do grupo $2 \mathrm{~A}$. Foi mantida a flutuação de $135 \mathrm{Mpa}$ ,utilizada no grupo $2 \mathrm{~A}$.

As lajes 2 e 3 atingiram os 2 milhões de ciclos sem apresentar sinais de fadiga, contudo neste grupo aconteceu o imprevisto já mencionado anteriormente, por isto, neste grupo apenas foram realizados os ensaios dinâmicos. Então não foi possível analisar o desempenho dessas lajes no ensaio estático após o carregamento cíclico. A figura 93 mostra o comportamento da laje 2 na última hora do ensaio. 


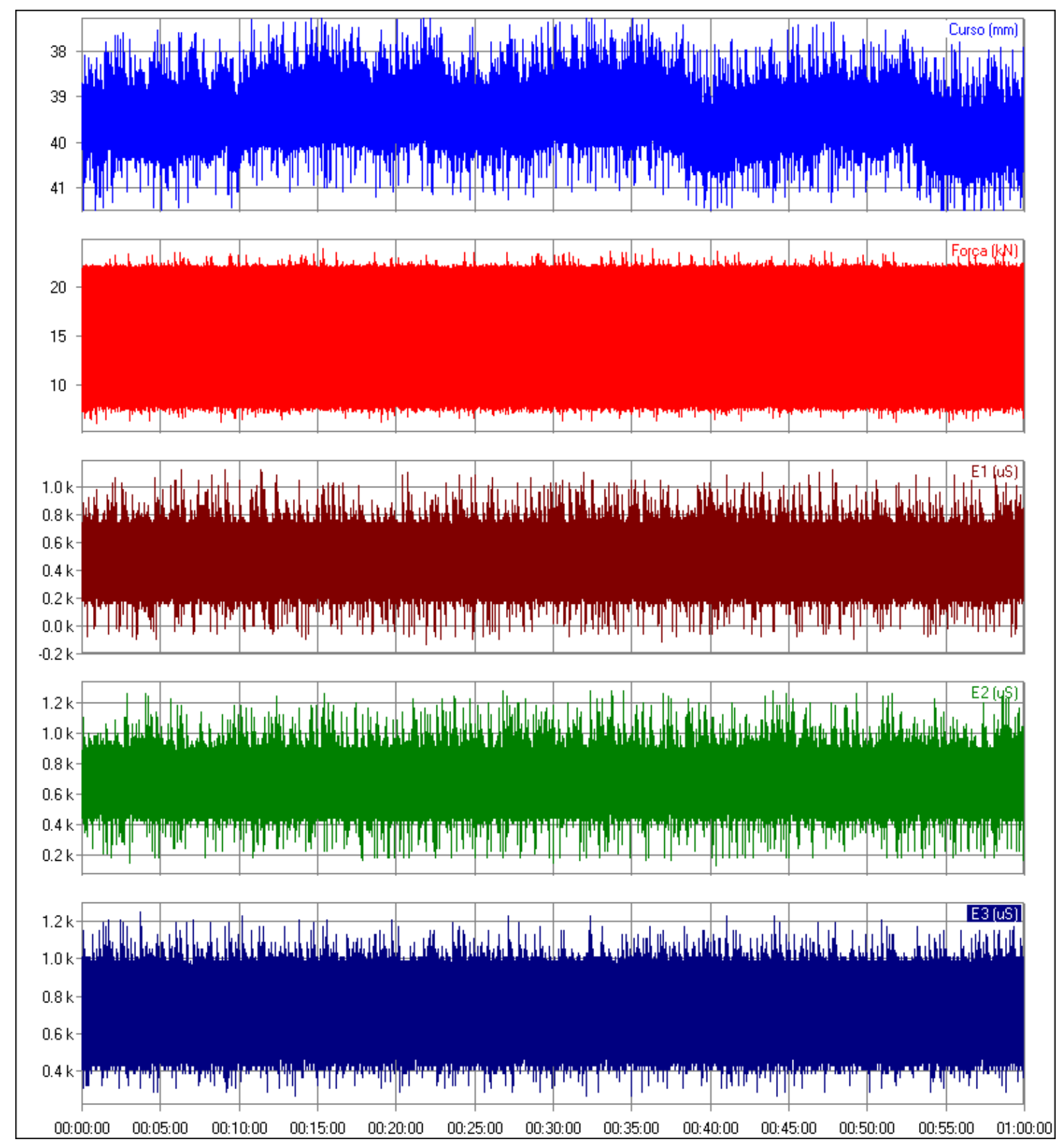

Figura 93 - Comportamento da laje 2 durante a última hora do ensaio dinâmico

Na tabela 41 têm-se os valores das flutuações de tensão no início e no final do ensaio das lajes 2 e 3.

Tabela 41- Flutuação de tensão

\begin{tabular}{c|cc}
\hline Grupo 2B & $\Delta \sigma_{\text {início }}(\mathrm{MPa})$ & $\Delta \sigma_{\text {final }}(\mathrm{MPa})$ \\
\hline laje2 & 120 & 102 \\
laje3 & 135 & 117 \\
\hline
\end{tabular}




\section{CONSIDERAÇÕES FINAIS}

\subsection{CONCLUSÕES}

Através dos resultados obtidos nos ensaios de barra ao ar é possível concluir que :

a) Os aços das barras isoladas com diâmetro de $10 \mathrm{~mm}$ fabricados no Brasil apresentam uma resistência à fadiga superior aos aços fabricados na Europa , considerados na publicação do FIB.

b) Comparando os resultados com a curva de Wöhler da Norma brasileira,com base nos resultados desta pesquisa é possível perceber que a NBR6118-2003 está do lado seguro.

c) Quando Comparados o comportamento das barras isoladas com as telas soldadas foi constado uma pior resistência à fadiga das telas soldadas. Isto é consequência principalmente do processo de soldagem que gera uma alteração de forma e composição localizadas, que fragilizam a peça neste ponto, acelerando o processo de fadiga. De qualquer forma, para os ensaios realizados os resultados apontam um comportamento superior ao indicado na norma..

d) Os resultados obtidos para as barras isoladas para uma flutuação de $198 \mathrm{MPa}$ apresentaram uma grande dispersão. Como a quantidade de amostras ensaiadas não foi suficiente, e por isto não foi possível tirar conclusões confiáveis. Mais ensaios devem ser realizados para que se possam tirar conclusões mais precisas a respeito.

Através dos ensaios realizados nas lajes foi possível concluir que:

a) Quando comparado o comportamento estático das lajes armadas com barras com o das armadas com telas, foi constatado um comportamento semelhante ao observado nos ensaios de tração, ou seja, as barras isoladas e as telas soldadas apresentam um comportamento semelhante e com resistências características muito próximas.

b) Foi comparado o desempenho de lajes do mesmo subgrupo no ensaio de ruptura e foi possível perceber que os corpos-de-prova que sofreram o carregamento dinâmico estavam mais deformáveis do que os que não foram submetidos ao ensaio dinâmico. Contudo tanto para as lajes com tela quanto para as lajes com barras o comportamento durante o ensaio estático foi de acordo com o previsto nos cálculos. Isto quer dizer que apesar de sofrerem algum dano pela fadiga. $\mathrm{O}$ dano por fadiga 
não comprometeu a capacidade resistente da peça, mesmo tendo sido aplicadas às lajes flutuações de tensões superiores às estabelecidas pela norma.

c) Quando comparado o comportamento das lajes armadas com telas soldadas com o das barras isoladas após os ensaios dinâmicos, foi possível perceber um desempenho semelhante dos dois tipos de laje . Contudo isto não significa que elas sofreram danos semelhantes nos ensaios de fadiga realizados, uma vez que as lajes armadas com barras isoladas foram submetidas a flutuações de tensões bem maiores. Então é natural que além de uma menor capacidade resistente à fadiga das lajes armadas com telas, elas também sofrem um dano maior quando solicitadas dinamicamente.

d) Quando solicitadas dinamicamente as lajes armadas com barras isoladas apresentaram um desempenho acima do previsto pelas normas, uma vez que foi aplicada uma flutuação de tensão baseada na combinação frequente de ações, mas sem a verificação da fadiga das armaduras. Assim sendo o carregamento aplicado na laje foi maior do que o previsto pela NBR-6118 e mesmo assim as lajes não apresentaram nenhum sinal de fadiga.

Este desempenho das lajes se assemelha a curva média apresentada no item 4.1 deste trabalho, uma vez que quando as barras estão nas lajes elas tendem a trabalhar em conjunto, portanto o valor médio representa de forma fidedigna o comportamento dessas barras.

Os cálculos apresentados no item 4.1 mostram que para rupturas com 2 milhões de ciclos a flutuação de tensão corresponde é de $233 \mathrm{MPa}$. Contudo, acredita-se que quando mergulhadas no concreto o desempenho das barras ainda é superior ao desempenho médio.

A hipótese da melhoria do comportamento das barras quando embebidas em concreto é reforçada pela laje 1 do grupo 1B, que teve flutuação media durante o ensaio de aproximadamente $230 \mathrm{MPa}$. Esta além de suportar os 2 milhões de ciclos apresentou desempenho satisfatório nos ensaios de ruptura estática realizados.

Para confirmar se realmente ocorre uma melhoria devido à presença do concreto e para se saber com precisão o valor da flutuação de tensão que leva a peça à ruptura por fadiga se fazem necessários uma maior quantidade de ensaios.

Com relação às telas soldadas quando submetidas a carregamentos dinâmicos, foi possível perceber um desempenho inferior ao das barras isoladas. Isto se deve principalmente à solda. Contudo, assim como no caso das barras isoladas, as telas 
apresentaram um comportamento superior ao previsto pela NBR 6118-2003. Uma vez que para as lajes armadas com telas soldadas foi aplicada uma flutuação de $135 \mathrm{MPa}$ e não se obteve nenhuma ruptura, quando o valor sugerido pela NBR é de apenas $85 \mathrm{MPa}$.

e)Por fim é importante mencionar que nas lajes concretadas em duas etapas não foi percebido nenhum surgimento de fissuras ou sinal de deslizamento entre os concretos de idades diferentes. Contudo o comportamento dessas lajes será analisado com maior profundidade nas dissertações de mestrado dos alunos Edielce Cristina Caixeta e Paulo de Sá Pereira Cavalcanti, cujos títulos são respectivamente : "Investigação experimental da fadiga em lajes de pontes com ou sem pré-lajes" e "Fadiga da ligação capa-pré-laje em tabuleiros de pontes rodoviárias.".

\subsection{SUGESTÕES PARA TRABALHOS FUTUROS}

Como sugestão para trabalhos futuros pode-se citar:

a) Realizar um estudo mais detalhado, ou seja, ampliar a quantidade de amostras para que seja possível definir com maior clareza o comportamento das barras isoladas e telas soldadas quando acima de 2 milhões de ciclos, isto é, entre 5 e 10 milhões de ciclos.

b) Realizar ensaios de lajes armadas com barras isoladas com flutuações de tensões maiores, com a finalidade de se obter rupturas por fadiga e se descobrir com maior precisão o limite à fadiga das peças.

c) Realizar um estudo a respeito do desempenho da contribuição entre fissuras para as peças que foram submetidas a ensaios dinâmicos.

d) Aplicar os resultados obtidos nos ensaios de barra ao ar para a verificação a fadiga das armaduras.

e) Aplicar os resultados obtidos nos ensaios de laje de modo a se reduzir a margem de segurança usado nas verificações à fadiga. 


\section{ANEXO A - ANÁLISE DAS RUPTURAS POR FADIGA}

Para que fosse possível comprovar a ruptura por fadiga das barras da laje 1 do subgrupo 2 A . Foram escolhidas algumas barras dessa laje e algumas barras rompidas por fadiga nos ensaios de barra ao ar, para que elas fossem analisadas com um microscópio de varredura eletrônica.

$\mathrm{O}$ aspecto de uma ruptura por fadiga possui duas zonas características que podem ser associadas ao comportamento da peça durante as solicitações. A primeira zona é originada a partir do ponto de nucleação e se caracteriza pelo surgimento de estrias, comumente chamada de marcas de praia, que vão se formando a cada novo ciclo de tensões, ou seja, esta zona é produzida pela propagação da fissura. A segunda zona caracteriza o ponto onde a seção remanescente não é mais capaz de resistir as solicitações e então ocorre a ruptura repentina da peça, o aspecto desta zona é um aspecto rugoso e em alguns casos ele apresenta uma elevação em relação ao nível da zona 1 , devido ao rompimento brusco do material.

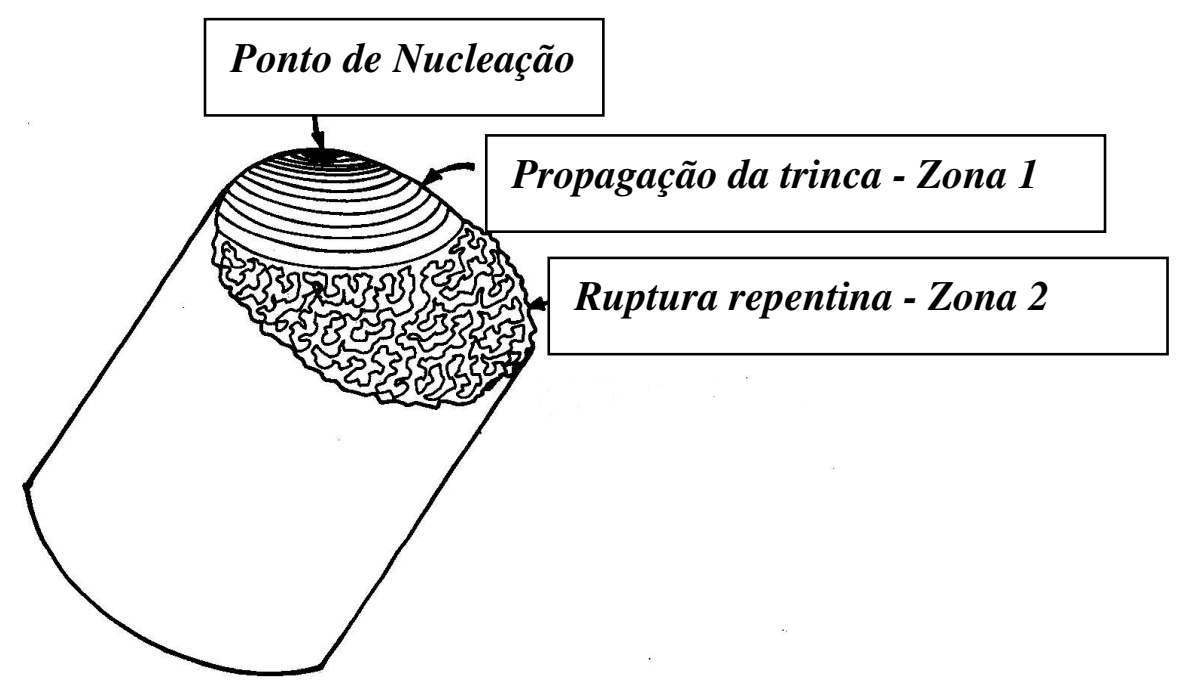

Figura A1 - Representação das zonas de uma ruptura por fadiga

A seguir serão apresentadas as figuras que ilustram as superfícies de ruptura das barras ensaiadas. Antes porém, é importante mencionar que no caso das barras que 
estavam imersas no concreto, não é possível perceber com grande nitidez as superfícies de fratura ,isto é, os pontos de nucleação e as marcas de praia características das rupturas por fadiga. Uma vez que mesmo após a ruptura da barra o ensaio não foi interrompido e por este motivo acredita-se que a superfície de ruptura tenha sido um pouco danificada, perdendo assim um pouco do aspecto visual característico de uma superfície com ruptura por fadiga.

Nas figuras A2 , A3 e A4 serão apresentados os resultados da microscopia eletrônica realizada na barra rompida por fadiga no através do ensaio de barra ao ar.

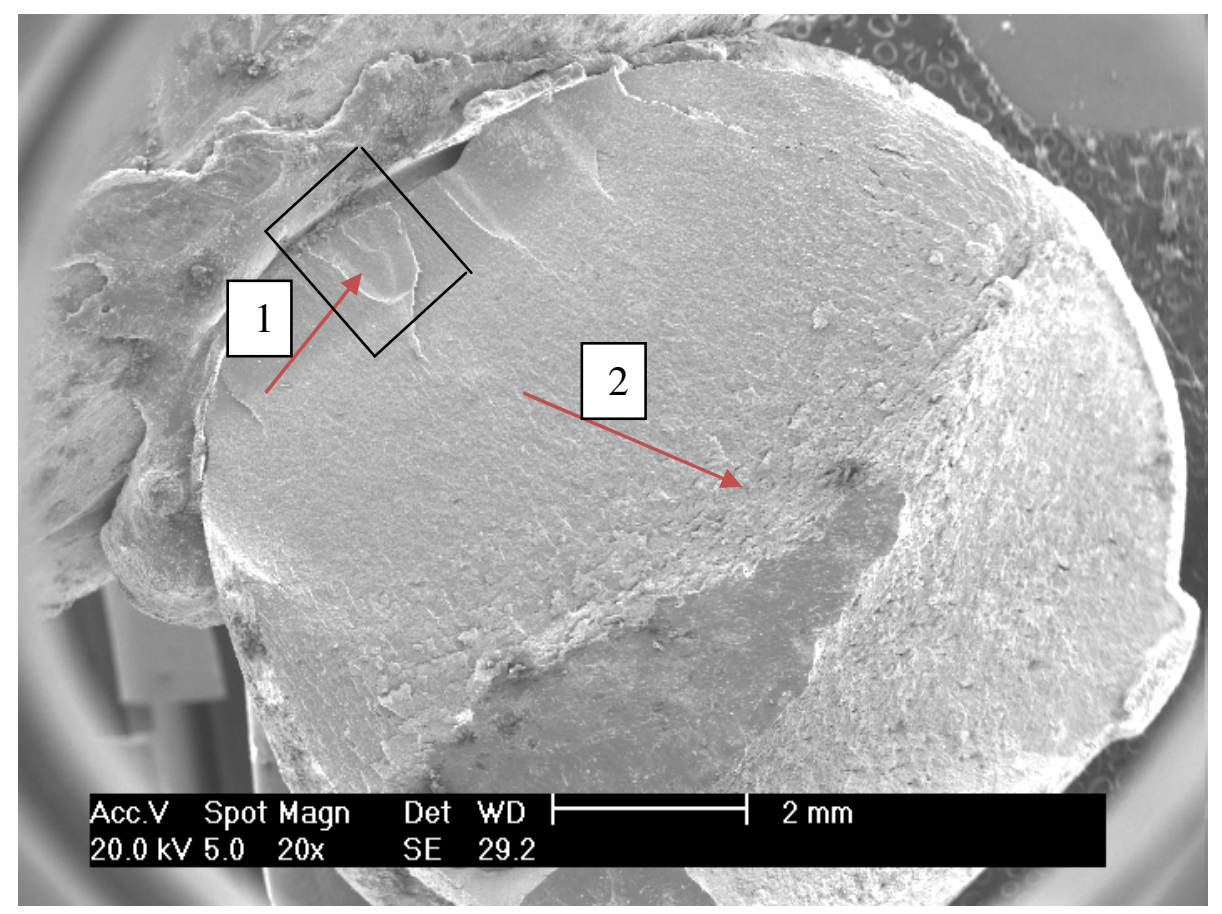

Figura A2 - Visualização da superfície de ruptura de uma barra após o ensaio de barra ao ar

A região indica pelo número 1 mostra o possível ponto de iniciação da fissura e sua propagação. A região 2 mostra a zona da ruptura repentina, onde pode ser percebido o desnível entre as zonas e um superfície mais rugosa. As figuras A3 e A4 mostrarão respectivamente as zonas 1 e 2 ampliadas. 

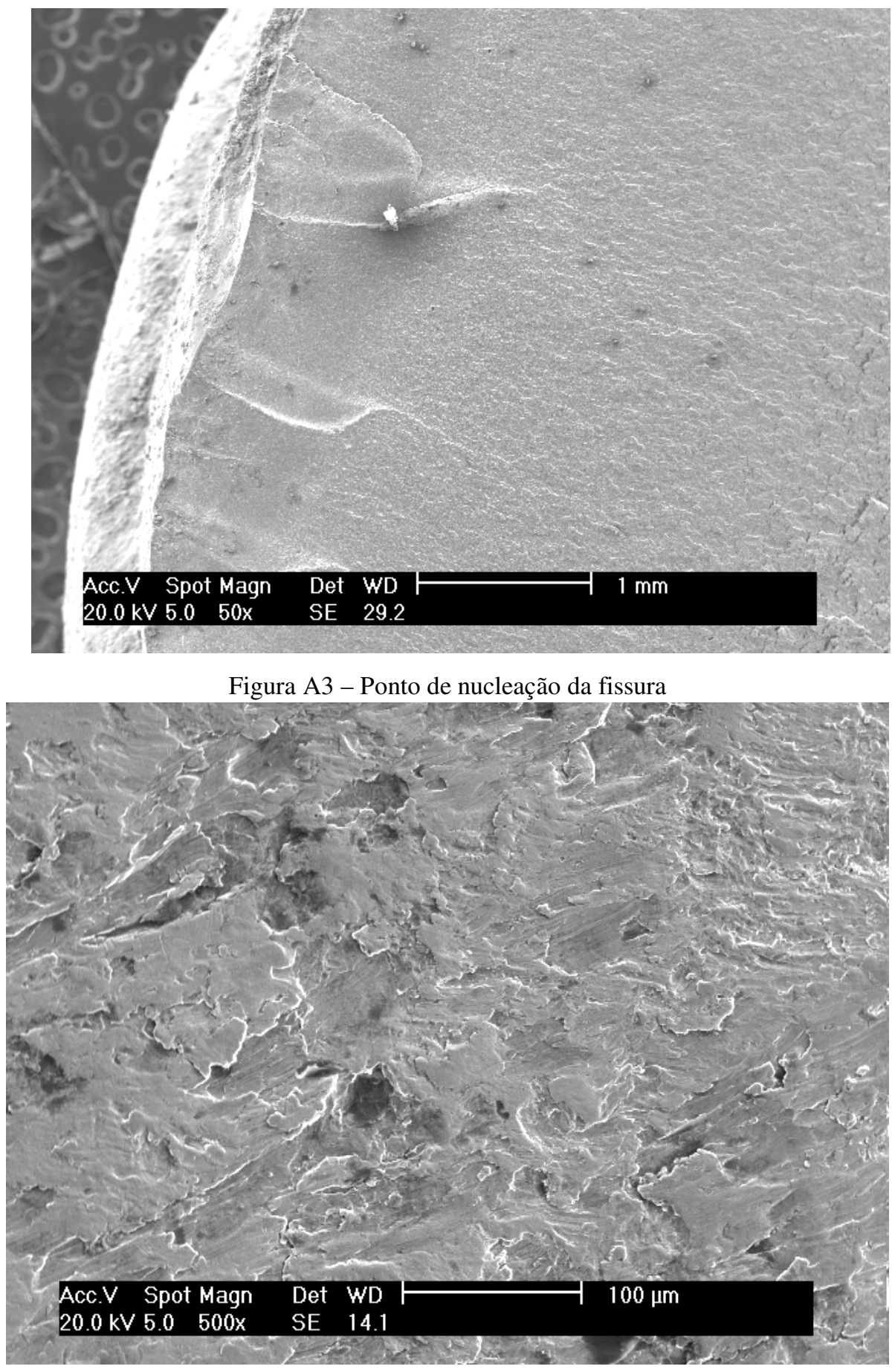

Figura A3 - Região da ruptura abrupta

Nas figuras A4, A5 e A6 serão mostradas as superfícies de uma barra retirada da laje 1 do grupo $2 \mathrm{~A}$, para que seja comprovada a ruptura por fadiga desta laje. 


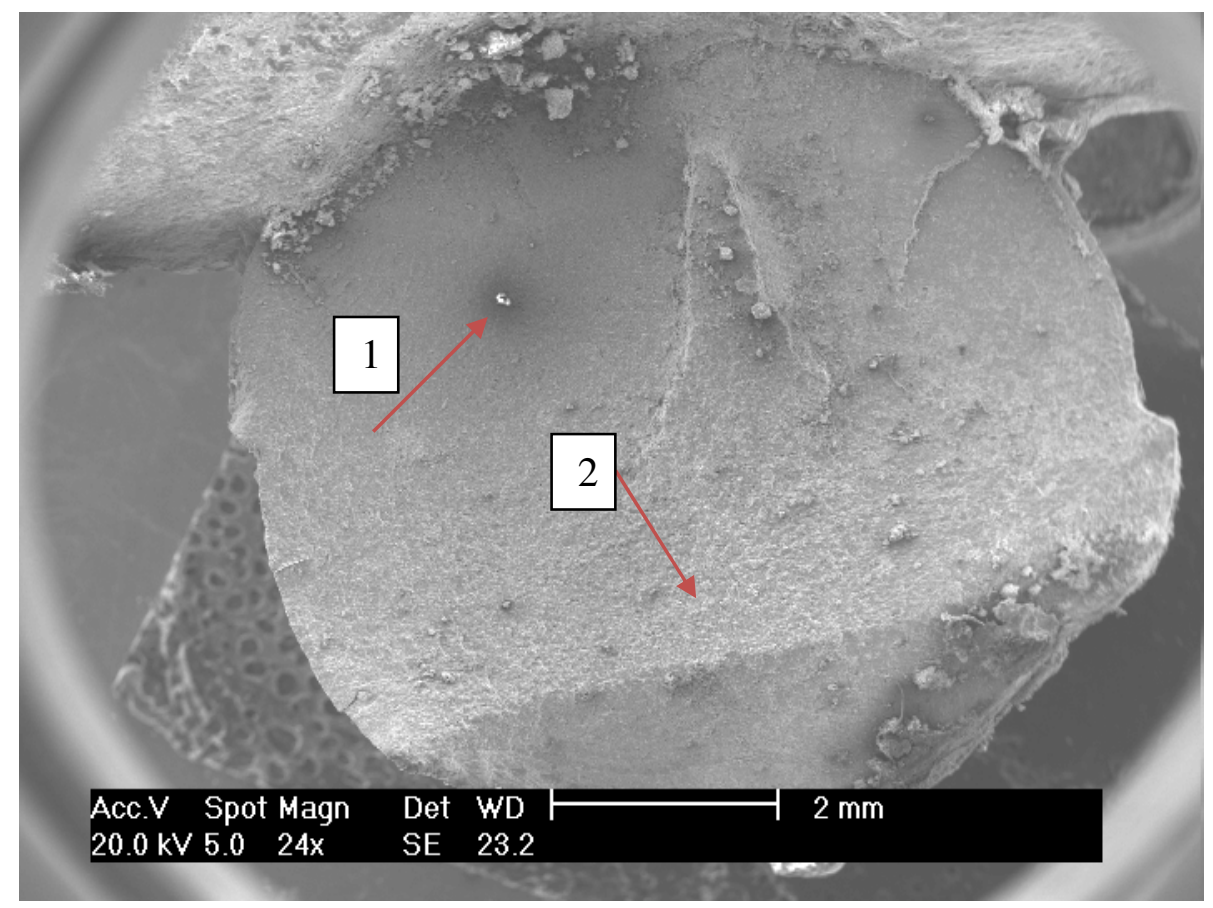

Figura A4 - Visualização da superfície de ruptura de uma barra da laje 1 do subgrupo 2 A

Assim como apresentado anteriormente as regiões 1 e 2 serão ampliadas para que seja possível ver com nitidez as marcar de praia referentes a propagação da trinca e a região de ruptura repentina.

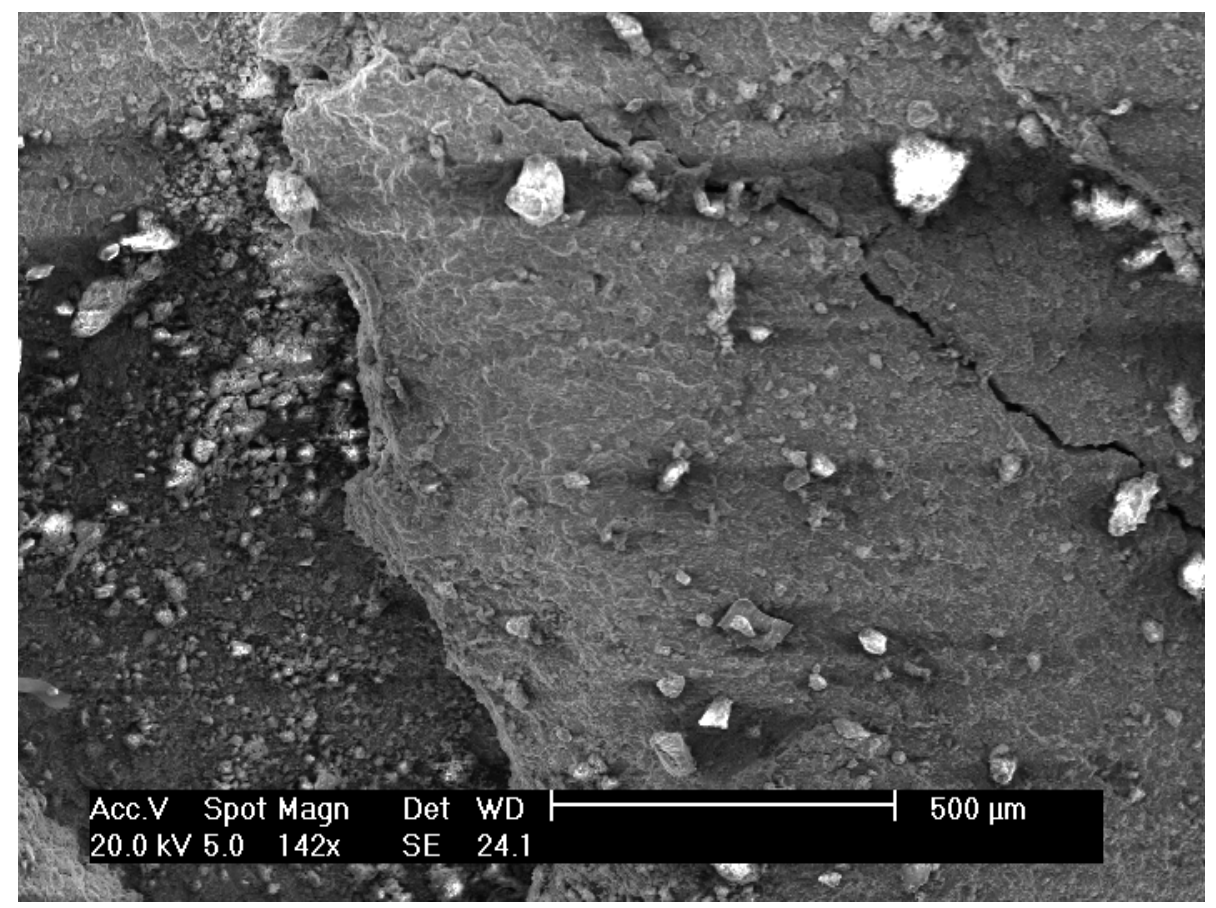

Figura A5 - Ponto de nucleação da fissura 


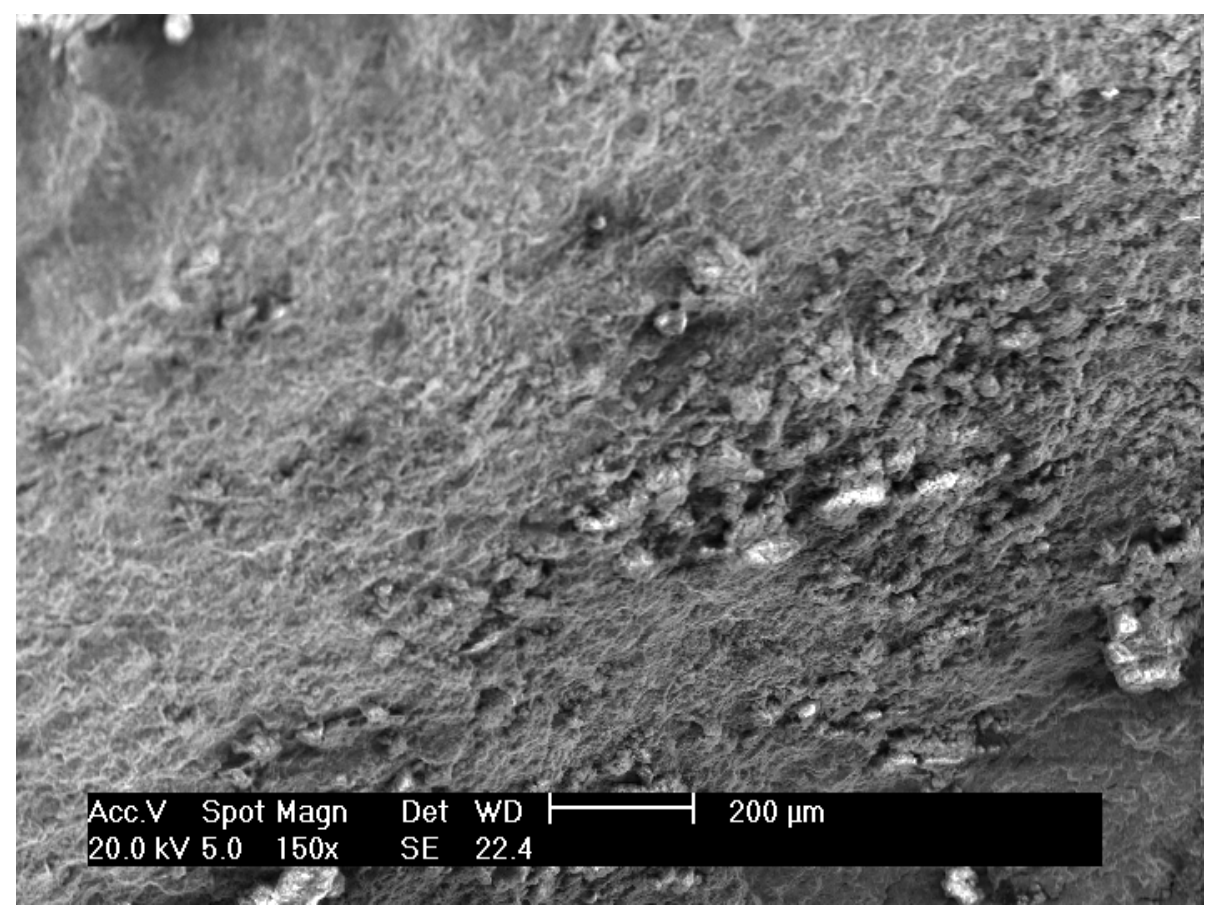

Figura A6 - Região da ruptura abrupta

Como mencionado anteriormente neste anexo é possível perceber que nas figuras referentes a barra imersa no concreto, as marcas de praia referentes a propagação das fissuras não estão muito nitidias na figura A5, já na figura A6 é possível perceber a região da ruptura repentina da barra, bem como na figura A4 é possível perceber a elevação do nível na região indicada pelo número 2.

Através do exposto é possível concluir que as superfícies de ruptura apresentadas tanto pela barra que foi utilizada na laje 1 do subgrupo 2 A e quanto pela barra que foi ensaiada por fadiga ao ar apresentam os mesmos aspectos nas superfícies de ruptura. Aspectos estes que caracterizam a ruptura por fadiga. Então é possível concluir que a laje 2 do subgrupo $2 \mathrm{~A}$ teve uma ruptura por fadiga. 
ANEXO B - TABELAS DOS RESULTADOS OBTIDOS PARA OS DIVERSOS

GRUPOS ENSAIADOS.

Tabela B.1 - Resultados do ensaio de ruptura da laje L1 do Grupo 1A.

\begin{tabular}{ccccc}
\hline $\begin{array}{c}\text { Curso } \\
(\mathbf{m m})\end{array}$ & $\begin{array}{c}\text { Forca } \\
(\mathbf{k N})\end{array}$ & $\begin{array}{c}\mathbf{E 2} \\
\mathbf{\% o}\end{array}$ & $\begin{array}{c}\mathbf{E 3} \\
\mathbf{\% o}\end{array}$ & $\begin{array}{c}\mathbf{E 4} \\
\mathbf{\% o}\end{array}$ \\
\hline$-0,14$ & 0 & & & \\
0,00 & 3,00 & & & \\
0,27 & 8,00 & 0,000 & 0,000 & 0,020 \\
0,65 & 14,92 & 0,118 & 0,115 & 0,059 \\
1,15 & 15,96 & 0,697 & 0,890 & 0,117 \\
1,75 & 18,44 & 1,116 & 1,329 & 0,390 \\
2,25 & 19,74 & 1,197 & 1,628 & 0,779 \\
3,07 & 21,45 & 1,396 & 1,866 & 1,208 \\
4,17 & 24,97 & 1,777 & 2,264 & 1,636 \\
4,72 & 26,28 & 1,956 & 2,423 & 1,792 \\
5,22 & 27,06 & 2,096 & 2,562 & 1,910 \\
5,77 & 29,28 & 2,235 & 2,741 & 2,065 \\
6,15 & 30,33 & 2,436 & 2,901 & 2,163 \\
6,76 & 31,63 & 2,595 & 3,040 & 2,299 \\
10,77 & 33,72 & 2,775 & 3,298 & 2,533 \\
11,76 & 34,77 & 2,855 & 3,140 & 2,610 \\
12,70 & 35,55 & 3,135 & 3,736 & 2,688 \\
13,69 & 36,20 & 3,894 & 9,303 & 2,747 \\
14,68 & 36,99 & 4,574 & $\mathrm{x}$ & 3,805 \\
\hline
\end{tabular}

Tabela B.2 - Resultados do ensaio de ruptura da laje L2 do Grupo 1A.

\begin{tabular}{ccc}
\hline $\begin{array}{c}\text { Curso } \\
(\mathbf{m m})\end{array}$ & $\begin{array}{c}\text { Forca } \\
(\mathbf{k N})\end{array}$ & $\begin{array}{c}\mathbf{E 3} \\
\mathbf{\% o}\end{array}$ \\
\hline 0,00 & 3,00 & \\
0,79 & 10,35 & 0,274 \\
1,83 & 17,27 & 0,513 \\
3,04 & 23,8 & 0,851 \\
3,65 & 27,19 & 1,209 \\
4,69 & 35,42 & 1,388 \\
11,45 & 36,86 & 2,005 \\
13,98 & 37,77 & 2,104 \\
15,79 & 38,03 & 2,184 \\
18,22 & $\mathrm{x}$ & 2,225 \\
\hline
\end{tabular}


Tabela B.3 - Resultados do ensaio de ruptura da laje L3 do Grupo 1A.

\begin{tabular}{ccc}
\hline $\begin{array}{c}\text { Curso } \\
(\mathbf{m m})\end{array}$ & $\begin{array}{c}\text { Forca } \\
(\mathbf{k N})\end{array}$ & $\begin{array}{c}\mathbf{E 3} \\
\mathbf{\% o}\end{array}$ \\
\hline 0,00 & 0,00 & 0,000 \\
0,35 & 3,00 & 0,000 \\
0,56 & 4,34 & 0,760 \\
0,89 & 6,95 & 0,820 \\
1,49 & 12,18 & 1,159 \\
3,03 & 23,14 & 2,036 \\
7,54 & 32,02 & 2,852 \\
9,03 & 33,07 & 2,992 \\
10,7 & 35,03 & 3,151 \\
15,68 & 36,6 & 5,562 \\
18,2 & 36,99 & 7,176 \\
21,62 & 38,55 & 9,865 \\
34,1 & 38,68 & 11,958 \\
\hline
\end{tabular}

Tabela B.4 - Resultados do ensaio de ruptura das lajes L2 e L4 do Grupo 1B.

Laje L1

\begin{tabular}{cccc} 
Curso & Força & $\mathbf{E 3}$ & $\mathbf{E E}$ \\
$(\mathbf{m m})$ & $(\mathbf{k N})$ & $\%$ o & $\%$ \\
\hline 0,00 & 3,00 & - & - \\
0,82 & 5,65 & 0,000 & 0,000 \\
1,74 & 13,61 & 0,046 & 0,372 \\
2,58 & 20,27 & 0,225 & 0,691 \\
3,57 & 27,72 & 0,485 & 1,087 \\
4,45 & 36,20 & 0,705 & 1,505 \\
5,44 & 44,12 & 0,885 & 1,863 \\
6,43 & 50,70 & 1,164 & 2,300 \\
6,76 & 53,30 & 1,204 & 2,400 \\
7,26 & 57,88 & 1,305 & 2,619 \\
8,25 & 61,80 & 1,285 & 5,560 \\
8,74 & 64,02 & 1,325 & 8,442 \\
9,23 & 65,45 & 1,384 & 12,060 \\
11,60 & 67,67 & 1,404 & 17,168 \\
13,03 & 68,07 & $\mathrm{x}$ & 17,784 \\
13,85 & 68,46 & $\mathrm{x}$ & 18,042 \\
\hline
\end{tabular}

Laje L2

\begin{tabular}{cccc}
\hline $\begin{array}{c}\text { Curso } \\
(\mathbf{m m})\end{array}$ & $\begin{array}{c}\text { Força } \\
(\mathbf{k N})\end{array}$ & $\begin{array}{c}\text { E1 } \\
\text { \%o }\end{array}$ & $\begin{array}{c}\text { E2 } \\
\text { \%o }\end{array}$ \\
\hline$-0,05$ & 0,00 & - & - \\
0,00 & 3,00 & - & - \\
0,15 & 10,46 & 0,531 & 0,552 \\
0,21 & 13,74 & 0,686 & 0,673 \\
0,86 & 20,53 & 1,034 & 0,874 \\
2,89 & 48,35 & 2,484 & 1,857 \\
4,05 & 58,40 & 3,044 & 2,440 \\
5,54 & 63,36 & 4,089 & 2,782 \\
8,67 & 68,20 & 4,360 & 3,042 \\
\hline
\end{tabular}


Tabela B.5 - Resultados do ensaio de ruptura da laje L4 do Grupo 1B.

\begin{tabular}{ccccc}
\hline $\begin{array}{c}\text { Curso } \\
(\mathbf{m m})\end{array}$ & $\begin{array}{c}\text { Força } \\
(\mathbf{k N})\end{array}$ & $\begin{array}{c}\mathbf{E 1} \\
\mathbf{\%}\end{array}$ & $\begin{array}{c}\mathbf{E 2} \\
\mathbf{\%}\end{array}$ & $\begin{array}{c}\mathbf{E 4} \\
\mathbf{\%}\end{array}$ \\
\hline 0,00 & 3,00 & - & - & - \\
1,13 & 15,30 & 0,763 & 0,874 & 1,009 \\
1,79 & 24,19 & 1,150 & 1,296 & 1,331 \\
2,61 & 33,07 & 1,536 & 1,596 & 1,672 \\
3,28 & 41,17 & 1,904 & 1,958 & 2,074 \\
3,99 & 49,26 & 2,290 & 2,259 & 2,476 \\
4,71 & 53,96 & 2,562 & 2,560 & 2,717 \\
5,86 & 62,71 & 3,451 & 2,962 & 3,320 \\
7,56 & 65,19 & $\mathrm{X}$ & 3,082 & 3,400 \\
9,71 & 67,28 & $\mathrm{X}$ & 3,504 & 3,501 \\
21,09 & 72,24 & $\mathrm{X}$ & 5,150 & 5,008 \\
\hline
\end{tabular}

Tabela B.6 - Resultados do ensaio de ruptura da laje L2 do Grupo 2A.

\begin{tabular}{|c|c|c|c|c|c|}
\hline $\begin{array}{c}\text { Curso } \\
(\mathrm{mm})\end{array}$ & $\begin{array}{c}\text { Força } \\
(\mathbf{k N})\end{array}$ & $\begin{array}{l}\text { E1 } \\
\% 0\end{array}$ & $\begin{array}{l}\text { E2 } \\
\% 0\end{array}$ & $\begin{array}{c}\mathbf{E 3} \\
\% 。\end{array}$ & $\begin{array}{c}\text { EE } \\
\% 0\end{array}$ \\
\hline$-0,10$ & 0,00 & - & - & - & - \\
\hline 0,00 & 3,00 & - & - & - & - \\
\hline 0,08 & 8,51 & 0,659 & 0,111 & 0,025 & 0,759 \\
\hline 0,19 & 10,35 & 0,890 & 0,251 & 0,160 & 0,798 \\
\hline 0,73 & 15,44 & 1,182 & 0,251 & 0,546 & 1,192 \\
\hline 0,96 & 18,31 & 1,382 & 0,291 & 0,689 & 1,409 \\
\hline 1,23 & 18,84 & 1,483 & 0,351 & 0,933 & 1,528 \\
\hline 1,23 & 19,35 & 1,543 & 0,391 & 0,953 & 1,547 \\
\hline 2,11 & 21,19 & 1,723 & 1,473 & 1,136 & 1,842 \\
\hline 2,61 & 23,14 & 1,865 & 1,693 & 1,421 & 2,000 \\
\hline 2,66 & 23,53 & 1,885 & 1,693 & 1,421 & 2,000 \\
\hline 2,92 & 24,84 & 2,005 & 1,913 & 1,746 & 2,197 \\
\hline 3,60 & 25,36 & 2,065 & 2,054 & 1,869 & 2,394 \\
\hline 3,92 & 28,11 & 2,366 & 2,374 & 2,153 & 2,669 \\
\hline 4,42 & 29,80 & 2,526 & 2,574 & 2,153 & 2,866 \\
\hline 4,80 & 30,59 & 2,688 & 2,775 & 2,234 & 3,063 \\
\hline 5,19 & 31,89 & 2,889 & 2,955 & 2,417 & 3,299 \\
\hline 5,74 & 33,32 & 3,049 & 3,134 & 2,377 & 3,516 \\
\hline 6,18 & 34,77 & 3,291 & 3,355 & 2,459 & 3,929 \\
\hline 6,73 & 35,68 & 3,551 & 3,536 & 2,479 & 4,402 \\
\hline 7,12 & 35,94 & 3,932 & 3,696 & $\mathrm{x}$ & 5,229 \\
\hline 11,62 & 36,46 & 8,432 & 4,677 & $\mathrm{x}$ & 13,695 \\
\hline 12,56 & 36,60 & 9,456 & 4,817 & $\mathrm{x}$ & 14,542 \\
\hline 13,38 & 37,25 & 10,742 & 5,077 & $\mathrm{x}$ & 15,449 \\
\hline
\end{tabular}




\begin{tabular}{llllll}
14,31 & 37,51 & 11,846 & 5,238 & $\mathrm{x}$ & 16,551 \\
15,20 & 37,64 & 13,192 & 5,418 & $\mathrm{x}$ & 17,733 \\
\hline
\end{tabular}

Tabela B.7 - Resultados do ensaio de ruptura da laje L3 do Grupo 2A.

\begin{tabular}{cccccc}
\hline $\begin{array}{c}\text { Curso } \\
(\mathbf{m m})\end{array}$ & $\begin{array}{c}\text { Força } \\
(\mathbf{k N})\end{array}$ & $\begin{array}{c}\text { E1 } \\
\text { \%o }\end{array}$ & $\begin{array}{c}\text { E2 } \\
\text { \%o }\end{array}$ & $\begin{array}{c}\text { E3 } \\
\text { \%o }\end{array}$ & $\begin{array}{c}\text { EE } \\
\text { \%o }\end{array}$ \\
\hline$-0,28$ & 0,00 & - & - & - & - \\
0,00 & 3,00 & - & - & - & - \\
0,14 & 4,07 & 0,000 & 0,095 & 0,049 & 0,003 \\
0,90 & 15,83 & 0,444 & 1,866 & 0,247 & 0,410 \\
1,39 & 16,35 & 0,987 & 3,520 & 0,644 & 1,012 \\
2,88 & 24,06 & 1,855 & 11,624 & 1,833 & 2,002 \\
4,81 & 29,80 & 2,479 & 16,311 & 2,428 & 2,565 \\
6,40 & 35,03 & 3,306 & 20,747 & $x$ & 3,322 \\
7,34 & 36,86 & 4,052 & 23,027 & x & 3,788 \\
8,33 & 39,21 & 5,825 & 25,590 & x & 4,603 \\
8,82 & 40,12 & 6,853 & 26,445 & $x$ & 5,069 \\
9,26 & 40,64 & 8,183 & 27,205 & $x$ & 5,573 \\
9,59 & 40,90 & 9,654 & 27,079 & $x$ & 6,156 \\
\hline
\end{tabular}

Tabela B 8 - Resultados do ensaio de ruptura da laje L1 do Grupo 3A.

\begin{tabular}{ccc}
\hline $\begin{array}{c}\text { Curso } \\
(\mathbf{m m})\end{array}$ & $\begin{array}{c}\text { Força } \\
(\mathbf{k N})\end{array}$ & $\begin{array}{c}\text { EE } \\
(\%)\end{array}$ \\
\hline$-0,71$ & 0,00 & 0,000 \\
0,00 & 3,00 & 0,000 \\
0,91 & 6,16 & 0,290 \\
2,89 & 14,40 & 1,130 \\
3,05 & 15,83 & 1,266 \\
4,75 & 23,02 & 1,989 \\
6,89 & 30,85 & 2,792 \\
7,80 & 35,29 & 3,221 \\
8,90 & 37,37 & 4,100 \\
9,87 & 38,82 & 4,979 \\
11,79 & 40,25 & 7,344 \\
13,77 & 41,82 & 8,537 \\
\hline
\end{tabular}


Tabela B.9 - Resultados do ensaio de ruptura da laje L2 do Grupo 3A.

\begin{tabular}{cccc}
\hline $\begin{array}{c}\text { Curso } \\
(\mathbf{m m})\end{array}$ & $\begin{array}{c}\text { Forca } \\
(\mathbf{k N})\end{array}$ & $\begin{array}{c}\mathbf{E 3} \\
(\boldsymbol{\%})\end{array}$ & $\begin{array}{c}\mathbf{E E} \\
(\boldsymbol{\%})\end{array}$ \\
\hline$-0,10$ & 0,00 & 0,000 & 0,000 \\
0,00 & 3,00 & 0,000 & 0,000 \\
0,70 & 6,69 & 0,292 & 0,571 \\
1,64 & 12,05 & 0,705 & 0,984 \\
2,62 & 16,49 & 1,078 & 1,397 \\
3,45 & 21,06 & 1,472 & 1,771 \\
3,89 & 23,14 & 1,641 & 1,941 \\
4,49 & 25,89 & 1,865 & 2,165 \\
5,43 & 29,94 & 2,238 & 2,528 \\
6,42 & 34,64 & 2,652 & 2,942 \\
7,41 & 38,81 & 3,024 & 3,433 \\
8,23 & 42,34 & 3,459 & 4,280 \\
9,29 & 44,82 & 3,852 & 5,293 \\
10,16 & 45,87 & 4,101 & 6,185 \\
\hline
\end{tabular}

Tabela B.10 - Resultados do ensaio de ruptura da laje L3 do Grupo 3A.

\begin{tabular}{|c|c|c|c|c|c|}
\hline $\begin{array}{c}\text { Curso } \\
(\mathrm{mm})\end{array}$ & $\begin{array}{c}\text { Força } \\
(\mathbf{k N})\end{array}$ & E1 & $\begin{array}{l}\mathrm{E} 2 \\
(\% \circ)\end{array}$ & $\begin{array}{l}\mathrm{E3} \\
(\% \circ)\end{array}$ & $\begin{array}{l}\mathrm{EE} \\
(\% \circ)\end{array}$ \\
\hline$-0,02$ & 0,00 & 0,000 & 0,000 & 0,000 & 0,000 \\
\hline 0,00 & 3,00 & 0,000 & 0,000 & 0,000 & 0,000 \\
\hline 0,16 & 17,40 & 0,644 & 0,270 & 0,687 & 0,542 \\
\hline 1,20 & 19,62 & 0,884 & 1,162 & 1,009 & 0,864 \\
\hline 2,14 & 22,88 & 1,305 & 1,599 & 1,392 & 1,227 \\
\hline 3,01 & 25,89 & 1,645 & 2,057 & 1,816 & 1,591 \\
\hline 4,06 & 29,28 & 1,986 & 2,395 & 2,137 & 1,893 \\
\hline 4,99 & 32,16 & 2,346 & 2,712 & 2,541 & 2,216 \\
\hline 5,93 & 35,03 & 2,808 & 3,010 & 2,984 & 2,558 \\
\hline 6,97 & 38,16 & 3,449 & 3,347 & $\mathrm{x}$ & 3,022 \\
\hline 8,13 & 40,12 & 4,470 & 3,626 & $\mathrm{x}$ & 3,668 \\
\hline 8,79 & 41,95 & 5,873 & 3,964 & $\mathrm{x}$ & 4,555 \\
\hline 10,60 & 43,78 & 8,878 & 4,658 & $\mathrm{x}$ & 6,795 \\
\hline 11,70 & 45,21 & 10,220 & 5,115 & $\mathrm{x}$ & 7,803 \\
\hline 12,64 & 46,51 & 11,783 & 5,592 & $\mathrm{x}$ & 8,933 \\
\hline 13,63 & 46,91 & 13,286 & 6,009 & $\mathrm{x}$ & 10,142 \\
\hline
\end{tabular}




\begin{tabular}{llllll}
14,62 & 48,09 & 14,669 & 6,585 & $\mathrm{x}$ & 11,273 \\
17,42 & 48,35 & 18,135 & 8,115 & $\mathrm{x}$ & 15,316 \\
19,46 & 49,00 & 19,618 & 9,009 & $\mathrm{x}$ & 17,908 \\
\hline
\end{tabular}

Tabela B.11 - Resultados do ensaio de ruptura da laje L1 do Grupo 3B.

\begin{tabular}{ccccc}
\hline $\begin{array}{c}\text { Curso } \\
(\mathbf{m m})\end{array}$ & $\begin{array}{c}\text { Forca } \\
(\mathbf{k N})\end{array}$ & $\begin{array}{c}\mathbf{E 1} \\
\mathbf{\% o}\end{array}$ & $\begin{array}{c}\mathbf{E 3} \\
\mathbf{\% o}\end{array}$ & $\begin{array}{c}\mathbf{E E} \\
\mathbf{\% o}\end{array}$ \\
\hline$-0,32$ & 0,00 & 0,000 & 0,000 & 0,000 \\
0,00 & 3,00 & 0,000 & 0,000 & 0,000 \\
1,42 & 14,92 & 0,769 & 0,983 & 0,689 \\
1,69 & 16,61 & 0,828 & 1,024 & 0,729 \\
2,20 & 23,14 & 1,043 & 1,235 & 0,978 \\
2,62 & 28,63 & 1,224 & 1,413 & 1,188 \\
3,56 & 36,86 & 1,560 & 1,822 & 1,568 \\
4,44 & 42,47 & 1,897 & 2,231 & 1,868 \\
5,26 & 48,48 & 2,213 & 2,620 & 2,288 \\
6,26 & 53,96 & 2,529 & 2,947 & 2,547 \\
7,14 & 59,19 & 2,846 & 3,438 & 2,767 \\
8,90 & 65,32 & 3,301 & 7,139 & 4,487 \\
14,29 & 70,42 & 3,874 & $\mathrm{X}$ & $\mathrm{X}$ \\
20,61 & 70,94 & 4,131 & $\mathrm{X}$ & $\mathrm{X}$ \\
26,99 & 73,03 & 16,077 & $\mathrm{X}$ & $\mathrm{X}$ \\
\hline
\end{tabular}

Tabela B.12 - Resultados do ensaio de ruptura da laje L2 do Grupo 3B.

\begin{tabular}{cccc}
\hline $\begin{array}{c}\text { Curso } \\
(\mathbf{m m})\end{array}$ & $\begin{array}{c}\text { Forca } \\
(\mathbf{k N})\end{array}$ & $\begin{array}{c}\mathbf{E 2} \\
\% 0\end{array}$ & $\begin{array}{c}\mathbf{E E} \\
\% 0\end{array}$ \\
\hline$-0,24$ & 0 & 0 & 0 \\
0 & 3,00 & 0 & 0 \\
3,8 & 36,07 & 1,439 & 1,889 \\
4,51 & 45,88 & 2,002 & 2,528 \\
4,96 & 51,35 & 2,272 & 2,809 \\
5,23 & 57,1 & 2,584 & 3,168 \\
5,84 & 63,23 & 2,98 & 11,978 \\
6,83 & 68,33 & 3,354 & 21,209 \\
7,14 & 68,84 & 3,541 & 23,066 \\
7,71 & 69,63 & 3,75 & 24,085 \\
10,83 & 73,16 & $\mathrm{x}$ & $\mathrm{x}$ \\
\hline
\end{tabular}


Tabela B.13 - Resultados do ensaio de ruptura da laje L3 do Grupo 3B.

\begin{tabular}{cccccc}
\hline $\begin{array}{c}\text { Curso } \\
(\mathbf{m m})\end{array}$ & $\begin{array}{c}\text { Forca } \\
(\mathbf{k N})\end{array}$ & $\begin{array}{c}\mathbf{E 2} \\
\mathbf{\%}\end{array}$ & $\begin{array}{c}\mathbf{E 3} \\
\mathbf{\%}\end{array}$ & $\begin{array}{c}\mathbf{E 4} \\
\mathbf{\%}\end{array}$ & $\begin{array}{c}\mathbf{E E} \\
\mathbf{\%}\end{array}$ \\
\hline$-0,18$ & 0,00 & 0,000 & 0,000 & 0,000 & 0,000 \\
0,00 & 3,00 & 0,000 & 0,000 & 0,000 & 0,000 \\
0,92 & 16,09 & 0,205 & 0,245 & 0,200 & 0,200 \\
1,47 & 21,57 & 0,521 & 0,537 & 0,635 & 0,523 \\
1,97 & 27,06 & 0,858 & 0,932 & 0,992 & 0,854 \\
2,13 & 31,89 & 1,254 & 1,244 & 1,329 & 1,126 \\
2,46 & 37,25 & 1,551 & 1,577 & 1,665 & 1,399 \\
2,90 & 41,03 & 1,848 & 1,848 & 1,963 & 1,613 \\
3,34 & 46,26 & 2,165 & 2,181 & 2,299 & 1,906 \\
3,78 & 52,13 & 2,462 & 2,493 & 2,616 & 2,198 \\
4,27 & 56,18 & 2,759 & 2,784 & 2,853 & 2,751 \\
5,37 & 61,28 & 3,096 & 3,033 & 3,270 & 5,821 \\
6,37 & 64,93 & 3,313 & 3,159 & 3,329 & 19,065 \\
8,67 & 67,80 & 3,591 & 3,346 & $\mathrm{x}$ & 22,182 \\
12,63 & 71,85 & 4,026 & 3,721 & $\mathrm{x}$ & $\mathrm{x}$ \\
19,56 & 72,77 & 4,304 & $\mathrm{x}$ & $\mathrm{x}$ & $\mathrm{x}$ \\
\hline
\end{tabular}




\section{ANEXO C - EQUIPE TÉCNICA DO LABORATÓRIO DE ESTRUTURAS E MATERIAIS - LEM}

Este anexo descreve toda a equipe técnica do LEM, bem como algumas das atividades realizadas durante o desenvolvimento desta pesquisa. Convém salientar sua grande importância e o excelente trabalho desenvolvido em todas as áreas requisitadas por esta pesquisa.

Abaixo estão relacionados todos os intergrantes desta equipe técnica:

Antonio Coelho Jacomini

Rui Coelho Jacomini

Valdinéia dos Santos Silva

José Ferreira Leite Neto

Juliana Raw

Ivan Tessarolo

Algumas atividades realizadas durante os ensaios de barra ao ar:

Corte, preparação e montagem dos corpos de prova;

Auxílio na execução dos ensaios;

Manutenção da máquina de ensaios Dartec

Algumas atividades realizadas durante os ensaios de fadiga das lajes de concreto:

Projeto e confeccção das formas das lajes;

Corte, dobra e montagem das armações;

Auxílio na instrumentação;

Secagem e pesagem dos materiais para concretagem;

Concretagem;

Auxílio nos ensaios de caracterização dos materiais;

Montagem do pórtico de ensaio;

Transporte horizontal e vertical dos corpos de prova;

Manutenção da bomba hidráulica utilizada nos ensaios, entre outros.

Desta forma, manifesta-se neste anexo um reconhecimento do árduo trabalho desenvolvido por esta equipe técnica, a qual sempre se mostrou disposta a realizar o trabalho proposto, executando-o da melhor forma possível e com grande qualidade técnica. 
AMERICAN CONCRETE INSTITUTE - (ACI). Considerations for design of concrete structures subjected to fatigue loading - 215R-74 - Revised 1992, reapproved 1997. $\overline{1989 .}$

. Projeto de estruturas de concreto protendo - NBR 7197. Rio de Janeiro:

. Barras e fios de aço destinados a armadura para concreto armado - NBR 7480. Rio de Janeiro: 1996.

. Concreto - Ensaio de compressão de corpos-de-prova cilíndricos - NBR 5739. Rio de Janeiro: 1994.

. Concreto - Argamassa e concreto - Determinação da resistência à tração por compressão diametral de corpos-de-prova cilíndricos - NBR 7222. Rio de Janeiro: 1994.

. Concreto - Determinação do módulo de deformação Estática e Diagrama - Tensão Deformação - NBR 8522. Rio de Janeiro: 1984.

. Materiais metálicos - Determinação das propriedades mecânicas à tração - NBR 6152. Rio de Janeiro: 1992.

. Método de ensaio de fadiga de barras de aço para concreto armadoNBR 7478. Rio de Janeiro: 1982.

ASSOCIAÇÃO BRASILEIRA DE NORMAS TÉCNICAS - (ABNT). Projeto de estruturas de concreto - NBR-6118. Rio de Janeiro, 2003.

BARSOM, J. M., ROLFE, S. T. Fracture and fatigue control in structures. New Jersey: Prentice Hall, 1987.

BRITISH STANDARDS INSTITUTION - (BSI). Carbon steel for the reinforcement of concrete - BSI 4449/88. London: 1997.

BUELTA, M. A. B. Ensaios de fadiga de barras de aço CA50 de $16 \mathrm{~mm}$ para concreto armado. São Paulo: EPUSP/LEM, 2002. (Relatório Técnico, R.T. n. 03/26).

CALAVERA, R. J. Proyecto y calculo de estructuras de hormigon armado para edificios. 2.ed. S.1.: Intemac, 1991. v.2.

CALLISTER, W. D. Materials science and engineering: an introduction. 5ed. New York: John Wiley \& Sons, 2000.

COMITÉ EURO-INTERNATIONAL DU BÉTON (CEB). Fatigue of concrete structures: state of the art report. Bulletin d'Information n.188, Lausanne: 1988. 
. RC elements under cyclic loading: state of the art. Bulletin d'Information n.210, London: Thomas Telford, 1996.

CEB-FIP Model Code 1990: design code. Bulletin d'Information n.213/214. London: Thomas Telford, 1993.

. Fatigue of concrete structures: state of the art report. Bulletin d’Information n.188, Lausanne: 1988.

. Structural concrete: textbook on behaviour, design and perfonamce.

Lausane: 1999. v.2.

DEUTSCHES INSTITUT FÜR NORMUNG E.V. (DIN). Reinforcing steel: reinforcing steel bars testing - DIN 488 Part 3, Berlin: Beuth Verlag GMBH, 1986.

EUROCODE 2 (EC2). Design of concrete structures. Brussels, 2005.

ESPECIFICAÇÃO BRASILEIRA 3 (EB3). Barras e fios destinados a armaduras de concreto armado. Rio de Janeiro, 1967.

FEDERATION INTERNATIONALE DU BETON - (FIB). Structural Concrete Textbook on ehaviour, Design and Performance - FIB Bulletins 1,2 and 3-1999.

FERNANDES, R. M., El DEBS, A. L. H. C. A influência das ações repetidas na aderência aço-concreto. In: SIMPÓSIO EPUSP SOBRE ESTRUTURAS DE CONCRETO, 4., São Paulo, 2000. Anais. São Paulo: EPUSP, 2000. 1 CD-ROM.

GASPAR, R. Dimensionamento das almas de pontes celulares. 2003. 231p. Tese (Doutorado). Escola Politécnica, Universidade de São Paulo. São Paulo, 2003.

CAIXETA, E.C. Investigação experimental da fadiga em lajes de pontes com ou sem pré-lajes. Dissertação em andamento.

Cavalcanti, P.S.P. Fadiga da ligação capa-pré-laje em tabuleiros de pontes rodoviárias. Dissertação em andamento.

GASPAR, R. e all. Análise Experimental de Fadiga de Barras de Aço para Concreto Armado. XXXI Jornadas Sul Americanas de Engenharia Estrutural, Mendoza/Argentina, 2004

LUCHI, L.R. - Reavaliação do Trem-Tipo à luz das cargas reais nas rodovias brasileiras. 2006. 256p. Tese (Doutorado). Escola Politécnica, Universidade de São Paulo. São Paulo, 2006.

INSTITUTO ARGENTINO DE NORMALIZACION - (IRAM). Aços para armadura de concreto: parte 10: ensaio de fadiga em barras - projeto de norma mercosul 02:00-020-10. Buenos Aires: 1996.

MALLET G. Fatigue of reiforced concrete. London: HMSO, 1991.

MATOS, F. Ensaios de fadiga em vergalhões. São José dos Campos: CTA, 1995. (Relatório Técnico, RT GDQ/EXP-Q-332/95). 
OLIVEIRA, P. L., PINHEIRO, L. M. Análise de critérios de fadgia para pavimentos de concreto. In: CONGRESSO BRASILEIRO DO CONCRETO, 42., Fortaleza, 2000. Anais. São Paulo: Ibracon, 2000. 1 CD ROM.

SURESH, S.; RITCHIE, R., O., A Geometric Model for Fatigue Crack Closure Induced by Fracture Surface Roughness, Metallurgical Transactions A, New York, 13A (9): 1627-31, 1982.

SOUZA, S. A. Ensaios mecânicos de materiais metálicos: fundamentos teóricos e práticos. 5 ed. São Paulo: Edgard Blücher, 2000.

TILLY, G. P.; MOSS D. S. (1982). Long endurance fatigue of steel reinforcement. In: IABSE COLLOQUIUM ON FATIGUE OF STEEL AND CONCRETE STRUCTURES, Lausanne, 1982. Proceedings. Zurich, IABSE. p. 229- 238.

HELGASON, T.; HANSON, J. M. (1974). Investigation of design factors affecting fatigue strength of reinforcing bars - statistical analysis. In: ABELES SYMPOSIUM: FATIGUE OF CONCRETE, Hollywood, 1972-1973. Papers. Detroit, ACI Publication SP- 41. p. 107-138.

AGARWAL, A. C.; BIRKEMOE, P. C.; GOEL, A. P.; SWEENEY, R. A. P.; THOMPSON, J. C.; TOPPER, T. H. (1994). Issues in structural fatigue design and evaluation. CanadianJournal of Civil Engineering, p. 903-912, Dec. 